CHARACTERIZATION OF ZEOLITE MEMBRANES BY GAS PERMEATION

A THESIS SUBMITTED TO

THE GRADUATE SCHOOL OF NATURAL AND APPLIED SCIENCES

OF

MIDDLE EAST TECHNICAL UNIVERSITY

BY

BELMA SOYDAŞ

IN PARTIAL FULFILLMENT OF THE REQUIREMENTS

FOR

THE DEGREE OF DOCTOR OF PHILOSOPHY

IN

CHEMICAL ENGINEERING

JUNE 2009 
Approval of the thesis:

\section{“CHARACTERIZATION OF ZEOLITE MEMBRANES BY GAS PERMEATION"}

submitted by BELMA SOYDAŞ in partial fulfillment of the requirements for the degree of Doctor of Philosophy in Chemical Engineering Department, Middle East Technical University by,

Prof. Dr. Canan Özgen

Dean, Graduate School of Natural and Applied Sciences

Prof. Dr. Gürkan Karakaş

Head of Department, Chemical Engineering

Assoc. Prof. Dr. Halil Kalıpçılar

Supervisor, Chemical Engineering Dept., METU

Prof. Dr. Ali Çulfaz

Co-Supervisor, Chemical Engineering Dept., METU

\section{Examining Committee Members:}

Prof. Dr. Hayrettin Yücel

Chemical Engineering Dept., METU

Assoc. Prof. Dr. Halil Kalıpçılar

Chemical Engineering Dept., METU

Prof. Dr. Müjgan Çulfaz

Chemical Engineering Dept., Gazi University

Prof. Dr. Önder Özbelge

Chemical Engineering Dept., METU

Prof. Dr. Levent Yilmaz

Chemical Engineering Dept., METU

Date: 
I hereby declare that all information in this document has been obtained and presented in accordance with academic rules and ethical conduct. I also declare that, as required by these rules and conduct, I have fully cited and referenced all material and results that are not original to this work.

Name, Last name : Belma Soydaş

Signature 


\title{
ABSTRACT \\ CHARACTERIZATION OF ZEOLITE MEMBRANES BY GAS PERMEATION
}

\author{
Soydaş, Belma \\ Ph.D., Department of Chemical Engineering \\ Supervisor: Assoc. Prof. Dr. Halil Kalıpçılar \\ Co-supervisor: Prof. Dr. Ali Çulfaz
}

June 2009, 188 pages

Zeolite membranes are attractive materials to separate gas and liquid mixtures. MFI is a widely studied zeolite type due to its ease of preparation and comparable pore size with the molecular size of many substances. In this study MFI type membranes were synthesized over porous $\alpha-\mathrm{Al}_{2} \mathrm{O}_{3}$ supports and characterized with XRD, SEM and gas permeation measurements.

In the first part of this study the effect of soda concentration of the synthesis solution on the membrane morphology and crystal orientation was investigated. The synthesis was carried out from solutions with a molar composition of (06.5) $\mathrm{Na}_{2} \mathrm{O}: 25 \mathrm{SiO}_{2}: 6.9 \mathrm{TPABr}: 1136 \mathrm{H}_{2} \mathrm{O}$ at $150^{\circ} \mathrm{C}$. At soda concentrations between 0.45 and 1.8 the membrane layers with $(\mathrm{h} 0 \mathrm{~h}) / \mathrm{c}$-directed orientation were obtained. At lower and higher soda concentrations membrane layer formed from randomly oriented crystals. The (h0h)/c-oriented membranes showed $\mathrm{H}_{2} / \mathrm{n}-\mathrm{C}_{4} \mathrm{H}_{10}$ ideal selectivities of 478 and 36 at $25^{\circ} \mathrm{C}$ and $150^{\circ} \mathrm{C}$, respectively. 
In the second part, MFI membranes were synthesized from mixtures with different concentrations of template molecules. Tetrapropylammonium hydroxide, tetrapropylammonium bromide or mixture of both types were used as template. The nucleation period, the size of MFI crystals, membrane thickness decreased as the tetrapropylammonium hydroxide concentration increased. Besides conversion of $\mathrm{SiO}_{2}$ in the synthesis solution to MFI passed through a maximum with increasing concentration of tetrapropylammonium hydroxide in the synthesis solution. When tetrapropylammonium bromide was used as template thicker membranes were obtained.

In the third part MFI type membranes with a thickness of $1.5-2 \mu \mathrm{m}$ were synthesized by mid-synthesis addition of silica to the synthesis medium. The membranes synthesized with and without mid-synthesis addition of silica have $n-\mathrm{C}_{4} \mathrm{H}_{10} / \mathrm{i}-\mathrm{C}_{4} \mathrm{H}_{10}$ ideal selectivities of 47 and 8 at $100^{\circ} \mathrm{C}$, respectively. The change of composition during the synthesis increases the crystal growth rate and the size of the crystals forming the membrane, thus better quality membranes can be obtained by midsynthesis addition of silica to the synthesis medium.

In the last part of this study, thin MFI type zeolite membranes were synthesized in a recirculating flow system at $95^{\circ} \mathrm{C}$ on the inner side of the tubular $\alpha$-alumina supports. A membrane synthesized by two consecutive synthesis steps had a separation selectivity of 38 and 86 for equimolar mixtures of $n-\mathrm{C}_{4} \mathrm{H}_{10} / \mathrm{CH}_{4}$ and $n-\mathrm{C}_{4} \mathrm{H}_{10} / \mathrm{N}_{2}$ at $25^{\circ} \mathrm{C}$, respectively. The membrane selectively permeated large $n-\mathrm{C}_{4} \mathrm{H}_{10}$ over small $\mathrm{CH}_{4}$ and $\mathrm{N}_{2}$, suggesting that the separation is essentially adsorption-based and the membrane has few nonselective intercrystalline pores.

Keywords: Zeolite, Oriented MFI, MFI membrane, Synthesis in a flow system, Gas Separation 


\title{
öz
}

\section{ZEOLITT MEMBRANLARIN GAZ GEÇIRGENLİK ÖLÇÜMLERIYLE KARAKTERIZASYONLARI}

\author{
Soydaş, Belma \\ Doktora, Kimya Mühendisliği Bölümü \\ Danışman: Doç. Dr. Halil Kalıpçılar \\ Eş Danışman: Prof. Dr. Ali Çulfaz
}

Haziran 2009, 188 sayfa

Zeolit membranlar gaz ve sıvı karışımlarını ayırmak için uygun malzemelerdir. MFI tipi zeolitler molekül boyutundaki gözenekleri ve kolay hazırlanabilmeleri sayesinde geniş ölçüde çalışılan zeolit türleridir. $\mathrm{Bu}$ çalışmada gözenekli $\alpha-\mathrm{Al}_{2} \mathrm{O}_{3}$ destekler üzerinde MFI tipi zeolit membranlar sentez edilmiş ve X-1şınları kırınım desenleri, elektron tarama mikroskobu ve gaz geçirgenlik ölçümleri ile karakterize edilmiştir.

$\mathrm{Bu}$ çalışmanın birinci bölümünde sentez çözeltisindeki soda derişiminin membran morfolojisi ve kristal yönelimi üzerine etkisi incelenmiştir. Sentez (06.5) $\mathrm{Na}_{2} \mathrm{O}: 25 \mathrm{SiO}_{2}: 6.9$ TPABr: $1136 \mathrm{H}_{2} \mathrm{O}$ bileşimindeki sentez çözeltisinden $150^{\circ} \mathrm{C}$ sıcaklıkta yapılmıştır. Soda derişimi 0.25 ve 1.5 aralığında olduğunda (h0h)/cyönelimli membran tabakası elde edilmiştir. Daha düşük ve daha yüksek soda derişimlerinde mebranlar rastgele yönelimli kristallerden oluşmuştur. (h0h)/c- 
yönelimli membranlar $25^{\circ} \mathrm{C}$ ve $150^{\circ} \mathrm{C}$ 'de sirasiyla 478 ve $36 \mathrm{H}_{2} / \mathrm{n}-\mathrm{C}_{4} \mathrm{H}_{10}$ ideal seçiciliği göstermişlerdir.

İkinci bölümde, farklı derişimlerde şablon molekülleri içeren karışımlardan MFI tipi membranlar sentez edilmiştir. Şablon molekül olarak tetrapropilamonyum hidroksit , tetrapropilamonyum bromür veya her iki türün karışımı kullanılmıştır. Tetrapropilamonyum hidroksit derişimi arttıkça çekirdeklenme süresi, MFI kristallerinin boyu ve membran kalınlığı azalmıştır. Bunun yanı sıra çözeltideki tetrapropilamonyum hidroksit derişiminin artmasıyla çözeltideki $\mathrm{SiO}_{2}$ 'nin MFI'ye dönüşümü bir maksimumdan geçmiştir. Şablon olarak tetrapropilamonyum bromür kullanıldığında daha kalın membranlar elde edilmiştir.

Üçüncü bölümde, sentez esnasında sentez ortamına silika eklenerek 1.5-2 $\mu \mathrm{m}$ kalınlığında MFI tipi membranlar elde edilmiştir. Sentez esnasında silika eklenerek ve eklenmeden sentez edilen membranlar sirasiyla 47 ve $8 n-\mathrm{C}_{4} \mathrm{H}_{10} / \mathrm{i}-\mathrm{C}_{4} \mathrm{H}_{10}$ ideal seçiciliğine sahiptirler. Sentez esnasında sentez bileşiminin değiştirilmesi membranı oluşturan kristallerin büyüme hızını ve boyunu artırmaktadır ve bu nedenle sentez esnasında sentez ortamına silika ekleyerek daha kaliteli membranlar elde edilebilmektedir.

$\mathrm{Bu}$ çalışmanın son bölümünde, döngülü akış sisteminde $95^{\circ} \mathrm{C}$ 'de $\alpha-\mathrm{Al}_{2} \mathrm{O}_{3}$ tüp desteklerin iç yüzeyinde ince MFI tipi membanlar sentez edilmiştir. Ardışık iki sentez sonunda edilen membranlar eşmolar $n-\mathrm{C}_{4} \mathrm{H}_{10} / \mathrm{CH}_{4}$ and $\mathrm{n}-\mathrm{C}_{4} \mathrm{H}_{10} / \mathrm{N}_{2}$ karışımlarının ayrımında $25^{\circ} \mathrm{C}$ 'de sırasıyla 38 ve 36 ayırma seçiciliğine sahiptirler. Membranlar küçük $\mathrm{CH}_{4}$ and $\mathrm{N}_{2}$ moleküllerindense büyük $\mathrm{n}-\mathrm{C}_{4} \mathrm{H}_{10}$ moleküllerini seçici olarak geçirmektedir bu da membranlarda adsorpsiyona dayalı bir ayırma olduğunu ve membranların çok az sayıda kristaller arası seçici olmayan gözeneğe sahip olduğunu göstermektedir.

Anahtar Kelimeler: Zeolit, Yönelimli MFI , MFI membran, Akış Sisteminde Sentez, Gaz Ayrımı 
to my family and

to my never grown up brother, Burak...

viii 


\section{ACKNOWLEDGEMENTS}

I would like to express profound gratitude to my supervisor Assoc. Prof. Dr. Halil Kalıpçılar and my co-supervisor Prof. Dr. Ali Çulfaz for their invaluable supports, encouragements, supervisions and useful suggestions throughout this study. Their moral supports and continuous guidance enabled me to complete my work successfully.

I would like to extend my thanks to Prof. Dr. Müjgan Çulfaz and Prof. Dr. Levent Yilmaz for their valuable comments and discussions during the progress of this study.

I would like to thank both the Central Laboratory and the Machine Shop technicians of the Chemical Engineering Department for their help during the study.

I want to thank my friend and my room mate Canan Gücüyener for the friendship we had and her endless patience to my endless request about figures in my thesis. I also want to thank my friend and my room mate, Hale Ay, for bringing the silence to our room which has precious importance for the thesis writer. I would like to thank to my dear friend Ela Eroğlu, I always feel her support regardless of the distances.

I would also like to show my appreciation to my old and new lab mates Zeynep Çulfaz, Eser Dinçer, Özge Güvenir, Değer Şen, Özlem Dede, Sezin Akbay, Berna Arıcan for bringing fun to our lab.

I would like to show my special thanks to my love, Burçin Tarkan Sözer, for being my life happy, easy and quiet. In many ways he has made available his support. 
Finally, I am as ever, especially indebted to my parents Melahat Soydaş and Ahmet Soydaş for their love and support throughout my life. My sincere thanks go to my sister Sema Soydaş and my brother Burak Soydaş for being my best friends at every stage of my life. 


\section{TABLE OF CONTENTS}

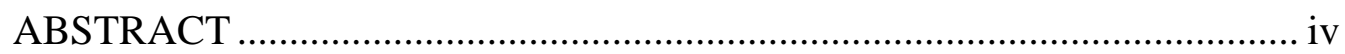

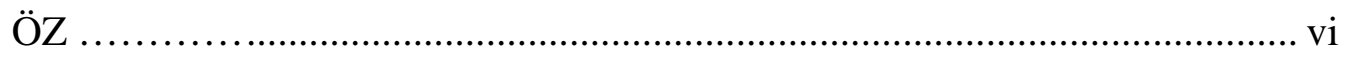

DEDICATION ............................................................................... viii

ACKNOWLEDGEMENTS _................................................................... ix

TABLE OF CONTENTS ...................................................................

LIST OF TABLES …....................................................................... $\mathrm{xv}$

LIST OF FIGURES ........................................................................... $\mathrm{xvii}$

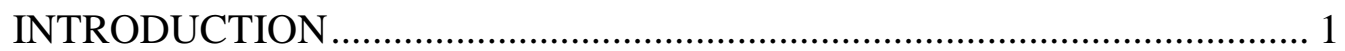

LITERATURE SURVEY …................................................................ 5

2.1 Description of zeolites and zeolite membranes ................................ 5

2.2 Synthesis of zeolite membranes ..................................................... 8

2.3 Factors effecting the membrane properties ................................... 10

2.3.1 Effect of support seeding on membrane properties....................... 11

2.3.2 Effects of hydroxyl, soda, template concentrations on membrane

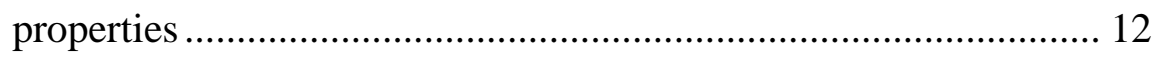

2.4 Crystal orientation in MFI type zeolite membranes ........................ 14

2.5 Characterization of the membranes ................................................ 17

2.6 Permeation through MFI membranes ............................................... 19

2.7 Gas separation with the MFI membranes........................................ 21

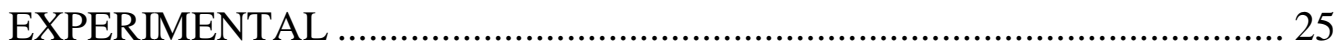

3.1 Materials for Synthesis of MFI type zeolite powders and membranes

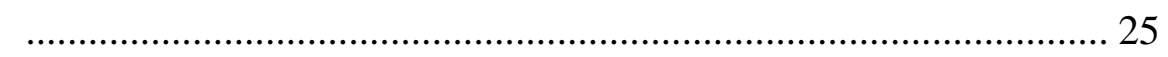

3.2 Type of supports used for membrane synthesis ........................... 25

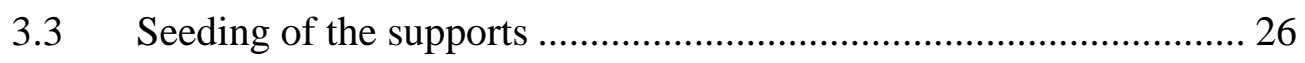

3.3.1 Vacuum seeding technique..................................................... 26

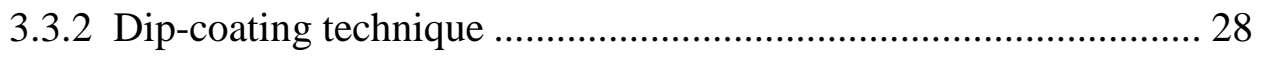

3.3.3 Preparation of MFI crystals for use as seed ................................. 29 
3.4 Synthesis of MFI type zeolite membranes with different soda concentrations of crystallization solution.

3.5 Synthesis of MFI type zeolite membrane and powder with different template concentrations of crystallization solution

3.6 Synthesis of membranes with mid-synthesis addition of silica to the synthesis medium 36

3.7 Separation of binary and ternary gas mixtures by MFI type zeolite membranes synthesized in a flow system. 39

3.7.1 Membrane synthesis and characterization. 39

3.7.2 Separation of binary and ternary gas mixtures 41

3.7.3 Operation of gas chromatograph 43

RESULTS AND DISCUSSION 45

4.1 Effect of soda concentration on the morphology of the MFI type zeolite membranes 45

4.1.1 Membrane Synthesis on Seeded and Unseeded Supports 46

4.1.2 Effect of soda concentration on crsytallinity 50

4.1.3 Effect of soda concentration on membrane morphology 55

4.1.4 Characterization of membranes with single gas permeation measurements

4.1.5 Synthesis of MFI films on nonporous glass with different soda concentrations 64

4.2 Synthesis of MFI type zeolite membranes and powder with different template concentrations of crystallization solution 72

4.2.1 Synthesis of membranes on alumina supports with different amounts of TPAOH as template.

4.2.2 Synthesis of membranes on alumina supports using TPAOH and $\mathrm{TPABr}$ as mixed template 78

4.2.3 Comments on the crystallization of MFI powder from solutions containing different amounts of TPAOH and TPABr 84

4.3 Effect of mid synthesis addition of silica to the synthesis medium on the properties of MFI type zeolite membranes 93

4.3.1 Selection of the synthesis compositions 95 
4.3.2 Selection of the composition change times 98

4.3.3 Characterization of the membranes 102

4.4 Separation of binary and ternary gas mixtures by MFI type zeolite membranes synthesized in a flow system.

4.4.1 Membrane preparation and characterization with XRD and SEM116

4.4.2 Gas permeation through membranes synthesized in the recirculating flow and batch system 119

4.4.3 Separation of ternary gas mixtures with a good quality membrane 127

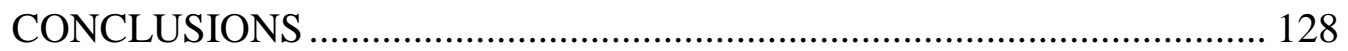

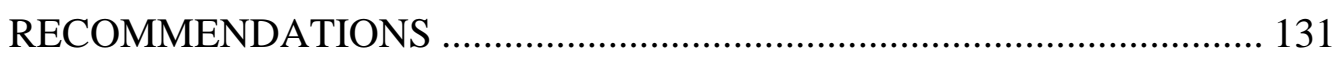

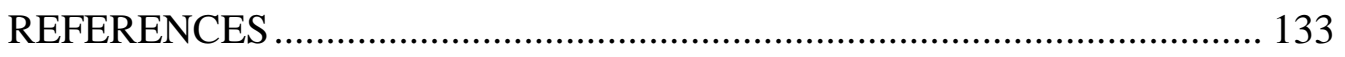

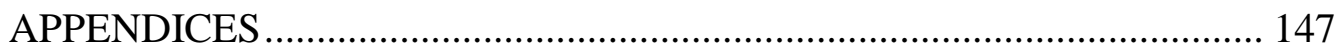

A. SAMPLE CALCULATION OF SYNTHESIS RECIPE FROM A BATCH

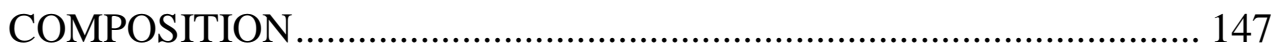

B. SAMPLE CALCULATION FOR MAXIMUM YIELD AND PERCENT

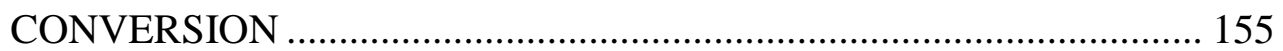

C. PREPARATION OF HOME MADE $\mathrm{Al}_{2} \mathrm{O}_{3}$ DISKS ………………….... 158

D. SAMPLE CALCULATION FOR SINGLE GAS PERMEANCE AND IDEAL SELECTIVITY ……………………………………….... 160

E. CALIBRATION OF MASS FLOW CONTROLLERS ............................ 162

F. CALIBRATION OF GAS CHROMOTOGRAPH .................................... 164

G. SAMPLE CALCULATION FOR THE DETERMINATION OF GAS COMPOSITIONS IN GAS MIXTURES .............................................. 167

22 SAMPLE CALCULATION FOR THE DETERMINATION OF PERMEANCES AND SEPARATION SELECTIVITIES OF BINARY

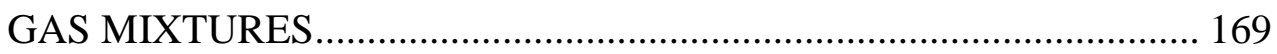

I. SAMPLE CALCULATION FOR THE DETERMINATION OF PERMEANCES AND SEPARATION SELECTIVITIES OF TERNARY

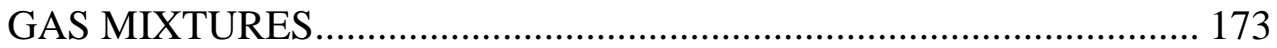

J. CALCULATION OF AMOUNT OF SILICA ADDED DURING

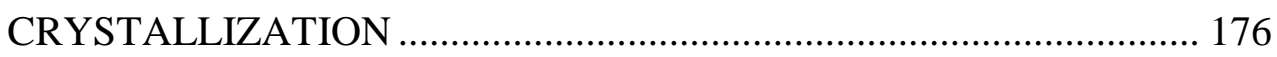


K. LIST OF SYNTHESIZED MEMBRANES ............................................ 178

L. LIST OF MEMBRANES SYNTHESIZED WITH COMPOSITION

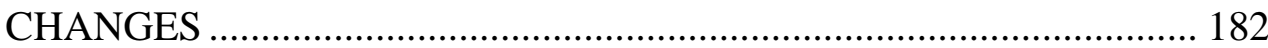

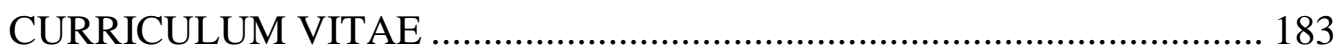




\section{LIST OF TABLES}

TABLES

Table 2.1 Studies for the separation of multicomponent gas mixtures in the literature

Table 3.1 The operation conditions of X-ray diffractometer..... 32

Table 3.2 Operating conditions of GC 43

Table 4.1 Single gas permeances through the (h0h)/c-oriented membrane $\mathrm{M}(1)$

Table 4.2 Synthesis conditions for the powders and membranes with different batch compositions (T: TPA; $\mathrm{S}: \mathrm{SiO}_{2} ; \mathrm{N}: \mathrm{Na}_{2} \mathrm{O} ; \mathrm{H}: \mathrm{H}_{2} \mathrm{O}$ ) The silica source is LUDOX AS-30

Table 4.3 Single gas permeances through the membranes synthesized with different amounts of TPAOH in the batch

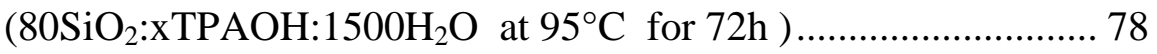

Table 4.4 Single gas permeances through the membranes synthesized with different synthesis solutions containing TPABr or TPAOH as template source; $16(\mathrm{TPAOH}-\mathrm{TPABr}): 80 \mathrm{SiO}_{2}: 10 \mathrm{Na}_{2} \mathrm{O}: 2500 \mathrm{H}_{2} \mathrm{O}$ at $150^{\circ} \mathrm{C}$ for $24 \mathrm{~h}$.

Table 4.5 Crystallization results and particle size of powder and crystals on the membrane with different synthesis conditions (T: TPA; $\mathrm{S}: \mathrm{SiO}_{2} ; \mathrm{N}$ : $\mathrm{Na}_{2} \mathrm{O} ; \mathrm{H}: \mathrm{H}_{2} \mathrm{O}$ ). Crystallization temperatures and sources of reactants are shown in table 4.2 ................................................ 93

Table 4.6 Synthesis solution compositions used in the ternary diagram .......... 96

Table 4.7 Estimated liquid phase compositions of the synthesis solution at different synthesis times at $95^{\circ} \mathrm{C}$ and atmospheric pressure ........ 100

Table 4.8 Liquid phase compositions of the synthesis solution used in the ternary diagram (T: TPA; $\mathrm{S}: \mathrm{SiO}_{2} ; \mathrm{H}: \mathrm{H}_{2} \mathrm{O}$ ) 102 
Table 4.9 Synthesis conditions and properties of the membranes prepared with composition change during the synthesis, synthesis temperature: $95^{\circ} \mathrm{C}$

Table 4.10 Synthesis conditions and properties of the membranes prepared with composition change during the synthesis 108

Table 4.11 Single gas permeances through the membranes synthesized with constant composition $80 \mathrm{SiO}_{2}: 30 \mathrm{TPAOH}: 1500 \mathrm{H}_{2} \mathrm{O}$ (BS115), $80 \mathrm{SiO}_{2}: 9 \mathrm{TPAOH}: 1500 \mathrm{H}_{2} \mathrm{O}(\mathrm{BS} 119)$ at $72 \mathrm{~h}$ and mid-synthesis addition of silica at $24 \mathrm{~h}(\mathrm{BS} 121)$ and $124 \mathrm{~h}(\mathrm{BS} 125)$ at $95^{\circ} \mathrm{C} \ldots . .113$

Table 4.12 Gas permeances and separation selectivities of the membranes synthesized with mid synthesis addition of silica in \%50/\%50 n$\mathrm{C}_{4} \mathrm{H}_{10} / \mathrm{CH}_{4}$ and $\mathrm{n}-\mathrm{C}_{4} \mathrm{H}_{10} / \mathrm{N}_{2}$ binary mixtures

Table 4.13 Synthesis method, number of synthesis steps and $\mathrm{N}_{2}$ permeances 115

Table 4.14 The permeances and $\mathrm{n}-\mathrm{C}_{4} \mathrm{H}_{10}, \mathrm{CH}_{4}$ permeate compositions for the ternary gas mixture separation at 1.9 bar feed pressure (Mixture composition: $\left.\mathrm{CH}_{4}: 70 \% ; \mathrm{CO}_{2}: 20 \% ; n-\mathrm{C}_{4} \mathrm{H}_{10} 10 \%\right)$................... 127

Table A.1 Molecular weights of reactants.............................. 148

Table A.2 Amount of reagents for $100 \mathrm{~g}$ batch preparation..................150

Table A.3 Amount of reagents calculated for $100 \mathrm{~g}$ batchs for all compositions used in this study. ...

Table D1. Single gas permeation experiment data for membrane BS125 at $100^{\circ} \mathrm{C}$

Table H.1 Feed, retentate and permeate compositions in binary mixture separation with BS170 membrane.

Table I.1 Feed, retentate and permeate compositions in ternary mixture separation with BS170 membrane.

Table K1. List of synthesized membranes at different synthesis conditions...179

Table L1. Synthesis conditions and properties of the membranes prepared with composition change during the synthesis, synthesis temperature: $95^{\circ} \mathrm{C}$ 


\section{LIST OF FIGURES}

\section{FIGURES}

Figure 2.1 Pore structure in a MFI crystal with its typical coffin shape............ 6

Figure 2.2 The representative XRD patterns and schematic drawings of different crystal orientations in MFI type zeolite membranes........ 15

Figure 2.3 Randomly (a) and c-oriented (b) membrane structures [this study] 17 Figure 2.4 Comparison of pore size of MFI type zeolites with the kinetic

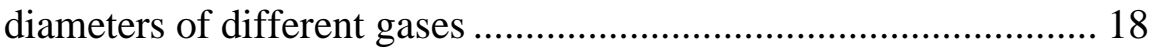

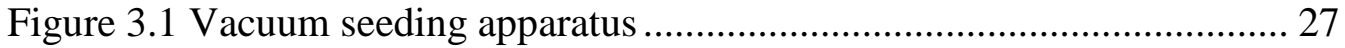

Figure 3.2. The schematic drawing of the dipcoating setup ............................ 28

Figure 3.3 The surface SEM images of the unseeded commercial $\alpha-\mathrm{Al}_{2} \mathrm{O}_{3}$ disc supports (a), seeded with $350 \mathrm{~nm}$ seed crystals by dip-coating technique (b), seeded with $350 \mathrm{~nm}$ seed crystals by vacuum seeding technique (c) and seeded with $1 \mu \mathrm{m}$ seed crystals by vacuum

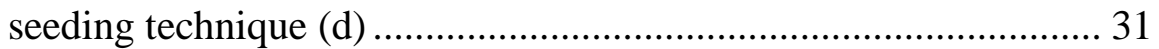

Figure 3.4 Schematic drawing of the single gas permeation setup................. 33

Figure 3.5 Schematic drawing of the system working under atmospheric pressure

Figure 3.6 The schematic drawing of the system used during the synthesis of membranes with mid-synthesis change of composition

Figure 3.7 The schematic drawing of the recirculating flow system used for membrane synthesis 40

Figure 4.1 XRD patterns of powder MFI, unseeded membrane M(1u) and seeded membrane (M1), the asterisks shows the $\alpha-\mathrm{Al}_{2} \mathrm{O}_{3}$ peaks .... 46

Figure 4.2 a) Pore structure of MFI crystals b) Representation of $c$-oriented and (h0h) oriented crystals 48 
Figure 4.3 Surface and cross section SEM images of membranes synthesized on unseeded $\mathrm{M}(1 \mathrm{u})(\mathrm{a}, \mathrm{c})$ and seeded $\mathrm{M}(1)(\mathrm{b}, \mathrm{d}) \quad \alpha-\mathrm{Al}_{2} \mathrm{O}_{3}$ supports $\left(1.0 \mathrm{Na}_{2} \mathrm{O}: 25 \mathrm{SiO}_{2}: 6.9 \mathrm{TPABr}: 1136 \mathrm{H}_{2} \mathrm{O} \quad \mathrm{T}=150^{\circ} \mathrm{C} \quad \mathrm{t}=24 \mathrm{~h}\right)$, the arrow shows the zeolite layer.

Figure 4.4 XRD patterns of the powders synthesized with different amounts of soda in the batch. $x=0.5(\mathrm{a}) ; 1.0$ (b); 1.5 (c); 2.0 (d); 2.5 (e); 3.0 (f); $5.0(\mathrm{~g}) ; 6.5$ (h) $\left(\mathrm{x} \mathrm{Na}_{2} \mathrm{O}: 25 \mathrm{SiO}_{2}: 6.9 \mathrm{TPABr}: 1136 \mathrm{H}_{2} \mathrm{O} \quad \mathrm{T}=150^{\circ} \mathrm{C}\right.$ $\mathrm{t}=24 \mathrm{~h})$ 51

Figure 4.5 Percent conversion of the powder synthesized with different soda content in the batch (x $\mathrm{Na}_{2} \mathrm{O}: 25 \mathrm{SiO}_{2}: 6.9 \mathrm{TPABr}: 1136 \mathrm{H}_{2} \mathrm{O} \quad \mathrm{T}=$ $\left.150^{\circ} \mathrm{C} \quad \mathrm{t}=24 \mathrm{~h}\right)$

Figure 4.6 XRD patterns of the membranes synthesized with different amounts of soda in the batch. $\mathrm{x}=0.5(\mathrm{a}) ; 1.0$ (b); 1.5 (c); 2.0 (d); 2.5 (e); 3.0 (f); 5.0 (g); 6.5 (h) $\left(x \mathrm{Na}_{2} \mathrm{O}: 25 \mathrm{SiO}_{2}: 6.9 \mathrm{TPABr}: 1136 \mathrm{H}_{2} \mathrm{O} \quad \mathrm{T}=150^{\circ} \mathrm{C}\right.$ $\mathrm{t}=24 \mathrm{~h})$ 53

Figure 4.7 The intensity fraction and fractional weight change of the membranes with the soda content of the synthesis solution 55

Figure 4.8 Surface SEM images of membranes synthesized on seeded $\alpha-\mathrm{Al}_{2} \mathrm{O}_{3}$ supports $\mathrm{x}=0.25$ (a); 0.4 (b); 0.5 (c); 0.65 (d); 1.0 (e); 1.25 (f); 2.0 $(\mathrm{g}) ; 3.0(\mathrm{~h})\left(\mathrm{x} \mathrm{Na} \mathrm{Na}_{2} \mathrm{O}: 25 \mathrm{SiO}_{2}: 6.9 \mathrm{TPABr}: 1136 \mathrm{H}_{2} \mathrm{O} \mathrm{T}=150^{\circ} \mathrm{C} \mathrm{t}=24 \mathrm{~h}\right.$ )

Figure 4.9 Cross section SEM images of membranes synthesized on seeded $\alpha$ $\mathrm{Al}_{2} \mathrm{O}_{3}$ supports $\mathrm{x}=0.25(\mathrm{a}) ; 0.5$ (b); 0.65 (c); 0.85 (d); 1.0 (e); 1.25 (f); $2.0(\mathrm{~g}) ; 6.5(\mathrm{~h})\left(\mathrm{xNa}_{2} \mathrm{O}: 25 \mathrm{SiO}_{2}: 6.9 \mathrm{TPABr}: 1136 \mathrm{H}_{2} \mathrm{O} \quad \mathrm{T}=150^{\circ} \mathrm{C}\right.$ $\mathrm{t}=24 \mathrm{~h})$. The arrow shows zeolite layer. 58

Figure 4.10 Degree of preferred orientation of the membranes synthesized with different soda content. 59

Figure 4.11 Permeances of single gases through oriented (M1) and non-oriented $\mathrm{M}(6.5)$ membranes $\left(\diamond, \diamond: \mathrm{H}_{2} ; \square, \mathbf{\square}: \mathrm{N}_{2} ; \Delta, \boldsymbol{\Delta}: \mathrm{CO}_{2} ; \circ, \bullet: \mathrm{n}-\mathrm{C}_{4} \mathrm{H}_{10}\right.$; empty symbols for oriented and filled symbols for non-oriented membranes). 
Figure 4.12 Permeances of single gases through non-oriented (M6.5) membrane

$\left(\diamond, \triangleleft: \mathrm{H}_{2} ; \square, \mathbf{\square}: \mathrm{N}_{2} ; \Delta, \boldsymbol{\Delta}: \mathrm{CO}_{2} ; \circ, \bullet: \mathrm{n}_{-} \mathrm{C}_{4} \mathrm{H}_{10}\right)$

Figure 4.13 XRD patterns of the powder (a); glass (b); alumina (c) surfaces. (Seeded surface, $1.0 \mathrm{Na}_{2} \mathrm{O}: 25 \mathrm{SiO}_{2}: 6.9 \mathrm{TPABr}: 1136 \mathrm{H}_{2} \mathrm{O} \quad \mathrm{T}=150^{\circ} \mathrm{C}$ $\mathrm{t}=24 \mathrm{~h})$

Figure 4.14 XRD patterns of the MFI layers on glass surfaces synthesized with different amounts of soda in the batch. $x=6.5$ (a); 3.0 (b); 1.0 (c) (x $\left.\mathrm{Na}_{2} \mathrm{O}: 25 \mathrm{SiO}_{2}: 6.9 \mathrm{TPABr}: 1136 \mathrm{H}_{2} \mathrm{O} \quad \mathrm{T}=150^{\circ} \mathrm{C} \quad \mathrm{t}=24 \mathrm{~h}\right) \ldots . .67$

Figure 4.15 Photographs of zeolite films synthesized with $1.0 \mathrm{Na}_{2} \mathrm{O}: 25 \mathrm{SiO}_{2}: 6.9 \mathrm{TPABr}: 1136 \mathrm{H}_{2} \mathrm{O}$ molar batch on unseeded (a) and seeded (b) glass surfaces 68

Figure 4.16 Surface SEM images of the zeolite films synthesized with $1.0 \mathrm{Na}_{2} \mathrm{O}: 25 \mathrm{SiO}_{2}: 6.9 \mathrm{TPABr}: 1136 \mathrm{H}_{2} \mathrm{O}$ molar batch on unseeded (a) and seeded (b) glass surfaces

Figure 4.17 Photographs of zeolite films synthesized with $x=1.0$ (a); 3.0 (b); 6.5

(c) moles of soda on seeded glass surfaces

Figure 4.18 Surface SEM images of the films synthesized with $(a, b) x=1.0$, (c, d) $x=3.0,(e, f) x=6.5$ moles of soda on seeded glass surfaces.... 70

Figure 4.19 Cross section SEM images of the films synthesized with (a) $x=1.0$, (b) $x=3.0$, (c) $x=6.5$ moles of soda on seeded glass surfaces....... 71

Figure 4.20 XRD patterns of the powders remained from membranes (a) and membranes (b) synthesized with different amounts of TPAOH in the batch $\left(80 \mathrm{SiO}_{2}: \mathrm{xTPAOH}: 1500 \mathrm{H}_{2} \mathrm{O} \quad \mathrm{T}=95^{\circ} \mathrm{C} \quad \mathrm{t}=72 \mathrm{~h}\right) \ldots \ldots . .74$

Figure 4.21 The intensity fraction and fractional weight change of the membranes synthesized with different amounts of TPAOH in the batch $\left(80 \mathrm{SiO}_{2}: \mathrm{xTPAOH}: 1500 \mathrm{H}_{2} \mathrm{O} \quad \mathrm{T}=95^{\circ} \mathrm{C} \quad \mathrm{t}=72 \mathrm{~h}\right)$. 75

Figure 4.22 Surface (a, c, e, g) and cross section (b, d, f, h) SEM images of membranes synthesized with different amounts of TPAOH in the batch $\mathrm{x}=5 \quad(\mathrm{a}, \mathrm{b}) ; \mathrm{x}=9 \quad(\mathrm{c}, \mathrm{d}) ; \mathrm{x}=16 \quad(\mathrm{e}, \mathrm{f}) ; \mathrm{x}=30 \quad(\mathrm{~g}, \mathrm{~h})$ $80 \mathrm{SiO}_{2}: \mathrm{xPAOH}: 1500 \mathrm{H}_{2} \mathrm{O} \quad \mathrm{T}=95^{\circ} \mathrm{C}$ 77 
Figure 4.23 XRD patterns of the powders and membranes synthesized with different synthesis solutions containing a mixture of TPABr and TPAOH.

Figure 4.24 XRD patterns of the powders and membranes synthesized with different synthesis solutions containing a mixture of TPABr and TPAOH. 80

Figure 4.25 SEM images of the surface (a, c, e) and cross section (b, d, f) of the membrane synthesized with different synthesis solutions containing TPABr or TPAOH as template source; TPAOH $(a, b)$, $\mathrm{TPAOH}+\mathrm{TPABr} \quad$ (c, d), TPABr $\quad(\mathrm{e}, \quad$ f) $\quad 22(\mathrm{TPAOH}-$ TPABr): $80 \mathrm{SiO}_{2}: 21 \mathrm{Na}_{2} \mathrm{O}: 3600 \mathrm{H}_{2} \mathrm{O}$ at $150^{\circ} \mathrm{C}$ for $24 \mathrm{~h}$. 81

Figure 4.26 SEM images of the surface (a, c, e) and cross section (b, d, f) of the membrane synthesized with different synthesis solutions containing TPABr or TPAOH as template source; TPAOH $(a, b)$, TPAOH+TPABr (c, d), TPABr (e, f). The synthesis was carried out at $150^{\circ} \mathrm{C}$ for $24 \mathrm{~h}$ and the mixture composition is 16 (TPAOHTPABr): $80 \mathrm{SiO}_{2}: 10 \mathrm{Na}_{2} \mathrm{O}: 2500 \mathrm{H}_{2} \mathrm{O}$

Figure 4.27 Scattering data on conversion of silica in batch to MFI and relative crystallinity for all MFI powders with all molar batch compositions reported in this work 86

Figure 4.28 Conversion of silica in batch to MFI for the powders with different batch compositions at atmospheric pressure and $95^{\circ} \mathrm{C}(\mathrm{O})$ $\mathrm{S}_{80} \mathrm{~T}_{30} \mathrm{H}_{1500},(\diamond) \mathrm{S}_{80} \mathrm{~T}_{16} \mathrm{H}_{1500},(\Delta) \mathrm{S}_{80} \mathrm{~T}_{9} \mathrm{H}_{1500},(\square) \mathrm{S}_{80} \mathrm{~T}_{5} \mathrm{H}_{1500}$. (T: TPA; $\left.\mathrm{S}: \mathrm{SiO}_{2} ; \mathrm{H}: \mathrm{H}_{2} \mathrm{O}\right)$ 88

Figure 4.29 Conversion of silica in batch to MFI as a function of template TPAOH amount: $(\Delta)$ Set 1 data, this work, $95^{\circ} \mathrm{C}$; ( $\square$ ) Data of Çulfaz et al. [29], $80^{\circ} \mathrm{C}$; (O) Data of Yang et al. [24], $95^{\circ} \mathrm{C}$; (

Data of Li et al. [89], $100^{\circ} \mathrm{C}$ 90

Figure 4.30 Particle size distribution of powder synthesized with different amounts of TPAOH in the batch $\left(80 \mathrm{SiO}_{2}: \mathrm{xPAOH}: 1500 \mathrm{H}_{2} \mathrm{O} \mathrm{T}=\right.$ $\left.95^{\circ} \mathrm{C} \mathrm{t}=72 \mathrm{~h}\right)$ 
Figure 4.31 Crystal sizes of the powder and membranes synthesized with different amounts of TPAOH in the batch $\left(80 \mathrm{SiO}_{2}: \mathrm{xTPAOH}: 1500 \mathrm{H}_{2} \mathrm{O} \quad \mathrm{T}=95^{\circ} \mathrm{C} \mathrm{t}=72 \mathrm{~h}\right)$

Figure 4.32 Synthesis solution compositions used by other researchers in the literature..... 96

Figure 4.33 (a) Conversion and (b) crystallization of silica in batch to silicalite for the powders synthesized with constant composition of $80 \mathrm{SiO}_{2}: 30 \mathrm{TPAOH}: 1500 \mathrm{H}_{2} \mathrm{O}$ at atmospheric pressure and $95^{\circ} \mathrm{C}$; (c) the particle size in synthesis mixture with the molar composition $\quad 80 \mathrm{SiO}_{2}: 30 \mathrm{TPAOH}: 1500 \mathrm{H}_{2} \mathrm{O} \quad(\bullet) \quad$ and 80 $\mathrm{SiO}_{2}: 9 \mathrm{TPAOH}: 1500 \mathrm{H}_{2} \mathrm{O}$ 99

Figure 4.34 Solution compositions during the course of crystallization with mid synthesis addition of silica at different synthesis times 101

Figure 4.35 XRD patterns of the membranes before changing the composition (a), after $48 \mathrm{~h}$ of crystallization following the composition change (b), and after $72 \mathrm{~h}$ of crystallization without composition change (c). The patterns of membranes BS-121 (a), BS-122 (b) and BS175 (c). 104

Figure 4.36 Intensity and weight fractions of membranes prepared with and without mid-synthesis addition of silica. 105

Figure 4.37 Particle size distributions of the powders remained from membranes synthesized with constant composition and mid synthesis addition of silica at different synthesis times 106

Figure 4.38 The particle size in synthesis mixture with the molar composition 80 $\mathrm{SiO}_{2}: 30 \mathrm{TPAOH}: 1500 \mathrm{H}_{2} \mathrm{O}(\bullet), 80 \mathrm{SiO}_{2}: 9 \mathrm{TPAOH}: 1500 \mathrm{H}_{2} \mathrm{O}$ and with composition change during synthesis $(\boldsymbol{\Delta})$ as a function of synthesis time 107

Figure 4.39 Surface (a, c, e) and cross section (b, d, f) SEM images of the membranes before silica addition (a, b) 24 h, (c, d) 48 h, (e, f) 72 h 109

Figure 4.40 Surface (a, c) and cross section (b, d) SEM images of the membranes after silica addition (a, b) 24+48 h, (c, d) 48+24 h. 110 
Figure 4.41 Surface (a, c, e) and cross section (b, d, f) SEM images of the membranes after silica addition (a, b) $24+72 \mathrm{~h},(\mathrm{c}, \mathrm{d}) 48+72 \mathrm{~h},(\mathrm{e}$, f) $72+72$

Figure 4.42. XRD patterns of the surfaces of membranes F3 and B2, and of the residual powder obtained from membrane synthesis in the flow system, arrows show the MFI peaks

Figure 4.43 The cross-section and surface SEM micrographs of membranes F3 (a) surface, (b) cross section from glazed part, (c) cross section on porous alumina and B2 (d) surface, (e) cross section from glazed part, (f) cross section on porous alumina. Membranes B2 and F3 were synthesized with two synthesis steps in batch and recirculating flow systems, respectively.

Figure 4.44 Single gas permeances at $200^{\circ} \mathrm{C}$ as a function of kinetic diameter 120

Figure $4.45 n-\mathrm{C}_{4} \mathrm{H}_{10}$ permeances as pure component and in $50 \%-50 \%$ mixture and $\mathrm{n}-\mathrm{C}_{4} \mathrm{H}_{10} / \mathrm{i}-\mathrm{C}_{4} \mathrm{H}_{10}$ separation selectivities as a function of temperature for F2 membrane. Solid lines: Single gas permeances, Dashed lines: Mixture permeances.

Figure $4.46 \mathrm{~N}_{2}, \mathrm{CO}_{2}, \mathrm{CH}_{4}$ and $\mathrm{n}-\mathrm{C}_{4} \mathrm{H}_{10}$ permeances through membrane $\mathrm{F} 2$ as single gas and in 50\%-50\% binary mixtures as a function of temperature (घ: $\left.\mathrm{N}_{2} ; \bullet: \mathrm{CO}_{2} ; \bullet: \mathrm{CH}_{4} ; \mathbf{\Delta}: \mathrm{n}-\mathrm{C}_{4} \mathrm{H}_{10}\right)$. Solid lines show single gas permeances, and dashed lines show the permeances in the mixtures.

Figure 4.47 Ideal selectivities and separation for $50 \%-50 \%$ mixture as a function of temperature for $\mathrm{F} 2$ membrane (a) $n-\mathrm{C}_{4} \mathrm{H}_{10}$ over $\mathrm{CH}_{4}$, $\mathrm{CO}_{2}$ and $\mathrm{N}_{2}$ and (b) $\mathrm{i}-\mathrm{C}_{4} \mathrm{H}_{10}$ over $\mathrm{CH}_{4}$ and $\mathrm{N}_{2}$. Solid lines: Separation selectivities, Dashed lines: Ideal selectivities 125

Figure 4.48 Effect of $n-C_{4} H_{10}$ concentration in the feed on the $n-C_{4} H_{10} / C_{4}$ separation selectivities and $\mathrm{C}_{4} \mathrm{H}_{10}$ permeance as a function of temperature 126

Figure B1. XRD pattern of BSt105 powder sample 157 
Figure C.1. Pore size distribution of alumina disc with surface area (a) and

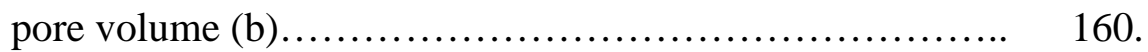

Figure E.1 Calibration of the mass flow controller for $n-C_{4} \mathrm{H}_{10} \ldots \ldots \ldots \ldots . .163$

Figure E. 2 Calibration of the mass flow controller for $\mathrm{i}-\mathrm{C}_{4} \mathrm{H}_{10} \ldots \ldots \ldots \ldots .164$

Figure E.3 Calibration of the mass flow controller for $\mathrm{CH}_{4} \ldots \ldots \ldots \ldots \ldots . \ldots 164$

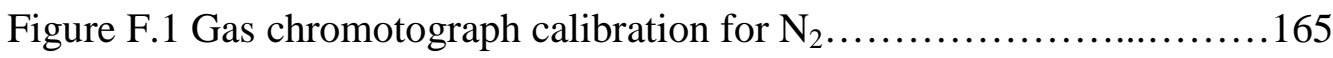

Figure F.2 Gas chromotograph calibration for $\mathrm{CH}_{4} \ldots \ldots \ldots \ldots \ldots \ldots \ldots \ldots \ldots$

Figure F.3 Gas chromotograph calibration for $\mathrm{CO}_{2} \ldots \ldots \ldots \ldots \ldots \ldots \ldots \ldots 167$

Figure F.4 Gas chromotograph calibration for $n-\mathrm{C}_{4} \mathrm{H}_{10} \ldots \ldots \ldots \ldots \ldots \ldots \ldots . \ldots \ldots$

Figure F.5 Gas chromotograph calibration for $\mathrm{i}-\mathrm{C}_{4} \mathrm{H}_{10} \ldots \ldots \ldots \ldots \ldots \ldots \ldots . \ldots \ldots$

Figure G.1 Sample GC output for permate and retentate stream (This output belongs to membrane BS170)........................... 169 


\section{CHAPTER 1}

\section{INTRODUCTION}

Membrane processes are attractive processes to separate gas and liquid mixtures $[1,2]$. For an efficient process, membranes with low cost and high performance are needed. Much attention has recently been focused on zeolites since they are recognized as attractive membrane materials with their microporous crystalline structures.

Zeolite membranes are thin films of zeolite crystals deposited on a porous and mechanically stable support. Zeolite film, which is much thinner than the support, performs separation, whereas the support provides mechanical strength and has little effect on the separation [3-5]. Separation performance of a membrane basically depends on the selection of the zeolite type [6].

MFI type zeolites consist of straight and zig-zag pores with a pore opening of nearly $0.55 \mathrm{~nm}[7,8]$, which are comparable with the kinetic diameter of many small molecules like $\mathrm{N}_{2}, \mathrm{CO}_{2}, \mathrm{SF}_{6}$ and light hydrocarbons. Besides MFI type zeolites are hydrophobic and organophilic materials. Therefore MFI type zeolites are appropriate materials to make membranes for the separation of gaseous and liquid mixtures of commercially important substances [3, 7, 9-11].

MFI type membranes are typically obtained by hydrothermal synthesis from hydrogels [12, 13] or clear solution [4, 14] at temperatures between 150 and $200^{\circ} \mathrm{C}$ in autoclaves [15-19]. In the synthesis from hydrogels, amorphous phase formed at the beginning of the synthesis is converted to zeolite [20,21]. The final product may also contain small amounts of unreacted amorphous gel. On the other hand, no amorphous phase exists during the synthesis from clear 
solutions so the solid product is expected to be only crystalline zeolite and free from amorphous particles. In addition crystals synthesized from clear solutions are much smaller and have narrower crystal size distribution than those from hydrogels [22-24]. Thus thinner membranes with better quality are obtained by using clear synthesis solutions.

MFI membranes are synthesized on disks or small tubes in laboratory scale. However, membranes with large surface area in a small volume are desired for industrial applications. Long tubes with small inside diameters or honeycomb monoliths are preferable support geometries to make MFI membranes for industrial use. Nevertheless, as the autoclave size gets larger, homogeneous synthesis conditions in terms of concentration and temperature gradients can be barely obtained through the support during the course of crystallization in autoclaves [25-27]

Alternative to batch synthesis several attempts have been performed to synthesize zeolite membranes in semi-continuous [28], continuous [27] and recirculating flow systems [29]. In a recirculating flow system much more uniform synthesis conditions can be provided and settling of the crystals from the bulk can be prevented due to the flow of synthesis solution along the support. Therefore large size membranes with high quality can be obtained by synthesis in recirculating flow systems.

A good quality membrane should have some characteristics that depend on only the intrinsic properties of the zeolite type, be defect free and have high permeability and selectivity simultaneously. Although the defects in the membrane layer increases the permeability, they diminish the selectivity. The membrane quality is affected from the composition of synthesis mixture, types of raw materials and support, support geometry, seeding, synthesis temperature and synthesis method [30, 31]. In this study MFI type membranes were also synthesized and characterized. The main aim was to investigate the effects of 
composition of synthesis solution and method on membrane morphology and gas separation performance. For this purpose, this study was divided into four main parts.

In the first part the effect of soda concentration on the membrane morphology and crystal orientation was investigated. Membranes were synthesized over porous $\alpha-\mathrm{Al}_{2} \mathrm{O}_{3}$ supports from synthesis solutions with a molar composition of (0-6.5) $\mathrm{Na}_{2} \mathrm{O}: 25 \mathrm{SiO}_{2}: 6.9 \mathrm{TPABr}: 1136 \mathrm{H}_{2} \mathrm{O}$ at $150^{\circ} \mathrm{C}$. The soda content in the batch composition was changed in a wide range between 0 and 6.5 with small intervals.

In the second part our objective was to investigate the effects of template and hydroxyl ion concentrations on the crystallization rate and crystal size of the MFI powders and membranes. Both powder and membrane synthesis were done from a series of initially clear solutions with different tetrapropylammonium hydroxide or bromide concentrations in batch and recirculating flow systems. Using clear solutions and increasing the template and hydroxyl ion concentrations were expected to provide smaller crystals and consequently a thinner layer.

In the third part, the composition of the synthesis solution was changed by adding silica to the synthesis solution during the course of crystallization so that the $\mathrm{SiO}_{2} / \mathrm{TPAOH}$ ratio of the solution was increased. The crystal growth rate was aimed to be controlled by mid-synthesis addition of silica. The membranes were also synthesized in a recirculating flow system operating at atmospheric pressure. This system, as opposed to the autoclave, allows the addition of chemicals to the synthesis medium without interrupting the crystallization. 
In the last part of the study the main purpose was to separate binary and ternary gas mixtures. Tubular membranes were synthesized in a recirculating flow system and used in the separation of equimolar binary mixtures of $n-\mathrm{C}_{4} \mathrm{H}_{10} / \mathrm{i}$ $\mathrm{C}_{4} \mathrm{H}_{10}, \mathrm{n}-\mathrm{C}_{4} \mathrm{H}_{10} / \mathrm{CH}_{4}, \mathrm{n}-\mathrm{C}_{4} \mathrm{H}_{10} / \mathrm{CO}_{2}, \mathrm{n}-\mathrm{C}_{4} \mathrm{H}_{10} / \mathrm{N}_{2}$ and ternary mixture of $\mathrm{CO}_{2}$, $\mathrm{CH}_{4}$ and $\mathrm{n}-\mathrm{C}_{4} \mathrm{H}_{10}$ between 25 and $200^{\circ} \mathrm{C}$. 


\section{CHAPTER 2}

\section{LITERATURE SURVEY}

\subsection{Description of zeolites and zeolite membranes}

Zeolites are crystalline, hydrated aluminosilicates of alkali or alkaline earth metal cations [32]. Their three dimensional networks are constructed of $\mathrm{SiO}_{4}$ and $\mathrm{AlO}_{4}$ tetrahedra linked through oxygen atoms [33]. Zeolites act as molecular sieves due to their micropores whose dimensions are of the same order of magnitude as molecular diameters.

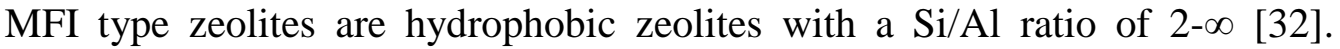
Silicalite- 1 is the aluminum-free member and ZSM-5 is the aluminum containing member of the MFI group. They contain two types of channels (Figure 2.1); the straight channels with an aperture of $0.53 \times 0.56 \mathrm{~nm}$ are linked to each other by zig-zag channels with an aperture of $0.51 \times 0.55 \mathrm{~nm}[7,8]$.

Membrane is a semipermeable barrier between two phases through which fluids are selectively permeated based on their sorption and diffusion properties [34]. Membrane performance depends on the properties of the membrane materials. Zeolites are broadly used to prepare membranes for the separation of gaseous and liquid mixtures of commercial importance [3, 7, 9-11] because of their high thermal and chemical stability, ease of preparation, hydrophobic/hydrophilic nature for pervaporation separation as well as their appropriate pore size for molecular sieving. 


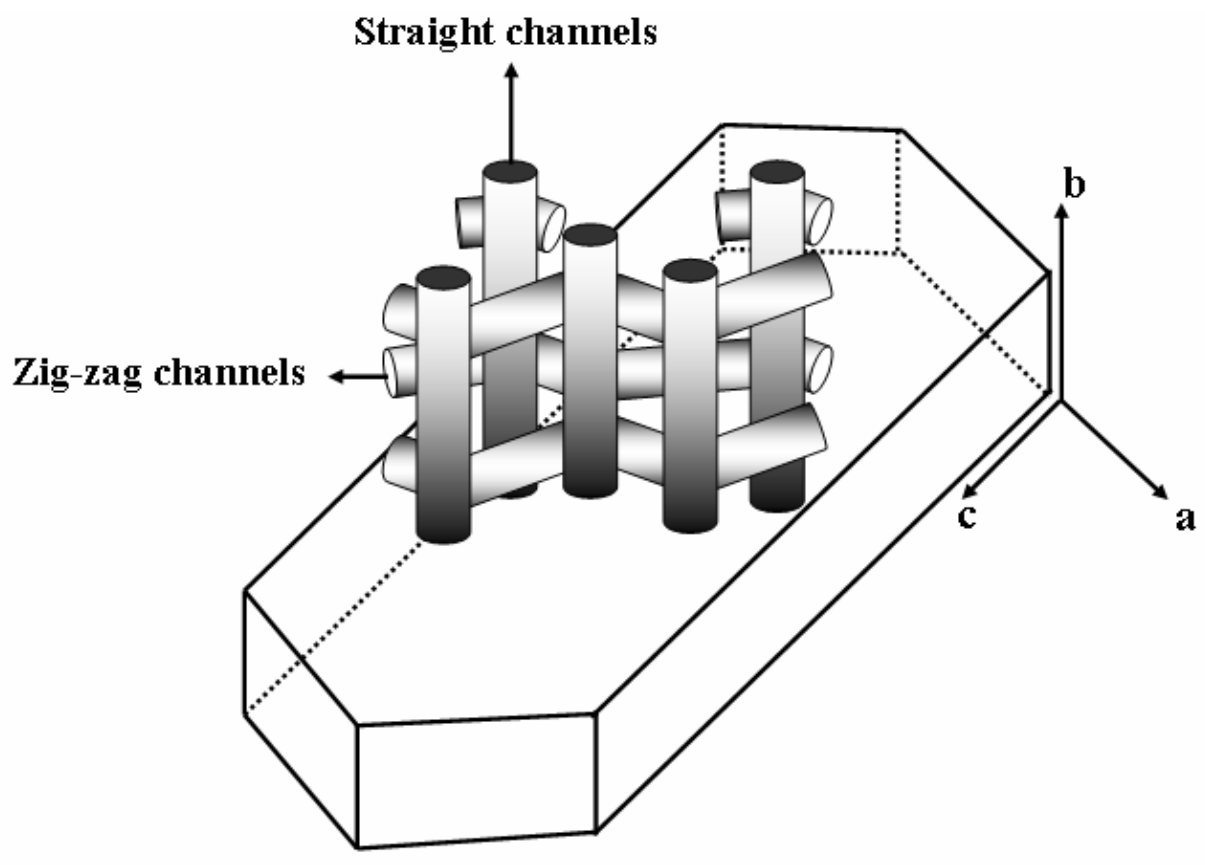

Figure 2.1 Pore structure in a MFI crystal with its typical coffin shape

Membrane performance is expressed by reporting permeances, ideal selectivities and separation selectivities. The permeance of a gas through the membrane is defined as the flux per unit driving force and calculated as

$$
\text { Permeance }=\frac{\text { Molar flux }}{\text { Driving force }}=\left(\frac{\Delta \mathrm{n}}{\mathrm{A} \times \Delta \mathrm{t}}\right) \times \frac{1}{\Delta \mathrm{P}}
$$

where driving force is usually the transmembrane pressure difference. The ideal selectivity is defined as the ratio of the permeances of pure gases and calculated by Equation 2.2.

$$
\text { Ideal Selectivity, }{ }_{\mathrm{A} / \mathrm{B}}=\frac{\text { Permeance of } \mathrm{A}}{\text { Permeance of } \mathrm{B}}
$$


For binary mixtures, separation selectivity is defined by Equation 2.3

$$
\text { Separation Selectivity, }{ }_{\mathrm{A} / \mathrm{B}}=\frac{\left[\mathrm{y}_{\mathrm{A}} / \mathrm{y}_{\mathrm{B}}\right]_{\text {permeate }}}{\left[\mathrm{x}_{\mathrm{A}} / \mathrm{x}_{\mathrm{B}}\right]_{\text {feed }}}
$$

where, $\mathrm{y}_{\mathrm{A}}$ and $\mathrm{y}_{\mathrm{B}}$ are the mole fractions of components $\mathrm{A}$ and $\mathrm{B}$ in the gas mixture at the permeate side and $\mathrm{x}_{\mathrm{A}}$ and $\mathrm{x}_{\mathrm{B}}$ are the mole fractions of these components at the feed side of the membrane.

The separation selectivity is also defined in the studies carried out with zeolite membranes as the ratio of permeances of the gas pairs in the mixture using a log-mean pressure difference through the membrane based on partial pressures in feed, permeate and retentate sides [10].

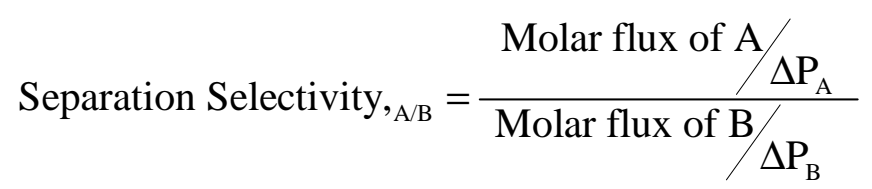

Where $\Delta \mathrm{P}_{\mathrm{A}, \mathrm{B}}$ is the log-mean pressure difference of the components through the membrane and calculated as

$$
\Delta P_{A, B}=\frac{\left(P_{A, B}^{\text {feed }}-P_{A, B}^{\text {permeate }}\right)-\left(P_{A, B}^{\text {retentate }}-P_{A, B}^{\text {permeate }}\right)}{\ln \left(\frac{P_{A, B}^{\text {feed }}-P_{A, B}^{\text {permeate }}}{P_{A, B}^{\text {retentate }}-P_{A, B}^{\text {permeate }}}\right)}
$$




\subsection{Synthesis of zeolite membranes}

Zeolite membranes are usually synthesized as a thin layer on a macroporous support $[3,4,17,18,35,36]$. The support provides the mechanical strength to the membrane while the zeolite layer accomplishes the separation. The porous support can either be disc $[14,18,37]$ or tubular [38-40] shape. For industrial applications, tubular membranes are more suitable than discs because larger surface area in a unit volume can be obtained with tubes. On the other hand in laboratory scale synthesis, investigating membrane preparation conditions can be easier with disc shape supports $[41,42]$.

MFI type zeolite membranes are typically synthesized in batch systems by placing the support into gel or clear synthesis solution at temperatures between $100^{\circ} \mathrm{C}$ and $200^{\circ} \mathrm{C}$ at autogeneous pressures [35, 37, 43]. During the synthesis from gels, a dense amorphous layer forms on the support, in which crystallization takes place $[20,21]$ to yield a continuous MFI layer. Crystal growth proceeds until all the gel is consumed. The gel that may fill the support pores is also converted to zeolite. Pore filling results in zeolite membranes with low flux $[19,44,45]$. Several attempts have been carried out to prevent the penetration of the gel into support pores to get higher fluxes. For instance Yan et al. [44] synthesized ZSM-5 membranes on porous $\alpha-\mathrm{Al}_{2} \mathrm{O}_{3}$ supports. The support pores were initially filled with carbon, so that ZSM-5 crystals formed only on the surface. The carbon filler was then burned out to open the support pores. Thus thinner membranes were obtained.

No amorphous phase forms during the synthesis from clear solutions. The clear solution synthesis starts with the hydrolysis of silica in tetrapropylammonium hydroxide solution at room temperature [22, 46, 47]. This solution consists of silica in the form of nanoparticles with composition and structure similar to MFI crystals [24, 47]. Therefore all solid product that formed from a clear solution is expected to be crystalline zeolite. Another advantage of using the 
clear solution is that crystals are much smaller and also crystal size distribution is narrower than those obtained from the gel systems [22-24]. Small crystal size with a narrow size distribution is desired to obtain the uniform thickness along the membrane which strongly affects the membrane quality. Hedlund et al. [14] synthesized MFI membranes in batch systems at $100^{\circ} \mathrm{C}$ from clear synthesis solutions. They observed dense and thin $(5 \mu \mathrm{m})$ membranes with high fluxes on alumina supports which seeded with colloidal MFI seed crystals synthesized from clear synthesis solution. Choi et al. [48] prepared MFI type zeolite membranes at 145 and $175{ }^{\circ} \mathrm{C}$ from clear synthesis solution in autoclaves. They observed a-oriented or h0h/c-oriented membranes with a thickness of $3 \mu \mathrm{m}$ and $8 \mu \mathrm{m}$, respectively.

Alternative to batch synthesis several attempts have been performed to synthesize zeolite membranes in semi-continuous [27], continuous [28] and recirculating flow systems [29] to improve the membrane quality by providing more uniform synthesis conditions in the synthesis medium. Richter et al. [28] synthesized ZSM-5 membranes on the inner surface of tubes and capillaries at $150^{\circ} \mathrm{C}$. They supplied the fresh synthesis solution continuously with a flow rate of $0.25 \mathrm{~cm} / \mathrm{min}$ through the capillary and tubes during the hydrothermal treatment. By this way they prevented the depletion of the precursor solution during crystallization and obtained homogenous membranes of $30 \mu \mathrm{m}$ thickness with $\mathrm{H}_{2} / \mathrm{SF}_{6}$ ideal selectivity above the Knudsen selectivity.

Çulfaz et al. [29] prepared MFI type zeolite membranes at $95^{\circ} \mathrm{C}$ in a recirculating flow system where the synthesis solution was pumped out from a reservoir, flowed over the porous support and returned to the same reservoir by means of a peristaltic pump with flow rates of 6,24 and $48 \mathrm{ml} / \mathrm{min}$. Membranes were prepared on seeded tubular alumina supports from clear synthesis solutions at $80^{\circ} \mathrm{C}$ and $95^{\circ} \mathrm{C}$ at atmospheric pressure. The membranes had a thickness of $2 \mu \mathrm{m}$ and separated equimolar mixture of $n-\mathrm{C}_{4} \mathrm{H}_{10}$ and i$\mathrm{C}_{4} \mathrm{H}_{10}$ with a separation selectivity of 7.6 at $200^{\circ} \mathrm{C}$. High separation 
performance of membranes was attributed to the more uniform conditions provided by the flow of synthesis solution along the support.

During the synthesis some defects or pinholes can form in the membrane. The separation performance of the membranes depends on the size and concentrations of non-zeolitic pores. The non-zeolitic pores diminish the selectivity but increases the permeability. The defects in the MFI films are often plugged by following multiple syntheses procedures, in which synthesis is repeated on the same membrane using brand new synthesis solution each time. These multiple synthesis steps which are carried on until the membranes become impermeable to $\mathrm{N}_{2}$ before calcination improve the membrane quality by plugging the nonzeolitic pores [3, 7, 19]. Caro et al. [19] recently reported that zeolite membranes with thicknesses around $20 \mu \mathrm{m}$ exhibit good separation selectivities. The selectivity may increase with increasing membrane thickness, but this increase is usually accompanied by a decrease of flux. Therefore thin zeolite membranes with good quality are required to combine high permeability with high selectivity $[19,49]$.

\subsection{Factors effecting the membrane properties}

There are some factors that affect the membrane quality such as source of the reactants and composition of the synthesis solution. MFI type zeolites are typically prepared from solutions composed of $\mathrm{SiO}_{2}, \mathrm{Al}_{2} \mathrm{O}_{3}, \mathrm{Na}_{2} \mathrm{O}, \mathrm{H}_{2} \mathrm{O}$ and often an organic template [32]. During the synthesis of MFI membranes on alumina supports, and the synthesis solution does not contain $\mathrm{Al}_{2} \mathrm{O}_{3}$, some aluminum can incorporate in to the zeolite framework because of aluminum leaching from the support. The aluminum incorporation leads to increase the hydrophilicity of the membrane which strongly affects its separation performance. Besides the synthesis composition, synthesis temperature and seeding of the support also affect the membrane structure and defects and consequently membrane separation performances. 


\subsubsection{Effect of support seeding on membrane properties}

Zeolite membranes are crystallized on blank or seeded supports. For seeding zeolite crystals, prepared separately, are deposited onto the support surface before membrane synthesis. Different seeding techniques such as dipcoating $[20,38,50-52]$, vacuum seeding $[53,54]$ or rubbing $[55,56]$ are used to obtain closed-packing seed layers. Because seed layers with loose-packing may originate defects in the membrane layer [17].

Caro et al. [19] reviewed that the use of seeds offers a way to control the growth of a zeolite layer on the support surface and seeding the support surface reduces the effect of the surface chemistry of the support. Membrane synthesis on seeded supports requires shorter synthesis times [17, 20] and gives better separation performances than the membranes synthesized on unseeded supports $[4,14,57,38]$.

Lai et al. [20] synthesized silicalite membranes with surface seeding. They resulted that the seeding of the supports leads to start the crystallization on the support surface. Bernal et al. [58] suggested that the zeolite membranes prepared with seeding may exhibit a film composed of oriented crystals since the seed crystals grow preferentially towards the bulk of the solution which causes a well intergrown oriented zeolite layer.

Zhang et al. [43] investigated the effect of seed size on the formation of seed layers and zeolite membranes. The membranes were synthesized on the supports which coated with $100 \mathrm{~nm}, 600 \mathrm{~nm}, 1.5 \mu \mathrm{m}, 3 \mu \mathrm{m}$ and $7.5 \mu \mathrm{m}$ MFI seed crystals. They obtained a uniform and dense membrane layer with $2 \mu \mathrm{m}$ thickness when the support was seeded with $100 \mathrm{~nm}$ crystals. With the increase of seed size from $600 \mathrm{~nm}$ to $3 \mu \mathrm{m}$ the seed layer became coarser and consequently intergrowth of the membrane became poorer. They also observed that a continuous membrane cannot be obtained if the supports were coated 
with large $(7.5 \mu \mathrm{m})$ seed crystals because of the formation of discontinuous seed layer.

Dinçer et al. [54] investigated the effect of seed amount on the membrane quality. They loaded different amounts of seed crystals by vacuum seeding and reported that a low amount of seed crystals forming a thin and uniform layer on the support surface led to the formation of compact and uniform ZSM-5 membrane layers whereas asymmetric ZSM-5 layers formed with increasing the seed amount.

Li et al. [59] showed that continuous mordenite or ZSM-5 type membranes can be prepared from the same synthesis solution under the same hydrothermal conditions by using mordenite or MFI seeds. They suggested that the zeolitic phase can be controlled by varying the type of seed crystals.

\subsubsection{Effects of hydroxyl, soda, template concentrations on membrane properties}

The choice of synthesis composition is critical to prepare good quality MFI membranes. A wide range of concentration of components in the synthesis solution was researched to produce good quality membranes [19, 30, 31]. A good zeolite membrane is likely to be thin and have no nonzeolitic pores. The membrane thickness depends on the number and size of its constituent crystals. The $\mathrm{Na}_{2} \mathrm{O} / \mathrm{SiO}_{2}, \mathrm{OH}^{-} / \mathrm{SiO}_{2}$ and $\mathrm{TPA}^{+} / \mathrm{SiO}_{2}$ ratios in the synthesis mixture affect the crystal size and consequently the membrane thickness. The organic molecules like TPAOH or TPABr serves as template (structure directing agent) during the formation of MFI type zeolites so they are encapsulated in the pores of the crystal. Therefore they have to be removed from the pores by thermal treatment after synthesis. 
Kim et al. [60, 61] synthesized template free ZSM-5 crystals and investigated the effect of $\mathrm{Na}_{2} \mathrm{O}$ content on the crystal purity and morphology. They reported that if the $\mathrm{SiO}_{2} / \mathrm{Al}_{2} \mathrm{O}_{3}$ ratio is lower than 30 the $\mathrm{Na}_{2} \mathrm{O}$ content should be as low as possible to obtain pure ZSM-5. They also found that the crystal size decreased with the increase in $\mathrm{Na}_{2} \mathrm{O}$ content. They concluded that $\mathrm{Na}^{+}$ cation acts as a structure directing agent and enhances the nucleation and crystallization rate. They reported that the crystallization period to reach 100 $\%$ crystallinity decreased from $36 \mathrm{~h}$ to $30 \mathrm{~h}$ as $\mathrm{Na}_{2} \mathrm{O} / \mathrm{SiO}_{2}$ molar ratio of the synthesis solution increased from 0.09 to 0.14 .

Wong et al. [30, 31] investigated the effects of alkalinity on zeolite growth rate by using synthesis solution containing a mixture of TPABr and TPAOH. At constant temperature and $\mathrm{TPA}^{+} / \mathrm{SiO}_{2}$ ratio, the growth rate of the zeolite layer increased from $0.03 \mu \mathrm{m} / \mathrm{h}$ to $0.15 \mu \mathrm{m} / \mathrm{h}$ with increasing the $\mathrm{OH}^{-} / \mathrm{SiO}_{2}$ ratio from 0.07 to 0.27 . On the other hand, poor intergrowth among the crystals in the membrane layer was obtained and dissolution of MFI crystals was observed at high $\mathrm{OH}^{-} / \mathrm{SiO}_{2}$ ratios. They concluded that low $\left(\mathrm{OH}^{-} / \mathrm{SiO}_{2}<0.18\right)$ and high $\left(\mathrm{OH}^{-} / \mathrm{SiO}_{2}>0.45\right)$ concentrations of $\mathrm{OH}^{-}$have detrimental effect on the membrane quality.

Wang and Yan [62] varied $\mathrm{OH}^{-} / \mathrm{SiO}_{2}$ ratio from 0.1 to 1.0 by changing the TPAOH concentration of the synthesis mixture. They observed that crystal size passed through a minimum at $\mathrm{OH}^{-} / \mathrm{SiO}_{2}$ of 0.5 . They concluded that nucleation was inhibited at high and low TPAOH concentrations leading to formation fewer, yet larger crystals.

In the formation of MFI type zeolite membranes, it is also important to optimize the $\mathrm{SiO}_{2} / \mathrm{TPA}^{+}$ratio to obtain highly intergrown crystals in the membrane layer [26]. Noack et al. [26] reviewed the effect of $\mathrm{SiO}_{2} /(\mathrm{TPAOH}+\mathrm{TPABr})$ ratio during the synthesis of MFI membranes at $180^{\circ} \mathrm{C}$ over $72 \mathrm{~h}$ on seeded supports. The $\mathrm{SiO}_{2} /(\mathrm{TPAOH}+\mathrm{TPABr})$ ratio was changed between 3.3 and $\infty$. Membranes with highest $\mathrm{H}_{2} / \mathrm{SF}_{6}$ ideal selectivity of 249 
were obtained from mixtures with a $\mathrm{SiO}_{2} / \mathrm{TPA}^{+}$ratio of 30 . On the other hand, the mechanical stability of membranes decreased with increasing $\mathrm{SiO}_{2} / \mathrm{TPA}^{+}$ ratio.

\subsection{Crystal orientation in MFI type zeolite membranes}

MFI type zeolite structures exhibit an anisotropic pore geometry with their straight and zig-zag channels. Since this anisotropic structure results in an anisotropy in mass transport the orientation of the crystals can strongly influence the permeation behavior [19].

Figure 2.2 shows the different configurations of crystals on a surface and their corresponding XRD patterns. When the MFI crystals form a randomly oriented membrane layer, the XRD patterns of the membrane and powder MFI are likely to be the same as shown in Figure 2.2.a. The MFI crystals can be oriented on the surface in four different configurations. When the crystals oriented in a specific direction, the reflections from planes parallel to surface appear more strongly in the XRD pattern. For instance, in a membrane with aoriented crystals(Figure 2.2.b), the zig-zag channels are perpendicular to the support surface while the straight channels are parallel to the surface. Therefore the reflection from (200) plane shows strong intensity in the XRD pattern of a-oriented membranes. In these types of membranes, the permeating molecules should diffuse through zig-zag channels between feed and retentate sides $[19,59]$. The b-oriented MFI membranes are the most favorable type for gas separation. In this kind of orientation, the straight channels of the MFI crystals are perpendicular to the surface (Figure 2.2.c), therefore the diffusion rate is expected to be high in this configuration. 


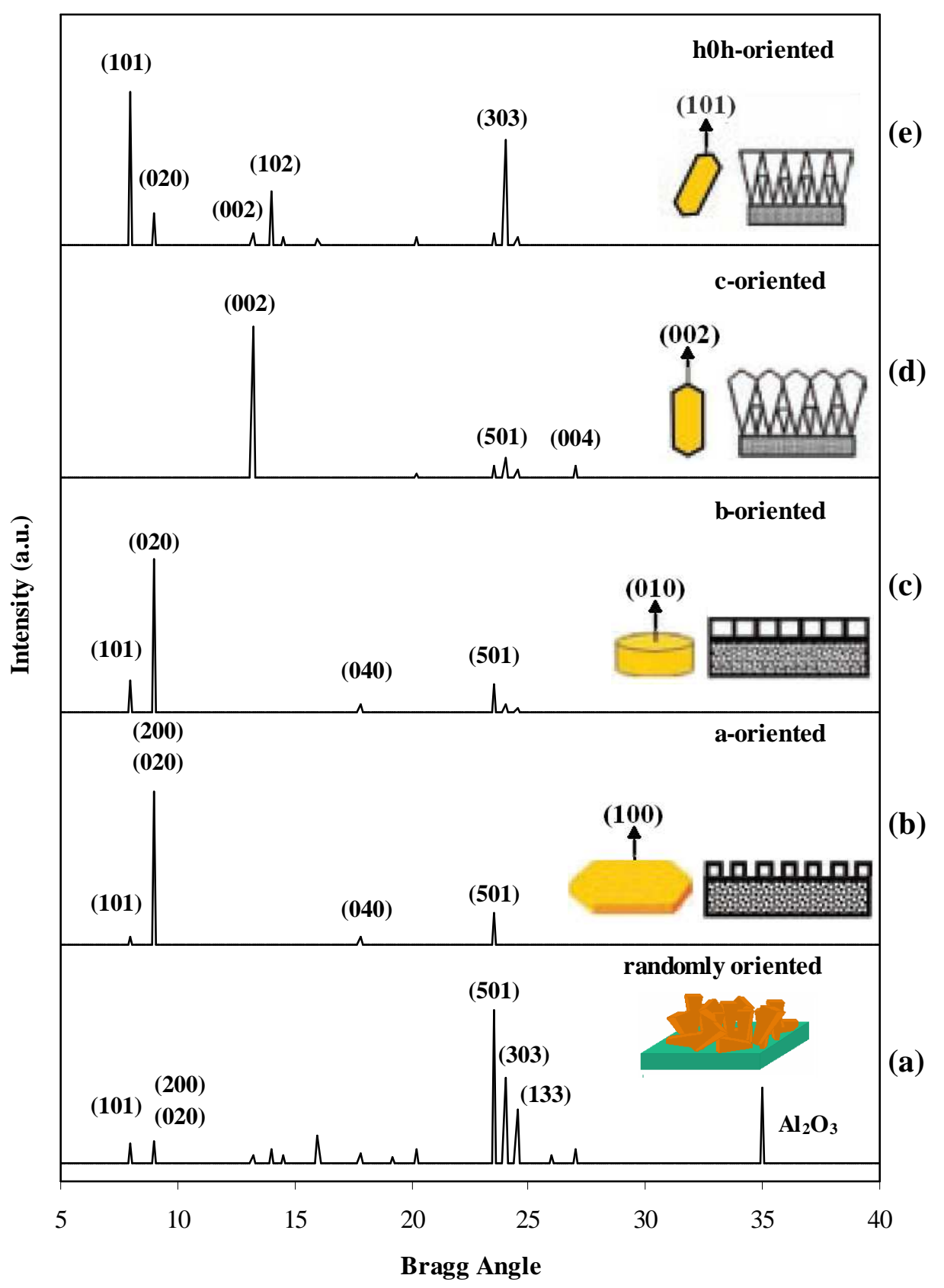

Figure 2.2 The representative XRD patterns and schematic drawings of different crystal orientations in MFI type zeolite membranes.

Other types of orientation are c-directed (Figure 2.2.d) and h0h-directed (Figure 2.2.e) orientations. In c-directed membranes, both straight and zig-zag channels become parallel to the surface and in h0h-directed membranes, the 
crystals make a $34^{\circ}$ angle with the normal to the surface. Therefore a gas molecule can penetrate form one side of the membrane to the other side by jumping between the straight and zig-zag channels. The diffusion rate in these kind of membranes is likely to be the lowest among all types.

The orientation of crystals along a certain direction during the membrane synthesis mainly depends on the composition of synthesis mixture [ 63, 64]. Wang and Yan [62] reported that the $\mathrm{OH}^{-} / \mathrm{Si}$ and $\mathrm{Na}^{+} / \mathrm{TPA}^{+}$ratio of the synthesis mixture mainly affects the crystal orientation in MFI membranes. For instance, b-oriented membranes were obtained from solutions with $\mathrm{OH}^{-} / \mathrm{Si}$ ratio of 0.36 and $\mathrm{Na}^{+} / \mathrm{TPA}^{+}$ratio of 0.13 . On the other hand, randomly oriented membranes were obtained from solutions with $\mathrm{OH}^{-} / \mathrm{Si}$ ratio of 0.82 and $\mathrm{Na}^{+} / \mathrm{TPA}^{+}$ratio of 1.56 .

In addition to synthesis composition crystal orientation also depends on the seeding the support surface. If a randomly oriented seed layer is used coriented or (h0h)-oriented films are obtained. On the other hand, if the membrane is synthesized on a support coated with a- or b-oriented seed crystals, the final membrane layer will also be a- or b-oriented $[65,66]$.

Since the MFI crystals grow faster in c-direction than a- and b-directions, most MFI membranes are c-oriented with a columnar structure $[42,65,66]$ as shown in Figure 2.3. Many researches [30, 31, 36, 43, 59, 67, 68] have suggested that during the hydrothermal reaction the seed crystals grow with an evolutionary columnar growth mechanism which may be responsible for this type of orientation. According to this mechanism, at early stages of the secondary growth, the seed crystals can grow in all possible directions with the different growth rates and these crystals intersect and grow into one another as time proceeds. Finally, the crystals with the fastest growth rate normal to the film towards the solution phase survived at the surface while others are embedded 
under the growing layer. Therefore, the crystals forming the membrane layer have columnar structure and exhibit a preferred orientation.
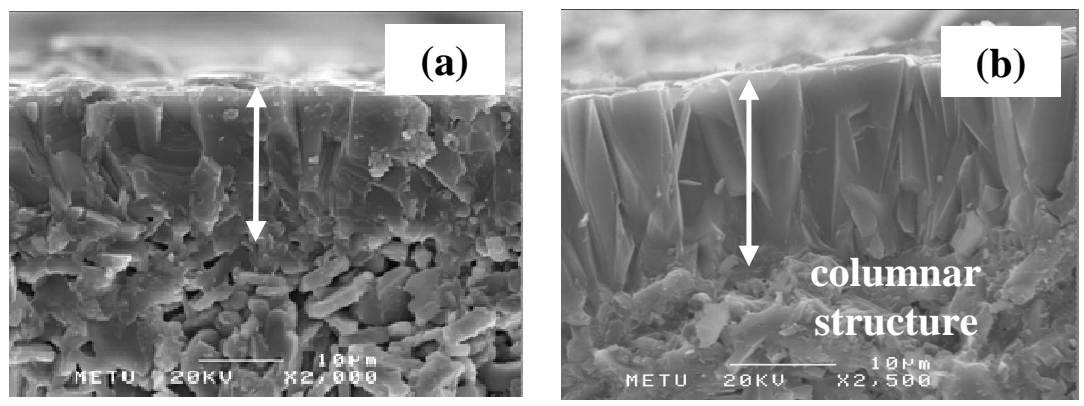

Figure 2.3 Randomly (a) and c-oriented (b) membrane structures [this study]

\subsection{Characterization of the membranes}

Zeolite membranes are often characterized by X-ray diffraction for phase identification and scanning electron microscopy for morphology determination. Single gas permeation tests using molecules with different kinetic diameters are also used to characterize membranes.

Gas permeation tests can be done by two methods which are distinguished by the sweep gas utilization [42]. In a method without sweep gas an absolute pressure drop is maintained across the membrane throughout the experiment $[18,38,52]$. The biggest advantage of the absolute pressure drop method is that single gas permeation rates can be measured directly, quickly and simply. Another method is the Wicke Kallenbach method [4, 14, 15, 37]. In this method, both feed and permeate side are at the same pressure. At the permeate side an inert sweep gas like helium, argon or nitrogen flows to carry the permeated molecules to out of the membrane cell. The major drawback is that the permeation of the feed components can be affected from the counter 
diffusion of the inert sweep gas [42]. Besides the permeated gas mixture should be analyzed to be able to calculate the permeance.

Light alkanes $\left(\mathrm{C}_{1}-\mathrm{C}_{4}\right)$ and inorganic gases are usually used for permeation studies since the pore size and adsorption properties of MFI type zeolites are suitable for the separation of those gases. Figure 2.4 compares the pore size of MFI crystals with the kinetic diameter of some hydrocarbons and permanent gases. Separation performance of membranes are affected from the differences in kinetic diameters, and diffusivities, and adsorption strengths $[25,69,70]$.

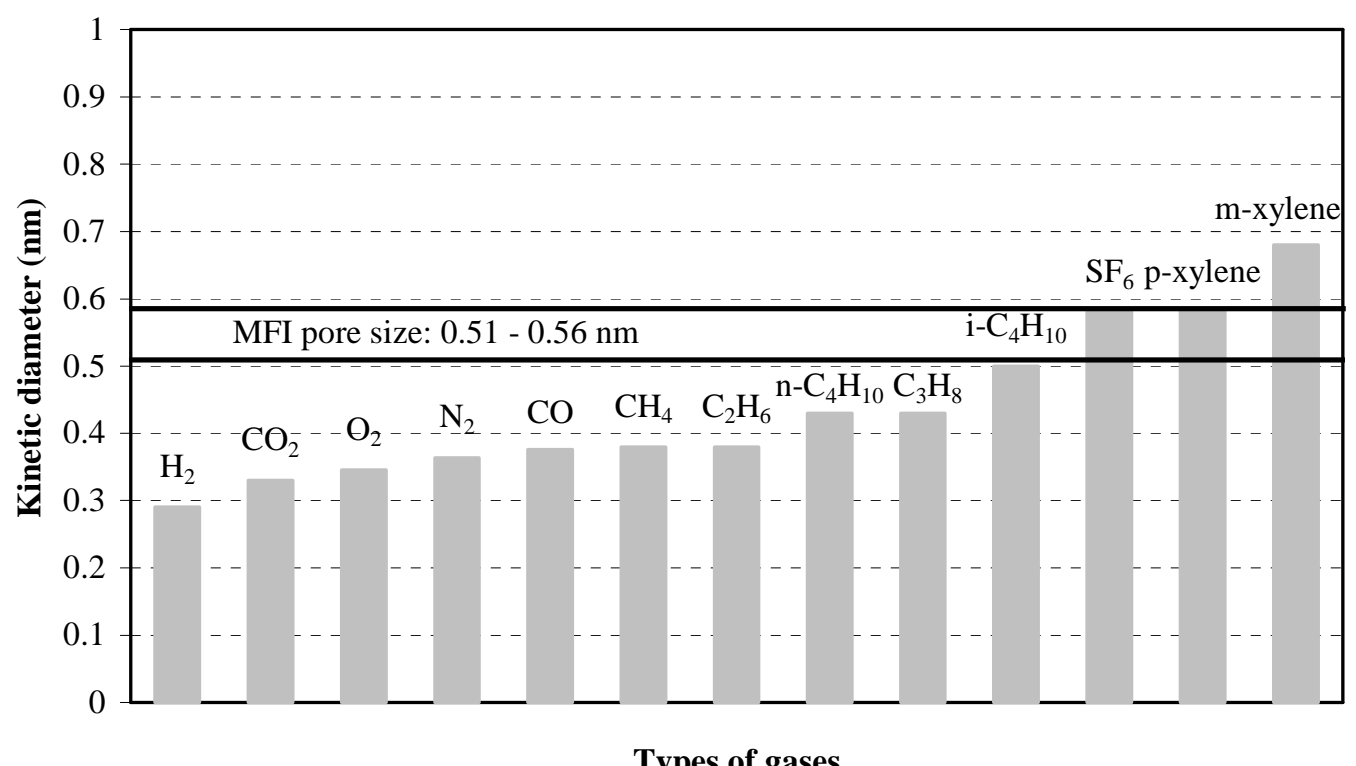

Figure 2.4 Comparison of pore size of MFI type zeolites with the kinetic diameters of different gases

Several criteria like $\mathrm{H}_{2} / \mathrm{SF}_{6}[3]$ or $\mathrm{N}_{2} / \mathrm{SF}_{6}[9,40,51,71]$ ideal selectivities were used to evaluate the membrane quality. Bernal et al. [51] used $\mathrm{N}_{2} / \mathrm{SF}_{6}$ ideal selectivity of 10 as quality criterion whereas MacDougall et al. [72] have 
claimed that in a defect free MFI membrane $\mathrm{N}_{2} / \mathrm{SF}_{6}$ ideal selectivity can be as low as 4. Since the $\mathrm{SF}_{6}$ molecules have comparable kinetic diameter with MFI type zeolite pores, they cannot easily diffuse into the zeolite pores as $\mathrm{N}_{2}$ can do. So $\mathrm{N}_{2} / \mathrm{SF}_{6}$ ideal selectivity can be taken as quality criterion [27-29]. Besides, Noack et al. [15] considered that a membrane with $\mathrm{H}_{2} / \mathrm{SF}_{6}$ ideal selectivity greater than 40 can be viewed as a good quality membrane. In some studies $n-\mathrm{C}_{4} \mathrm{H}_{10} / \mathrm{i}-\mathrm{C}_{4} \mathrm{H}_{10}$ ideal or separation selectivities were used as a measure of membrane quality $[35,37,57,71]$, since isomers cannot be separated in mesopores. Knudsen diffusion dominates in mesopores and separation of gases is based on the differences in molecular weights. Therefore separation of butane isomers that can only be accomplished by MFI membranes without defects is a good indication of membrane quality.

\subsection{Permeation through MFI membranes}

In zeolite pores both surface diffusion and activated gaseous diffusion contribute to the total flux of gases $[16,69,70]$. The permeance resulting from activated gaseous diffusion is independent of pressure drop. The permeation through non-zeolitic pores in which Knudsen diffusion and viscous flow take place should be taken into consideration in addition to permeation through zeolitic pores. Similar to activated gaseous diffusion the permeance from Knudsen diffusion is independent of the pressure drop across the membrane whereas the permeance from viscous flow increases with increasing feed pressure [73].

Van de Graaf et al. [74] have investigated the pressure dependence of the permeances of helium and neon. They reported that only at low temperatures (200-210 K) permeances slightly increased with increasing pressure drop across the membrane. Jareman et al. [5] and Gopalakrishnan et al. [21] have also investigated the effects of applied feed pressure on the single gas permeances. They showed that the changing the feed pressure with constant 
permeate pressure did not affect the $\mathrm{H}_{2}, \mathrm{~N}_{2}$ and $\mathrm{He}$ permeances. Gopalakrishnan et al. [75] also suggested that pressure-independent permeation of the small molecules indicate defect-free membrane structure and pressure dependent permeation of larger molecules indicate adsorption dependency.

On the other hand, temperature has strong influence on the permeation through MFI membranes. Bakker et al. [69] proposed a transport mechanism for the weakly adsorbing gases and light hydrocarbons. According to this mechanism since the increase in temperature enhances the mobility of adsorbed species, permeation rate increases with increasing temperature and goes through a maximum and then decreases. As a result of further increase in temperature the permeance reaches a minimum. At a sufficiently high temperature the adsorption becomes negligible and only diffusion controls the permeance. Therefore after permeance reaches to minimum it starts to increase again with increasing temperature. Strongly adsorbing molecules have a minimum in permeance at higher temperatures than weakly adsorbing molecules.

Coronas et al. [25], on the other hand, proposed that not only the adsorption and diffusion properties of the gas molecules in the zeolite pores but also the presence of non-zeolitic pores affects the permeation behaviour. The nonzeolitic pores are usually in the mesopore range, in which Knudsen diffusion governs the permeation of gas molecules. The permeation with Knudsen mechanism is weakly temperature dependent. Thereofore membranes with different relative amounts of zeolite and non-zeolitic pores exhibit different temperature dependency [9]. If the membrane has large number of mesoporous defects, the permeance slightly change with temperature, whereas the permeances through membranes with few defects are expected to show strong temperature dependency. 


\subsection{Gas separation with the MFI membranes}

Zeolite membranes are capable of separating compounds by molecular sieving, competitive adsorption, and differences in diffusion rates. In mixtures of strongly and weakly adsorbing molecules the permeation of weakly adsorbing molecules is inhibited by the strongly adsorbing molecules resulting in pore blocking effects. For example in $\mathrm{n}-\mathrm{C}_{4} \mathrm{H}_{10} / \mathrm{i}-\mathrm{C}_{4} \mathrm{H}_{10}[10,16,19]$ or hydrocarbon/methane mixture the preferentially adsorbed molecules hinder the passage of the other components in the mixture. Hence, if the species are affected from the others in the mixture, separation selectivity cannot be predicted from the ideal selectivity of pure components.

Since the effect of adsorption becomes negligible as temperature increases the existence of molecular sieving effect can be monitored at high temperatures. Jareman et al. [76] separated hexane isomers by using MFI type membranes. The kinetic diameters of $\mathrm{n}-\mathrm{C}_{6} \mathrm{H}_{14}$ and 2,2DMB (2,2 dimethylbutane) molecules are 0.43 and $0.6 \mathrm{~nm}$, respectively. $\mathrm{n}-\mathrm{C}_{6} \mathrm{H}_{14}$ is smaller but 2,2DMB is larger than the MFI pores. They obtained $n-\mathrm{C}_{6} \mathrm{H}_{14} / 2,2 \mathrm{DMB}$ separation selectivity as 85 at $400^{\circ} \mathrm{C}$. High separation selectivity at such a high temperature was attributed to the separation by molecular sieving and to very high quality of the membrane.

Poshusta et al. [9] investigated single gas and mixture permeances of $\mathrm{CO}_{2}$ and $\mathrm{CH}_{4}$ at different temperatures. They observed that membranes with the largest permeation through non-zeolitic pores had the lowest $\mathrm{CO}_{2} / \mathrm{CH}_{4}$ mixture selectivity. The highest $\mathrm{CO}_{2} / \mathrm{CH}_{4}$ mixture selectivity was 5.5 at room temperature. The selectivity decreased with temperature because of a decrease in adsorption at high temperatures. 
Vroon et al. [3] synthesized MFI membranes with a thickness of $2 \mu \mathrm{m}$ by multiple synthesis steps. They used those membranes in the separation of $50 \% / 50 \%$ binary gas mixtures. The membrane had separation selectivity of $n-$ $\mathrm{C}_{4} \mathrm{H}_{10} / \mathrm{i}-\mathrm{C}_{4} \mathrm{H}_{10}$ over 10 and $n-\mathrm{C}_{4} \mathrm{H}_{10} / \mathrm{CH}_{4}$ over 18 at $200^{\circ} \mathrm{C}$. High selectivities obtained during the separation of butane isomers at high temperatures was attributed to the blocking of non-zeolitic pores by applying multiple synthesis.

Although there are many studies related with the separation of binary gas mixtures, separation of multicomponent gas mixtures [10, 39, 77] is very limited. The studies performed for the separation of multicomponent gas mixtures was summarized in Table 2.1.

Dong et al. [77] worked on the permeation of a simulated refinery gas stream including hydrogen and light hydrocarbons through MFI type zeolite membranes. According to their studies, this type of zeolite membrane shows rejection of hydrogen from the hydrogen/hydrocarbon mixture at low temperatures $\left(\mathrm{T}<100^{\circ} \mathrm{C}\right)$ while at high temperatures the membranes become permselective for hydrogen over hydrocarbons.

Natural gas purification is an important application of the multicomponent mixture separation [10]. Natural gas is a mixture of light hydrocarbons including mainly methane and in small amounts of ethane, propane, butanes and pentanes. Other compounds found in natural gas include carbon dioxide, helium, hydrogen sulphide and nitrogen. The composition of natural gas depends primarily on the production field.

The high hydrocarbons and $\mathrm{CO}_{2}$ contents of natural gas are very critical for industrial use. It is desired to remove these compounds from methane. Because carbon dioxide is highly corrosive and it has detrimental effects to pipelines and the equipment. High hydrocarbons, however, decrease the methane 
concentrations and cause detonation in gas combustion engines. In addition, the recovered hydrocarbons are more valuable than methane so that they may be used for other applications [10].

Table 2.1 Studies for the separation of multicomponent gas mixtures in the literature

\begin{tabular}{|c|c|c|c|c|}
\hline $\begin{array}{c}\text { Multicomponent } \\
\text { separation type }\end{array}$ & $\begin{array}{c}\text { Mixture } \\
\text { composition }\end{array}$ & \multicolumn{2}{|c|}{ Separation selectivity } & References \\
\hline $\begin{array}{l}\text { Hydrocarbons } \\
\text { from natural gas }\end{array}$ & $\begin{array}{c}83.5 \% \mathrm{CH}_{4} \\
7.5 \% \mathrm{C}_{2} \mathrm{H}_{6} \\
2 \% \mathrm{C}_{3} \mathrm{H}_{8} \\
0.5 \% \mathrm{n}-\mathrm{C}_{4} \mathrm{H}_{10} \\
0.3 \% \mathrm{i}-\mathrm{C}_{4} \mathrm{H}_{10} \\
0.13 \% \mathrm{n}-\mathrm{C}_{5} \mathrm{H}_{12} \\
0.11 \% \mathrm{i}-\mathrm{C}_{5} \mathrm{H}_{12} \\
0.1 \% \mathrm{n}-\mathrm{C}_{6} \mathrm{H}_{14} \\
0.3 \% \mathrm{CO}_{2} \\
\text { balance } \mathrm{N}_{2}\end{array}$ & $\begin{array}{c}\mathrm{RT} \\
\mathrm{n}-\mathrm{C}_{4} \mathrm{H}_{10} / \mathrm{CH}_{4}=14.5 \\
\mathrm{n}-\mathrm{C}_{4} \mathrm{H}_{10} / \mathrm{i}-\mathrm{C}_{4} \mathrm{H}_{10}=11 \\
\mathrm{C}_{3} \mathrm{H}_{8} / \mathrm{CH}_{4}=4.5 \\
\mathrm{C}_{2} \mathrm{H}_{6} / \mathrm{CH}_{4}=2.5 \\
\mathrm{C}_{3} \mathrm{H}_{8} / \mathrm{C}_{2} \mathrm{H}_{6}=2\end{array}$ & $\begin{array}{c}100^{\circ} \mathrm{C} \\
\mathrm{n}-\mathrm{C}_{4} \mathrm{H}_{10} / \mathrm{CH}_{4}=4 \\
\mathrm{n}-\mathrm{C}_{4} \mathrm{H}_{10} / \mathrm{i}-\mathrm{C}_{4} \mathrm{H}_{10}=13 \\
\mathrm{C}_{3} \mathrm{H}_{8} / \mathrm{CH}_{4}=1.5 \\
\mathrm{C}_{2} \mathrm{H}_{6} / \mathrm{CH}_{4}=3 \\
\mathrm{C}_{3} \mathrm{H}_{8} / \mathrm{C}_{2} \mathrm{H}_{6}=1\end{array}$ & 10 \\
\hline $\begin{array}{l}\text { Hydrogen / } \\
\text { Hydrocarbon } \\
\text { separation }\end{array}$ & $\begin{array}{c}84.5 \% \mathrm{H}_{2} \\
7.6 \% \mathrm{CH}_{4} \\
2.5 \% \mathrm{C}_{2} \mathrm{H}_{6} \\
2.5 \% \mathrm{C}_{2} \mathrm{H}_{4} \\
0.8 \% \mathrm{C}_{3} \mathrm{H}_{8} \\
1.5 \% \mathrm{C}_{3} \mathrm{H}_{6} \\
0.4 \% \mathrm{n}^{-} \mathrm{C}_{4} \mathrm{H}_{10} \\
0.3 \% \mathrm{i}-\mathrm{C}_{4} \mathrm{H}_{10}\end{array}$ & $\begin{array}{r}\mathrm{H}_{2} / \mathrm{Hyd} \\
0 \text { at } \\
0.09 \mathrm{a} \\
0.18 \mathrm{at} \\
2 \mathrm{at} \\
2.9 \text { at } \\
3.05 \text { at }\end{array}$ & $\begin{array}{l}\text { rocarbon } \\
25^{\circ} \mathrm{C} \\
75^{\circ} \mathrm{C} \\
105^{\circ} \mathrm{C} \\
50^{\circ} \mathrm{C} \\
200^{\circ} \mathrm{C} \\
500^{\circ} \mathrm{C}\end{array}$ & 39 \\
\hline $\begin{array}{c}\text { Removal of } \\
\text { pollutants from } \\
\text { indoor air }\end{array}$ & $\begin{array}{c}\text { n-hexane, } \\
\text { formaldehyde and } \\
\text { benzene (2-230 } \\
\text { ppm) in air }\end{array}$ & $\begin{array}{r}\text { n-hexane } \\
\text { formaldehy } \\
\text { benzene } \\
\text { at } 2\end{array}$ & $\begin{array}{l}\text { air }=250 \\
\text { de/air }=6.3 \\
\text { /air }=38 \\
5^{\circ} \mathrm{C}\end{array}$ & 77 \\
\hline
\end{tabular}


Arruebo et al. [10] investigated the performances of MFI type membranes on the separation of hydrocarbons from natural gas. They used the simulated natural gas feed with a composition of $85 \mathrm{~mol} \%$ methane and $15 \mathrm{~mol} \%$ higher hydrocarbons (the composition is given in Table 1.1). They separated the natural gas feed into two streams, a hydrocarbon rich stream and methane rich stream. They concluded that zeolite membranes were able to separate hydrocarbons from methane with a good selectivity. 


\title{
CHAPTER 3
}

\section{EXPERIMENTAL}

\subsection{Materials for Synthesis of MFI type zeolite powders and membranes}

\begin{abstract}
Throughout this study the following reactants were used in the synthesis of zeolite powder and membranes: 30 or $40 \mathrm{wt} \%$ colloidal suspension of silica particles in water (LUDOX AS-30 or LUDOX AS-40, Aldrich), or tetraethylorthosilicate (TEOS, $98 \mathrm{wt} \%$, Merck) as silica sources, tetrapropylammonium hydroxide (TPAOH, 25 or $40 \mathrm{wt} \%$ in water, Merck) or tetrapropylammonium bromide (TPABr powder, pure, Merck) as template sources, $\mathrm{NaOH}$ pellets (97 wt $\% \mathrm{NaOH}, 2 \mathrm{wt} \%$ water, Merck) as soda source and deionized water (DI water).
\end{abstract}

\subsection{Type of supports used for membrane synthesis}

The membranes were prepared on three different types of porous alumina supports. These were homemade and commercial $\alpha-\mathrm{Al}_{2} \mathrm{O}_{3}$ discs and commercial $\alpha-\mathrm{Al}_{2} \mathrm{O}_{3}$ tubes.

Homemade discs had a diameter of $20 \mathrm{~mm}$ and a thickness of $1 \mathrm{~mm}$. The average pore size was $1.3 \mu \mathrm{m}$, which was determined by mercury intrusion porosimeter. The procedure to prepare homemade $\alpha-\mathrm{Al}_{2} \mathrm{O}_{3}$ discs and the pore size distribution of those discs were given in detail in Appendix C.

Commercial $\alpha-\mathrm{Al}_{2} \mathrm{O}_{3}$ discs, which were purchased from Inocermic, Germany had a diameter of $20 \mathrm{~mm}$ and a thickness of $1 \mathrm{~mm}$. These discs had asymmetric 
structure composed of a thin top layer with pores $200-\mathrm{nm}$ in size and a thick macroporous body.

Commercial $\alpha-\mathrm{Al}_{2} \mathrm{O}_{3}$ tubes of Pall Exekia, USA had a length of $4.5 \mathrm{~cm}$ and an inner diameter of $0.7 \mathrm{~cm}$. The top layer on the inner surface has an average pore size of $0.2 \mu \mathrm{m}$. Before membrane synthesis, the tubes were cleaned by keeping in an ultrasonic bath for $10 \mathrm{~min}$, washing in $0.1 \mathrm{M} \mathrm{HNO}_{3}$ solution and rinsing with deionized water. The tubes were then dried at $80^{\circ} \mathrm{C}$. Both ends of the tubes were glazed with Duncan IN1001 Envision Glaze to create nonporous tips of about $1 \mathrm{~cm}$. The membranes had a permeation area of approximately $5.5 \mathrm{~cm}^{2}$.

Nonporous glass discs were also used for the synthesis of MFI type zeolite films. These discs were cut from microscope slides and had a diameter of 20 $\mathrm{mm}$ and a thickness of $1 \mathrm{~mm}$.

\subsection{Seeding of the supports}

Vacuum seeding and dipcoating techniques were used for the seeding of the supports throughout the study.

\subsubsection{Vacuum seeding technique}

Vacuum seeding apparatus was shown in Figure 3.1. In this system, a disc was sealed inside the rubber gasket and then placed between two polyamide dies. Screws were used to hold the disc in the module. A seed suspension was poured on the $\alpha-\mathrm{Al}_{2} \mathrm{O}_{3}$ disc and vacuum pump is used to take water in the suspension away. The seed suspension was $0.02 \mathrm{wt} \% 1 \mu \mathrm{m}$ size MFI crystals or $0.25 \mathrm{wt} \% 350 \mathrm{~nm}$ size MFI crystals in DI water. The suspension was stirred on a magnetic stirrer for $30 \mathrm{~min}$ and then ultrasonicated for $10 \mathrm{~min}$. to disperse the crystals uniformly. $4 \mathrm{ml}$ of this suspension was used to coat the surface of a disk. Only one side of a disk was seeded. The remaining part of suspension 
was stored in polypropylene bottles for further use. Stirring and ultrasonication was applied just before next use to redisperse the crystals settled during the storage. After seeding all $\alpha-\mathrm{Al}_{2} \mathrm{O}_{3}$ were dried at $150^{\circ} \mathrm{C}$ for 4 hours.

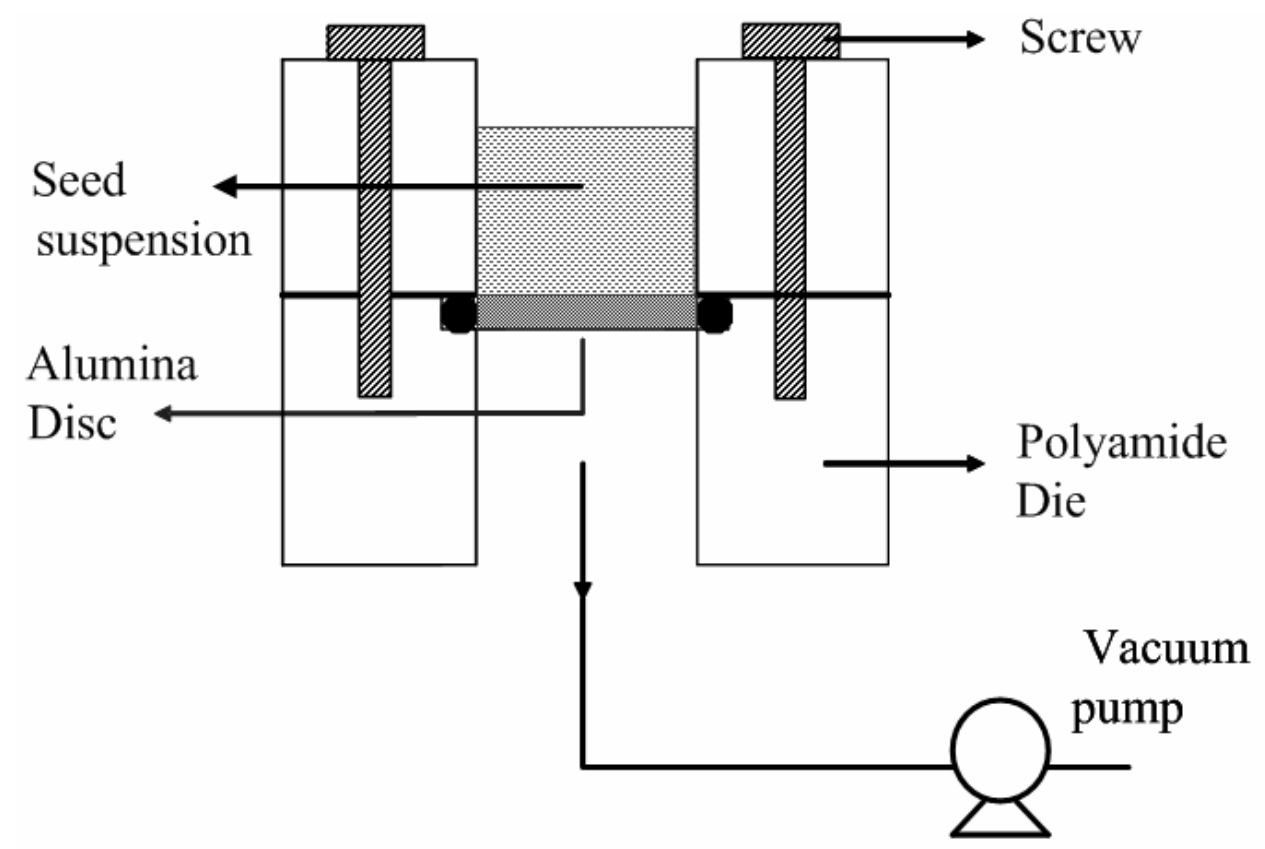

Figure 3.1 Vacuum seeding apparatus

The same apparatus was also used to coat the nonporous glass disks with seeding crystals. Since vacuum cannot be applied to the nonporous glass, the seed suspension was prepared by dispersing MFI crystals in dichloromethane, which is a highly volatile solvent, instead of water. $4 \mathrm{ml}$ of seed suspension with a composition of $0.02 \mathrm{wt} \% 1 \mu \mathrm{m}$ size MFI crystals in dichloromethane was put on the glass disc. Discs were kept at room temperature for $2 \mathrm{~h}$ to evaporate the dichloromethane and to precipitate the crystals onto the surface. After evaporating the solvent, discs were further dried at $150^{\circ} \mathrm{C}$ for 4 hours. 


\subsubsection{Dip-coating technique}

The schematic drawing of the dip-coating setup is shown in Figure 3.2. This setup can be applied to both tubular and disk shaped supports. In this setup a beaker filled with approximately $100 \mathrm{~mL}$ of seed suspension is placed on a plastic syringe with a capacity of $60 \mathrm{~mL}$. The support is held with a PTFE holder above the beaker. The beaker containing the seed suspension is slowly raised by pumping water from a reservoir to the syringe so that the support sinks into the seed suspension. After dipping, the support is kept in the seed suspension for 10 minutes and the water in the syringe is pumped out to remove the support from the seed suspension. The seed suspension moved up and down at a rate of $1-1.5 \mathrm{~cm} / \mathrm{h}$ during seeding. This procedure was repeated twice, reversing the support upside down in the second time to achieve more uniform coatings. In case of disk support two beakers are placed on a plastic syringe. By doing this two supports are dipped in each beaker to enable seeding of four disc supports at the same time.

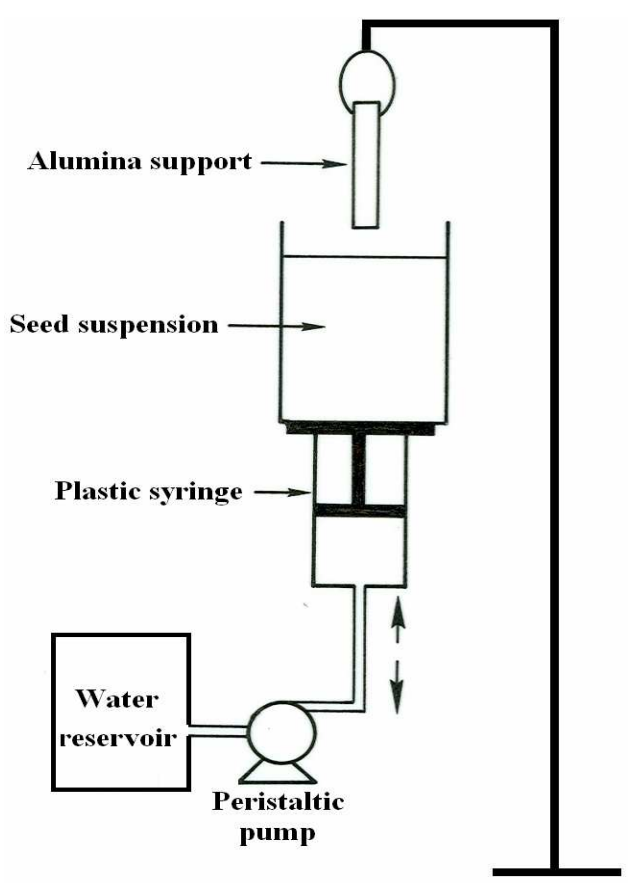

Figure 3.2. The schematic drawing of the dipcoating setup 
A seed suspension with a concentration of $0.25 \mathrm{wt} \%$ was prepared by dispersing $350 \mathrm{~nm}$ size MFI seed crystals in an aqueous solution of ammonia with a $\mathrm{pH}$ of 8 . The suspension was stirred on a magnetic stirrer for $30 \mathrm{~min}$ and then ultrasonicated for $10 \mathrm{~min}$. Stirring and ultrasonication was applied various times just before next use to redisperse the seeds that had settled during the period the seed suspension was stored. After seeding all $\alpha-\mathrm{Al}_{2} \mathrm{O}_{3}$ discs and tubes were dried at $150^{\circ} \mathrm{C}$ for 4 hours.

\subsubsection{Preparation of MFI crystals for use as seed}

In this study both submicron and micron sized crystals were used for seeding of the supports. Submicron seed crystals with a mean particle size of $350 \mathrm{~nm}$ were synthesized from the solutions with a molar composition of 1.0TPAOH:8.17 $\mathrm{SiO}_{2}: 0.08 \mathrm{Na}_{2} \mathrm{O}: 162.09 \mathrm{H}_{2} \mathrm{O}: 32.68 \mathrm{C}_{2} \mathrm{H}_{5} \mathrm{OH}$ in stainless steel autoclaves at $91^{\circ} \mathrm{C}$ for $24 \mathrm{~h}$. TEOS and $40 \%$ TPAOH were used as silica and template sources to synthesize the seed crystals, respectively. For the preparation of synthesis solution TPAOH was diluted with deionized water and TEOS was added into this solution. Then $\mathrm{NaOH}$ solution which was prepared by mixing $\mathrm{NaOH}$ pellets and deionized water in a separate cup was added. Since TEOS is immiscible with water, a two phase mixture was formed. The synthesis solution was mixed for $24 \mathrm{~h}$ at room temperature for the hydrolysis of TEOS and to obtain a clear solution.

Micron sized seed crystals were synthesized from the solutions with a molar composition of $6.5 \mathrm{Na}_{2} \mathrm{O}: 25 \mathrm{SiO}_{2}: 6.9 \mathrm{TPABr}: 1136 \mathrm{H}_{2} \mathrm{O}$ in stainless steel autoclaves at $130^{\circ} \mathrm{C}$ for $24 \mathrm{~h}$. LUDOX AS-30 and TPABr were used as silica and template sources to synthesize the micron sized seed crystals, respectively. For the preparation of synthesis solution $\mathrm{TPABr}$ and a part of distilled water was mixed, then $\mathrm{NaOH}$ pellets were added. This solution was stirred on a magnetic stirrer until all $\mathrm{NaOH}$ pellets and $\mathrm{TPABr}$ powder were dissolved in water. Then LUDOX AS-30 and the remaining water were added into this solution. The synthesis solution was stirred for $1 \mathrm{~h}$ and after stirring a blurry 
gel was obtained. The amounts of reactants to prepare $100 \mathrm{~g}$ of synthesis solution by both methods were given in Appendix A.

After previously decided period of time, the autoclaves were taken out of the oven and quenched to room temperature in cold tap water. The solid product was recovered from the mother liquid by centrifuging the contents of the autoclave at $640 \mathrm{~g}$ for $10 \mathrm{~min}$. The solid product was redispersed in DI water for washing and centrifuged again at the same centrifuging conditions. Washing was repeated several times until the $\mathrm{pH}$ of the solution above the solid dropped to nearly 8 . The solid products were dried in the centrifuging tubes at $80^{\circ} \mathrm{C}$ overnight, removed from the tubes and pounded in agate mortar.

The surface SEM images of the unseeded and seeded commercial $\alpha-\mathrm{Al}_{2} \mathrm{O}_{3}$ disc supports are shown in Figure 3.3. The seed crystals have uniform particle size distribution and the surfaces of the supports were totally coated with seed crystals by both seeding techniques. 

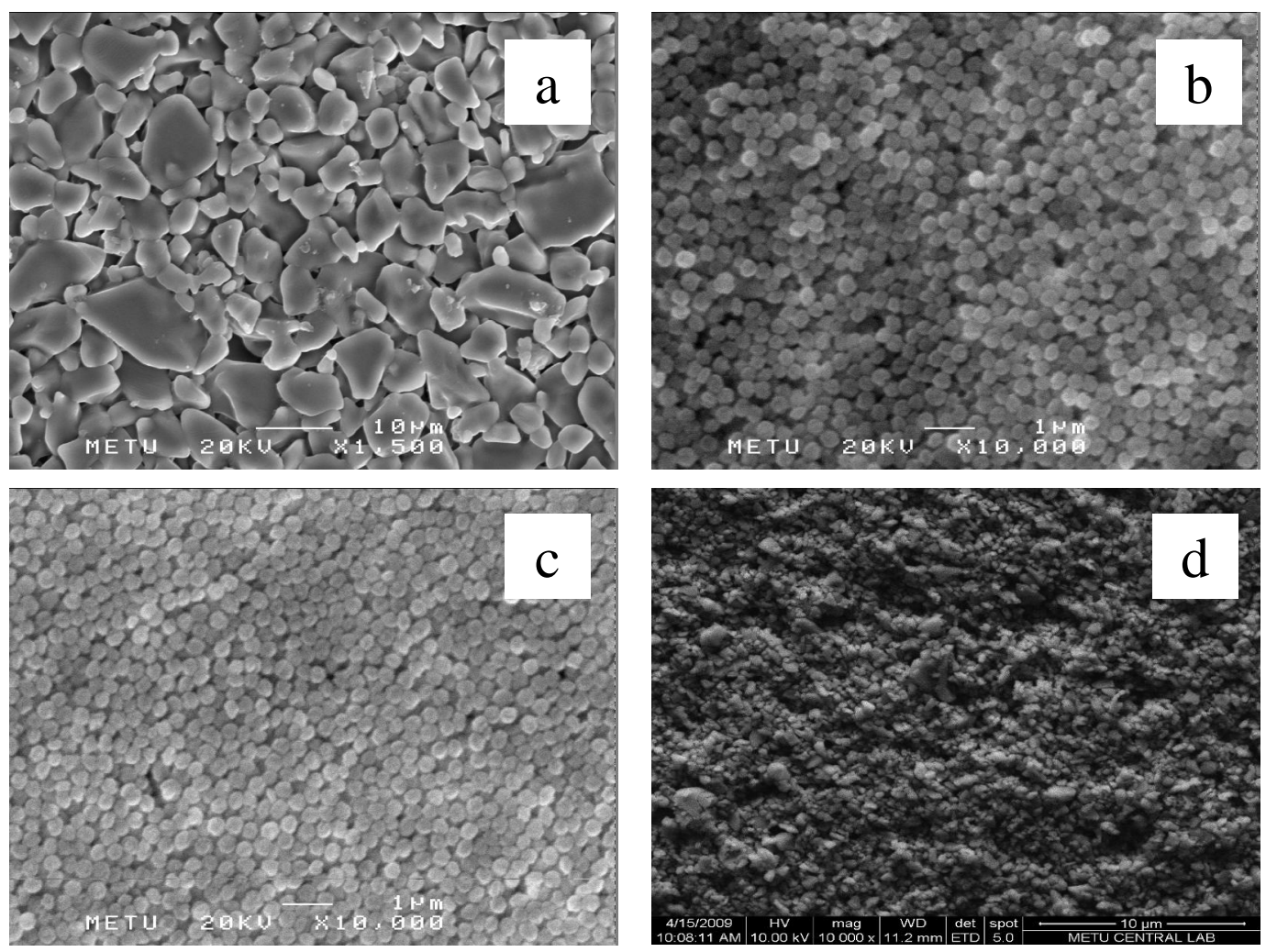

Figure 3.3 The surface SEM images of the unseeded commercial $\alpha-\mathrm{Al}_{2} \mathrm{O}_{3}$ disc supports (a), seeded with $350 \mathrm{~nm}$ seed crystals by dip-coating technique (b), seeded with $350 \mathrm{~nm}$ seed crystals by vacuum seeding technique (c) and seeded with $1 \mu \mathrm{m}$ seed crystals by vacuum seeding technique (d)

\subsection{Synthesis of MFI type zeolite membranes with different soda concentrations of crystallization solution}

The first part of the study was devoted to investigate the effect of soda concentration on the morphology and degree of orientation of MFI films and membranes.

Membranes were prepared on homemade $\alpha-\mathrm{Al}_{2} \mathrm{O}_{3}$ discs. These discs were seeded with $1 \mu \mathrm{m}$ sized MFI type zeolite crystals by vacuum seeding as described in Section 3.3. Membranes were synthesized from mixtures with a molar composition of $\mathrm{xNa}_{2} \mathrm{O}: 25 \mathrm{SiO}_{2}: 6.9 \mathrm{TPABr}: 1136 \mathrm{H}_{2} \mathrm{O}$ where $\mathrm{x}$ was 
changed between 0 and 6.9. LUDOX AS-30 and $1 \mathrm{M}$ stock solutions of $\mathrm{NaOH}$ and $\mathrm{TPABr}$ were used in the preparation of synthesis solutions. For the preparation of synthesis solution $\mathrm{NaOH}$ and $\mathrm{TPABr}$ solutions were mixed, then LUDOX and water were added into this solution. The synthesis solution was stirred for $1 \mathrm{~h}$. After stirring the synthesis solution was clear if $0.25<\mathrm{Na}_{2} \mathrm{O}<1.85$ and a blurry gel if $\mathrm{Na}_{2} \mathrm{O}>2.0$.

Membrane synthesis was carried out in stainless steel autoclaves with PTFE inserts having $35 \mathrm{ml}$ capacity at $150^{\circ} \mathrm{C}$ for $24 \mathrm{~h}$. The $\alpha-\mathrm{Al}_{2} \mathrm{O}_{3}$ discs were placed vertically in the middle of the inserts with PTFE holders. Following the hydrothermal treatment all membranes were washed with distilled water, and then dried at $80{ }^{\circ} \mathrm{C}$ overnight. Membranes were calcined at $450^{\circ} \mathrm{C}$ for 6 hours to remove the template from zeolite pores.

Membranes and the powder formed in the solution during the membrane synthesis were analyzed by X-ray diffraction (Philips PW1840 diffractometer) between $5-50^{\circ}$ Bragg angles using $\mathrm{Ni}$ filtered $\mathrm{Cu}-\mathrm{K} \alpha$ radiation. Operating conditions of the X-ray diffractometer was tabulated in Table 3.1. Membrane morphology was determined by JEOL JSM-6400 scanning electron microscope on gold coated samples at an accelarating voltage of $20 \mathrm{kV}$.

Table 3.1 The operation conditions of X-ray diffractometer

\begin{tabular}{|l|l|}
\hline Tube & $\mathrm{Cu}$ \\
\hline Filter & $\mathrm{Ni}$ \\
\hline Radiation & $\mathrm{Cu}-\mathrm{K} \alpha$ \\
\hline Voltage $(\mathrm{kV})$ & 30 \\
\hline Current $(\mathrm{mA})$ & 24 \\
\hline Speed $\left({ }^{\circ} 2 \theta / \mathrm{s}\right)$ & 0.1 \\
\hline Time constant $(\mathrm{s})$ & 1 \\
\hline Slit $(\mathrm{mm})$ & 0.2 \\
\hline
\end{tabular}


Single gas permeances of $\mathrm{H}_{2}, \mathrm{~N}_{2}, \mathrm{CO}_{2}, \mathrm{CH}_{4}, \mathrm{SF}_{6}, \mathrm{n}-\mathrm{C}_{4} \mathrm{H}_{10}$ and $\mathrm{i}-\mathrm{C}_{4} \mathrm{H}_{10}$ were measured at $25^{\circ} \mathrm{C}$ and $150^{\circ} \mathrm{C}$ with a dead-end membrane module. The schematic drawing of the single gas permeation setup is given in Figure 3.4. The feed pressure was between 1.4 and 2.8 bar absolute and the permeate side was at atmospheric pressure $(0.91$ bar). The flow rate of the permeate stream was measured by a bubble flow meter. For high temperature measurements, the module was wrapped with a heating tape, temperature was measured from the middle of the module and controlled by a temperature controller. The flow rate of the permeate stream was measured by a bubble flow meter. The ideal selectivity was defined as the ratio of single gas permeances. The calculation of single gas permeances and ideal selectivities are given in detail in Appendix D.

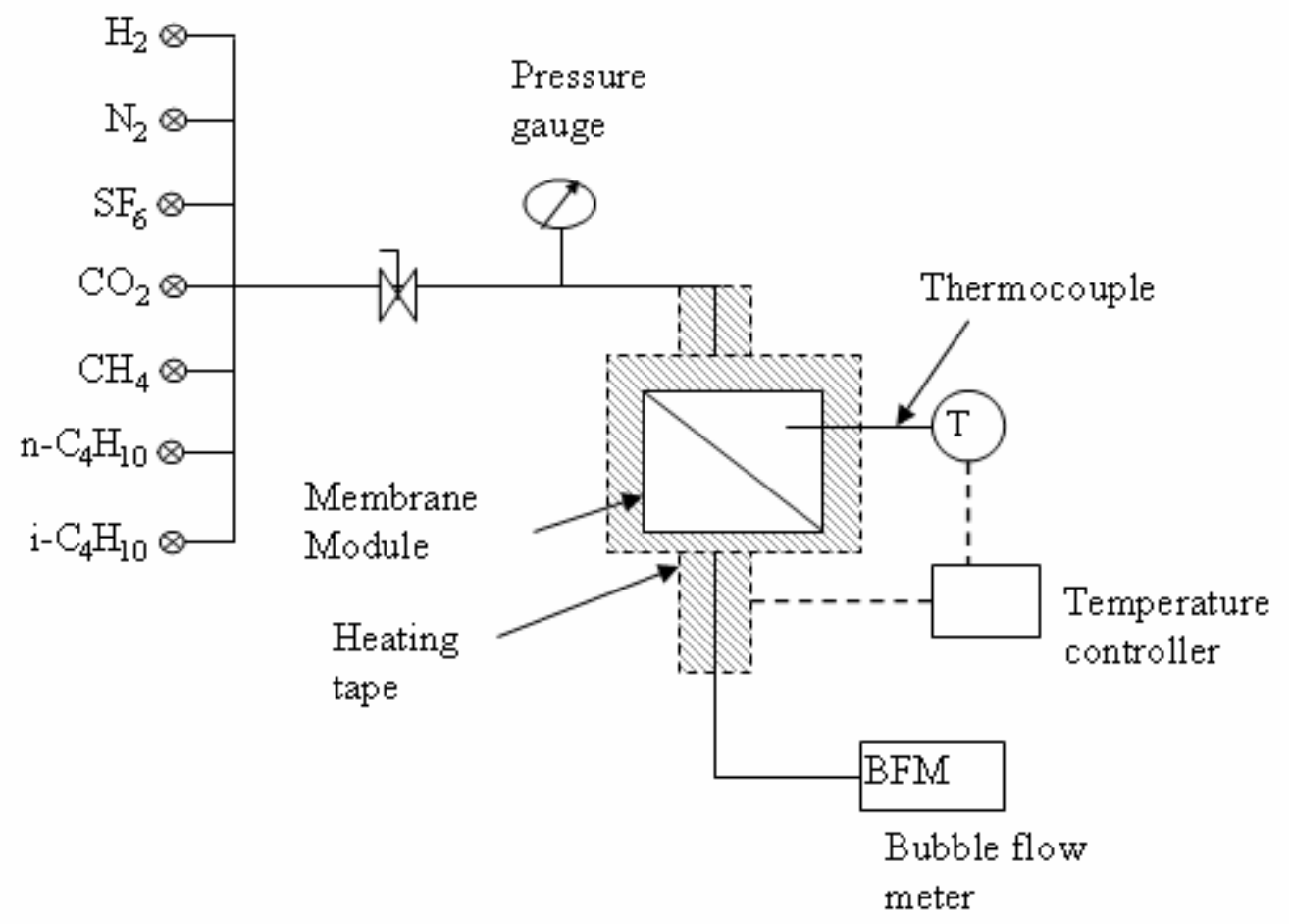

Figure 3.4 Schematic drawing of the single gas permeation setup 


\subsection{Synthesis of MFI type zeolite membrane and powder with different template concentrations of crystallization solution}

Both powder and membrane syntheses were carried out in this part of the study to investigate the effect of template concentration on the crystallization rate and the crystal size, which was the second part of the entire study.

MFI type zeolite was synthesized in powder form from solutions with a composition of $80 \mathrm{SiO}_{2} \cdot \mathrm{xTPAOH} .1500 \mathrm{H}_{2} \mathrm{O}$ where $\mathrm{x}$ was $5,9,16$ and 30 at 95 ${ }^{\circ} \mathrm{C}$ with LUDOX AS-30 as the silica source. The crystallization solution was prepared by mixing TPAOH and silica solutions and adding proper amount of deionized water. The resulting mixture was stirred vigorously at room temperature for $30 \mathrm{~min}$. so that a clear and homogenous solution was obtained.

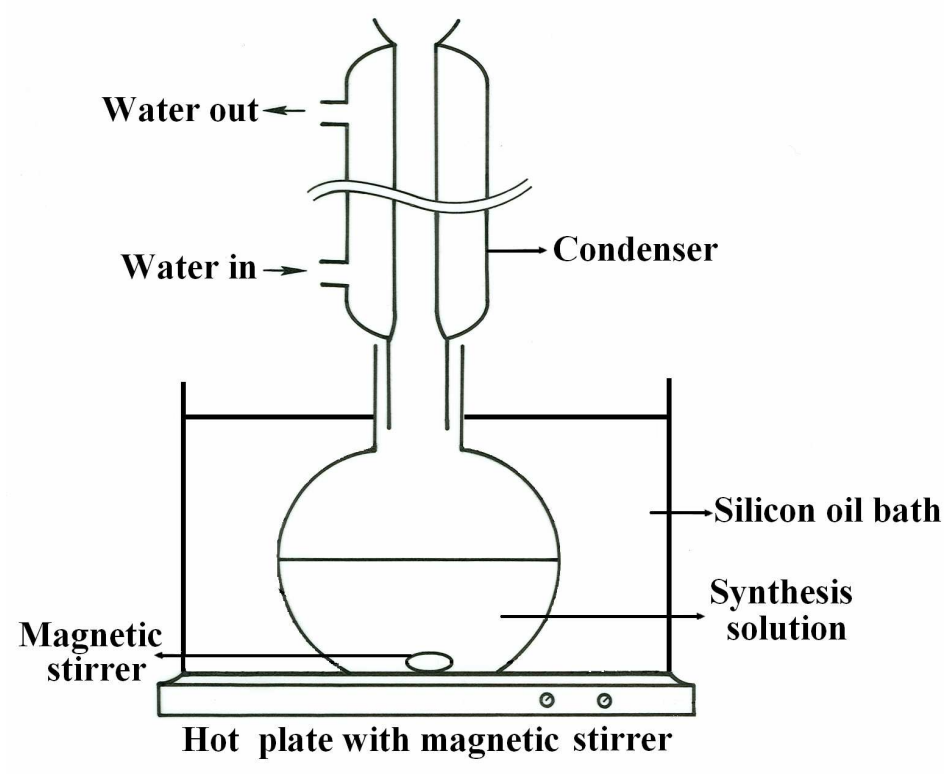

Figure 3.5 Schematic drawing of the system working under atmospheric pressure 
Synthesis of MFI powder was carried out at $95^{\circ} \mathrm{C}$ both in a glass reactor operating under atmospheric pressure with reflux and in autoclaves operating at autogenous pressure. The schematic drawing of the glass reactor working under atmospheric pressure is shown in Figure 3.5. In this system, $150 \mathrm{~g}$ of synthesis solution was put in a $250 \mathrm{~mL}$ glass flask that is placed on a magnetic stirrer and heater. The solution was stirred mildly during the synthesis. On top of the flask there was a condenser to provide reflux. Samples were taken from the flask at various times during the course of synthesis by temporarily taking the condenser off and sucking $10 \mathrm{~mL}$ of the synthesis solution fast by means of a pipette.

Besides synthesis in atmospheric pressure, membranes were synthesized in stainless steel autoclaves at autogenous pressure. The syntheses with the molar composition of $80 \mathrm{SiO}_{2} \cdot \mathrm{xTPAOH} .1500 \mathrm{H}_{2} \mathrm{O}$ where $\mathrm{x}$ was $5,9,16$ and 30 with LUDOX as the silica source were performed at $95{ }^{\circ} \mathrm{C}$ for $72 \mathrm{~h}$ on seeded and unseeded $\alpha-\mathrm{Al}_{2} \mathrm{O}_{3}$ discs. These supports were seeded with $350 \mathrm{~nm}$ sized seed crystals by vacuum seeding technique (see Section 3.3.1).

Several membranes were also synthesized from mixtures containing both $\mathrm{TPABr}$ and TPAOH as two types of template sources. The syntheses were performed using mixtures with a molar composition of (0-22)TPABr:(0-22) TPAOH:80SiO $2: 21 \mathrm{Na}_{2} \mathrm{O}: 3600 \mathrm{H}_{2} \mathrm{O}$ and (0-16)TPABr:(0-16) TPAOH: $80 \mathrm{SiO}_{2}: 10 \mathrm{Na}_{2} \mathrm{O}: 2500 \mathrm{H}_{2} \mathrm{O}$ at $150^{\circ} \mathrm{C}$ for $24 \mathrm{~h}$ on seeded $\alpha-\mathrm{Al}_{2} \mathrm{O}_{3}$ discs. The seeding of the supports was done with $350 \mathrm{~nm}$ sized seed crystals by dipcoating method which enables to seed four disc supports at the same time. For the preparation of synthesis solution $\mathrm{NaOH}$ and $\mathrm{TPABr}$ solutions were mixed, then LUDOX and water were added into this solution. The synthesis solution was stirred for $1 \mathrm{~h}$. The synthesis solution was clear when TPAOH was used and blurry when $\mathrm{TPABr}$ or (TPAOH and $\mathrm{TPABr}$ ) mixture was used as template. 
The samples taken from the synthesis solution in powder or membrane synthesis at atmospheric pressure and in autoclaves were centrifuged with a relative centrifugal force of $640 \mathrm{~g}(6000 \mathrm{rpm})$ for 30 minutes. The precipitated powder was redispersed in distilled water, and was centrifuged. This procedure was repeated several times until the $\mathrm{pH}$ of supernatant dropped to about 8 . The solid products were dried overnight at $80^{\circ} \mathrm{C}$. Percent yield and crystallinity changes with time were observed with the quantitatively recovered solid products. The calculations of maximum yield, crystallinity and conversion are given in detail in Appendix B.

Phase identification of the powders and membranes was made by X-ray diffractometer with $\mathrm{Ni}$ filtered $\mathrm{Cu}-\mathrm{K} \alpha$ radiation. Morphology of the membranes was determined by Scanning Electron Microscope (see Section 3.4). Particle size analysis of the powder samples were performed by MasterSizer 6000 Particle Size Analyzer. For particle size analysis, approximately $3 \mathrm{ml}$ of sample withdrawn from the reactor was put in a centrifuge tube and diluted with water. The diluted mixture was ultrasonicated for $2 \mathrm{~min}$. to break down the agglomerates and to distribute the crystals uniformly. The particle size analyzer has also an ultrasonication unit, which aims to prevent any agglomeration of the crystals during the analysis.

\subsection{Synthesis of membranes with mid-synthesis addition of silica to the synthesis medium}

In the third part of the study, MFI type membranes were synthesized from clear solutions in the flow system. The effect of mid-synthesis addition of silica to the synthesis medium during the course of crystallization on the properties of the resultant MFI type membranes was investigated. 
Membranes were prepared on unseeded commercial $\alpha-\mathrm{Al}_{2} \mathrm{O}_{3}$ disc supports. Composition change during the synthesis was carried out in a continuous flow system where the synthesis solution was flown over the disc shaped supports. The schematic drawing of the system is shown in Figure 3.6.

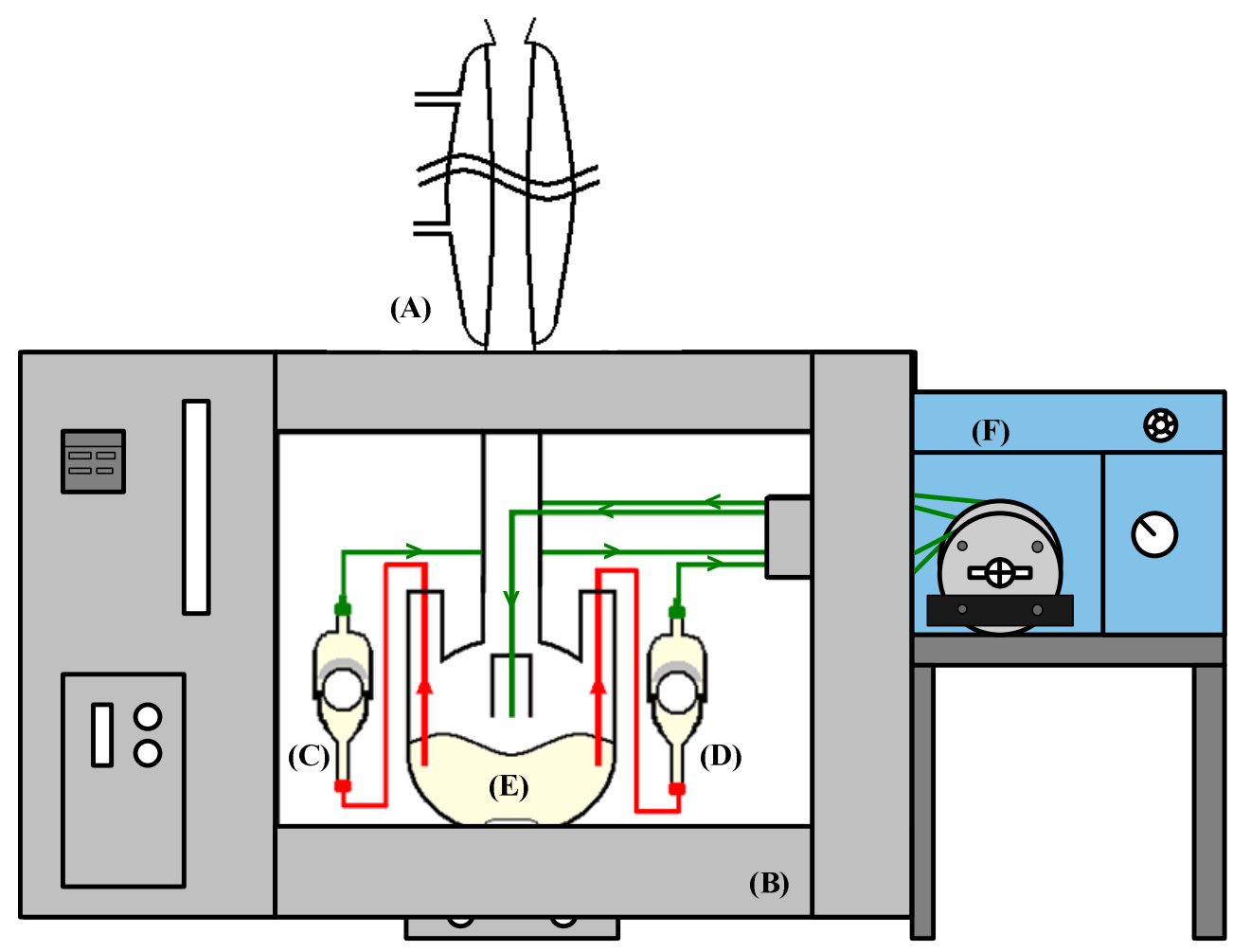
(A) Condenser
(B) Oven with magnetic stirrer
(C) Disk membrane module

(D) Disk membrane module

(E) Glass flask containing synthesis solution

(F) Peristaltic pump

Figure 3.6 The schematic drawing of the system used during the synthesis of membranes with mid-synthesis change of composition

The synthesis solution was kept in the reservoir, which is a $250 \mathrm{~mL}$ glass flask, with five entries one for the condenser, two for the entering streams and two for the exiting streams. There are two membrane modules which were held vertically next to the glass flask. All parts of the setup were placed in an oven 
with a magnetic stirrer. At the beginning of the synthesis two $\alpha-\mathrm{Al}_{2} \mathrm{O}_{3}$ discs supports were placed into the membrane modules. The synthesis of membranes began in the clear solution with a molar composition of $80 \mathrm{SiO}_{2}: 30 \mathrm{TPAOH}: 1536 \mathrm{H}_{2} \mathrm{O}$ at $95^{\circ} \mathrm{C}$. The flow rate of the synthesis solution was $6 \mathrm{ml} / \mathrm{min}$. The synthesis solution was prepared as described in Section 3.5. After 24, 48 and $72 \mathrm{~h}$, one of the modules was disconnected from the system and the overall composition of the synthesis solution in the container was changed to $80 \mathrm{SiO}_{2}: 9 \mathrm{TPAOH}: 1536 \mathrm{H}_{2} \mathrm{O}$ by adding silica (LUDOX AS-40), and crystallization was continued on the remaining support. The synthesis was completed in $72 \mathrm{~h}$ or extended for an additional $72 \mathrm{~h}$ after composition change.

Besides two membranes were separately prepared from the solutions with a molar composition of $80 \mathrm{SiO}_{2}: 9 \mathrm{TPAOH}: 1536 \mathrm{H}_{2} \mathrm{O}$ and $80 \mathrm{SiO}_{2}: 30 \mathrm{TPAOH}: 1536 \mathrm{H}_{2} \mathrm{O}$ without addition of silica during the course of synthesis. Constant composition syntheses were performed at $95^{\circ} \mathrm{C}$ for $72 \mathrm{~h}$. The flow rate of the synthesis solution was $6 \mathrm{ml} / \mathrm{min}$.

Following the hydrothermal treatment all membranes were washed with distilled water and then dried at $80^{\circ} \mathrm{C}$ overnight. Membranes were calcined at $450^{\circ} \mathrm{C}$ for $6 \mathrm{~h}$ to remove the template from MFI pores.

Phase identification of the powders and membranes was made by X-ray diffractometer and morphology of the membranes was determined by Scanning Electron Microscope (see Section 3.4.). Particle size analysis of the powders was performed with MasterSizer 6000 Particle Size Analyzer (see Section 3.5). The $\mathrm{H}_{2}, \mathrm{~N}_{2}, \mathrm{n}-\mathrm{C}_{4} \mathrm{H}_{10}$ and $\mathrm{i}-\mathrm{C}_{4} \mathrm{H}_{10}$ single gas permeation and $\mathrm{n}-\mathrm{C}_{4} \mathrm{H}_{10} / \mathrm{i}-\mathrm{C}_{4} \mathrm{H}_{10}$ binary gas mixture separation experiments were also conducted with those membranes at $25^{\circ} \mathrm{C}$ and $100^{\circ} \mathrm{C}$. The detailed explanation of single and binary gas permeation setups and procedures are given in Section 3.4 and 3.7, respectively. 


\subsection{Separation of binary and ternary gas mixtures by MFI type zeolite membranes synthesized in a flow system}

In the fourth part of the study, MFI type membranes that were synthesized from clear solutions in the flow system were used to separate mixtures of $\mathrm{N}_{2}$, $\mathrm{CH}_{4}, \mathrm{CO}_{2}, \mathrm{n}-\mathrm{C}_{4} \mathrm{H}_{10}$ and $\mathrm{i}-\mathrm{C}_{4} \mathrm{H}_{10}$.

\subsubsection{Membrane synthesis and characterization}

Membranes were synthesized on commercial tubular $\alpha-\mathrm{Al}_{2} \mathrm{O}_{3}$ supports. Before synthesis the tubes were seeded MFI crystals with a diameter of $350 \mathrm{~nm}$ by dip-coating (see Section 3.3.2).

The molar composition of the solution for the synthesis of membranes was $80 \mathrm{SiO}_{2}: 16 \mathrm{TPAOH}: 1536 \mathrm{H}_{2} \mathrm{O}$. The crystallization solution was prepared by mixing 25\% TPAOH and LUDOX AS-30 solutions and adding proper amount of deionized water. The resulting mixture was stirred vigorously at room temperature for $24 \mathrm{~h}$. so that a clear and homogenous solution was obtained. Membrane synthesis was carried out in the recirculating flow system at $95^{\circ} \mathrm{C}$ for $72 \mathrm{~h}$. The schematic drawing of the system is shown in Figure 3.7. The details of the continuous system have been reported earlier [29]. In this system the synthesis solution was kept in the reservoir, which is a $100 \mathrm{~mL}$ glass flask, with three entries for the condenser, for the entering stream, for the exiting stream and the last one for sample taking. The synthesis solution was recirculated along the membrane by means of a peristaltic pump. The membrane was held vertically in a glass module. The lines, between the reservoir and membrane module were platinium cured silicone tubing. The reservoir, the membrane module and the tubing were kept in a silicon oil bath at the synthesis temperature. The oil was heated by the hot plate with magnetic stirrer. 


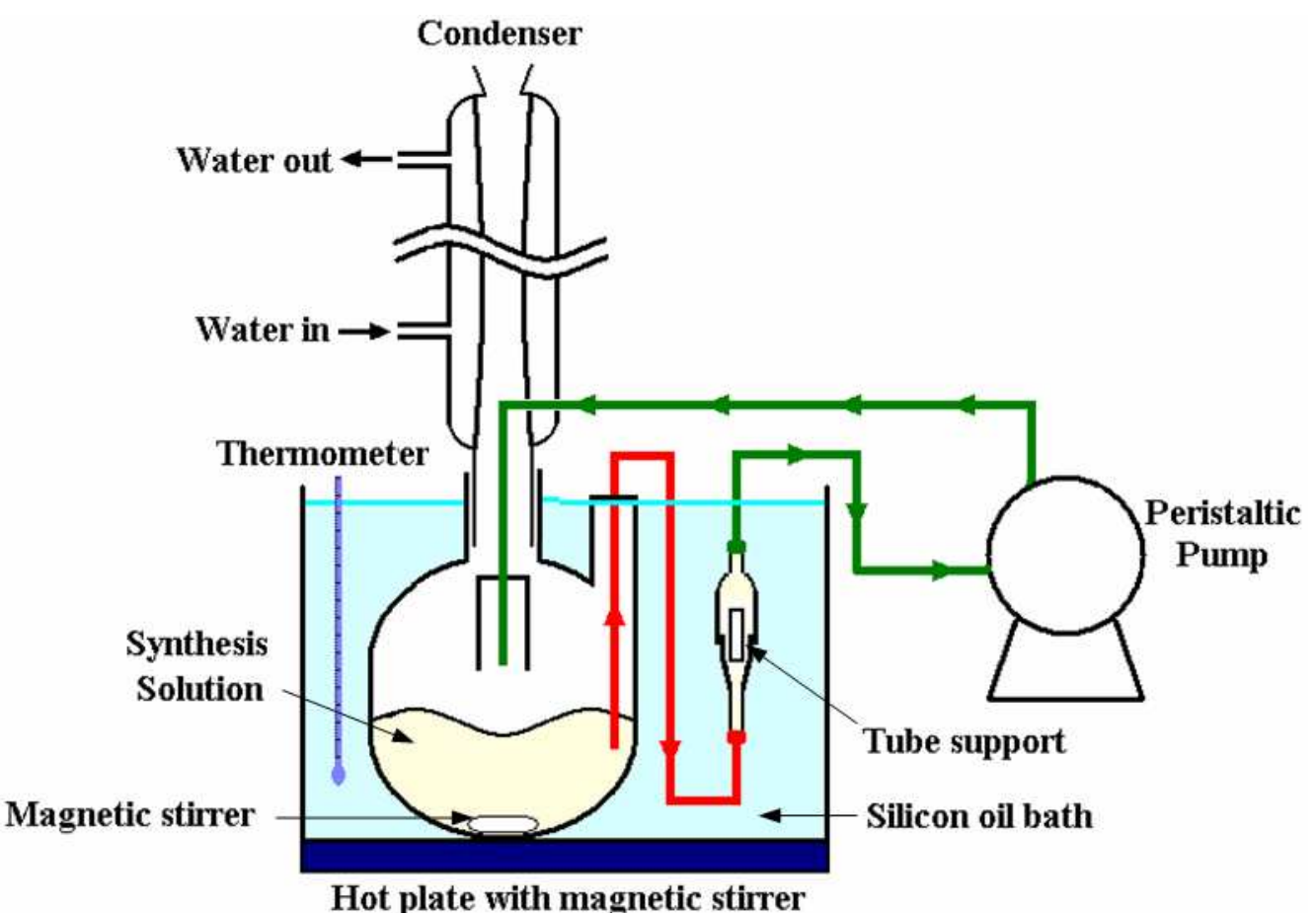

Figure 3.7 The schematic drawing of the recirculating flow system used for membrane synthesis

Some membranes were also synthesized at $95^{\circ} \mathrm{C}$ for 72 in stainless steel autoclaves with PTFE inserts. The support was vertically aligned during the synthesis both in flow and in batch systems. After synthesis, membranes were washed with distilled water until the $\mathrm{pH}$ was around 8 , and dried at $80^{\circ} \mathrm{C}$.

Membranes were characterized by X-ray diffractometer for phase identification and Scanning Electron Microscope for morphology determination (see Section 3.4). Single gas permeances of $\mathrm{N}_{2}, \mathrm{H}_{2}, \mathrm{CO}_{2}, \mathrm{CH}_{4}, \mathrm{n}-\mathrm{C}_{4} \mathrm{H}_{10}$ and $\mathrm{i}-\mathrm{C}_{4} \mathrm{H}_{10}$ were measured at $25-200^{\circ} \mathrm{C}$ in a dead-end module with a transmembrane pressure difference of 1 bar as described in Section 3.4. The permeate side was at atmospheric pressure $(0.91$ bar $)$ and the permeate flow rate was measured by a soap-bubble flow meter. The ratio of single gas permeances was defined as the ideal selectivity. 


\subsubsection{Separation of binary and ternary gas mixtures}

Equimolar n- $\mathrm{C}_{4} \mathrm{H}_{10} / \mathrm{CH}_{4}, \mathrm{n}-\mathrm{C}_{4} \mathrm{H}_{10} / \mathrm{CO}_{2}, \mathrm{n}-\mathrm{C}_{4} \mathrm{H}_{10} / \mathrm{N}_{2}, \mathrm{CH}_{4} / \mathrm{i}-\mathrm{C}_{4} \mathrm{H}_{10}, \mathrm{~N}_{2} / \mathrm{i}-\mathrm{C}_{4} \mathrm{H}_{10}$, n- $\mathrm{C}_{4} \mathrm{H}_{10} / \mathrm{i}-\mathrm{C}_{4} \mathrm{H}_{10}$ and $30 \%$ n- $\mathrm{C}_{4} \mathrm{H}_{10} / 70 \% \mathrm{CH}_{4}, 20 \%$ n- $\mathrm{C}_{4} \mathrm{H}_{10} / 80 \% \mathrm{CH}_{4}$ binary gas mixtures were separated in a steady-state separation process between 25 and $200^{\circ} \mathrm{C}$. A ternary gas mixture with a molar composition of $70 \% \mathrm{CH}_{4}, 20 \%$ $\mathrm{CO}_{2}$ and $10 \% n-\mathrm{C}_{4} \mathrm{H}_{10}$ was also separated at 20,100 and $200^{\circ} \mathrm{C}$. The schematic drawing of the setup used to separate binary and ternary gas mixtures is shown in Figure 3.8. This setup consists of three parts as feed, permeate and retentate. The feed pressure was at $2 \mathrm{bar}$ and had a flow rate of $40 \mathrm{~mL} / \mathrm{min}$. The flow rate of the feed gases was controlled with mass flow controllers. Permeate pressure was 1 bar and its flow rate was measured by a soap-bubble flow meter. The transmembrane pressure difference was provided by means of backpressure valves. Permeate and retentate flow rates were measured with bubble flow meters. Feed, permeate and retentate gas mixtures were analyzed on-line by a gas chromatograph (GC, Varian CP-3800) equipped with a TCD detector and Propak T packed column. In high temperature measurements, the module was wrapped with a heating tape; temperature was measured from the middle of the module and controlled by a temperature controller. The separation selectivity was defined as the ratio of component permeances determined using log-mean pressure differences [10] as shown in Appendix H and I. Steady state composition values of permeate and retentate gas mixtures were used for the permeance and separation selectivity calculations. 


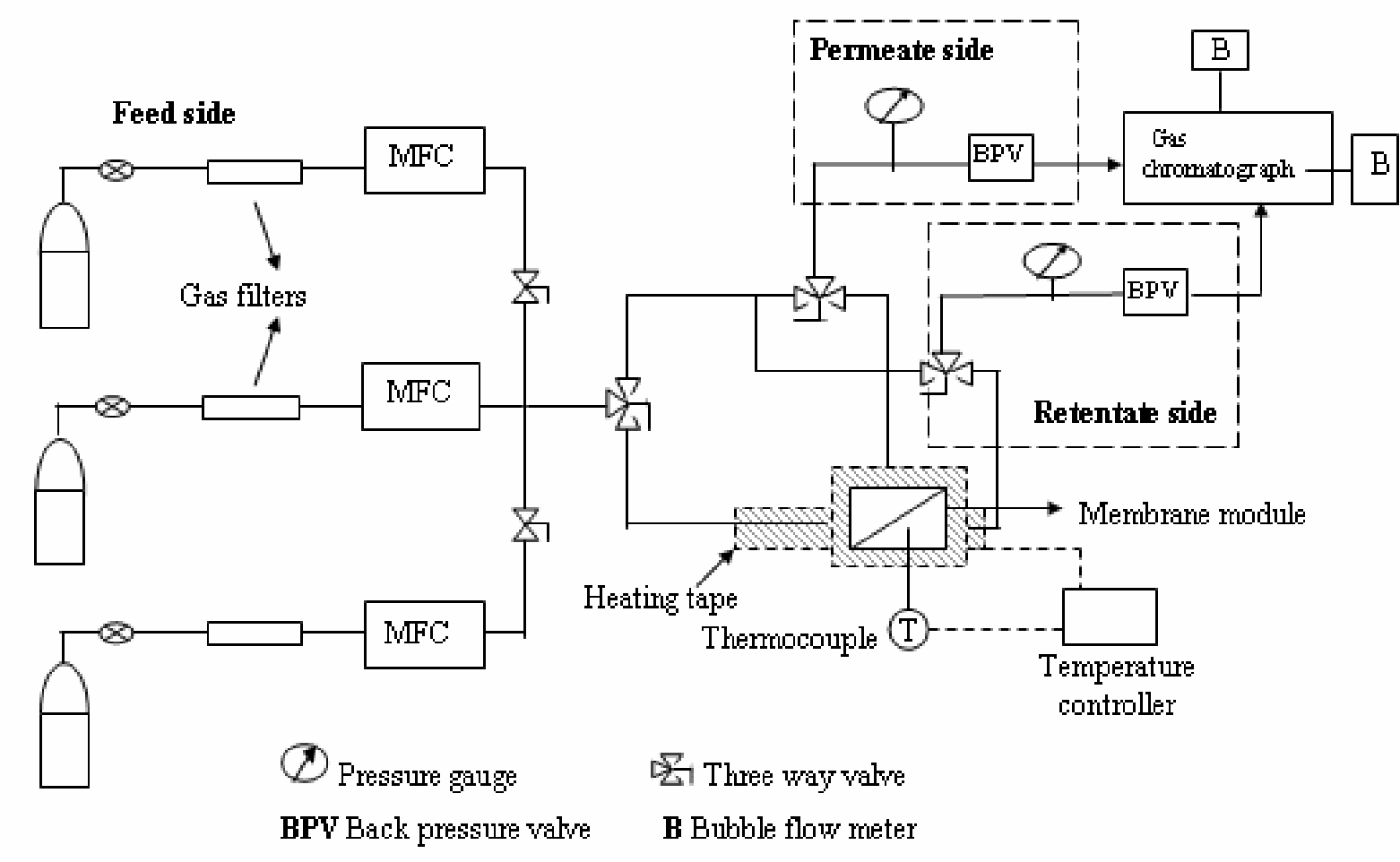

Figure 3.8 The schematic drawing of the binary and ternary gas mixture separation setup 


\subsubsection{Operation of gas chromatograph}

The operating conditions of the gas chromatograph (GC) are given in Table 3.2. A 10-port valve and two sample loops were mounted to the GC for the analysis of permeate and retentate side gas mixtures simultaneously. Two steps, sample loading and injection, involved during the analysis of permeate and retentate compositions by GC. Figure 3.9 shows the different positions of the 10-port valve during these steps. The GC analysis starts at Position I and the gas mixture from the retentate side of the system fills the first sample loop while the permeate side gas mixture is automatically injected into the GC column with He carrier gas. At Position II, the permeate gas mixture enters into the second sample loop while the retentate gas mixture in the first sample loop automatically injected into the GC column with He carrier gas. After this cyclic process the valve turns to Position I.

Table 3.2 Operating conditions of GC

\begin{tabular}{|l|l|}
\hline Column & Propak T \\
\hline Column temperature & $100^{\circ} \mathrm{C}$ \\
\hline Valve temperature & $120^{\circ} \mathrm{C}$ \\
\hline Detector & $\mathrm{TCD}$ \\
\hline Detector temperature & $120^{\circ} \mathrm{C}$ \\
\hline Sample flow rate & $40 \mathrm{ml} / \mathrm{min}$ \\
\hline Reference gas and flow rate & $\mathrm{He}, 30 \mathrm{ml} / \mathrm{min}$ \\
\hline Column pressure & $18 \mathrm{psi}$ \\
\hline
\end{tabular}

Prior to sample analysis, a calibration was done for $\mathrm{N}_{2}, \mathrm{CH}_{4}, \mathrm{CO}_{2}, \mathrm{n}-\mathrm{C}_{4} \mathrm{H}_{10}$ and i- $\mathrm{C}_{4} \mathrm{H}_{10}$ to determine their amounts in the gas mixture. Calibration curves were obtained by relating the chromatographic peak area to the partial pressures of 
each gas under fixed operating conditions of GC. The amount of each gas in the binary and ternary gas mixtures was determined from these calibration curves. The GC calibration curves for each gas were given in Appendix F.
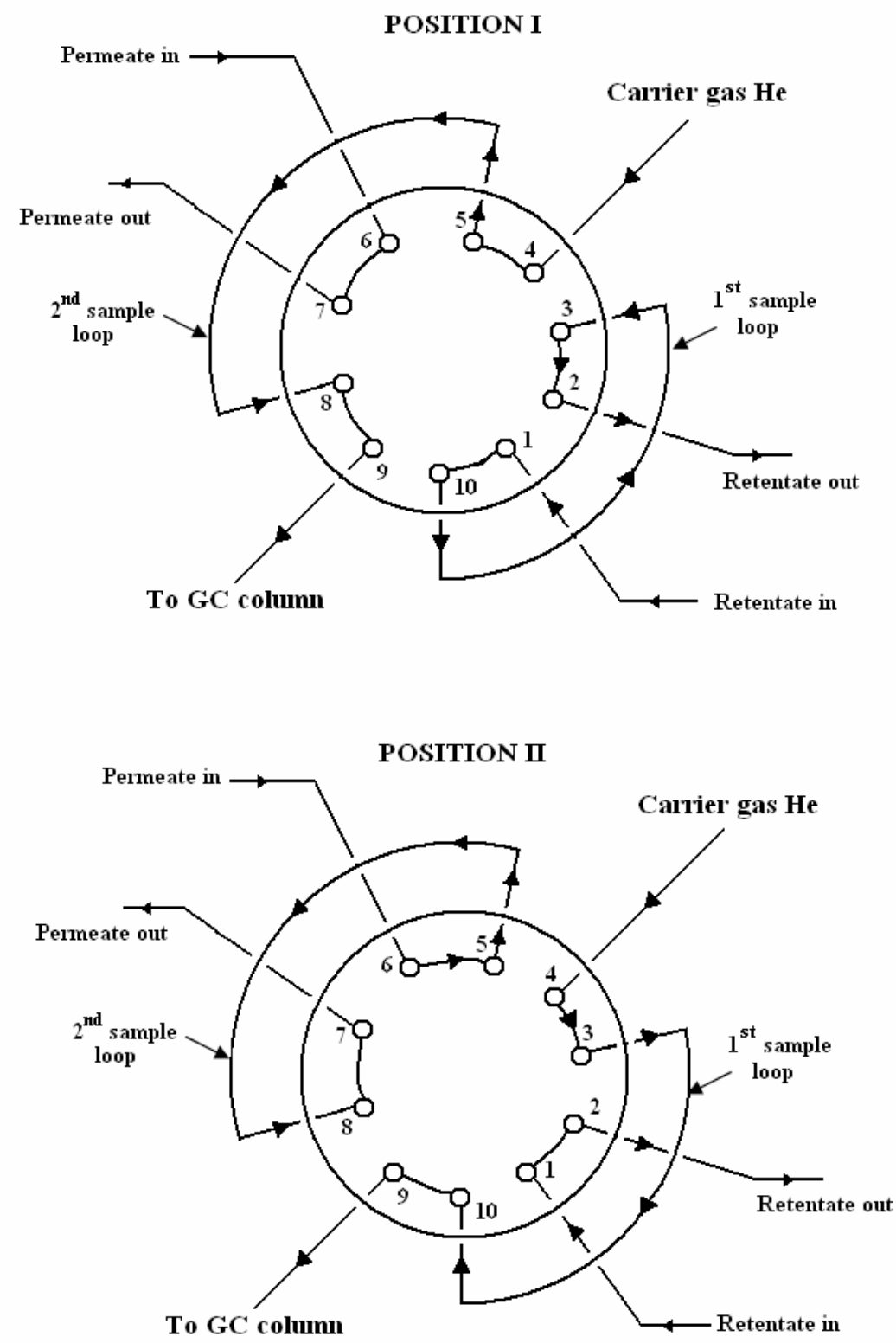

Figure 3.9 Positions of 10-port injection valve during the analysis of retentate and permeate gas streams. Permeate and retentate are analyzed in position I and II, respectively. 


\section{CHAPTER 4}

\section{RESULTS AND DISCUSSION}

\subsection{Effect of soda concentration on the morphology of the MFI type zeolite membranes}

MFI type crystals have two-dimensional channel network consisting of straight channels along the crystallographic $b$-axis and sinusoidal channels along the crystallographic $a$-axis. Orientation of MFI crystals in the membrane layer has, therefore, significant influence in the permeation characteristics and the separation performance of the MFI membranes. This orientation mainly depends on the composition of the synthesis mixture and seeding the support surface with MFI crystals [63, 64]. Seeding facilitates the growth of zeolites on the support and increases the reproducibility of membrane synthesis [4, 30, $31,59,78]$ in addition to controlling the preferred orientation $[36,43,68,59$, 80]. The crystal orientation is also sensitive to the $\mathrm{OH}^{-} / \mathrm{Si}$ ratio of the synthesis mixture, and preferentially oriented films are formed at $\mathrm{OH}^{-} / \mathrm{Si} \leq 0.64[30,31]$.

In this part of the study, MFI type zeolite membranes were synthesized over porous $\alpha-\mathrm{Al}_{2} \mathrm{O}_{3}$ supports from clear synthesis solutions with a molar composition of (0-6.5) $\mathrm{Na}_{2} \mathrm{O}: 25 \mathrm{SiO}_{2}: 6.9 \mathrm{TPABr}: 1136 \mathrm{H}_{2} \mathrm{O}$ at $150^{\circ} \mathrm{C}$. The effect of $\mathrm{Na}_{2} \mathrm{O}$ concentration on crystal orientation was investigated. The membranes were characterized by XRD, SEM and by measuring single gas permeances of $\mathrm{H}_{2}, \mathrm{~N}_{2}, \mathrm{CO}_{2}, \mathrm{CH}_{4}, \mathrm{n}-\mathrm{C}_{4} \mathrm{H}_{10}, \mathrm{i}-\mathrm{C}_{4} \mathrm{H}_{10}$. 


\subsubsection{Membrane Synthesis on Seeded and Unseeded Supports}

Membranes that were synthesized as described in Section 3.4 were coded as $M(x)$ to indicate the amount of soda in the synthesis solution. Two membranes were synthesized from the solutions with the same composition $\left(1 \mathrm{Na}_{2} \mathrm{O}: 25 \mathrm{SiO}_{2}: 6.9 \mathrm{TPABr}: 1136 \mathrm{H}_{2} \mathrm{O}\right)$ on the seeded and unseeded supports. Seeding of the supports were done by vacuum seeding technique and with 1 $\mu \mathrm{m}$ size crystals. The membrane $\mathrm{M}(1)$ was on the seeded and the membrane $\mathrm{M}(1 \mathrm{u})$ was on the unseeded support. Figure 4.1 shows the XRD patterns of those membranes and that of MFI powder.

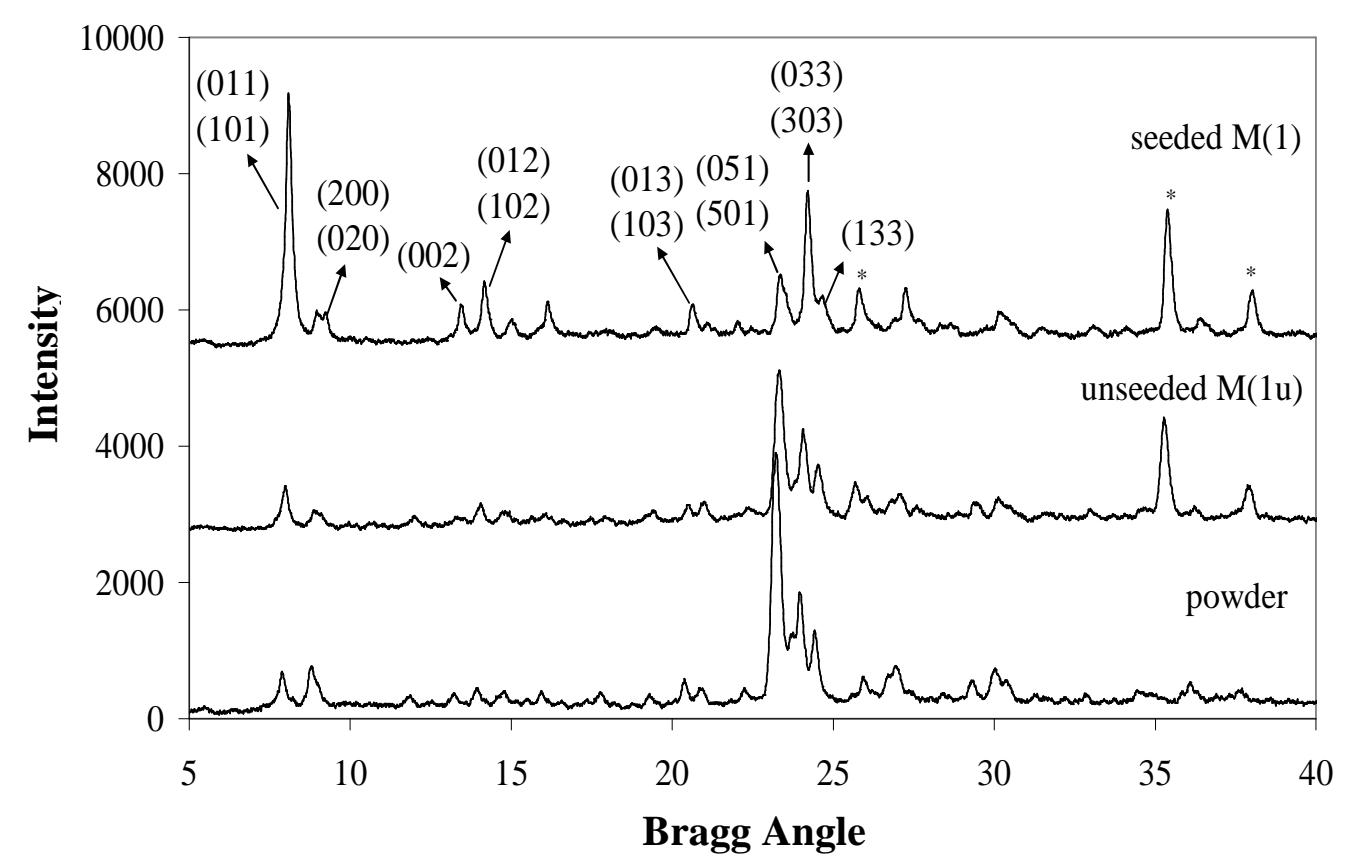

Figure 4.1 XRD patterns of powder MFI, unseeded membrane $\mathrm{M}(1 \mathrm{u})$ and seeded membrane (M1), the asterisks shows the $\alpha-\mathrm{Al}_{2} \mathrm{O}_{3}$ peaks

On the XRD patterns, only reflections originating from alumina and MFI type zeolite were observed. However, the MFI peaks at 8,14 and $24^{\circ}$ Bragg angles, 
which correspond to (101), (102) and (303) planes, respectively, are more pronounced when crystallization was carried out on the seeded support. The strong intensities of reflections from (101) and (303) planes in the seeded membrane $\mathrm{M}(1)$ indicate a preferred orientation in (h0h) direction $[3,6,36,43$, $59,67,79,81]$. Increase in reflections from (102)-(012) and (002) planes also indicate the presence of some $c$-oriented crystals [48]. Because of having both (h0h) and $c$-oriented crystals, we called this membrane as (h0h)/c-oriented membrane. The pore structure of MFI as well as the (h0h) and $c$-directed orientations were illustrated in Figure 4.2. On the other hand, the XRD pattern of the membrane synthesized on unseeded support was very similar to that of powder indicating that the MFI layer on the unseeded support is composed of randomly oriented crystals. Lovallo et al. [82] also observed that preferentially oritented MFI layers form on seeded surface while crystals are randomly oriented on unseeded surface. Similarly Li et al. [59] synthesized mordenite type zeolite membranes on alumina support seeded with mordenite crystals and they observed that the membrane was preferentially oriented. Seeding of the support apparently results in the orientation of crystals forming the membrane layer if appropriate synthesis gel is used [30, 31, 57].

SEM photographs of the membranes $\mathrm{M}(1)$ and $\mathrm{M}(1 \mathrm{u})$ were shown in Figure 4.3. The cross-sectional view of membrane M(1) shows a columnar structure as opposed to the cross-sectional view of membrane $\mathrm{M}(1 \mathrm{u})$. The columnar structure is due to $\mathrm{h} 0 \mathrm{~h} / \mathrm{c}$-orientation of MFI crystals on the surface. The thicknesses of both membranes are approximately $17 \mu \mathrm{m}$ whereas the crystals on membrane $\mathrm{M}(1 \mathrm{u})$ have a length of approximately $15 \mu \mathrm{m}$ and are greater than the crystals on membrane $\mathrm{M}(1)$, which are approximately $10 \mu \mathrm{m}$ (Figure 4.3a-b). The surface image of the membranes also shows that the crystals on seeded surface formed very intergrown layer so that no individual crystals can be seen on the membrane $\mathrm{M}(1)$ as opposed to the membrane $\mathrm{M}(1 \mathrm{u})$. A distinct seed layer was not observed in the cross-sections of the membrane $\mathrm{M}(1)$, suggesting that all the seed crystals participated in membrane formation. 
(a)
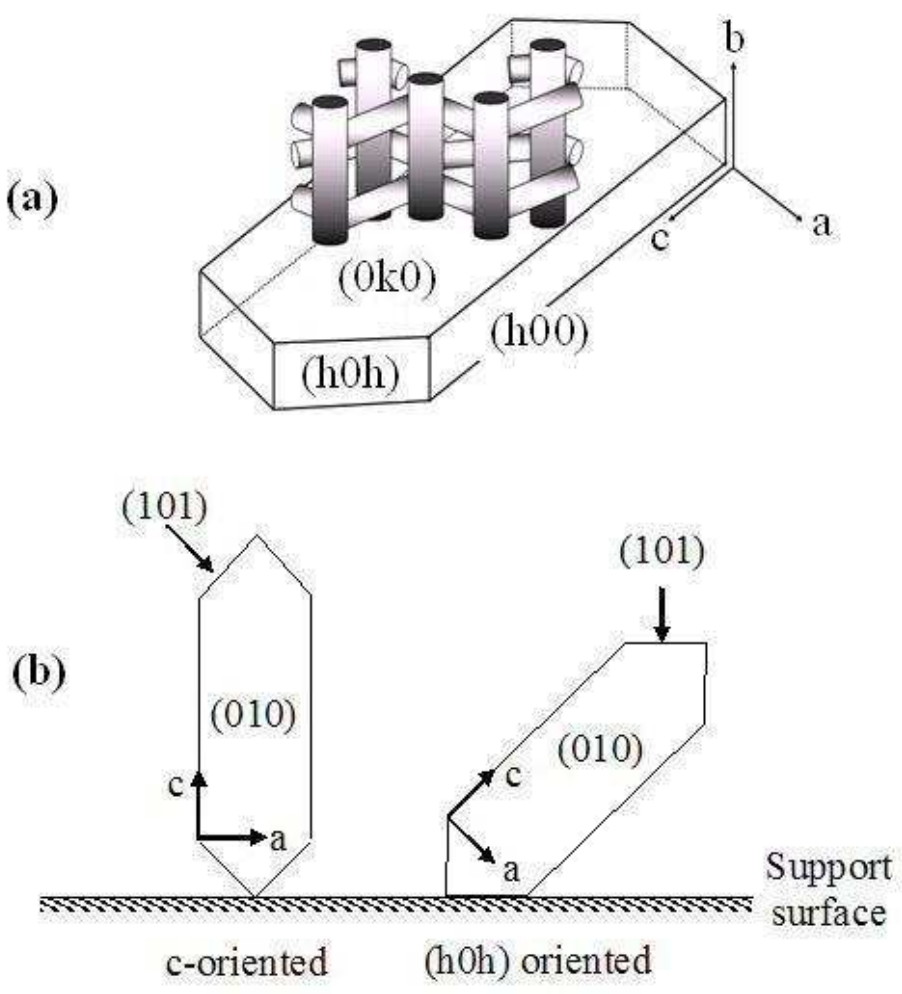

Figure 4.2 a) Pore structure of MFI crystals b) Representation of $c$-oriented and (hOh) oriented crystals

During the evolution of membrane layer on the seed-coated supports, the $\mathrm{h} 0 \mathrm{~h} / \mathrm{c}$-orientation is attributed to anisotropic growth of MFI crystals. The growth rate on the $c$-direction is relatively faster than the growth rate at other crystallographic directions; therefore, most MFI-membranes with $c$-directed orientation have a columnar structure as shown in Figure 4.3d, as opposed to the membrane synthesized on unseeded support as shown in Figure 4.3c. Previous studies also showed that (h0h) oriented membranes in addition to $c$ oriented membranes have columnar structure resulting from anisotropic growth of the crystals $[48,65]$. We therefore observed the columnar structure in the SEM photographs of the membranes with $(\mathrm{h} 0 \mathrm{~h}) / \mathrm{c}$-directed orientation. 

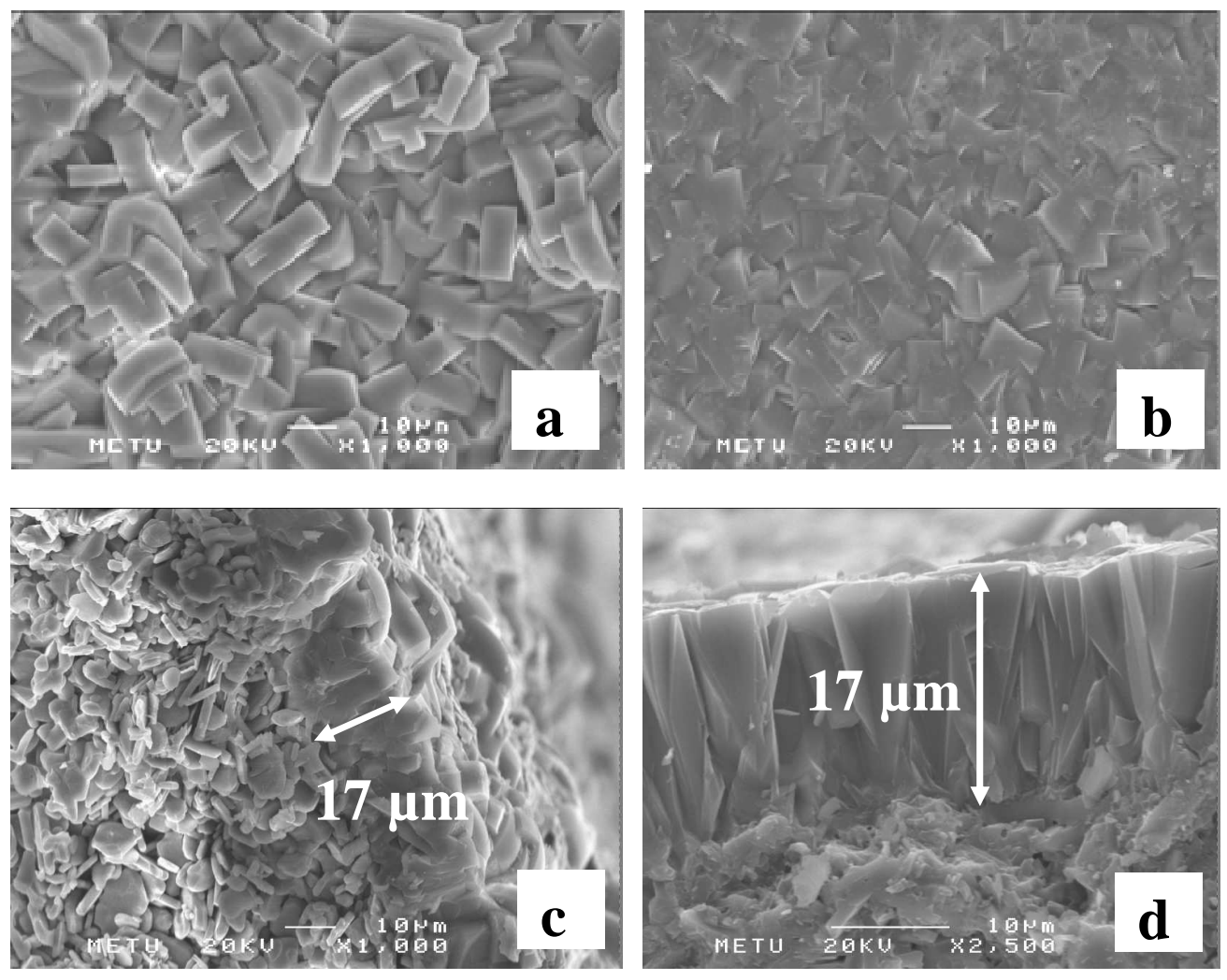

Figure 4.3 Surface and cross section SEM images of membranes synthesized on unseeded $\mathrm{M}(1 \mathrm{u}) \quad(\mathrm{a}, \mathrm{c})$ and seeded $\mathrm{M}(1) \quad(\mathrm{b}, \mathrm{d}) \quad \alpha-\mathrm{Al}_{2} \mathrm{O}_{3}$ supports $\left(1.0 \mathrm{Na}_{2} \mathrm{O}: 25 \mathrm{SiO}_{2}: 6.9 \mathrm{TPABr}: 1136 \mathrm{H}_{2} \mathrm{O} \quad \mathrm{T}=150^{\circ} \mathrm{C} \quad \mathrm{t}=24 \mathrm{~h}\right)$, the arrow shows the zeolite layer.

Seeding of the support contributes the orientation of crystals forming the membrane layer [30, 31, 36, 43, 59, 67, 68]. Bernal et al. [58] explained that heterogeneous nucleation occurs on the unseeded support and the crystals grow in all directions. On the seeded supports, however, crystals grow preferentially towards the bulk of the solution $[17,30,31]$. Since seed crystals provide surface for nucleation, a continuous layer composed of highly intergrown crystals with smaller size can be obtained on seeded supports [20, 43]. 


\subsubsection{Effect of soda concentration on crsytallinity}

The effect of soda concentration of the synthesis solution on the properties of MFI films was investigated. The MFI films were prepared on seed coated macroporous $\alpha-\mathrm{Al}_{2} \mathrm{O}_{3}$ disks.

The synthesis solution was clear when $0.25<\mathrm{Na}_{2} \mathrm{O}<1.85$ in the batch, however the synthesis solution turned to a blurry gel when $\mathrm{Na}_{2} \mathrm{O}>2.0$. Figure 4.4 shows the XRD patterns of the powders synthesized with different amounts of soda in the batch. Amorphous powder was obtained when the soda content of the batch was 1.0 and 1.5 moles. At lower and higher concentrations of soda, MFI type zeolite was the only crystalline phase formed in the bulk.

Figure 4.5 shows the percent conversion of the silica in batch to MFI for the powders with different soda concentration. No crystals form at $0.65<\mathrm{Na}_{2} \mathrm{O}<1.85$ soda concentrations. On the other hand highly crystalline MFI was obtained if $\mathrm{Na}_{2} \mathrm{O}<0.6$ or $\mathrm{Na}_{2} \mathrm{O}>2.0$. The maximum conversion was obtained from gels with $\mathrm{Na}_{2} \mathrm{O}=0.4$. For each composition, the synthesis was carried out more than three times. The results were highly reproducible. Each time an amorphous phase was obtained at $0.65<\mathrm{Na}_{2} \mathrm{O}<1.85$ soda concentrations while MFI phase was obtained at other soda concentrations.

Soda which is introduced as sodium hydroxide gives both $\mathrm{Na}^{+}$and $\mathrm{OH}^{-}$ions to the synthesis medium. High $\mathrm{Na}^{+}$concentration and alkalinity of the reaction medium cause much higher proportions of the silica to remain in the solution. This reduces the conversion of the silica to zeolite [83]. The function of the $\mathrm{OH}^{-}$ions can be considered as mineralizer which causes dissolution of the silica while $\mathrm{Na}^{+}$ions can act as a structure-directing agent as well as TPA ${ }^{+}$ which enhances the nucleation [60,61]. The amounts of soda in the range of $0.75<\mathrm{Na}_{2} \mathrm{O}<1.75$ may have unfavorable effect on zeolite formation. Similar to 
our results, Wang and Yan et al. [62] observed that no crystals formed in the bulk phase when $\mathrm{OH}^{-} / \mathrm{SiO}_{2}$ was higher than 0.64 or lower than 0.2 while the zeolite crystals appeared in the bulk phase when $\mathrm{OH}^{-} / \mathrm{SiO}_{2}$ was between 0.5 and 0.32. Since $\mathrm{OH}^{-}$ions were originated from TPAOH in their study they suggested that nucleation is suppressed at very high and very low TPAOH concentrations.

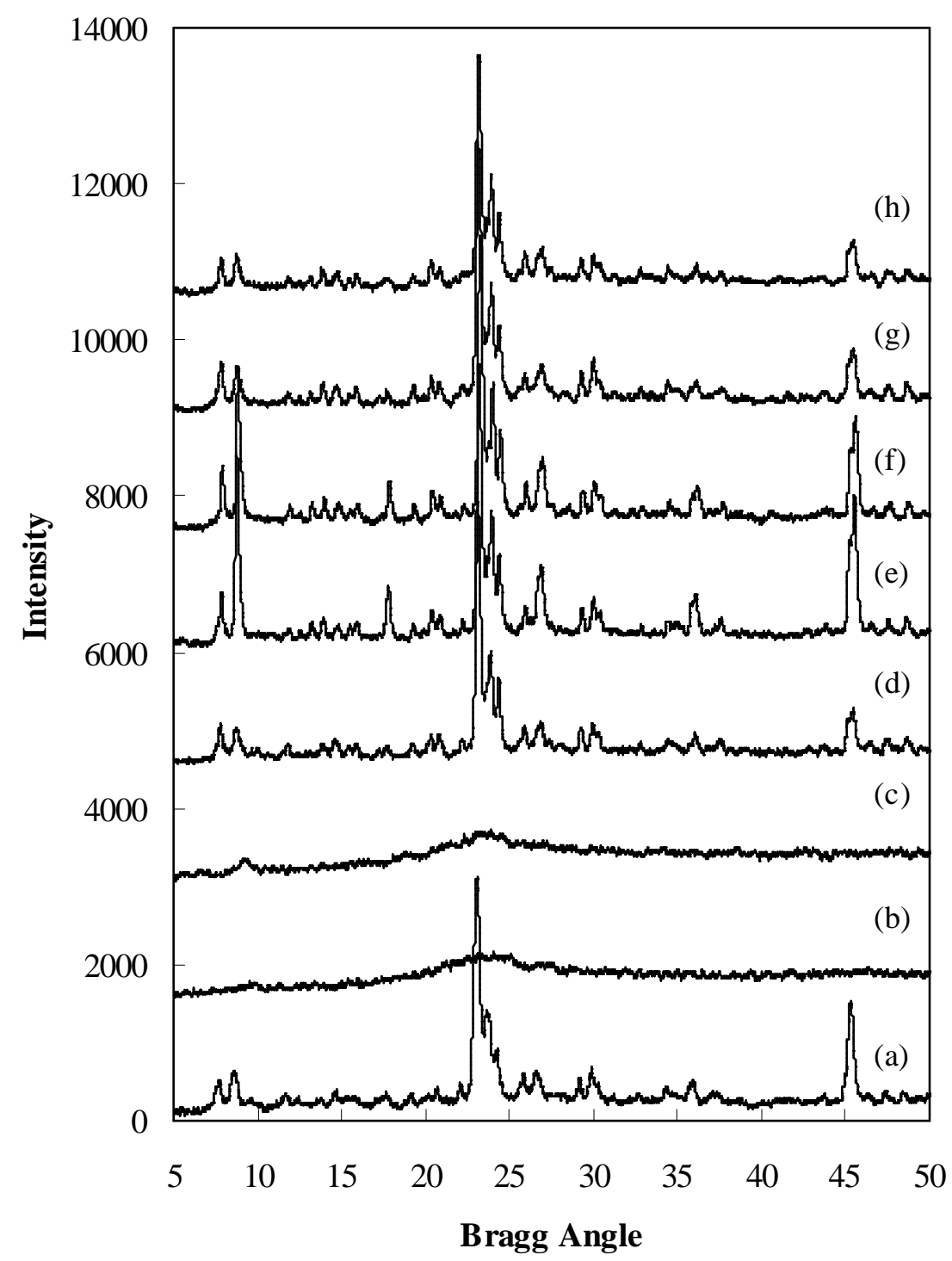

Figure 4.4 XRD patterns of the powders synthesized with different amounts of soda in the batch. $\mathrm{x}=0.5(\mathrm{a}) ; 1.0$ (b); 1.5 (c); 2.0 (d); 2.5 (e); 3.0 (f); 5.0 (g); 6.5 (h) $\left(\mathrm{x} \mathrm{Na}_{2} \mathrm{O}: 25 \mathrm{SiO}_{2}: 6.9 \mathrm{TPABr}: 1136 \mathrm{H}_{2} \mathrm{O} \quad \mathrm{T}=150^{\circ} \mathrm{C} \quad \mathrm{t}=24 \mathrm{~h}\right)$ 


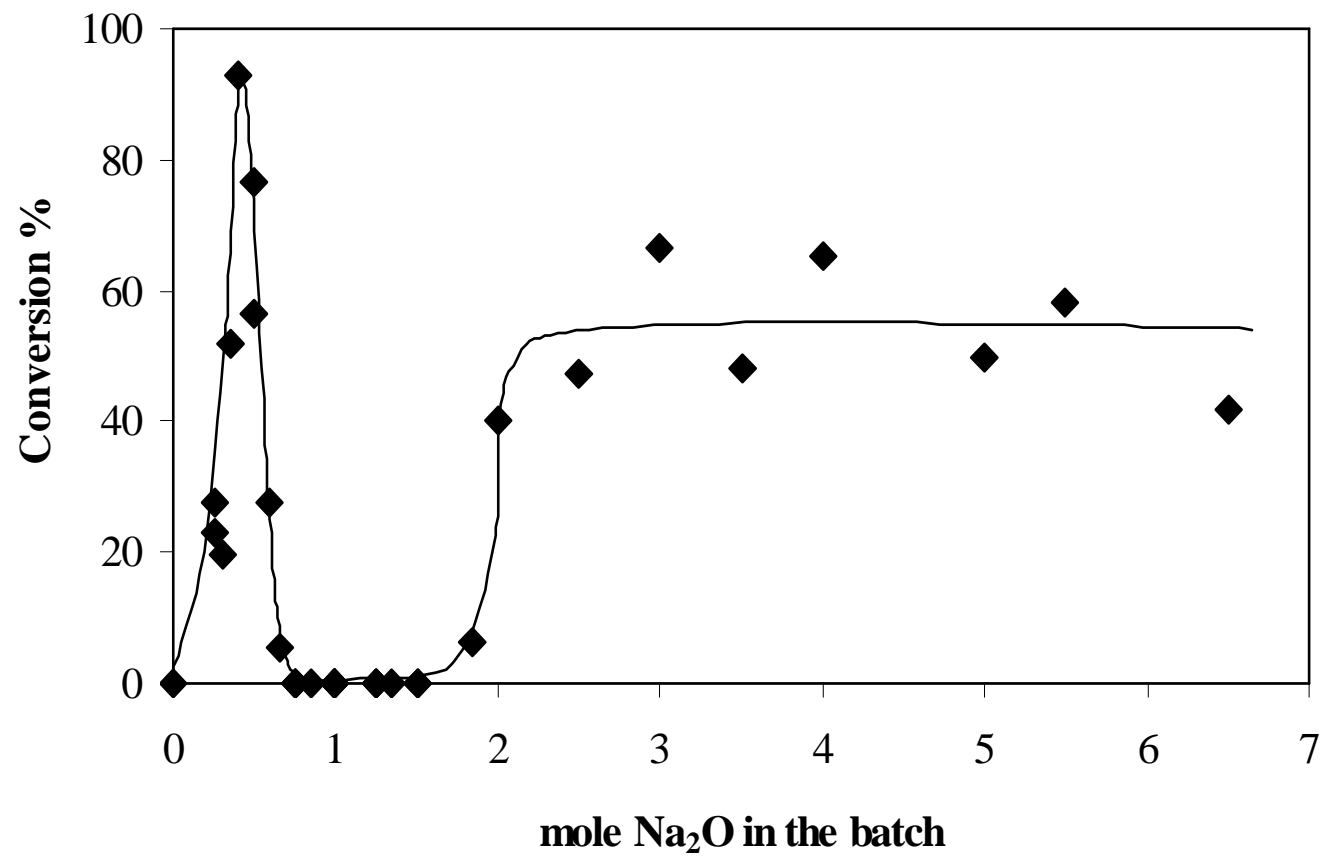

Figure 4.5 Percent conversion of the powder synthesized with different soda content in the batch $\left(\mathrm{x} \mathrm{Na}_{2} \mathrm{O}: 25 \mathrm{SiO}_{2}: 6.9 \mathrm{TPABr}: 1136 \mathrm{H}_{2} \mathrm{O} \quad \mathrm{T}=150^{\circ} \mathrm{C} \quad \mathrm{t}=24 \mathrm{~h}\right)$

Figure 4.6 shows the XRD patterns of the MFI films prepared on macroporous $\alpha-\mathrm{Al}_{2} \mathrm{O}_{3}$ supports. On the XRD patterns, only reflections originated from alumina and MFI type zeolite were observed. In contrast to powder results, MFI crystals formed on $\alpha-\mathrm{Al}_{2} \mathrm{O}_{3}$ supports even at 1.0 and 1.5 moles of soda. Moreover there were $(\mathrm{h} 0 \mathrm{~h}) / \mathrm{c}$-oriented crystals on $\alpha-\mathrm{Al}_{2} \mathrm{O}_{3}$ supports at 1.0 and 1.5 moles of soda. 


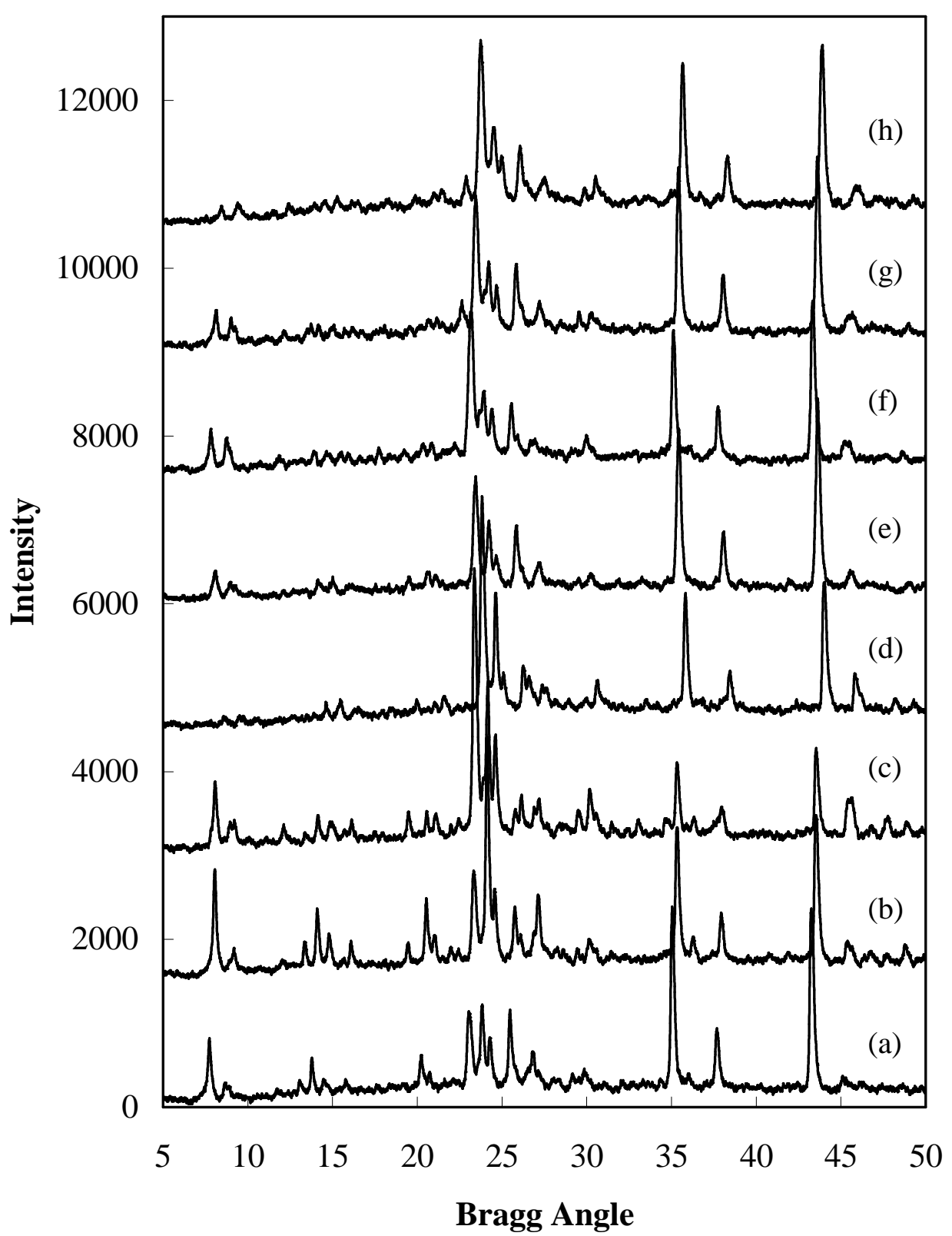

Figure 4.6 XRD patterns of the membranes synthesized with different amounts of soda in the batch. $\mathrm{x}=0.5(\mathrm{a}) ; 1.0$ (b); 1.5 (c); 2.0 (d); 2.5 (e); 3.0 (f); 5.0 (g); 6.5 (h) $\left(\mathrm{x} \mathrm{Na}_{2} \mathrm{O}: 25 \mathrm{SiO}_{2}: 6.9 \mathrm{TPABr}: 1136 \mathrm{H}_{2} \mathrm{O} \quad \mathrm{T}=150^{\circ} \mathrm{C} \quad \mathrm{t}=24 \mathrm{~h}\right)$ 
Figure 4.7 shows the XRD intensity fraction and fractional weight change of the membranes with soda content. The fractional weight change was calculated by Equation 4.1 .

Fractional weight change $=\frac{\left(W_{\text {membrane }}-W_{\text {support }}\right)}{\left(W_{\text {support }}\right)}$

where,

$\mathrm{W}_{\text {membrane }}=$ weight of the membrane $(\mathrm{g})$

$\mathrm{W}_{\text {support }}=$ weight of the blank support $(\mathrm{g})$

The intensity fraction was calculated using the strongest MFI peak at $23.5^{\circ}$ for randomly oriented membranes and at $24^{\circ}$ Bragg angle for oriented membranes together with the alumina peak at $35^{\circ}$ Bragg angle using Equation 4.2.

Intensity Fraction $=\frac{\left(I_{M F I}\right)_{\text {strongest }}}{\left(I_{M F I}\right)_{\text {strongest }}+\left(I_{\text {alumina }}\right)}$

where, I= intensity

Both intensity fraction and fractional weight change of the membranes exhibit similar trends which pass through a maximum at around 1 mole of $\mathrm{Na}_{2} \mathrm{O}$. With increasing amount of soda, MFI peaks get stronger while the alumina peaks become weaker since amount of MFI in the membrane increased with the increasing amount of soda. MFI crystals may form not only on the support surface but also in the pores of the support. At soda contents greater than 1, high alkalinity of solution may prevent MFI formation so that the amount of MFI in the membrane decreased. 


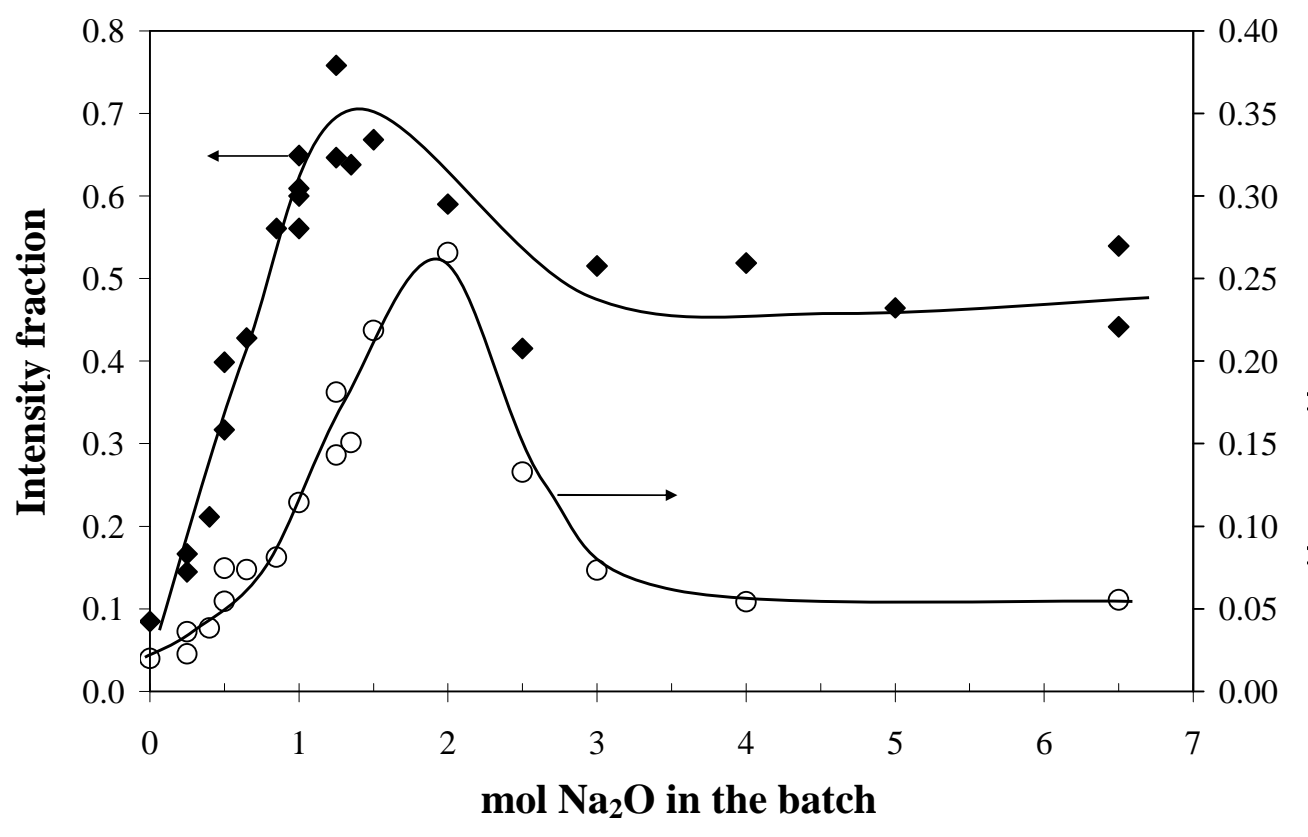

泀.

Figure 4.7 The intensity fraction and fractional weight change of the membranes with the soda content of the synthesis solution

\subsubsection{Effect of soda concentration on membrane morphology}

Figure 4.8 shows the surfaces of membranes prepared with different amounts of soda. Membrane $\mathrm{M}(0.5)$ which was synthesized from a batch with soda content of 0.5 had a MFI layer with large interzeolitic pores (Figure 4.8b). There was no apparent MFI layer on the membrane synthesized with a soda content of 0.25 (Figure 4.8a). The well intergrown MFI layer starts to form after a soda content of 0.65 . The aspect ratio of crystals increased with decreasing alkalinity of the synthesis mixture so that the crystals formed at the low alkalinities are more elongated than the crystals formed at high alkalinities (Figure 4.8) as also observed by Hasegawa et al. [68] in MFI membrane synthesis. 
Figure 4.9 shows the cross-section images of membranes prepared with different amounts of soda. The crystal morphology and support coverage depends on the soda content. When soda content of the synthesis solution was greater than 0.65 , the membranes were composed of highly intergrown MFI crystals, which were cubic in shape and had an average size of $10 \mu \mathrm{m}$. Membrane thickness slightly increased with increasing soda content; the MFI layers were between 10 and $17 \mu \mathrm{m}$-thick. The membrane layer was continuous with no detectable interzeolitic pores.

The preferred orientation of MFI crystals on the membranes was determined by using degree of orientation which was defined as follows [79]:

Degree of preferred orientation $=\frac{\left(\rho_{s}\right)}{\left(\rho_{s}\right)+\left(\rho_{r}\right)}$

s stands for the sample, $\mathrm{r}$ for the powder reference.

$\rho=\frac{\left(I_{303}\right)+\left(I_{133}\right)}{\left(I_{501}\right)+\left(I_{051}\right)}$

where, I= intensity

The degree of orientation is equal to one when all the crystals are oriented with the normal to the (303) and (133) plane perpendicular to support surface and equal to 0.5 when the crystals are randomly oriented. The crystals forming a continuous membrane layer oriented preferentially along $(\mathrm{h} 0 \mathrm{~h}) / \mathrm{c}$-axis with the degree of preferred orientation passing through a maximum with increasing soda content as shown in Figure 4.10. 

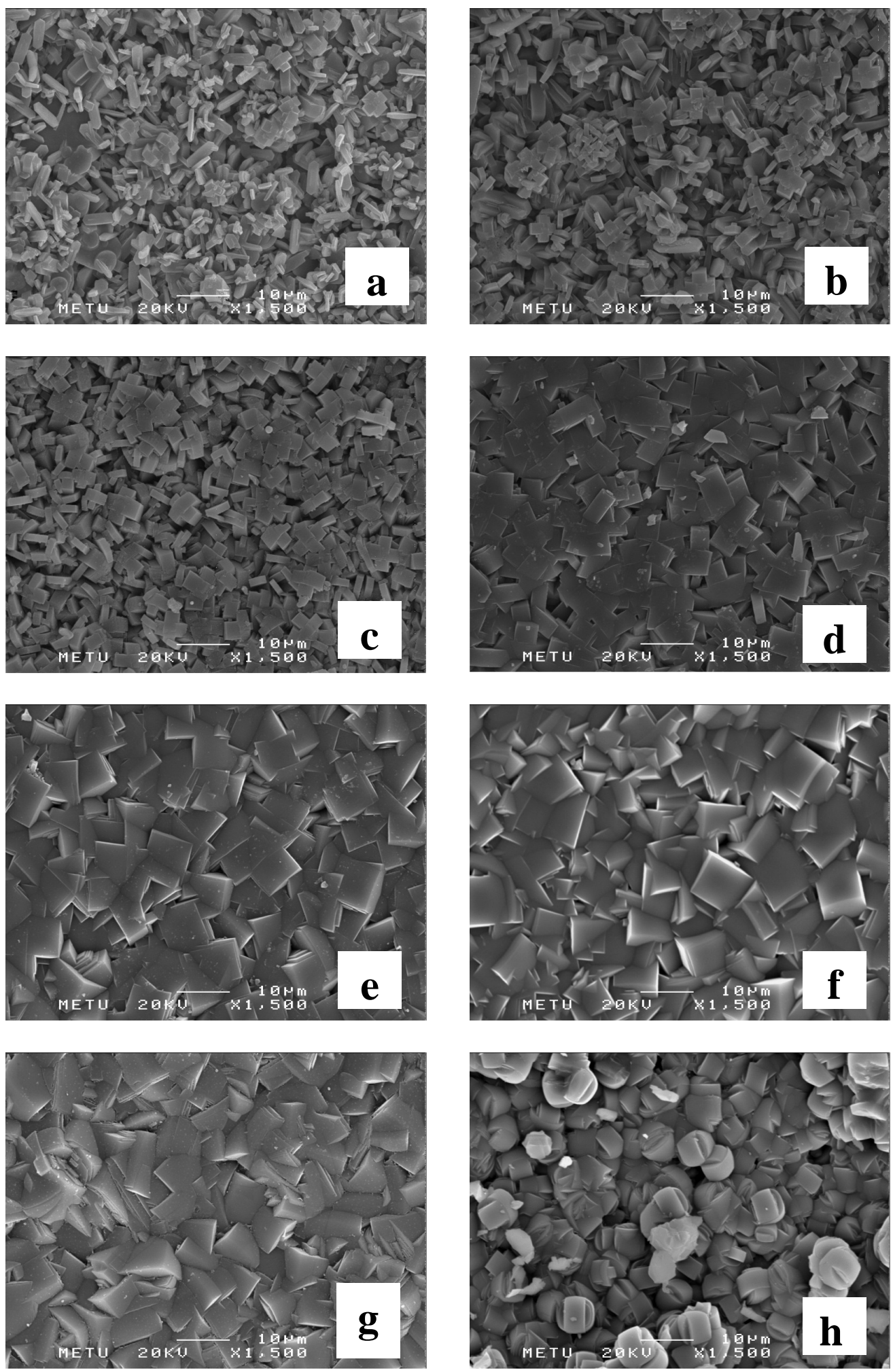

Figure 4.8 Surface SEM images of membranes synthesized on seeded $\alpha-\mathrm{Al}_{2} \mathrm{O}_{3}$ supports $\mathrm{x}=0.25$ (a); 0.4 (b); 0.5 (c); 0.65 (d); 1.0 (e); 1.25 (f); 2.0 (g); 3.0 (h) ( $\mathrm{Na}_{2} \mathrm{O}: 25 \mathrm{SiO}_{2}: 6.9 \mathrm{TPABr}: 1136 \mathrm{H}_{2} \mathrm{O} \quad \mathrm{T}=150^{\circ} \mathrm{C} \mathrm{t}=24 \mathrm{~h}$ ) 

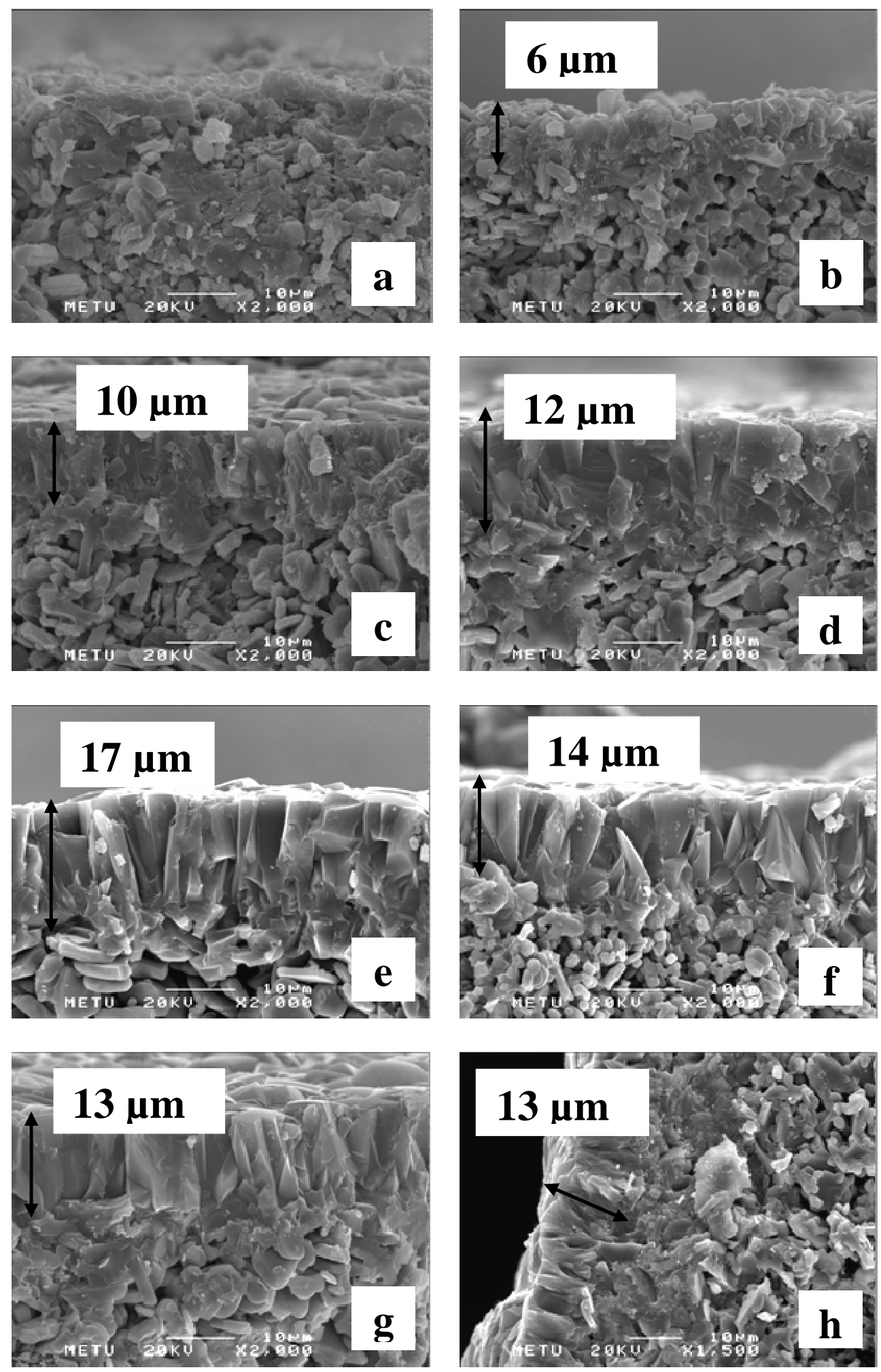

Figure 4.9 Cross section SEM images of membranes synthesized on seeded $\alpha$ $\mathrm{Al}_{2} \mathrm{O}_{3}$ supports $\mathrm{x}=0.25(\mathrm{a}) ; 0.5(\mathrm{~b}) ; 0.65$ (c); 0.85 (d); 1.0 (e); 1.25 (f); 2.0 (g); 6.5 (h) $\left(\mathrm{xNa}_{2} \mathrm{O}: 25 \mathrm{SiO}_{2}: 6.9 \mathrm{TPABr}: 1136 \mathrm{H}_{2} \mathrm{O} \quad \mathrm{T}=150^{\circ} \mathrm{C} \mathrm{t}=24 \mathrm{~h}\right)$. The arrow shows zeolite layer. 


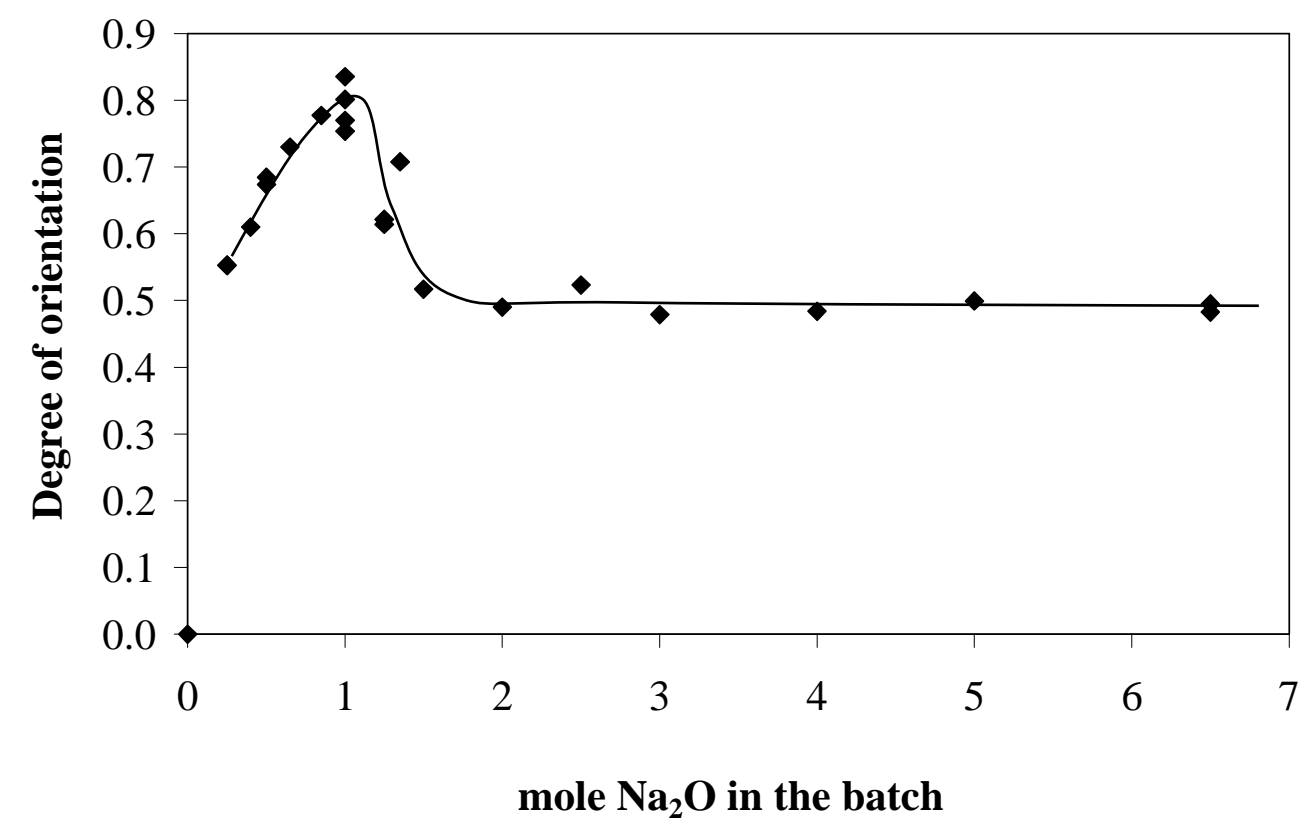

Figure 4.10 Degree of preferred orientation of the membranes synthesized with different soda content

The soda content of the synthesis batch influences the relative growth rates of the different crystallographic directions during powder synthesis and on the crystal orientation in the final membrane. At early stages of the membrane formation, the seed crystals grow in all possible directions with different growth rates $[4,43,59,82]$. As time proceeds, these crystals intersect and grow into one another. Finally, the crystals with the fastest growth rate normal to the film towards the solution phase survived at the surface while others are embedded under the growing layer. Besides, Wang and Yan [62] suggested that large aggregates of randomly oriented crystals formed on the support surface because of the agglomeration of silica precursors at high $\mathrm{Na}^{+}$ concentrations. 


\subsubsection{Characterization of membranes with single gas permeation measurements}

The gas separation performance of a zeolite membrane depends on the presence of non-zeolitic pores in the membrane layer. Different synthesis procedures could produce membranes with different relative amounts of zeolite and non-zeolitic pores. In this study an oriented membrane $\mathrm{M}(1)$ and a nonoriented membrane $\mathrm{M}(6.5)$ were characterized by single gas permeation measurements.

Figure 4.11 shows the pressure dependence of the single gas permeances through membranes $\mathrm{M}(1)$ and $\mathrm{M}(6.5)$. The oriented membrane has permeances with at least one order of magnitude lower than the non-oriented membrane at all pressures. Since no channels are present perpendicular to the support surface in MFI membranes with $(\mathrm{h} 0 \mathrm{~h}) / c$-directed orientation, permeating molecules diffuse through the membrane by jumping between the straight and sinusoidal channels [59], which is likely to result in a significantly low permeance through oriented membranes.

The permeances of $\mathrm{CO}_{2}$ and $n-\mathrm{C}_{4} \mathrm{H}_{10}$ slightly increased but $\mathrm{H}_{2}$ and $\mathrm{N}_{2}$ permeances remained nearly the same with increasing feed pressure. Jareman and Hedlund [84] and Gopalakrishnan et al. [75] also observed that feed pressure had no effect on the permeances of $\mathrm{H}_{2}, \mathrm{~N}_{2}$ and He. The pressureindependent permeation of the small molecules was ascribed to defect-free membrane structure. Pressure dependent permeation of larger molecules, however, indicates adsorption dependency [25]. 


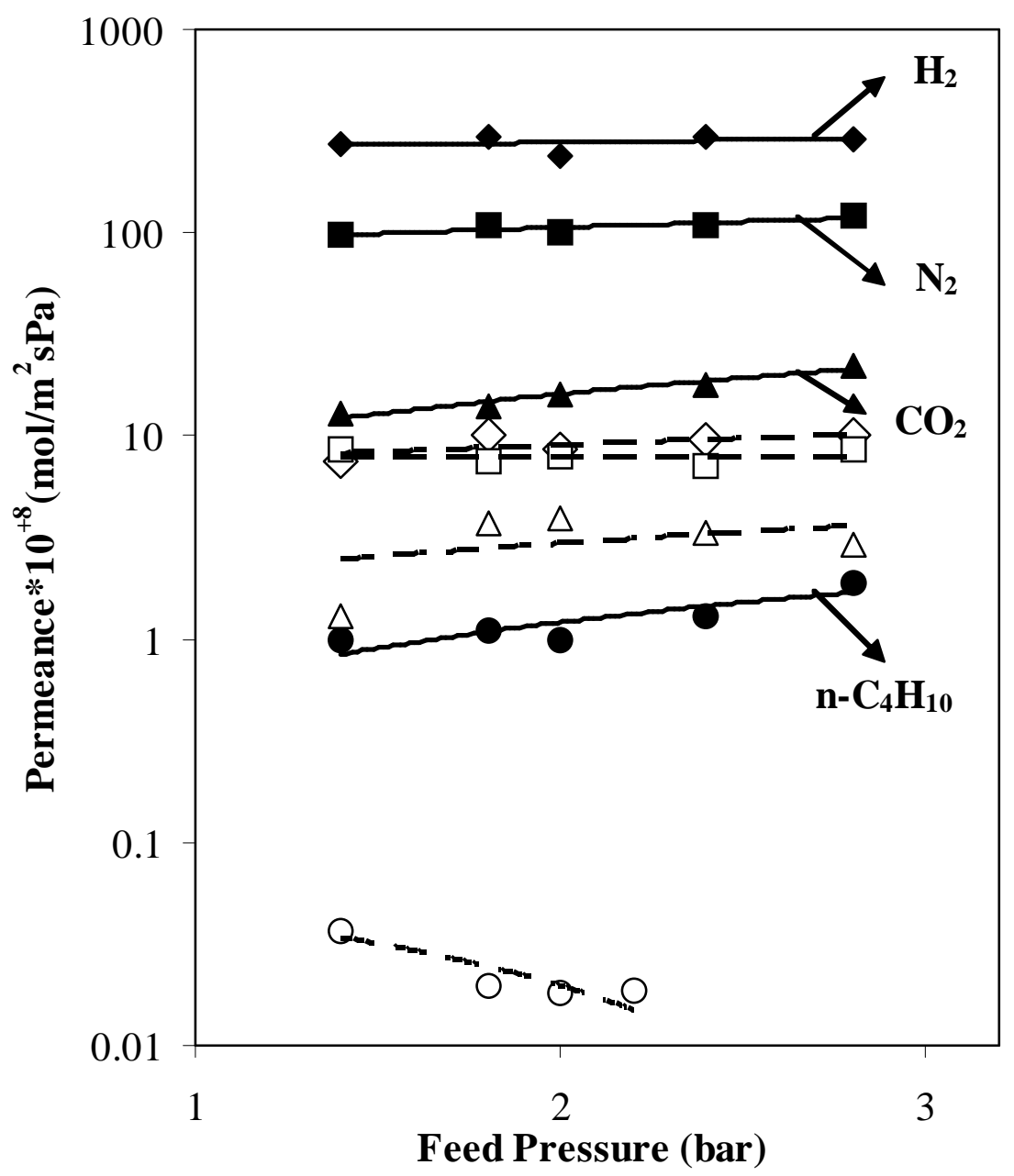

Figure 4.11 Permeances of single gases through oriented (M1) and nonoriented $\mathrm{M}(6.5)$ membranes $\left(\diamond, \diamond: \mathrm{H}_{2} ; \square, \mathbf{m}: \mathrm{N}_{2} ; \Delta, \boldsymbol{\Delta}: \mathrm{CO}_{2} ; \circ, \bullet: \mathrm{n}-\mathrm{C}_{4} \mathrm{H}_{10}\right.$; empty symbols for oriented and filled symbols for non-oriented membranes)

Table 4.1 shows single gas permeances and ideal selectivities for the (h0h)/coriented membrane $\mathrm{M}(1)$. The $\mathrm{H}_{2}$ and $\mathrm{N}_{2}$ permeances decreased while $\mathrm{CO}_{2}$ and $\mathrm{CH}_{4}$ permeances exhibited a maximum with increasing temperature. The $\mathrm{H}_{2} / \mathrm{n}$ $\mathrm{C}_{4} \mathrm{H}_{10}$ ideal selectivity was 478 at $25^{\circ} \mathrm{C}$ and 36 at $150^{\circ} \mathrm{C}$; these correspond to 90 and 7 times the Knudsen selectivity for these gases. Since the kinetic diameter of $n-C_{4} \mathrm{H}_{10}$ is closer to the dimensions of pore channels in MFI type zeolite than that of $\mathrm{H}_{2}$, low permeance for $n-\mathrm{C}_{4} \mathrm{H}_{10}$ and high $\mathrm{H}_{2} / \mathrm{n}-\mathrm{C}_{4} \mathrm{H}_{10}$ ideal 
selectivity is expected for a defect-free membrane. The $n-\mathrm{C}_{4} \mathrm{H}_{10} / \mathrm{i}-\mathrm{C}_{4} \mathrm{H}_{10}$ ideal selectivity, however, is about 0.5 at $25^{\circ} \mathrm{C}$ and slightly higher than one for higher temperatures. Lovallo and Tsapatsis [82] attributed the low $n-\mathrm{C}_{4} \mathrm{H}_{10} / \mathrm{i}$ $\mathrm{C}_{4} \mathrm{H}_{10}$ ideal selectivities and permeances to the c-directed orientation in which both butanes need to follow a zig-zag path during the permeation by jumping between the zeolite channels. Caro et al. [19] also reviewed that MFI membranes with columnar structure fails to separate $n-\mathrm{C}_{4} \mathrm{H}_{10} / \mathrm{i}-\mathrm{C}_{4} \mathrm{H}_{10}$ mixture. They suggested that separation of these gas pairs is based on shape selectivity of MFI pores but $n-\mathrm{C}_{4} \mathrm{H}_{10}$ and $\mathrm{i}-\mathrm{C}_{4} \mathrm{H}_{10}$ mainly transport along the grain boundaries between the individual microcrystals of the columnar microstructure.

Table 4.1 Single gas permeances through the (h0h)/c-oriented membrane $\mathrm{M}(1)$

\begin{tabular}{ccccccccc}
\hline & \multicolumn{3}{l}{ Permeance $10^{+8}\left(\mathrm{~mol} / \mathrm{m}^{2} \mathrm{sPa}\right)$} & \multicolumn{3}{c}{ Ideal Selectivity } \\
\cline { 2 - 9 } Temperature $\left({ }^{\circ} \mathrm{C}\right)$ & $\mathrm{H}_{2}$ & $\mathrm{~N}_{2}$ & $\mathrm{CO}_{2}$ & $\mathrm{CH}_{4}$ & $\mathrm{n}-\mathrm{C}_{4} \mathrm{H}_{10}$ & $\mathrm{H}_{2} / \mathrm{n}-\mathrm{C}_{4} \mathrm{H}_{10}$ & $\begin{array}{c}\mathrm{CH}_{4} / \\
\mathrm{n}-\mathrm{C}_{4} \mathrm{H}_{10}\end{array}$ & $\begin{array}{c}\mathrm{n}-\mathrm{C}_{4} \mathrm{H}_{10} / \\
\mathrm{i}-\mathrm{C}_{4} \mathrm{H}_{10}\end{array}$ \\
\hline 25 & 8.6 & 8.0 & 3.9 & 9.0 & 0.018 & 478 & 500 & 0.5 \\
50 & 7.8 & 7.0 & 8.5 & 13.7 & 0.019 & 413 & 721 & 1.0 \\
75 & 8.4 & 6.9 & 14.1 & 15.9 & 0.034 & 250 & 473 & 1.5 \\
100 & 7.0 & 6.5 & 15.1 & 15.9 & 0.128 & 55 & 124 & 5.8 \\
125 & 5.9 & 6.6 & 10.0 & 13.3 & 0.125 & 47 & 106 & 3.5 \\
150 & 5.3 & 4.3 & 4.4 & 9.5 & 0.147 & 36 & 65 & 2.7 \\
\hline
\end{tabular}

The temperature dependence of the single component permeances of membrane $M(6.5)$ at 1 bar is presented in Figure 4.12. $M(6.5)$ is a randomly oriented membrane. At all temperatures $\mathrm{H}_{2}$ is the fastest and the $n-\mathrm{C}_{4} \mathrm{H}_{10}$ is the slowest permeating molecule. Therefore this membrane has very high $\mathrm{H}_{2} / \mathrm{n}$ $\mathrm{C}_{4} \mathrm{H}_{10}$ ideal selectivities, which are 480 and 2000 at $25^{\circ} \mathrm{C}$ and $100^{\circ} \mathrm{C}$, respectively. Permeances decreased with increasing temperature. Bakker et al. 
$[69,70]$ proposed a transport mechanism for the weakly adsorbing gases and light hydrocarbons. According to this mechanism since the increase in temperature enhances the mobility of adsorbed species, initially permeation increases with increasing temperature and then decreases so that permeances pass through a maximum with increasing temperature.

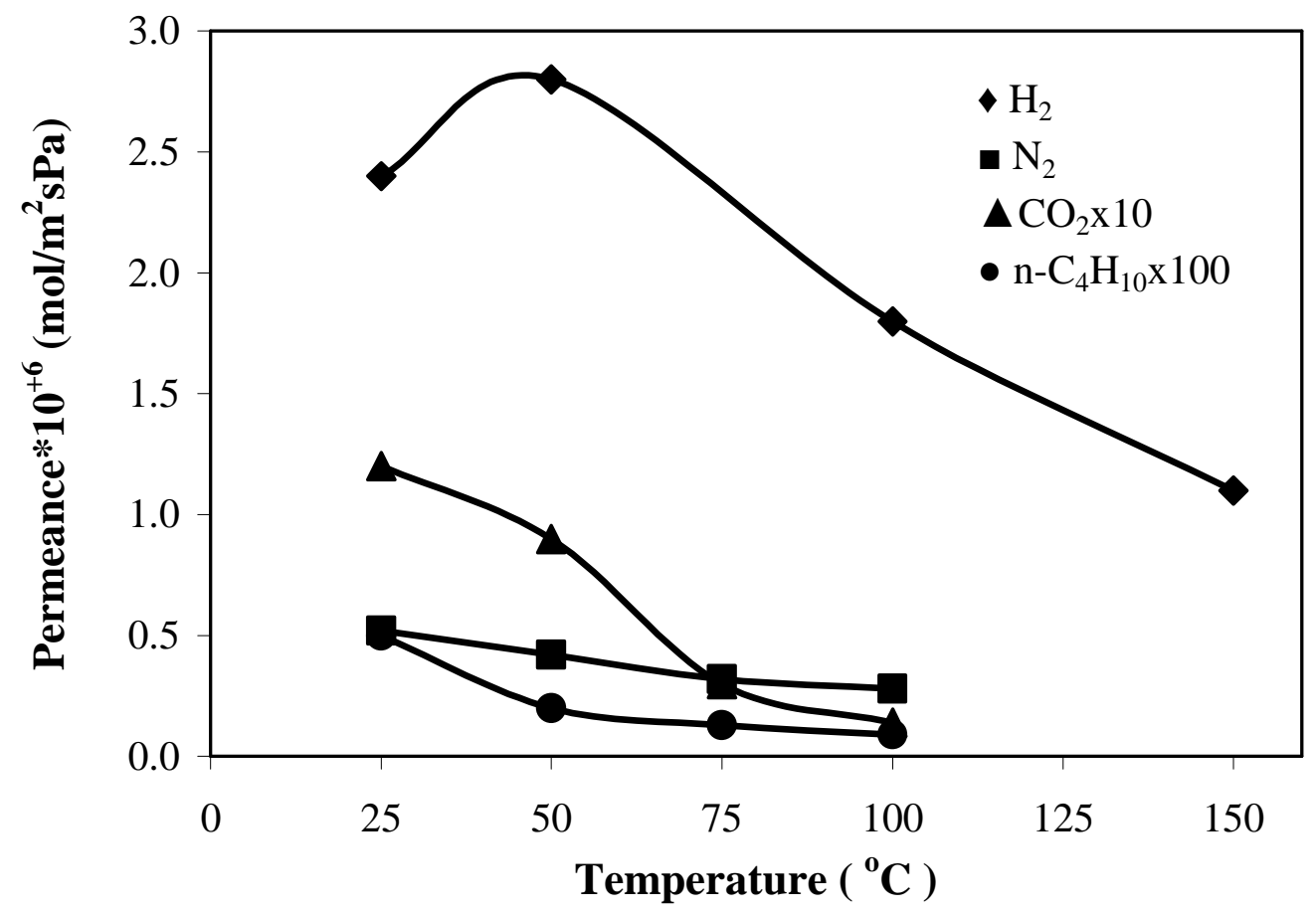

Figure 4.12 Permeances of single gases through non-oriented (M6.5) membrane $\left(\diamond, \diamond: \mathrm{H}_{2} ; \square, \mathbf{\square}: \mathrm{N}_{2} ; \Delta, \boldsymbol{\Delta}: \mathrm{CO}_{2} ; \circ, \bullet: \mathrm{n}-\mathrm{C}_{4} \mathrm{H}_{10}\right)$

Further increase in temperature the permeance reaches a minimum and increases again. At lower temperature, the adsorbed amount in zeolite is higher; the enhancement of the diffusivity by increasing temperature is dominant. At a certain temperature enhancement of diffusivity and reduction of the number of adsorbed molecule by increasing temperature become equal. In 
the studied temperature range here from $25^{\circ} \mathrm{C}$ to $100^{\circ} \mathrm{C}$, the effect of a decrease in adsorbing molecules with temperature on the permeance is dominant. So it can be the expected result to observe only decreasing part in permeances with increasing temperature. However, this proposed mechanism does not take the effect of defect into account. The number and size of defects in a membrane may change in each synthesis even which was carried out under the same conditions. Therefore Coronas et al. [25] suggested that the transport mechanism through a membrane may change depending on the defect density and consequently synthesis method.

\subsubsection{Synthesis of MFI films on nonporous glass with different soda concentrations}

The MFI films were also prepared on nonporous glass supports from synthesis mixtures with soda amount of 1, 3 and $6.5 \mathrm{~mol} / \mathrm{mole}$ batch. Figure 4.13 shows the XRD results of powder and films on porous seeded $\alpha-\mathrm{Al}_{2} \mathrm{O}_{3}$ and seeded nonporous glass support synthesized with 1 mole of soda content. In Section 4.1.2, it was shown that no zeolites formed in the bulk mixture but oriented MFI film was obtained on the $\alpha-\mathrm{Al}_{2} \mathrm{O}_{3}$ surface when the synthesis mixture contained 1 mole of soda. Interestingly randomly oriented MFI film was obtained on the glass surface when the synthesis mixture contained 1 mole of soda. It should be noted that the product formed in the bulk during the synthesis both on the alumina and on the glass surfaces was also amorphous.

Apparently the presence of a surface plays crucial role in the crystal growth and film formation process. The support can be a source of precursor materials (e.g., Si or $\mathrm{Na}$ from glass support or $\mathrm{Al}$ from alumina support, etc.) which can significantly alter the local synthesis chemistry on the surface and consequently affect the formation of the crystals. The surface structure of the support has also been shown to influence orientation of the zeolite film. Wang and Yan 


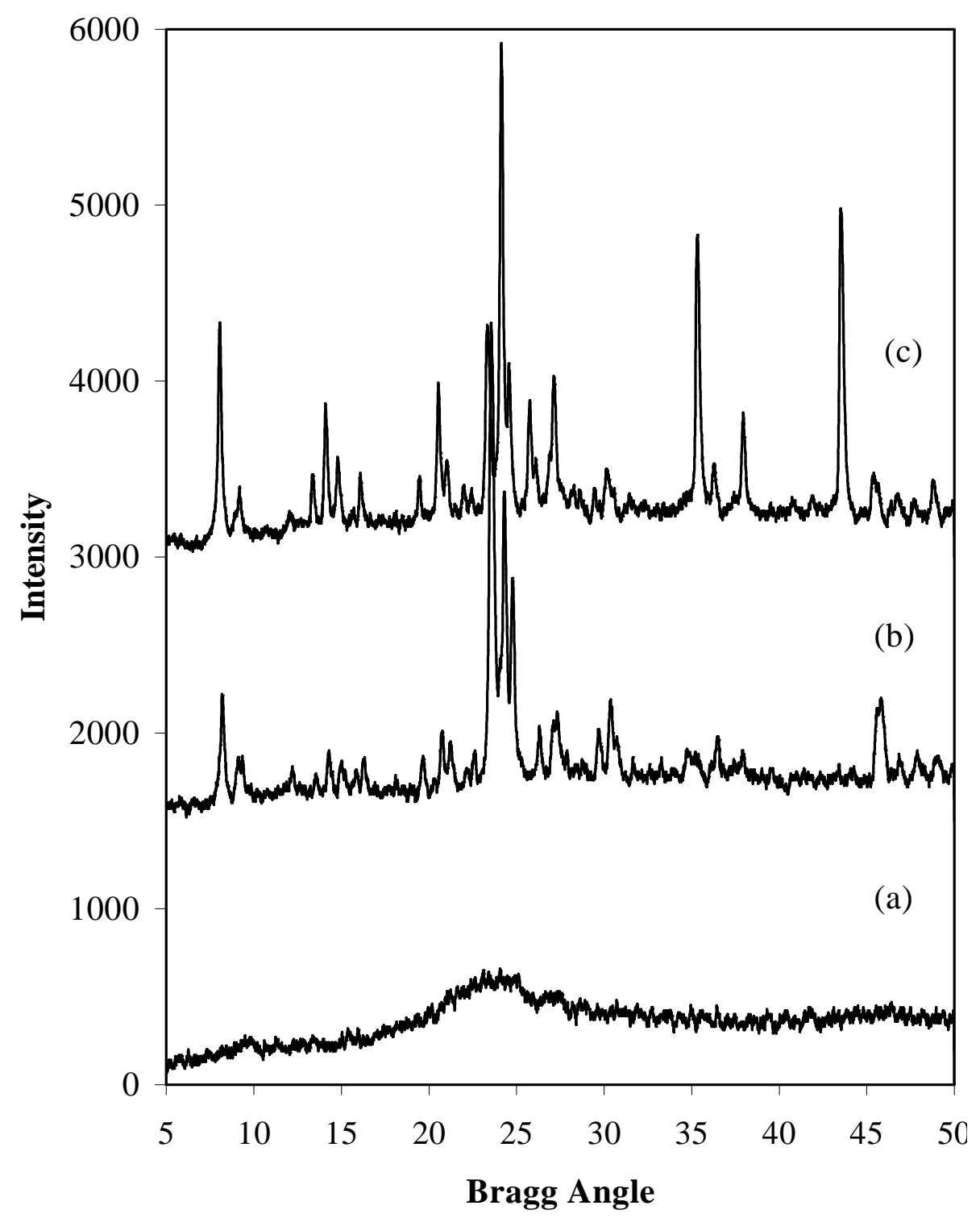

Figure 4.13 XRD patterns of the powder (a); glass (b); alumina (c) surfaces. (Seeded surface, $1.0 \mathrm{Na}_{2} \mathrm{O}: 25 \mathrm{SiO}_{2}: 6.9 \mathrm{TPABr}: 1136 \mathrm{H}_{2} \mathrm{O} \quad \mathrm{T}=150^{\circ} \mathrm{C} \mathrm{t}=24 \mathrm{~h}$ )

[62] observed that continuous zeolite films are obtained on stainless steel support while no crystals formed in the bulk phase when $\mathrm{OH}^{-} / \mathrm{Si}$ was higher than 0.64 or lower than 0.2 . They also suggested that the presence of a support surface play an important role in the film formation. Besides the seed crystals deposited onto the surface prior to hydrothermal treatment may cause crystallization on the surface. However, MFI films were also obtained on 
unseeded glass surfaces, indicating that presence of a support is more effective than seeding for the zeolite formation.

Figure 4.14 shows the XRD patterns of films on seeded glass surfaces synthesized with different moles of soda. The intensity of MFI peaks obtained from 1.0 and 3.0 moles of soda are higher than that of 6.5 moles of soda. This result also indicates that high soda concentration in the batch cause a much higher proportion of the silica to remain in the bulk which may suppress the zeolite formation on the surface. Besides small amounts of MFI crystals may accumulate on the glass surface, which may be significantly dissolved at high concentrations of soda.

Figure 4.15 shows the photographs of the MFI films synthesized on unseeded and seeded glass surfaces. Seeding of the glass surfaces were done by vacuum seeding with $1 \mu \mathrm{m}$ size MFI crystals. The difference between seeded and unseeded surfaces can be clearly seen; the surface of seeded glass was fully covered by a MFI film although uncoated regions can be seen on the unseeded glass. The MFI films were also inspected by SEM (Figure 4.16), which showed that the crystals were placed separately on the unseeded surface while they formed a dense and intergrown layer on the seeded surface.

Figure 4.17 shows the photographs of MFI films synthesized with 1.0, 3.0 and 6.5 moles of soda on seeded supports. The disk surface was completely opaque when $1 \mathrm{~mol}$ of soda/mole batch was used for synthesis. On the other hand, the disk surface was almost transparent when $6.5 \mathrm{~mol}$ of soda/mole batch was used. The surface SEM images of these samples (Figure 4.18) also show that the whole surface fully covered with MFI crystals at 1.0 and 3.0 moles of soda whereas the some parts on the surface of glass with 6.5 moles of soda seems like uncoated. 


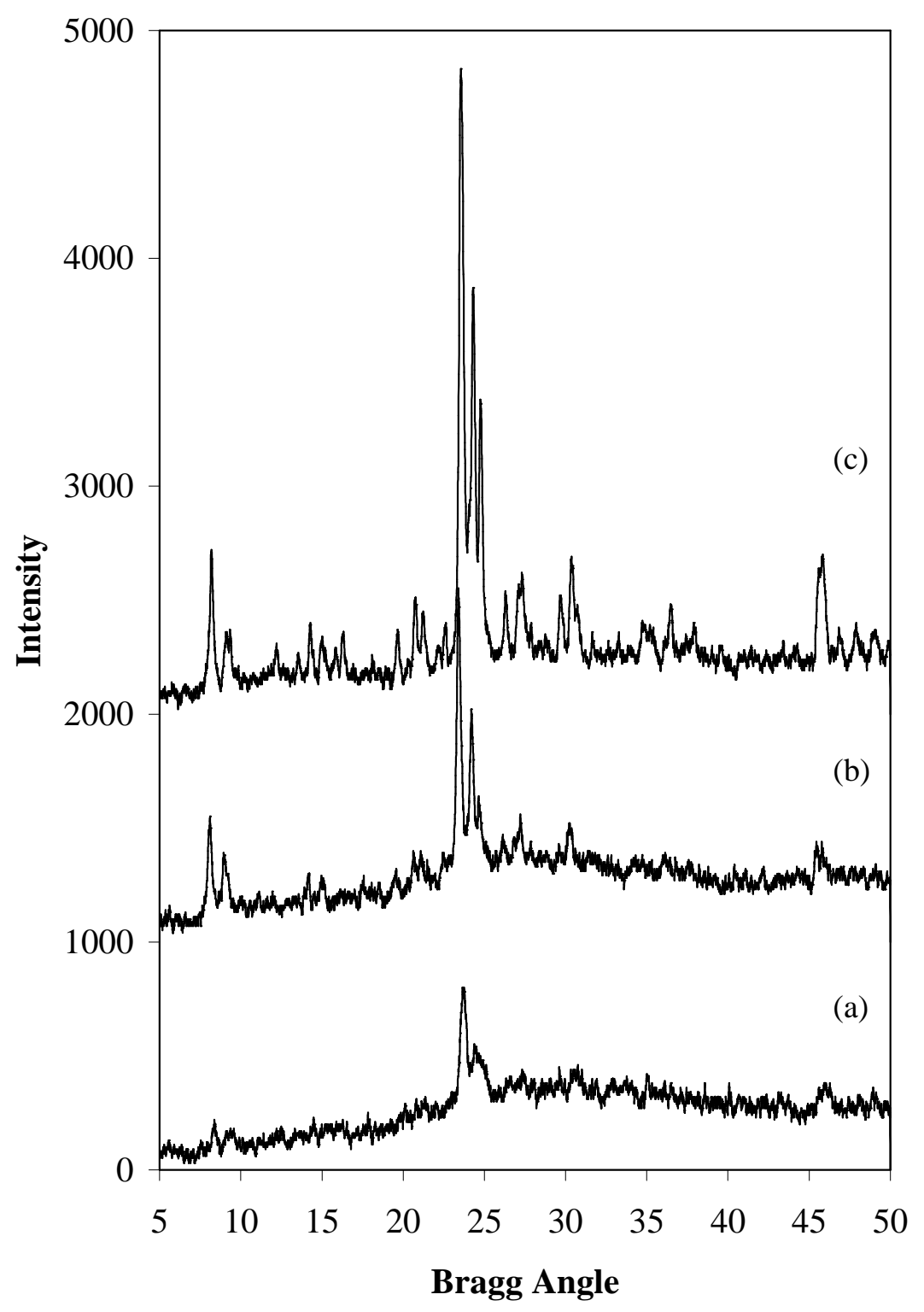

Figure 4.14 XRD patterns of the MFI layers on glass surfaces synthesized with different amounts of soda in the batch. $\mathrm{x}=6.5$ (a); 3.0 (b); 1.0 (c) (x $\left.\mathrm{Na}_{2} \mathrm{O}: 25 \mathrm{SiO}_{2}: 6.9 \mathrm{TPABr}: 1136 \mathrm{H}_{2} \mathrm{O} \quad \mathrm{T}=150^{\circ} \mathrm{C} \quad \mathrm{t}=24 \mathrm{~h}\right)$ 
Apparently the degree of coating increases with decreasing concentrations of soda in the synthesis mixture. The surfaces were coated with twinned and coffin shaped crystals at all soda contents. The crystal size was about $40 \mu \mathrm{m}$ when the soda concentration in the synthesis solution was 1.0, and it decreased to about $10 \mu \mathrm{m}$ as the soda concentration increased from 1.0 to 6.5. The cross section SEM images of the glasses in Figure 4.19 indicate that the thickness of the films decreases from about $90 \mu \mathrm{m}$ to $20 \mu \mathrm{m}$ as soda concentration increased from 1.0 to 6.5 moles in the synthesis batch. As a reminder the crystal size was about $10 \mu \mathrm{m}$ and $5 \mu \mathrm{m}$ on $\alpha-\mathrm{Al}_{2} \mathrm{O}_{3}$ surfaces when the soda concentration was 1.0 and 6.5, respectively. Also the film thicknesses on $\alpha$ $\mathrm{Al}_{2} \mathrm{O}_{3}$ surfaces decreased from $17 \mu \mathrm{m}$ to $10 \mu \mathrm{m}$ as soda concentration increased from 1.0 to 6.5 moles in the synthesis batch. Apparently the crystal sizes and film thicknesses on glass supports are much bigger than those of $\alpha$ $\mathrm{Al}_{2} \mathrm{O}_{3}$ surfaces. These results also strongly point out that the different support surfaces affect the local synthesis chemistry on the surface differently and change the crystal morphology.

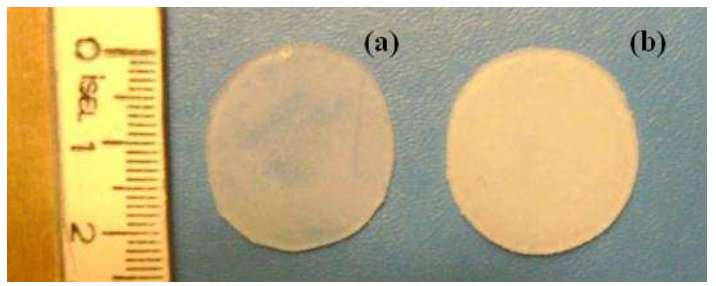

Figure 4.15 Photographs of zeolite films synthesized with $1.0 \mathrm{Na}_{2} \mathrm{O}: 25 \mathrm{SiO}_{2}: 6.9 \mathrm{TPABr}: 1136 \mathrm{H}_{2} \mathrm{O}$ molar batch on unseeded (a) and seeded (b) glass surfaces 

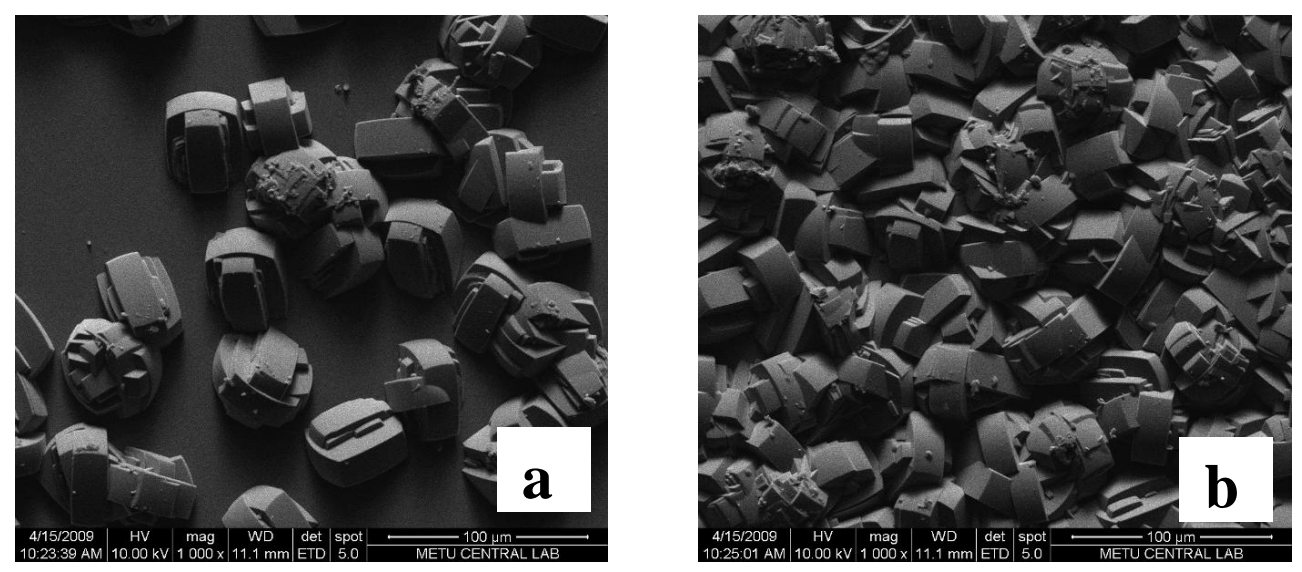

Figure 4.16 Surface SEM images of the zeolite films synthesized with $1.0 \mathrm{Na}_{2} \mathrm{O}: 25 \mathrm{SiO}_{2}: 6.9 \mathrm{TPABr}: 1136 \mathrm{H}_{2} \mathrm{O}$ molar batch on unseeded (a) and seeded (b) glass surfaces

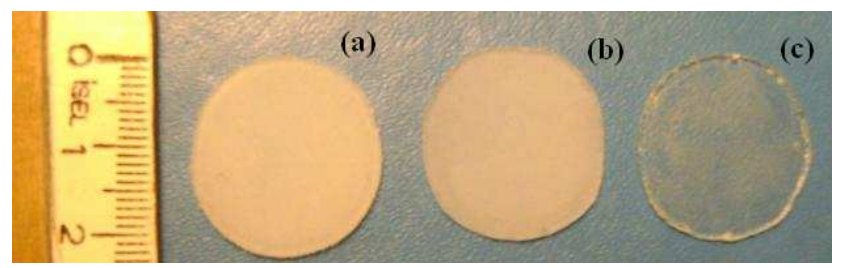

Figure 4.17 Photographs of zeolite films synthesized with $\mathrm{x}=1.0$ (a); 3.0 (b); 6.5 (c) moles of soda on seeded glass surfaces (x $\mathrm{Na}_{2} \mathrm{O}: 25 \mathrm{SiO}_{2}: 6.9 \mathrm{TPABr}: 1136 \mathrm{H}_{2} \mathrm{O}$ ) 

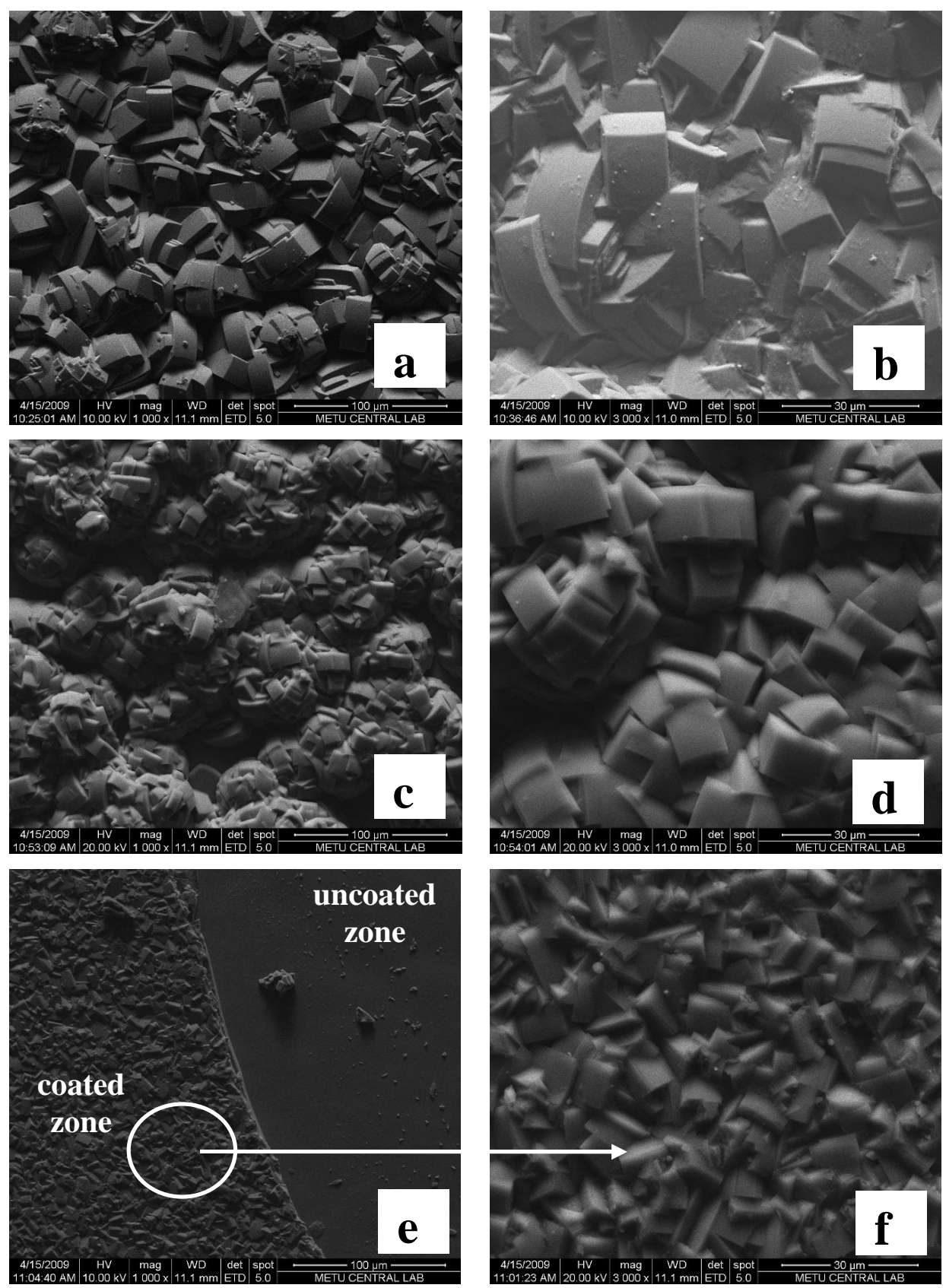

Figure 4.18 Surface SEM images of the films synthesized with $(a, b) x=1.0$, (c, d) $x=3.0,(e, f) x=6.5$ moles of soda on seeded glass surfaces (x $\mathrm{Na}_{2} \mathrm{O}: 25 \mathrm{SiO}_{2}: 6.9 \mathrm{TPABr}: 1136 \mathrm{H}_{2} \mathrm{O}$ ) 

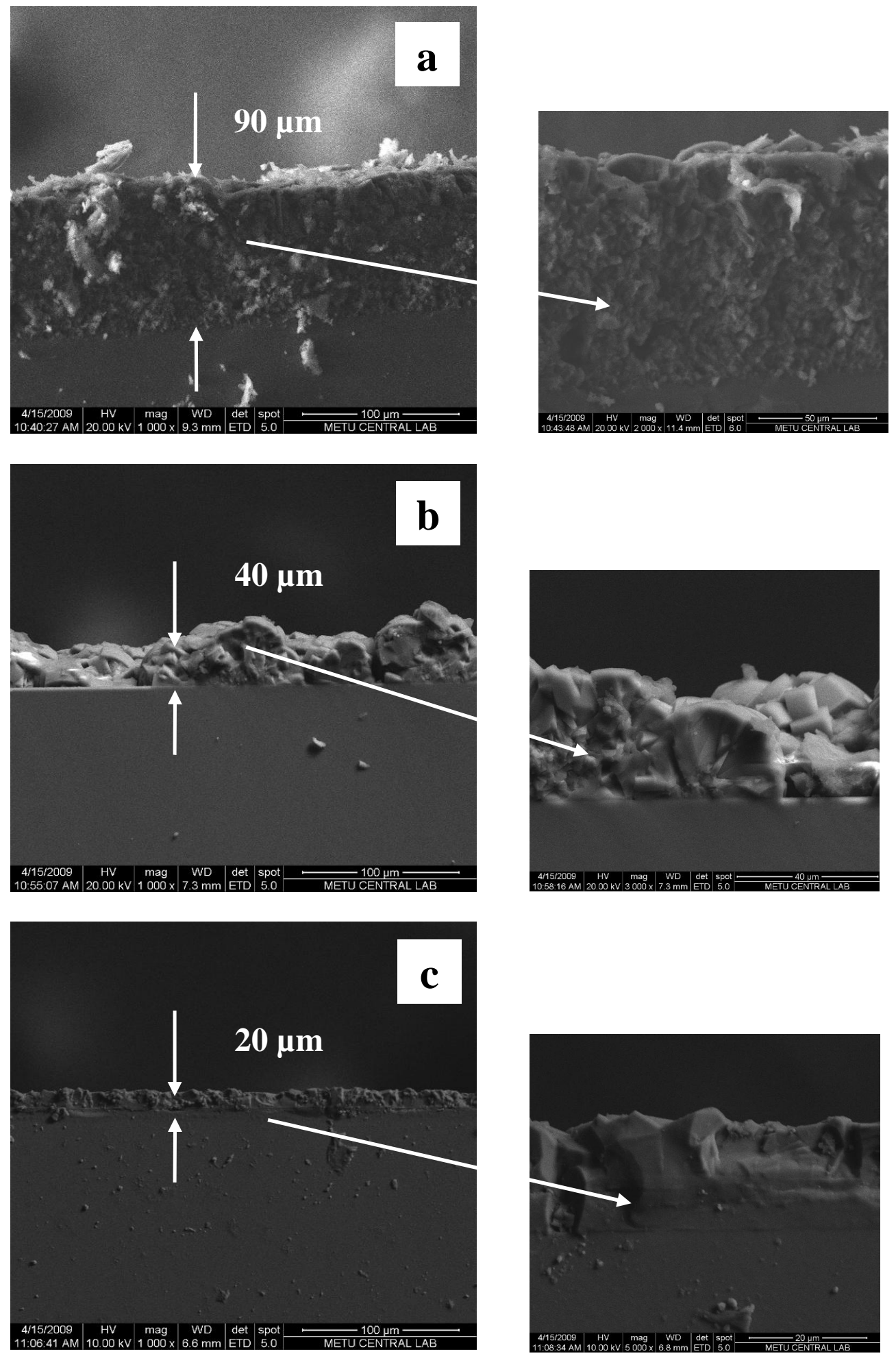

Figure 4.19 Cross section SEM images of the films synthesized with (a) $x=1.0$, (b) $\mathrm{x}=3.0$, (c) $\mathrm{x}=6.5$ moles of soda on seeded glass surfaces (x $\mathrm{Na}_{2} \mathrm{O}: 25 \mathrm{SiO}_{2}: 6.9 \mathrm{TPABr}: 1136 \mathrm{H}_{2} \mathrm{O}$ ) 


\subsection{Synthesis of MFI type zeolite membranes and powder with different template concentrations of crystallization solution}

In this part, MFI type zeolites were synthesized from clear solutions with different tetrapropylammonium hydroxide $(\mathrm{TPAOH})$ or bromide (TPABr) concentrations in autoclaves. Both powder and membrane syntheses were done. Membranes were synthesized on seeded commercial $\alpha-\mathrm{Al}_{2} \mathrm{O}_{3}$ disc supports. Seeding of the supports was done with $350 \mathrm{~nm}$ sized seed crystals and by both dip-coating and vacuum seeding method. Smaller crystals and consequently a thinner layer were expected by using clear solutions and increasing the template and hydroxyl ion concentrations.

Table 4.2 summarizes the synthesis conditions and, $\mathrm{TPA}^{+} / \mathrm{SiO}_{2}$ and $\mathrm{OH}^{-} / \mathrm{SiO}_{2}$ ratios of the synthesis solutions. Here the synthesis with only TPAOH is denoted as Set 1, and the syntheses with TPABr and TPAOH mixture were denoted as Set 2 and 3.

Table 4.2 Synthesis conditions for the powders and membranes with different batch compositions (T: TPA; $\mathrm{S}: \mathrm{SiO}_{2} ; \mathrm{N}: \mathrm{Na}_{2} \mathrm{O} ; \mathrm{H}: \mathrm{H}_{2} \mathrm{O}$ ) The silica source is LUDOX AS-30

\begin{tabular}{cccccc}
\hline & Batch Composition & Template Source & $\begin{array}{c}\text { Temperature } \\
\left({ }^{\circ} \mathrm{C}\right)\end{array}$ & $\mathrm{TPA}^{+} / \mathrm{SiO}_{2}$ & $\mathrm{OH}^{-} / \mathrm{SiO}_{2}$ \\
\cline { 2 - 5 } Set 1 & T:S:N:H & TPAOH & 95 & 0.063 & 0.063 \\
& $9: 80: 0: 1500$ & TPAOH & 95 & 0.113 & 0.113 \\
& $16: 80: 0: 1500$ & TPAOH & 95 & 0.20 & 0.20 \\
& $30: 80: 0: 1500$ & TPAOH & 95 & 0.375 & 0.375 \\
\hline \multirow{3}{*}{ Set2 } & $22: 80: 21: 3600$ & TPABr & 150 & 0.275 & 0.525 \\
& $22: 80: 21: 3600$ & TPABr+TPAOH & 150 & 0.275 & 0.663 \\
& $22: 80: 21: 3600$ & TPAOH & 150 & 0.275 & 0.80 \\
\hline \multirow{3}{*}{ Set 3 } & $16: 80: 10: 2500$ & TPABr & 150 & 0.20 & 0.25 \\
& $16: 80: 10: 2500$ & TPABr+TPAOH & 150 & 0.20 & 0.35 \\
& $16: 80: 10: 2500$ & TPAOH & 150 & 0.20 & 0.45 \\
\hline
\end{tabular}




\subsubsection{Synthesis of membranes on alumina supports with different amounts of TPAOH as template}

Figure 4.20 shows the XRD patterns of the powders and membranes synthesized using a molar batch composition of $80 \mathrm{SiO}_{2} \cdot \mathrm{xTPAOH} \cdot 1500 \mathrm{H}_{2} \mathrm{O}$ where $\mathrm{x}$ was 5, 9, 16 and 30 at $95^{\circ} \mathrm{C}$ with LUDOX AS-30 as the silica source (Set 1 in Table 4.2). The powders and membranes contain only MFI type zeolite crystals. The intensities of MFI peaks in the XRD patterns of powders synthesized with 16 and 30 moles of TPAOH are more pronounced than those with 5 and 9 moles of TPAOH (Figure 4.20a). The lower intensity may be the result of either the existence of the amorphous phase in the powder or the low product yield in powder synthesis. But if there was amorphous phase a stronger background reflection would be expected. The other reason may be the low product yield in powder synthesis. The product amount was insufficient so that the reflections from the amorphous substrate used in XRD analysis increases background radiation. On the other hand for the membranes (Figure 4.20b) the intensity of MFI peaks decreases as TPAOH concentration increases. This indicates that MFI crystals covered the surface at all concentrations but the amount of zeolite crystals forming the layer at high TPAOH concentrations is less than that of at low TPAOH concentrations. 

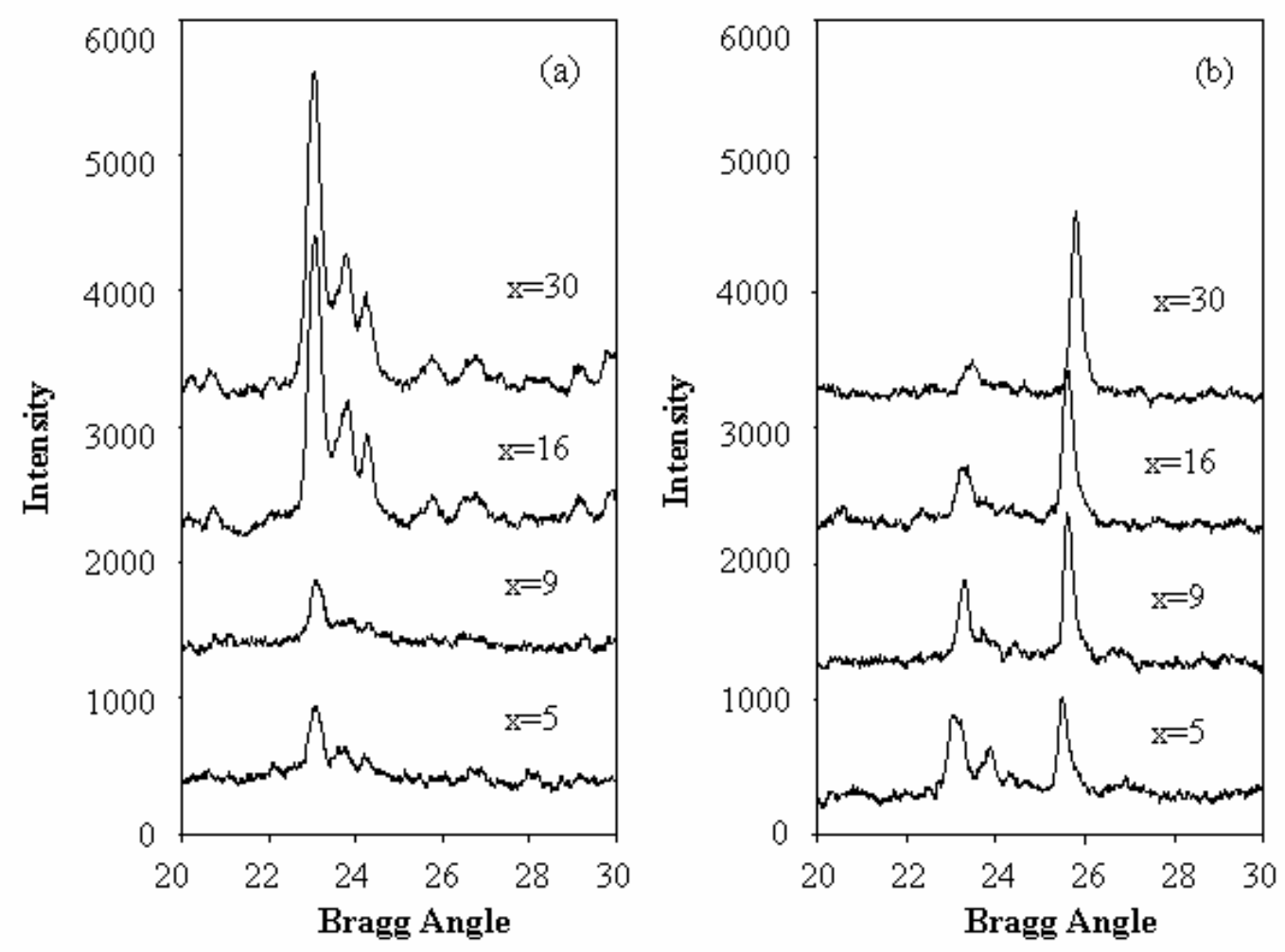

Figure 4.20 XRD patterns of the powders remained from membranes (a) and membranes (b) synthesized with different amounts of TPAOH in the batch $\left(80 \mathrm{SiO}_{2}: \mathrm{xTPAOH} 1500 \mathrm{H}_{2} \mathrm{O} \quad \mathrm{T}=95^{\circ} \mathrm{C} \quad \mathrm{t}=72 \mathrm{~h}\right.$ )

Figure 4.21 shows the intensity fraction and the fractional weight change of the membranes synthesized with different amounts of TPAOH in the batch. The intensity fraction was calculated from Equation 4.5 and fractional weight change was calculated from Equation 4.1 in Section 4.1.2. In the intensity fraction calculation, the MFI peaks at $23^{\circ}, 24^{\circ}$ and $24.5^{\circ}$ Bragg angles together with the alumina peak at $35^{\circ}$ Bragg angle from the XRD patterns were used.

Intensity fraction $=\frac{\left(I_{23^{\circ}}+I_{24^{\circ}}+I_{245^{\circ}}\right)_{\mathrm{MFI}}}{\left(I_{23^{\circ}}+I_{24^{\circ}}+I_{24.5^{\circ}}\right)_{\mathrm{MFI}}+\left(I_{35^{\circ}}\right)_{\text {alumina }}}$

where, $\mathrm{I}$ is the intensity 
Both intensity fraction and fractional weight change of the membranes decreased with increasing TPAOH concentrations in synthesis solution, suggesting that the amount of MFI decreases on the alumina surface with increasing amount of TPAOH. High amount of TPAOH provides high amount of $\mathrm{TPA}^{+}$and $\mathrm{OH}^{-}$ions to the medium. These $\mathrm{OH}^{-}$ions increase the solubility of silica so that yield decreases regardless of the high amount of $\mathrm{TPA}^{+}$ions. Thus thinner membranes are expected to obtain from TPAOH rich solutions.

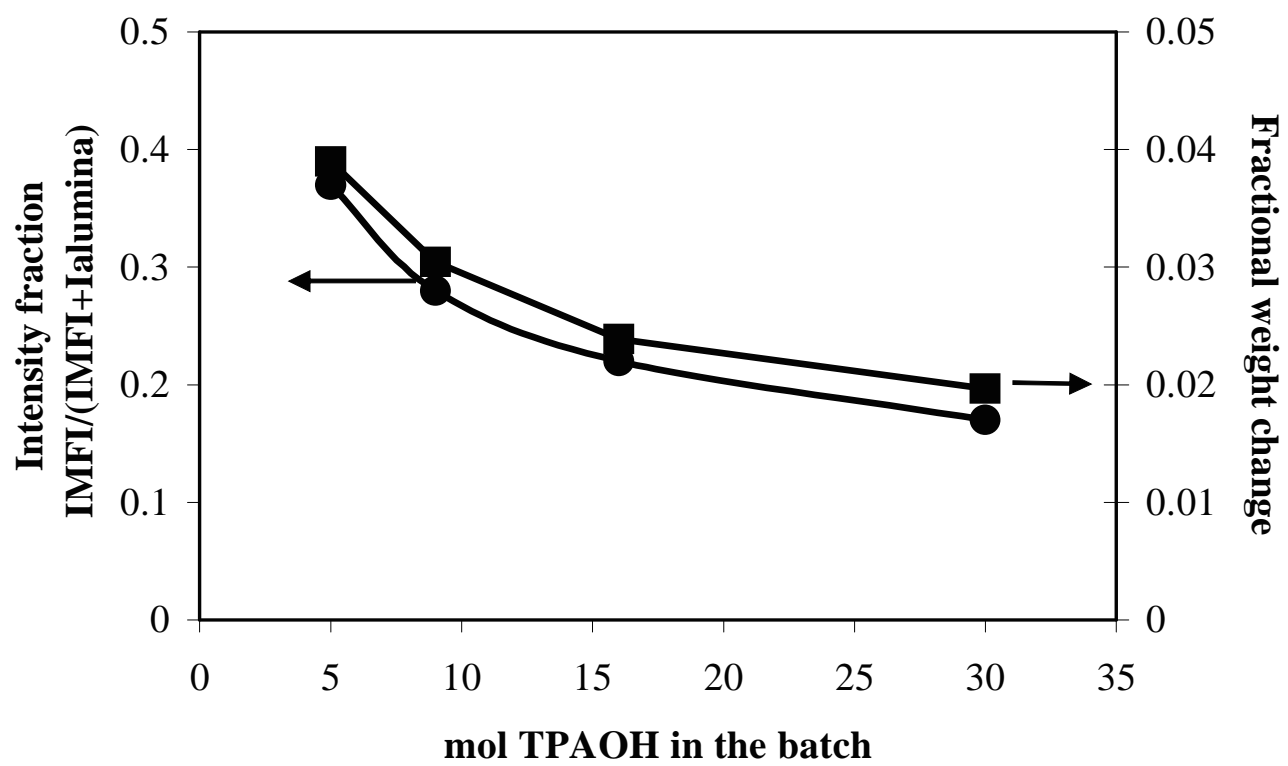

Figure 4.21 The intensity fraction and fractional weight change of the membranes synthesized with different amounts of TPAOH in the batch $\left(80 \mathrm{SiO}_{2}: \mathrm{xTPAOH}: 1500 \mathrm{H}_{2} \mathrm{O} \quad \mathrm{T}=95^{\circ} \mathrm{C} \quad \mathrm{t}=72 \mathrm{~h}\right.$ )

Figure 4.22 shows the surface and cross section images of the membranes synthesized with different TPAOH concentrations. Thin and continuous membranes were observed from all compositions. The zeolite layers forming the membranes consist of well intergrown crystals. As TPAOH concentrations 
increased from 5 to 30 moles both the crystal size and the membrane thickness decreased. The membranes had thicknesses of 4 and $2 \mu \mathrm{m}$ when the synthesis mixture contained 5 and 30 moles of template, respectively. Grain boundaries cannot be seen on the surface image of membrane made from solution with 30 moles of template because of very small size of crystals.

The membranes were characterized by single gas permeations before and after calcining the membranes. Measuring gas permeations, usually $\mathrm{N}_{2}$ permeances, through uncalcined membranes is a commonly employed method to determine the continuity of the zeolite layer forming the membrane [3, 7]. Since all MFI pores were plugged with template molecules before calcination, the membrane is expected to be impermeable to $\mathrm{N}_{2}$ if the zeolite layer is continuous and free of large nonzeolitic pores that cannot be blocked by template molecules. All membranes, which were only dried at $80{ }^{\circ} \mathrm{C}$ and $24 \mathrm{~h}$, were impermeable to $\mathrm{N}_{2}$ before calcination with a feed pressure of 2 bar, indicating that no large nonzeolitic pores exist on the membrane surface. 

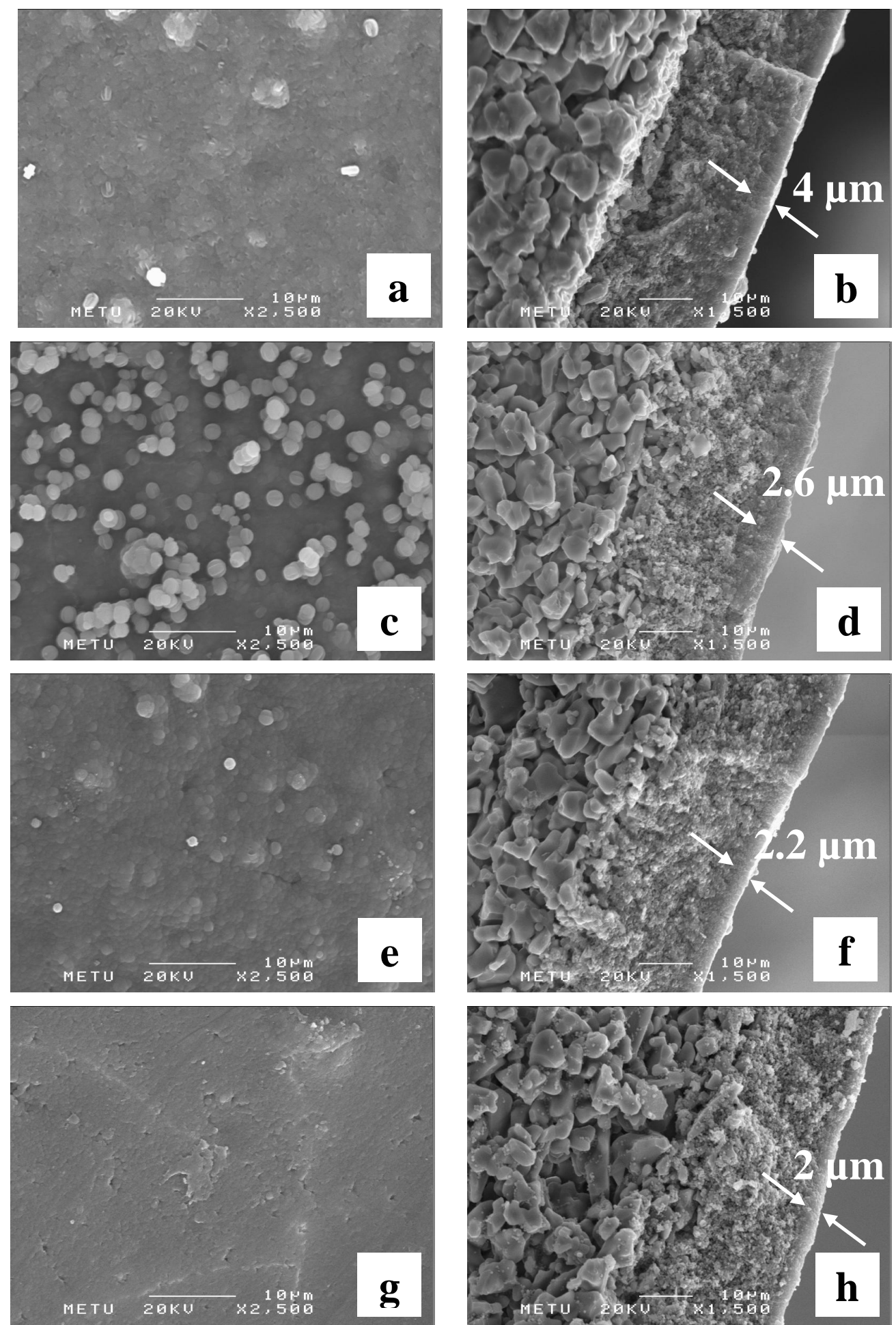

Figure 4.22 Surface (a, c, e, g) and cross section (b, d, f, h) SEM images of membranes synthesized with different amounts of TPAOH in the batch $\mathrm{x}=5$ (a, b); $\mathrm{x}=9(\mathrm{c}, \mathrm{d}) ; \mathrm{x}=16(\mathrm{e}, \mathrm{f}) ; \mathrm{x}=30(\mathrm{~g}, \mathrm{~h}) 80 \mathrm{SiO}_{2}: \mathrm{xTPAOH}: 1500 \mathrm{H}_{2} \mathrm{O} \mathrm{T}=95^{\circ} \mathrm{C}$ $\mathrm{t}=72 \mathrm{~h}$ 
Table 4.3 shows the single gas permeances and ideal selectivities of the membranes after calcination at $450^{\circ} \mathrm{C}$ for $15 \mathrm{~h}$. The membrane synthesized with 5 moles of TPAOH concentration has the highest $\mathrm{H}_{2} / n-\mathrm{C}_{4} \mathrm{H}_{10}$ ideal selectivity which is about 2000 at $200^{\circ} \mathrm{C}$. When we compared the membranes synthesized with 5, 16 and 30 moles of $\mathrm{TPAOH}$ it is seen that $\mathrm{n}-\mathrm{C}_{4} \mathrm{H}_{10}$ permeances increase with increasing TPAOH concentration while $n-\mathrm{C}_{4} \mathrm{H}_{10} / \mathrm{i}$ $\mathrm{C}_{4} \mathrm{H}_{10}$ ideal selectivities decrease. Increasing permeances can be expected because membrane thickness decreases with increasing TPAOH concentration.

Table 4.3 Single gas permeances through the membranes synthesized with different amounts of TPAOH in the batch $\left(80 \mathrm{SiO}_{2}\right.$ : $\mathrm{xTPAOH}: 1500 \mathrm{H}_{2} \mathrm{O}$ at $95^{\circ} \mathrm{C}$ for $72 \mathrm{~h}$ )

\begin{tabular}{cccccc}
\hline \multirow{2}{*}{$\mathrm{x}$} & $\begin{array}{c}\text { Temperature } \\
\left({ }^{\circ} \mathrm{C}\right)\end{array}$ & \multicolumn{2}{c}{ Permeance $\left(\mathrm{mol} / \mathrm{m}^{2} \mathrm{sPa}\right)$} & \multicolumn{2}{c}{ Ideal Selectivity } \\
\cline { 3 - 6 } & 25 & $\begin{array}{c}\mathrm{H}_{2} \\
\left(* 10^{-7}\right)\end{array}$ & $\begin{array}{c}\mathrm{n}-\mathrm{C}_{4} \mathrm{H}_{10} \\
\left(* 10^{-8}\right)\end{array}$ & $\mathrm{H}_{2} / \mathrm{n}-\mathrm{C}_{4} \mathrm{H}_{10}$ & $\mathrm{n}-\mathrm{C}_{4} \mathrm{H}_{10} / \mathrm{i}-\mathrm{C}_{4} \mathrm{H}_{10}$ \\
\hline \multirow{2}{*}{5} & 200 & 7.65 & 0.04 & 1759 & - \\
& 25 & 9.54 & 29.7 & 3.2 & - \\
\hline \multirow{2}{*}{9} & 200 & - & 614.0 & - & 13.0 \\
\hline \multirow{2}{*}{16} & 25 & 0.38 & 0.18 & 21 & 1.23 \\
& 200 & - & 1.37 & - & 10.7 \\
\hline \multirow{2}{*}{30} & 25 & 29.7 & 52.3 & 5.68 & 1.01 \\
& 200 & - & 94.3 & - & 1.71 \\
\hline
\end{tabular}

\subsubsection{Synthesis of membranes on alumina supports using TPAOH and TPABr as mixed template}

During the synthesis of Set 1 type of membranes, the concentrations of both hydroxyl $\left(\mathrm{OH}^{-}\right)$and template $\left(\mathrm{TPA}^{+}\right)$ion changed when the amount of TPAOH was changed. In order to observe the effect of hydroxyl ion concentration only, the syntheses were carried out from solutions containing a mixture of $\mathrm{TPABr}$ and TPAOH. Thus concentration of $\mathrm{TPA}^{+}$ion in the synthesis solution 
remained constant although the concentrations of $\mathrm{OH}^{-}$and $\mathrm{Br}^{-}$changed. Two sets of solutions containing 22 and 16 moles of $\mathrm{TPA}^{+}$per 80 moles of $\mathrm{SiO}_{2}$ were prepared (Set 2 and Set 3 in Table 4.2, respectively).

Figure 4.23 and 4.24 shows the XRD patterns of the powders and membranes synthesized with different synthesis solutions containing a mixture of TPABr and TPAOH in Sets 2 and 3. All powders and membranes have only MFI type zeolite crystals. These figures show that the MFI peak intensities in powder and on membrane are higher for the samples synthesized from the solution containing only TPABr than those from the solution containing only TPAOH or mixture of TPABr and TPAOH.
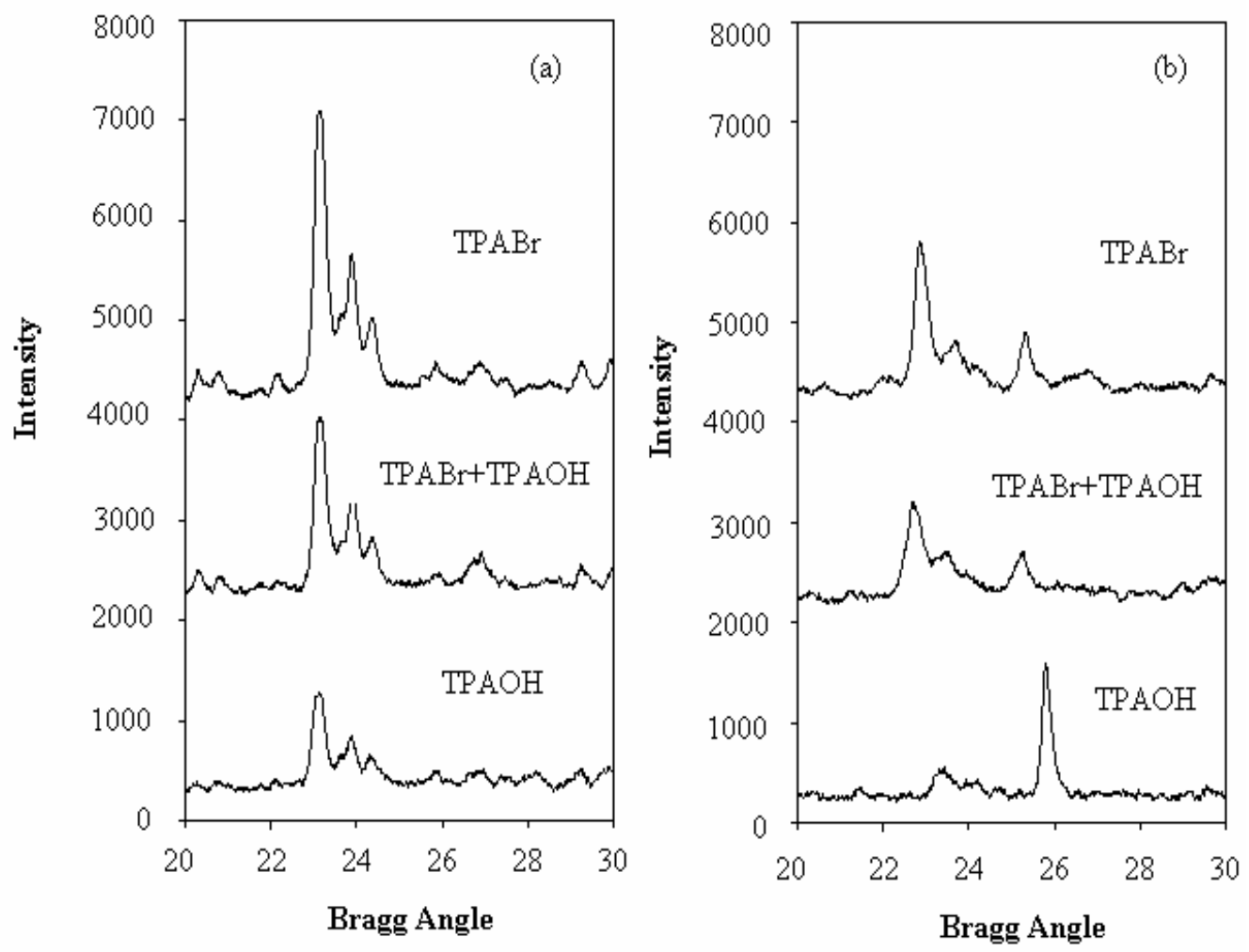

Figure 4.23 XRD patterns of the powders and membranes synthesized with different synthesis solutions containing a mixture of TPABr and TPAOH. 0-22(TPAOH-TPABr):80 $\mathrm{SiO}_{2}: 21 \mathrm{Na}_{2} \mathrm{O}: 3600 \mathrm{H}_{2} \mathrm{O}$ at $150^{\circ} \mathrm{C}$ for $24 \mathrm{~h}$. 
The surface and cross section images of the membranes in Sets 2 and 3 are given in Figure 4.25 and Figure 4.26, respectively. All membranes have a continuous zeolite layer with a uniform thickness. The size of crystals forming the membranes synthesized with only TPAOH and only TPABr in Set 2 were about 2 and $5 \mu \mathrm{m}$, respectively. Higher alkalinities favor the nucleation of a greater number of particles to form smaller crystallites. The thickness of the membranes synthesized with only TPAOH or TPABr were $3 \mu \mathrm{m}$ or $5 \mu \mathrm{m}$, respectively. In set 3, however, the thickness of the membranes synthesized with only TPAOH and only TPABr are 15 and $19 \mu \mathrm{m}$ which are much thicker than those of Set 2. The thickness differences in Set 2 and Set 3 are expected because $\mathrm{OH}^{-} / \mathrm{SiO}_{2}$ ratio in Set 2 is about two times greater than in that of Set 3 .
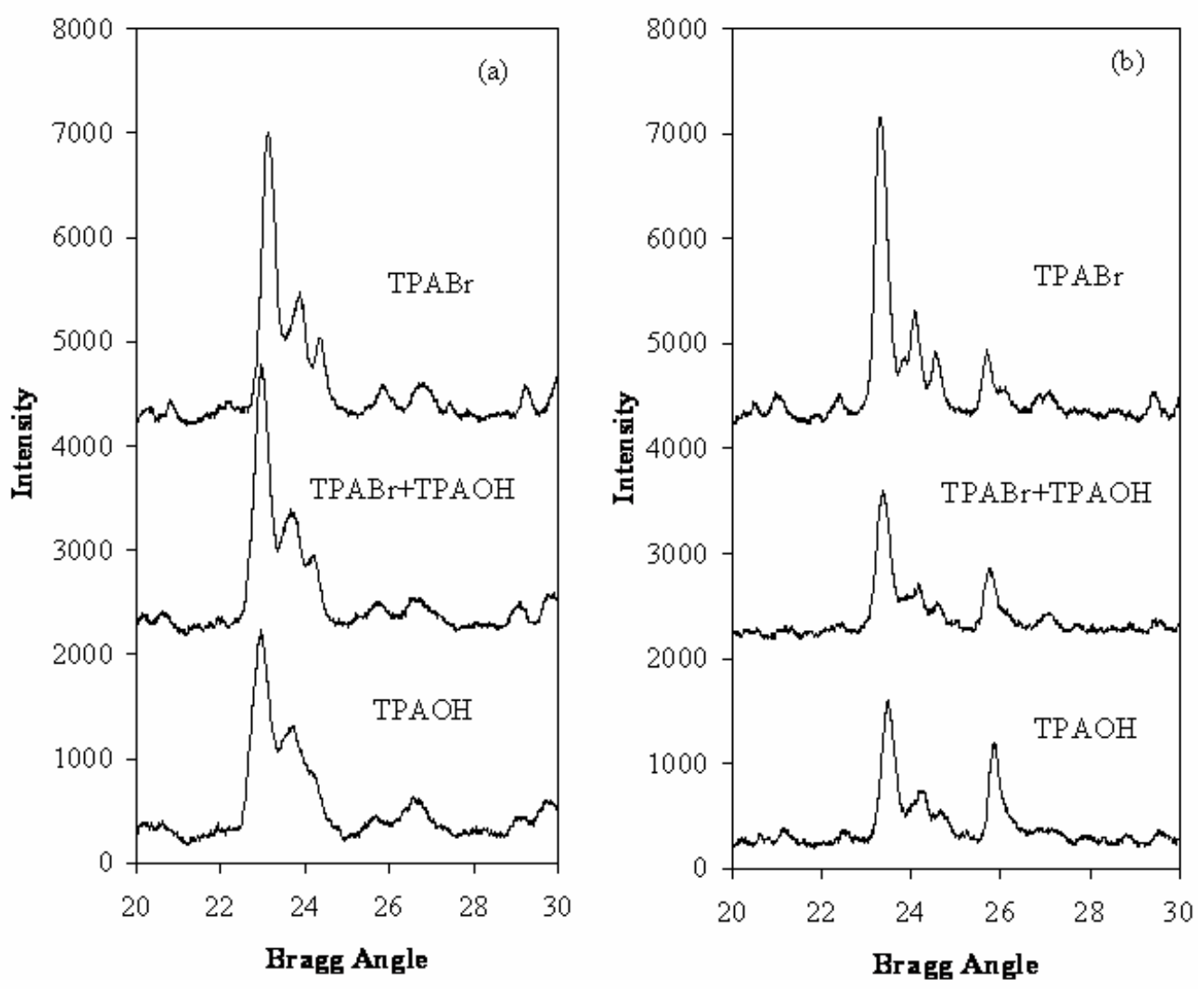

Figure 4.24 XRD patterns of the powders and membranes synthesized with different synthesis solutions containing a mixture of TPABr and TPAOH. 0-16(TPAOH-TPABr):80 $\mathrm{SiO}_{2}: 10 \mathrm{Na}_{2} \mathrm{O}: 2500 \mathrm{H}_{2} \mathrm{O}$ at $150^{\circ} \mathrm{C}$ for $24 \mathrm{~h}$. 

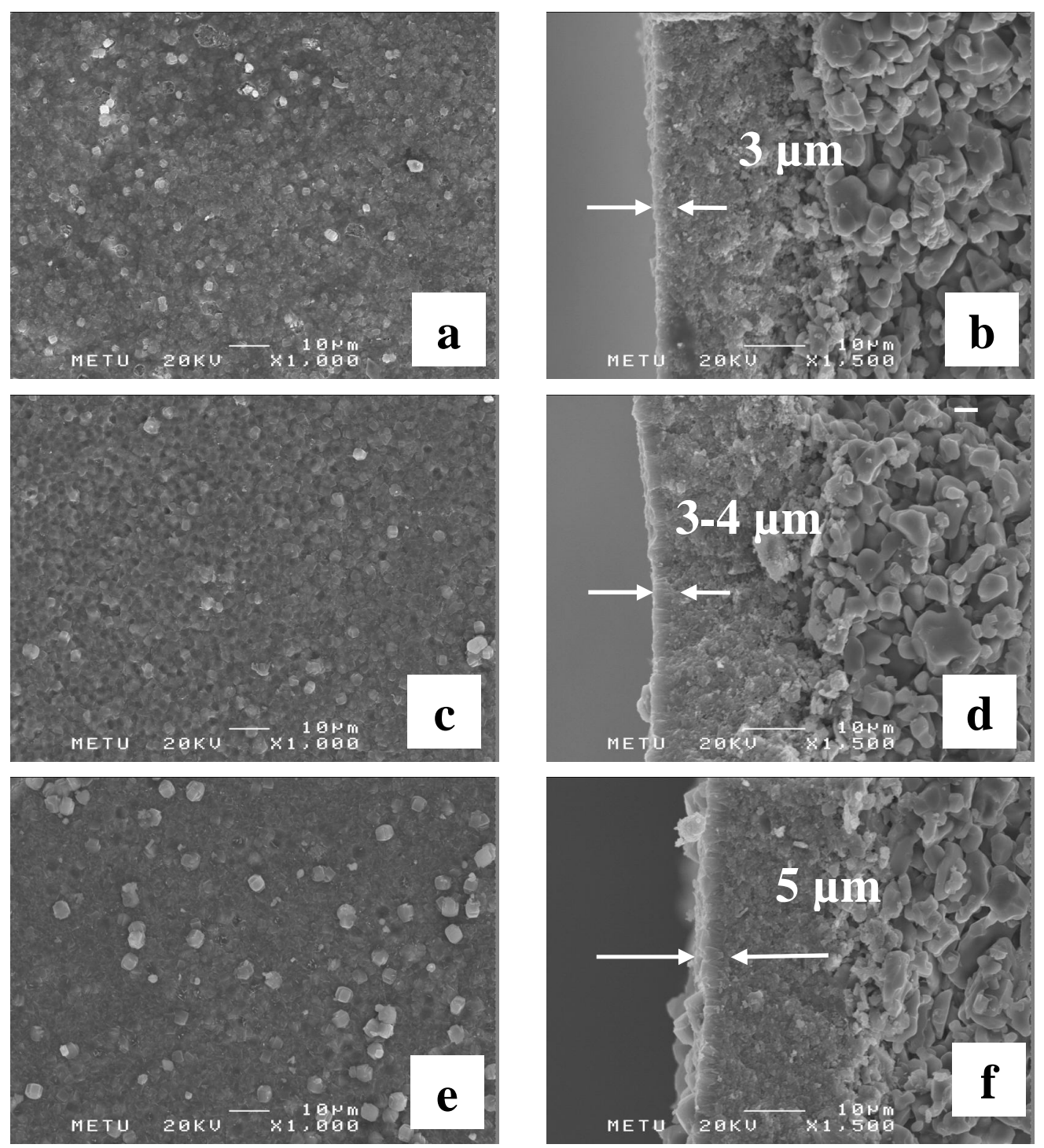

Figure 4.25 SEM images of the surface (a, c, e) and cross section (b, d, f) of the membrane synthesized with different synthesis solutions containing TPABr or TPAOH as template source; TPAOH (a, b), TPAOH+TPABr (c, d), TPABr (e, f) 22 (TPAOH-TPABr): $80 \mathrm{SiO}_{2}: 21 \mathrm{Na}_{2} \mathrm{O}: 3600 \mathrm{H}_{2} \mathrm{O}$ at $150^{\circ} \mathrm{C}$ for $24 \mathrm{~h}$. 

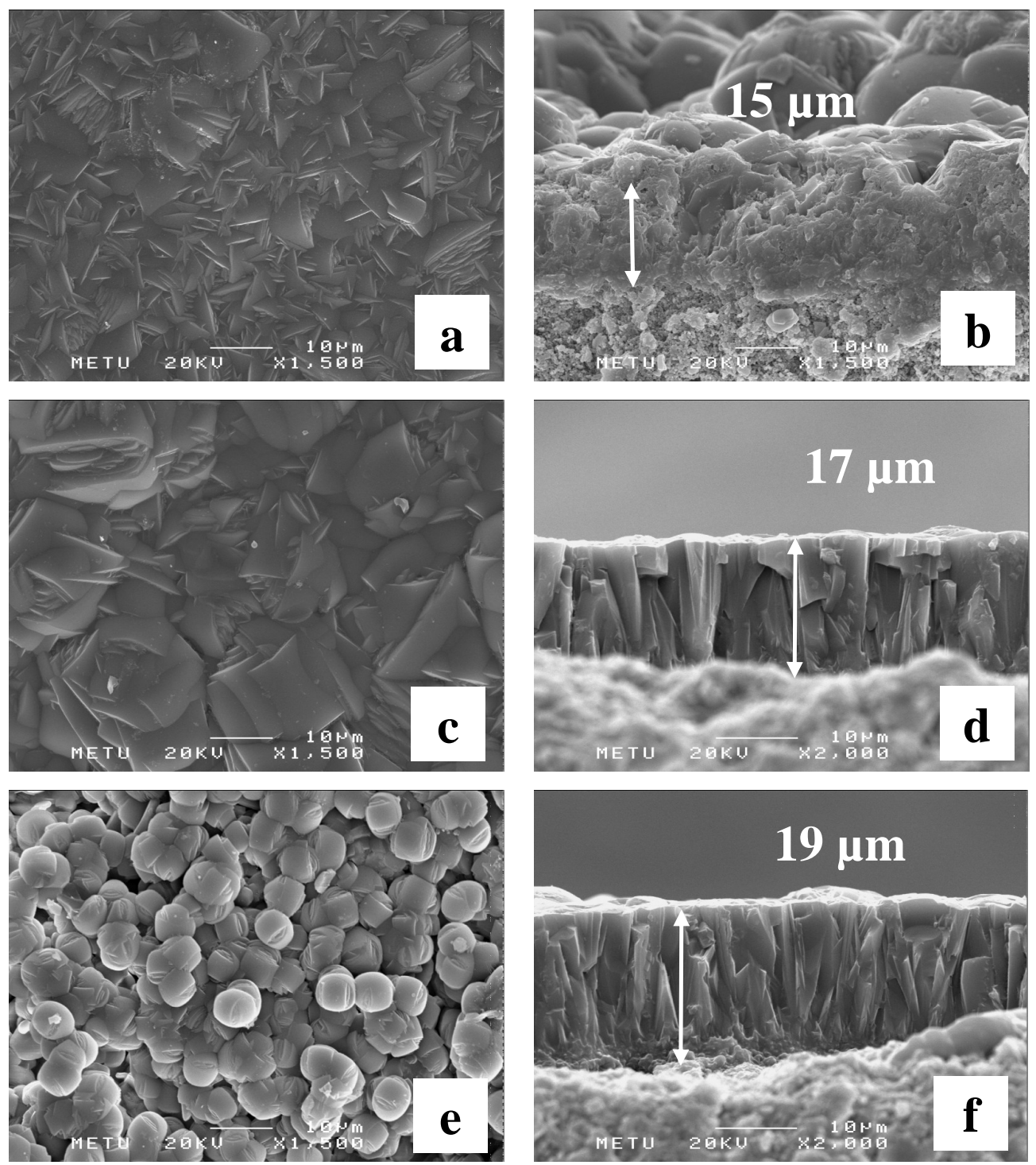

Figure 4.26 SEM images of the surface (a, c, e) and cross section (b, d, f) of the membrane synthesized with different synthesis solutions containing TPABr or TPAOH as template source; TPAOH $(a, b)$, TPAOH+TPABr (c, d), TPABr (e, f). The synthesis was carried out at $150^{\circ} \mathrm{C}$ for $24 \mathrm{~h}$ and the mixture composition is 16 (TPAOH-TPABr): $80 \mathrm{SiO}_{2}: 10 \mathrm{Na}_{2} \mathrm{O}: 2500 \mathrm{H}_{2} \mathrm{O}$. 
The single gas permances through the membranes (Set 3) synthesized with a mixture of $\mathrm{TPABr}$ and $\mathrm{TPAOH}$ were measured at 25 and $150^{\circ} \mathrm{C}$. Two membranes were synthesized for each composition in order to examine the reproducibility of the membranes. All these membranes were impermeable to $\mathrm{N}_{2}$ before calcination which suggests that membranes had only few defects. Table 4.4 shows the $n-\mathrm{C}_{4} \mathrm{H}_{10}$ and $\mathrm{i}-\mathrm{C}_{4} \mathrm{H}_{10}$ single gas permeation results of the membranes. These results imply that similar membranes have different permeances and ideal selectivities.

Table 4.4 Single gas permeances through the membranes synthesized with different synthesis solutions containing TPABr or TPAOH as template source; 16(TPAOH-TPABr): $80 \mathrm{SiO}_{2}: 10 \mathrm{Na}_{2} \mathrm{O}: 2500 \mathrm{H}_{2} \mathrm{O}$ at $150^{\circ} \mathrm{C}$ for $24 \mathrm{~h}$.

\begin{tabular}{|c|c|c|c|c|c|}
\hline \multirow{2}{*}{ Code } & \multirow{2}{*}{$\begin{array}{c}\text { Mole } \\
\text { TPAOH }\end{array}$} & \multirow{2}{*}{$\begin{array}{c}\text { Mole } \\
\text { TPABr }\end{array}$} & \multirow{2}{*}{$\begin{array}{c}\text { Temperature } \\
\left({ }^{\circ} \mathrm{C}\right)\end{array}$} & \multicolumn{2}{|c|}{ Permeance $\left(\mathrm{mol} / \mathrm{m}^{2} \mathrm{sPa}\right)$} \\
\hline & & & & $\begin{array}{c}\mathrm{n}-\mathrm{C}_{4} \mathrm{H}_{10} \\
\left(* 10^{-9}\right)\end{array}$ & $\begin{array}{l}\mathrm{i}-\mathrm{C}_{4} \mathrm{H}_{10} \\
\left(* 10^{-9}\right)\end{array}$ \\
\hline \multirow{2}{*}{ BS99 } & \multirow{2}{*}{22} & \multirow{2}{*}{ - } & 25 & 0.99 & 1.29 \\
\hline & & & 150 & 43.30 & 0.25 \\
\hline \multirow{2}{*}{ BS100 } & \multirow{2}{*}{22} & \multirow{2}{*}{ - } & 25 & 2.17 & 4.57 \\
\hline & & & 150 & 3.33 & 5.55 \\
\hline \multirow{2}{*}{ BS101 } & \multirow{2}{*}{11} & \multirow{2}{*}{11} & 25 & 2.14 & 0.51 \\
\hline & & & 150 & - & 1.11 \\
\hline \multirow{2}{*}{ BS102 } & \multirow{2}{*}{11} & \multirow{2}{*}{11} & 25 & 6.26 & 1.80 \\
\hline & & & 150 & - & 0.63 \\
\hline \multirow{2}{*}{ BS103 } & \multirow{2}{*}{ - } & \multirow{2}{*}{22} & 25 & 15.8 & 1.20 \\
\hline & & & 150 & 73.5 & 0.69 \\
\hline \multirow{2}{*}{ BS104 } & \multirow{2}{*}{ - } & \multirow{2}{*}{22} & 25 & 0.27 & 2.34 \\
\hline & & & 150 & 10.5 & 0.93 \\
\hline
\end{tabular}


One of the membranes (BS99) synthesized with TPAOH as template source has very low $n-\mathrm{C}_{4} \mathrm{H}_{10}$ and $\mathrm{i}-\mathrm{C}_{4} \mathrm{H}_{10}$ fluxes comparing to the other membrane (BS100). Membrane BS99 has $n-\mathrm{C}_{4} \mathrm{H}_{10} / \mathrm{i}-\mathrm{C}_{4} \mathrm{H}_{10}$ ideal selectivity of 173 at $150^{\circ} \mathrm{C}$ indicating that this membrane is $\mathrm{n}-\mathrm{C}_{4} \mathrm{H}_{10}$ selective whereas $\mathrm{BS} 100$ membrane BS100 is a $\mathrm{i}-\mathrm{C}_{4} \mathrm{H}_{10}$ selective membrane. Similar result was also observed in other membranes which was synthesized with TPAOH+TPABr (BS101-102) and TPABr (BS103-104). BS101 and BS102 have comparable n$\mathrm{C}_{4} \mathrm{H}_{10}$ permeances but there is two order of magnitude difference in between i$\mathrm{C}_{4} \mathrm{H}_{10}$ permeances. On the other hand $\mathrm{BS} 103$ is a $\mathrm{n}-\mathrm{C}_{4} \mathrm{H}_{10}$ selective membrane and has $\mathrm{n}-\mathrm{C}_{4} \mathrm{H}_{10} / \mathrm{n}-\mathrm{C}_{4} \mathrm{H}_{10}$ selectivity of 13 and 107 at 25 and $150^{\circ} \mathrm{C}$, respectively while BS104 membrane has $n-\mathrm{C}_{4} \mathrm{H}_{10} / \mathrm{n}-\mathrm{C}_{4} \mathrm{H}_{10}$ selectivity of 0.11 and 11 at 25 and $150{ }^{\circ} \mathrm{C}$, respectively. In this part of the study reproducibility was the main problem with respect to gas permeances. Totally 20 membranes were synthesized from solutions containing only TPAOH, or TPABr or a mixture of TPAOH and TPABr, to determine the reproducibility of synthesis method. Some membranes synthesized from a particular solution showed high n- $\mathrm{C}_{4} \mathrm{H}_{10} / \mathrm{i}-\mathrm{C}_{4} \mathrm{H}_{10}$ selectivity although some of the membranes synthesized from the same synthesis solution had a low selectivity. The reproducibility of the membranes should be improved.

\subsubsection{Comments on the crystallization of MFI powder from solutions containing different amounts of TPAOH and TPABr}

In this study both directly synthesized powders and powders remained from the membrane synthesis were examined for the nucleation period, percent conversion and particle size determination.

The samples taken from the synthesis solution in powder or membrane synthesis at atmospheric pressure were centrifuged with a relative centrifugal force of $640 \mathrm{~g}(6000 \mathrm{rpm})$ for 30 minutes. The dried products were recovered quantitatively for the determination of the product yield and the percent 
conversion of silica in the batch to MFI. The percent crystallinity and conversion calculations are given in detail in Appendix B.

In order to calculate the amount of pure MFI in the dried product, relative crystallinity of the samples was also taken in consideration. Relative crystallinity of the samples was based on the three characteristic peaks of MFI type zeolite at Bragg angles of $23^{\circ}, 24^{\circ}$ and $24.5^{\circ}$. Among all the samples obtained, the one in which the sum of the diffraction intensities of these three peaks was highest was assigned the reference with $100 \%$ crystallinity and the relative crystallinity of all other samples were determined accordingly.

$\%$ Crystallinity $=\frac{\left(I_{23^{\circ}}+I_{24^{\circ}}+I_{24.5^{\circ}}\right)_{\text {sample }}}{\left(I_{23^{\circ}}+I_{24^{o}}+I_{24.5^{\circ}}\right)_{\text {reference }}} x 100$

The extent of conversion of silica in the reactant mixture into MFI was expressed as

$\%$ conversion $=\frac{\left(\frac{\text { yield of solid product in grams }}{\text { grams of reactant mixture }}\right)\left(\begin{array}{c}\% \text { relative crystallinity } \\ \text { of product }\end{array}\right)}{\left(\frac{\text { maximum yield in grams }}{\text { grams of reactant mixture }}\right)}$

with maximum yield being defined as the quantity of MFI if all the silica in the starting reactant mixture was crystallized as product when the concentration of silica, which is the limiting reactant, reaches zero in the liquid phase $[85,86]$. In the maximum yield definition, the amount of template trapped in the MFI structure was also included with the assumption that in one unit cell, there exists 4 moles of tetrapropylammonium ions for every 96 moles of silica. 
After from the early stages of the synthesis we observed that all samples that can be recovered from the synthesis solution were pure and highly crystalline MFI. This is illustrated in Figure 4.27 with the relative crystallinity versus percent conversion data for the formation of crystalline MFI from silica in the starting batch (all sets in Table 4.2). The percent conversion may also be called as "yield based on silica" $[24,87]$. This observation that all products recovered are crystalline is different from what is commonly observed in the synthesis of zeolites from gels. Generally a solid product is obtained starting from the beginning of the synthesis and this product turns from amorphous to crystalline during the synthesis. The major difference between our system and the conventional systems mentioned is that our system uses clear solutions.

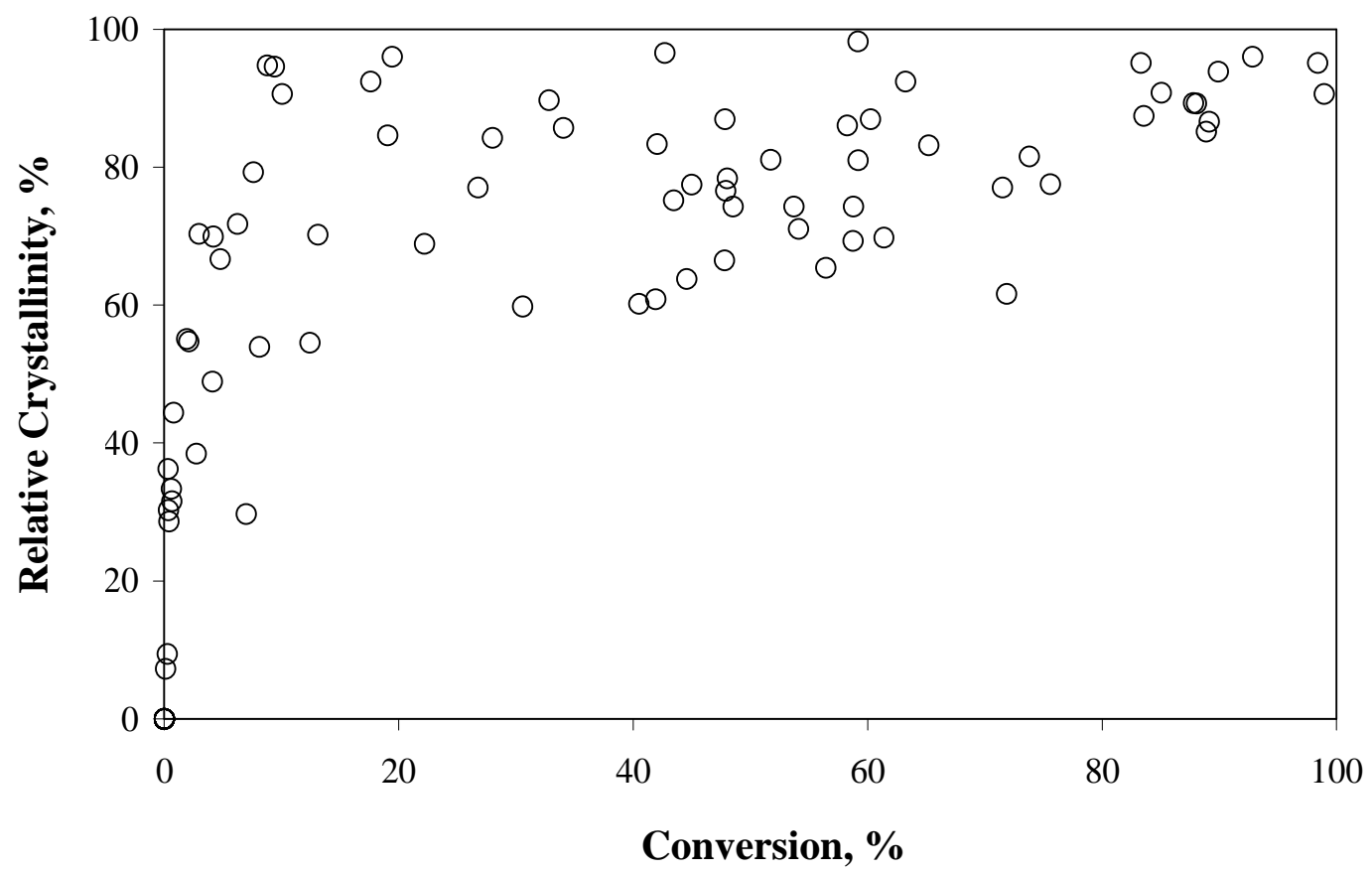

Figure 4.27 Scattering data on conversion of silica in batch to MFI and relative crystallinity for all MFI powders with all molar batch compositions reported in this work 
All samples that can be recovered from the clear synthesis solutions contained MFI as the only crystalline phase. The initially clear solution for synthesis of MFI is usually prepared by hydrolysis of silica in aqueous tetrapropylammonium hydroxide solution. This solution consists of silica in the form of nanoparticles with composition and structure similar to MFI crystals [24]. Gora et al. [22] who used TEOS as silica source in the synthesis of selfsupported MFI membranes from clear solution also reported a similar observation that zeolites grew from the clear homogenous solution and all the solid product that formed from this clear solution was crystalline zeolite.

The conversion curves obtained from batches with different TPAOH concentrations and at $95^{\circ} \mathrm{C}$ synthesis temperature were given in Figure 4.28. For all compositions percent conversion increases in an S-shaped curve. As template amount increases from 5 moles to 30 moles per 80 moles of $\mathrm{SiO}_{2}$ and 1500 moles of $\mathrm{H}_{2} \mathrm{O}$ in the batch, the nucleation period decreases from about $100 \mathrm{~h}$ to $20 \mathrm{~h}$ and crystallization is completed earlier. Here nucleation period was arbitrarily defined as time needed for the $1 \%$ conversion of the silica in the batch to MFI. In the synthesis studies from a clear solution [22, 47] it was observed that crystals grow from subcolloidal particles of size around $5 \mathrm{~nm}$. Since centrifugation conditions used in our study is not sufficient to recover such small particles the percent conversion were obtained as zero at the beginning of the synthesis.

It is clear that higher template amount reduces the nucleation period considerably. Similar results were observed by Crea et al. [17] who investigated the role of the $\mathrm{TPA}^{+}$ions in the crystallization rate of MFI. They concluded that the presence of $\mathrm{TPA}^{+}$is favoring the double-five rings that lead to nucleation and crystal growth of MFI. Unlike the rest of the synthesis compositions where maximum conversion approaches $100 \%$, the maximum conversion is only about $72 \%$ with the batch composition that has the highest 
amount of TPAOH. This is probably due to the high alkalinity of the synthesis medium in which a considerable part of the silica would remain in the solution phase rather than crystallizing as MFI. Schoeman et al. [47] noted that at high alkalinities the rate of crystal dissolution relative to the growth rate is expected to be larger than at a lower alkalinity. As a result of this fact the lower silica conversion can be expected at high alkalinity in consequence of high TPAOH concentration in the synthesis medium.

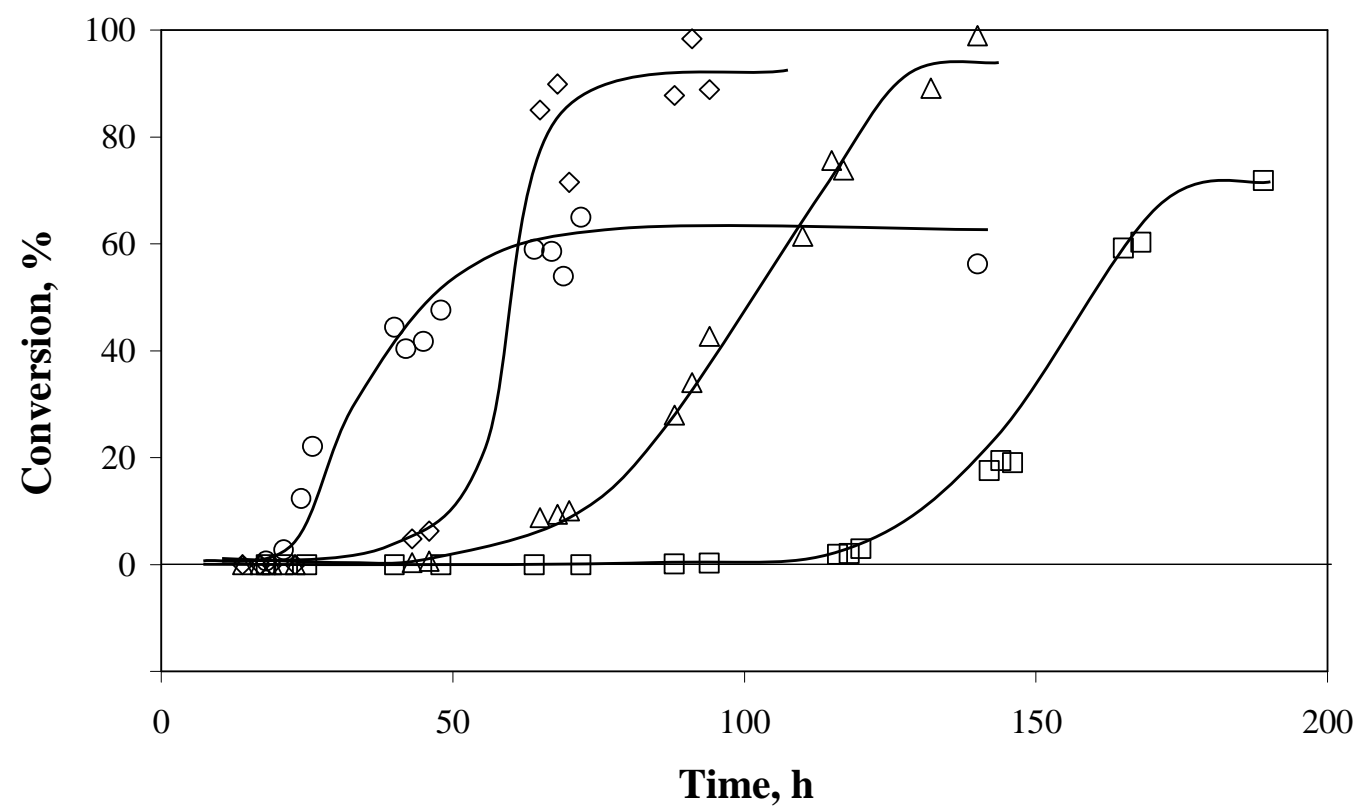

Figure 4.28 Conversion of silica in batch to MFI for the powders with different batch compositions at atmospheric pressure and $95^{\circ} \mathrm{C}(\circ) \mathrm{S}_{80} \mathrm{~T}_{30} \mathrm{H}_{1500},(\diamond)$ $\mathrm{S}_{80} \mathrm{~T}_{16} \mathrm{H}_{1500},(\Delta) \mathrm{S}_{80} \mathrm{~T}_{9} \mathrm{H}_{1500},(\square) \mathrm{S}_{80} \mathrm{~T}_{5} \mathrm{H}_{1500}$. (T: TPA; S:SiO ${ }_{2} ; \mathrm{H}: \mathrm{H}_{2} \mathrm{O}$ ) 
Figure 4.29 shows the percent conversion versus moles of TPAOH per mole of $\mathrm{SiO}_{2}$. It was seen that conversion of silica in the batch to MFI is passing through a maximum with increasing template concentration. Similar results were reported in the literature [24, 62, 89]. Yang et al. [24] explained the drop in silica conversion with increase of TPAOH concentration by the increase of silica solubility in basic solution. On the other hand Wang and Yan [62] speculated that at high TPAOH concentrations low silica conversion is a result of high alkalinity while at low TPAOH concentrations the lack of TPA molecules is responsible. Based on these observations it can be said that both high and low TPAOH concentrations have the detrimental effect on nucleation which is leading to lower the silica conversion.

Figure 4.30 shows the particle size distributions of powders synthesized with different TPAOH concentrations (Set 1). Narrow particle size distribution was observed with 16 and 30 moles of $\mathrm{TPAOH}$ and broader particle size distribution was observed with 5 and 9 moles of TPAOH per 80 moles of $\mathrm{SiO}_{2}$. The particle size analysis results also showed that as template amount increases, the median particle size decreases from $3.5 \mu \mathrm{m}$ with 5 moles of TPAOH per 80 moles of $\mathrm{SiO}_{2}$ to $0.35 \mu \mathrm{m}$ with 30 moles of TPAOH per 80 moles of $\mathrm{SiO}_{2}$. This might be due to increase in the number of nuclei at high TPAOH concentrations.

The comparison of the crystal size from powder synthesis and membrane synthesis were given in Figure 4.31. The crystal sizes in powder and on membrane surface are very similar. 


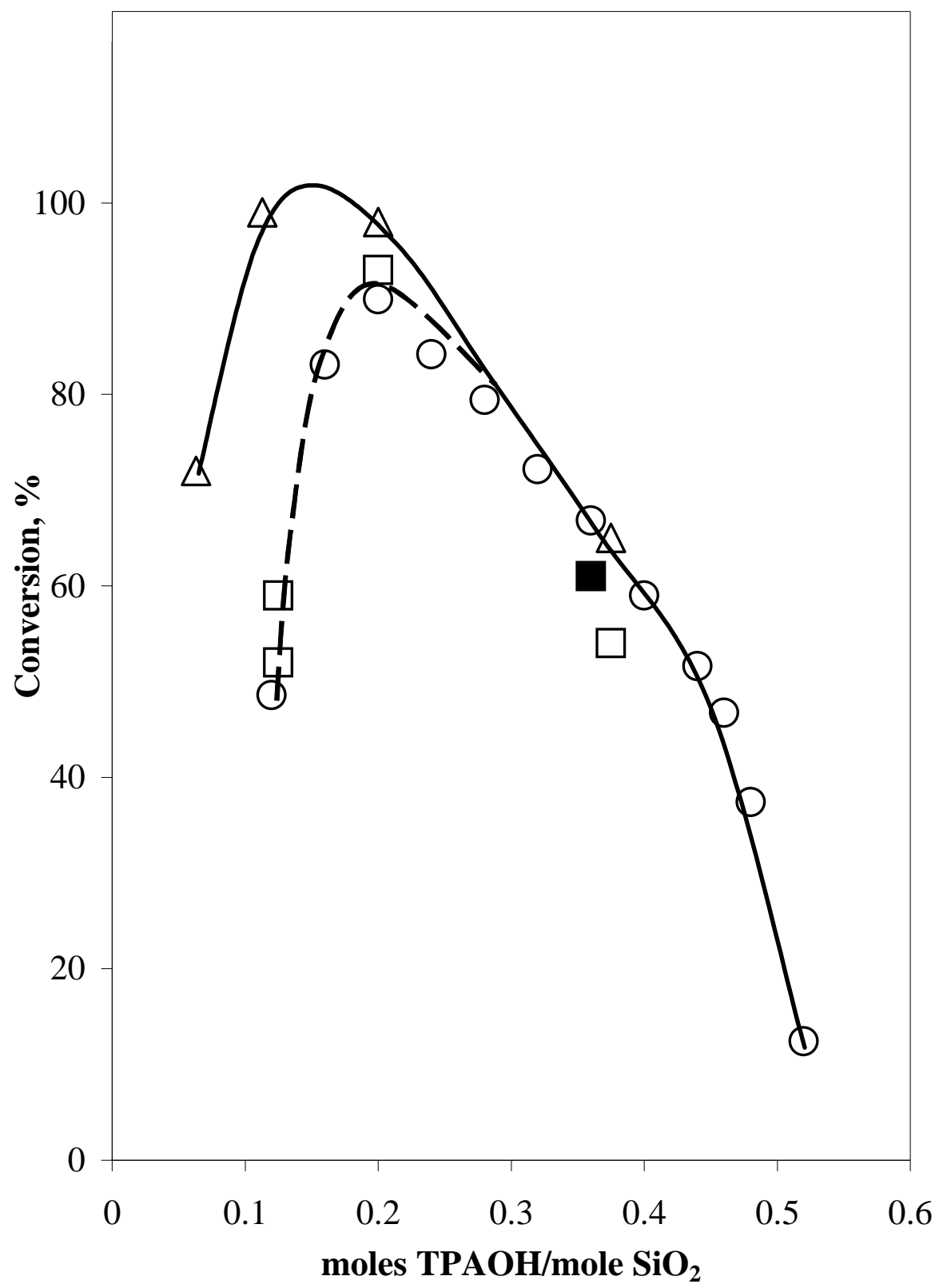

Figure 4.29 Conversion of silica in batch to MFI as a function of template TPAOH amount: $(\Delta)$ Set 1 data, this work, $95^{\circ} \mathrm{C}$; ( $\square$ ) Data of Çulfaz et al. [29], $80^{\circ} \mathrm{C}$; (०) Data of Yang et al. [24], $95^{\circ} \mathrm{C}$; (匹) Data of Li et al. [89], $100^{\circ} \mathrm{C}$ 


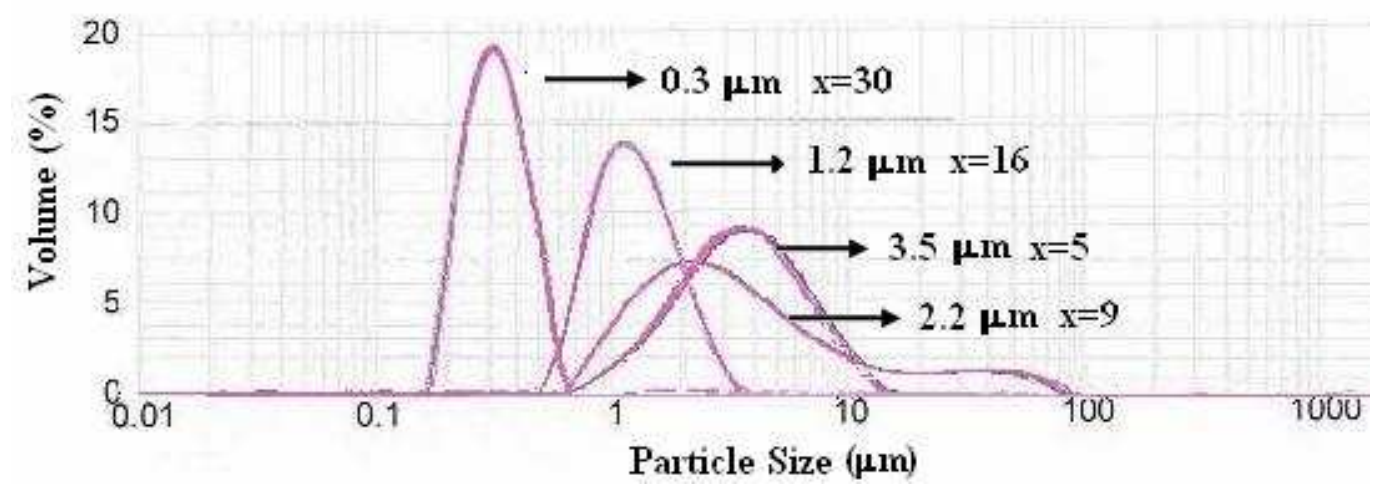

Figure 4.30 Particle size distribution of powder synthesized with different amounts of TPAOH in the batch $\left(80 \mathrm{SiO}_{2}: \mathrm{xTPAOH}: 1500 \mathrm{H}_{2} \mathrm{O} \quad \mathrm{T}=95^{\circ} \mathrm{C} \quad \mathrm{t}=\right.$ $72 \mathrm{~h})$

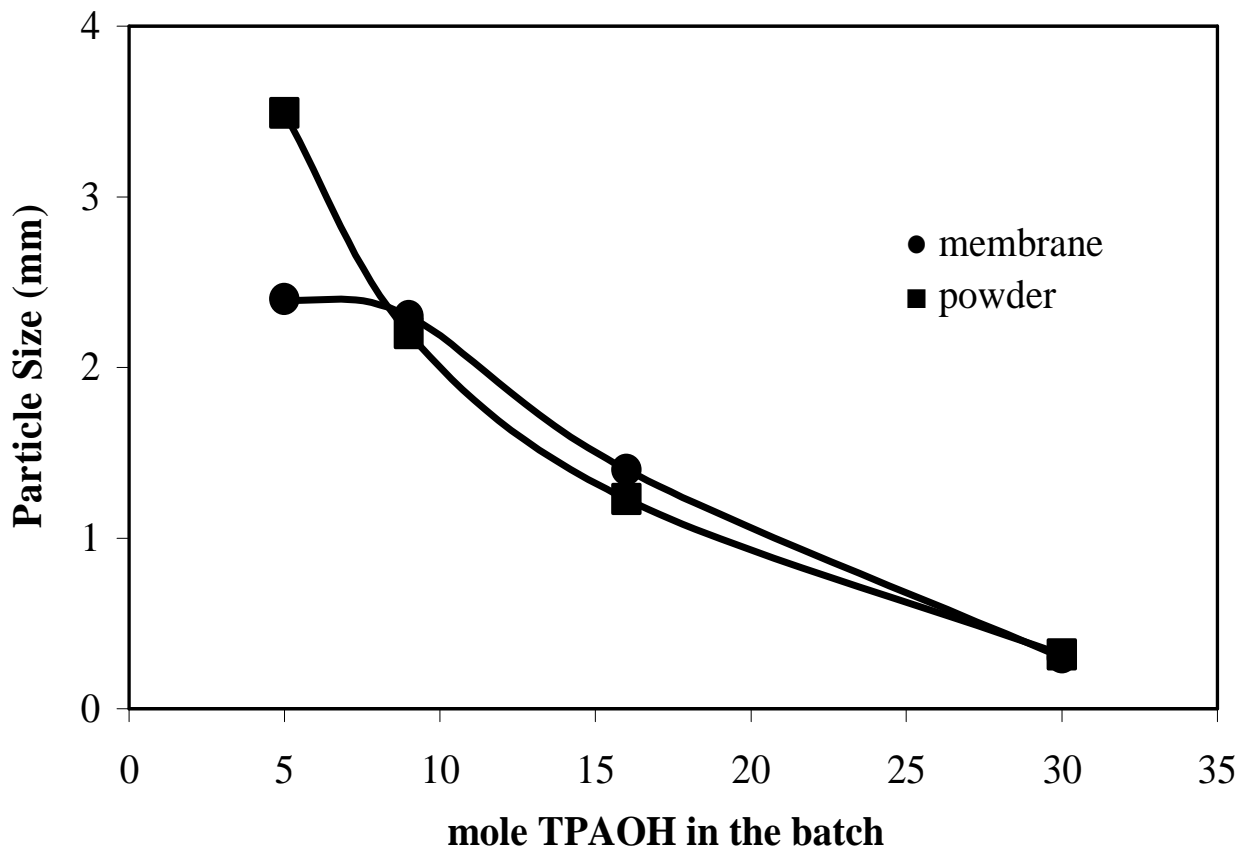

Figure 4.31 Crystal sizes of the powder and membranes synthesized with different amounts of TPAOH in the batch $\left(80 \mathrm{SiO}_{2}: \mathrm{xTPAOH}: 1500 \mathrm{H}_{2} \mathrm{O} \quad \mathrm{T}=\right.$ $95^{\circ} \mathrm{C} \mathrm{t}=72 \mathrm{~h}$ ) 
Table 4.5 shows the crystallization results and particle size of powder and crystals on the membrane with different synthesis conditions. As seen from this table the nucleation period and time to reach $90 \%$ of the maximum conversion level in Sets 2 and 3 at $150^{\circ} \mathrm{C}$ are very low compared to Sets 1 at $95^{\circ} \mathrm{C}$. Soda in the reaction mixture appears to have structure-directing effect and reduces the nucleation period [62]. Table 4.5 also shows the overall conversion rate which is calculated as the ratio of difference between $90 \%$ and $10 \%$ of maximum conversion to difference between time to reach to those conversion levels in terms of percent conversion per hour. The overall conversion rates in Set 3 are higher than the others. Another observation is that although the template amount of Set 1 is comparable in the range of 16-30 the maximum conversion in Set 2 is very low comparing to Set 1 . Since the $\mathrm{OH}^{-} / \mathrm{SiO}_{2}$ ratio very high in Set 2 it can be said that higher alkalinity gave lower silica conversion and higher concentration of silica remaining in the liquid phase. The results suggest that hydroxyl ion concentrations consequently alkalinity has stronger influence on conversion of the silica than $\mathrm{TPA}^{+}$ion concentration at this range of concentrations.

Table 4.5 also shows that the size of MFI crystals formed in the bulk solution and on the membrane surface are very similar. This may suggest that the alumina surface has little effect on the crystal size at these conditions although it is known that alumina dissolved from surface incorporates into the growing crystals to form ZSM-5 type zeolites [90]. On the other hand the formation of silicalite type zeolites is expected in the bulk solution since the synthesis mixture does not contain alumina. 
Table 4.5 Crystallization results and particle size of powder and crystals on the membrane with different synthesis conditions (T: TPA; $\mathrm{S}: \mathrm{SiO}_{2} ; \mathrm{N}: \mathrm{Na}_{2} \mathrm{O} ; \mathrm{H}$ : $\mathrm{H}_{2} \mathrm{O}$ ). Crystallization temperatures and sources of reactants are shown in table 4.2 .

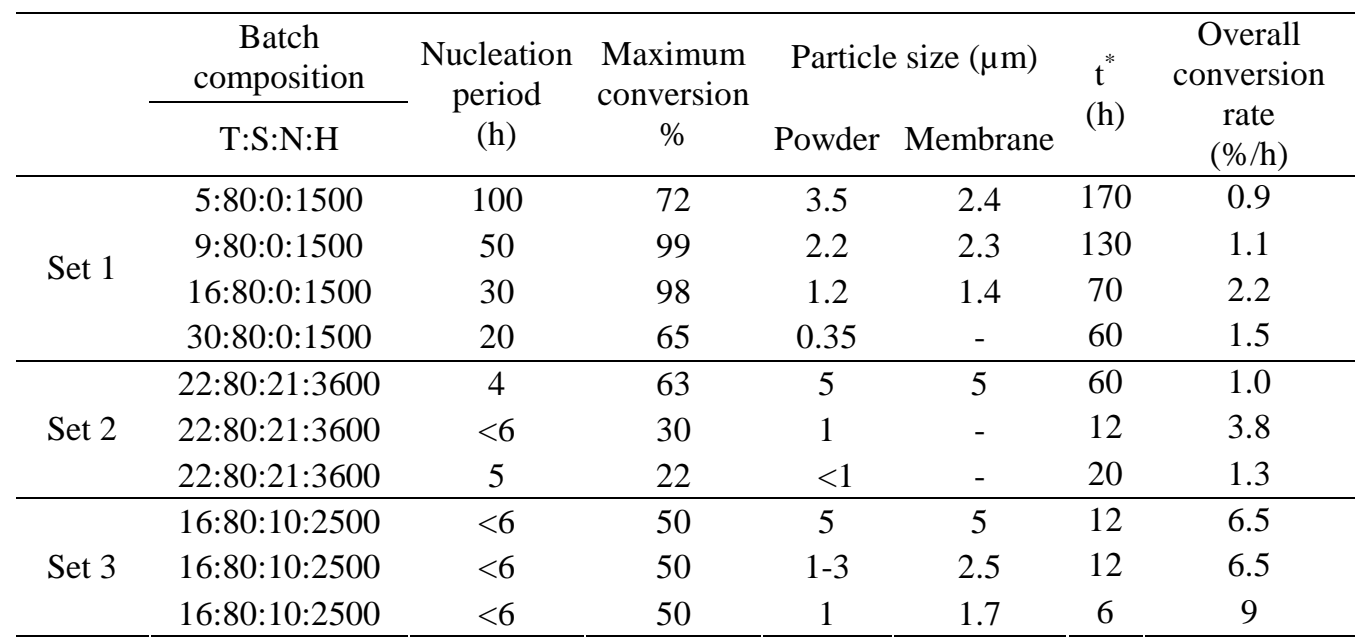

$\mathrm{t}^{*}$ : time to reach $90 \%$ of the maximum conversion level

\subsection{Effect of mid synthesis addition of silica to the synthesis medium on the properties of MFI type zeolite membranes}

The quality of a zeolite membrane depends on the continuity and thickness of the zeolite layer. A good zeolite layer is likely to be thin and have no nonzeolitic pores. Good quality membranes can be obtained by in-situ synthesis on bare supports, yet consecutive syntheses are often needed to obtain continuous zeolite layers. Many researchers have suggested that synthesis conditions such as synthesis temperature, solution composition and seeding the support surface prior to synthesis influence the permeation and separation properties of the membranes [19, 30, 31]. Seeding the support surface may improve the membrane quality if seed layers with high coverage and uniform thickness can be prepared. Many researchers have reported that closely packed seed layers are essential to obtain continuous and defect free membranes [17, 54, 68]. Seed 
crystals with narrow size distribution are needed to prepare closely packed seed layers.

Several methods have been developed for seeding up to now such as dip coating, vacuum seeding or rubbing. All these methods can be regarded as exsitu since they are applied to support surface before the synthesis of membrane layer. The size and uniform distribution of seed crystals strongly affects the separation properties of the resulting membrane layer $[17,68]$. It may, however, be difficult to deposit seed crystals onto the surface uniformly. Xomeritakis et al. [17] observed that the absence of close packed seed layer throughout the support can contribute to the development of dome-like defects.

Li et al. [91] proposed to make MFI membranes by changing the synthesis temperature at a time during the crystallization, called as two-stage varying temperature method. In this method, membrane synthesis begins at a low temperature to coat the surface with small crystals, and then temperature is increased. A large number of nuclei formed on the support at low temperature can rapidly grow at high temperature to yield thin and continuous membranes. They concluded that compared with the constant temperature synthesis twostage varying temperature method is very effective for the preparation of membranes of high quality due to the controlled rates of nuclei formation and crystal growth by changing the synthesis temperatures [91]. This method can also be named as in-situ seeding. In-situ seeding can be achieved by changing the synthesis composition during the course of crystallization.

In this part of the study, the composition of the synthesis solution was changed during the hydrothermal treatment by adding silica into the synthesis medium so that the silica/TPAOH ratio of the solution was increased. This ratio in the batch composition influences the crystallization rate and crystal size, and consequently thickness of the membranes. The crystal growth rate can be increased by increasing silica/TPAOH ratio of the solution after formation of a 
large number of nuclei at low silica/TPAOH ratio. The main aim was to coat the support surface with a high number of small nuclei at low silica/TPAOH ratio and increase the growth rate of those crystals by increasing the silica/TPAOH ratio.

The membranes with mid-synthesis addition of silica were synthesized in the recirculating flow system operating at atmospheric pressure. Since the crystallization temperature is low and the pressure is atmospheric, silica can be added into the synthesis solution and samples can be withdrawn from the system without interrupting the crystallization process. This is a major advantage of low temperature synthesis in the flow system over the conventional high temperature synthesis of zeolites in autoclaves.

Since the synthesis medium and procedure are very sophisticated, the formulations of synthesis solutions were kept as simple as possible. They contain only silica, organic template and deionized water. Soda and alumina, which have strong effect on nucleation and crystal growth, were not used in the formulations.

\subsubsection{Selection of the synthesis compositions}

Submicron size silicalite crystals are often synthesized from concentrated clear solutions as shown in Figure 4.32, because formation of a large number of nuclei is desired. On the other hand, one of the approaches to make silicalite membranes is to use very dilute solutions, which yield a small number of nuclei (Figure 4.32). The seeded support is put into the dilute solution so that only seed crystals grow further without formation of new generation of nuclei. Since almost no new crystals form on the surface, the membrane thickness will be close to the thickness of seed layer which can be controlled [66, 67]. 


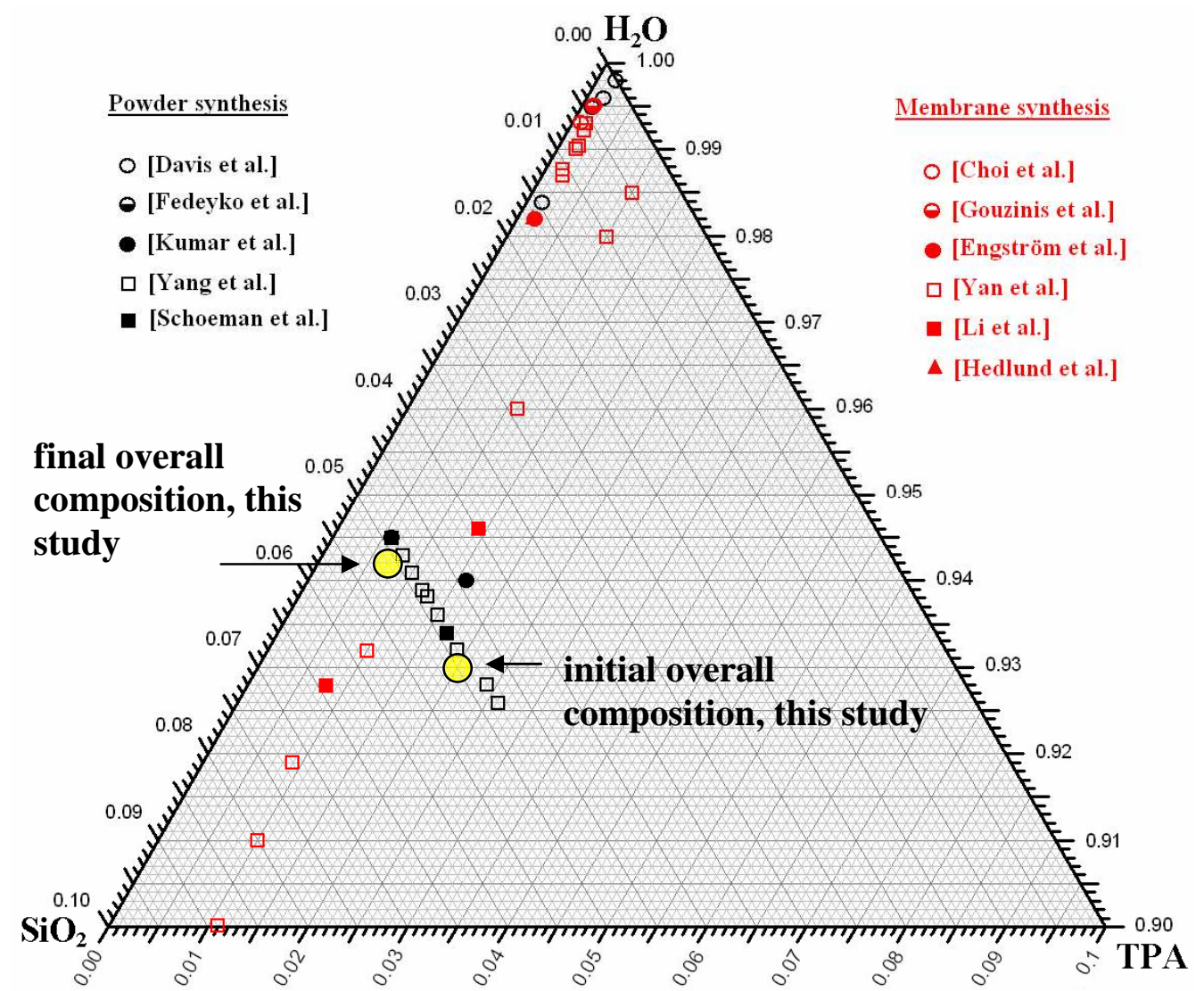

Figure 4.32 Synthesis solution compositions used by other researchers in the literature

Table 4.6 Synthesis solution compositions used in the ternary diagram

\begin{tabular}{lccc}
\hline \multirow{2}{*}{ Reference } & \multicolumn{3}{c}{$\mathrm{xSiO}_{2}: \mathrm{yTPAOH}: \mathrm{zH}_{2} \mathrm{O}$} \\
\cline { 2 - 4 } & $\mathrm{x}$ & $\mathrm{y}$ & $\mathrm{z}$ \\
\hline Davis et al. [92] & $5 / 20 / 100$ & 9 & 8100 \\
\hline Fedeyko et al. [93] & 40 & 9 & 9500 \\
\hline \multirow{2}{*}{ Kumar et al. [94] } & 25 & 9 & 530 \\
& 25 & 3 & 480 \\
\hline Yang et al. [24] & 25 & $3-13$ & 480 \\
\hline Schoeman et al. [47] & 25 & 9 & 480 \\
\hline Choi et al. [66] & $40 / 60$ & 9 & 9500 \\
\hline Gouzinis et al. [67] & 40 & 9 & 9500 \\
\hline Engström et al. [79] & 25 & 3 & 1500 \\
\hline \multirow{2}{*}{ Yan et al. [95] } & $0.5-9.5$ & 1 & 96.4 \\
& 6 & 1 & $525-1005$ \\
\hline \multirow{2}{*}{ Li et al. [80] } & 25 & 3 & 360 \\
\hline Hedlund et al. [36] & 25 & 9 & 595 \\
\hline
\end{tabular}


In this study, those two approaches were combined. The synthesis started with a concentrated solution $\left(80 \mathrm{SiO}_{2}: 30 \mathrm{TPAOH}: 1500 \mathrm{H}_{2} \mathrm{O}\right)$ to produce large number of nuclei or crystallites on the support surface (Figure 4.32). The crystallization of MFI takes place in the solution whose composition changes with time because of deposition of dissolved silica as zeolite nuclei or crystallite. The liquid phase was then enriched with silica to achieve further growth of crystallites. For this purpose silica sol $\left(\mathrm{SiO}_{2}: 5 \mathrm{H}_{2} \mathrm{O}\right)$ was used. The liquid solution after silica addition should be sufficiently dilute since we aimed that only the present nuclei or crystallites grow without formation of a new generation of nuclei on the support surface and also in the bulk.

The composition of liquid at the time silica sol was added and how much silica sol was added determined the final composition of the liquid phase. The former, which will be explained in detail in the next section, depends on the extent of crystallization. On the other hand the amount of silica sol to be added can be arbitrarily selected. Since both are ambiguous, we decided to set the overall composition of the system, including liquid and the particles, to $80 \mathrm{SiO}_{2}: 9 \mathrm{TPAOH}: 1500 \mathrm{H}_{2} \mathrm{O}$ after addition of silica sol.

The initial composition $\left(80 \mathrm{SiO}_{2}: 30 \mathrm{TPAOH}: 1500 \mathrm{H}_{2} \mathrm{O}\right)$ produces highly crystalline silicalite powder with an average particle size of $0.3 \mu \mathrm{m}$ and yield of $78 \%$ after $72 \mathrm{~h}$ crystallization at $95^{\circ} \mathrm{C}$. It is estimated that $10^{15}$ particles/100 $\mathrm{g}$ silica form from this composition. The final composition $\left(80 \mathrm{SiO}_{2}: 9 \mathrm{TPAOH}: 1500 \mathrm{H}_{2} \mathrm{O}\right)$, on the other hand, produces highly crystalline MFI powder with an average particle size of $2 \mu \mathrm{m}$ and yield of $100 \%$ after 144 $\mathrm{h}$ crystallization at $95^{\circ} \mathrm{C}$. It is estimated that $10^{11}$ particles $/ 100 \mathrm{~g}$ silica form from this composition. Apparently, the first overall composition promotes nucleation although the second one promotes crystal growth. 


\subsubsection{Selection of the composition change times}

The initial and final overall compositions were $80 \mathrm{SiO}_{2}: 30 \mathrm{TPAOH}: 1500 \mathrm{H}_{2} \mathrm{O}$ and $80 \mathrm{SiO}_{2}: 9 \mathrm{TPAOH}: 1500 \mathrm{H}_{2} \mathrm{O}$, respectively. For $100 \mathrm{~g}$ synthesis solution with $80 \mathrm{SiO}_{2}: 30 \mathrm{TPAOH}: 1500 \mathrm{H}_{2} \mathrm{O}$ overall composition, 73 g LUDOX AS-40 and $123 \mathrm{~g}$ deionized water were always added to make the overall composition $80 \mathrm{SiO}_{2}: 9 \mathrm{TPAOH}: 1500 \mathrm{H}_{2} \mathrm{O}$. However, the liquid composition after adding silica sol depends on the composition at the time silica was added. Because the amount crystallized depends on time.

Figure 4.33 shows the conversion (4.33.a) and crystallization (4.33.b) curves of the initial composition to silicalite during the powder synthesis. These curves were obtained without mid-synthesis addition of silica. The nucleation takes about 20 hours. After nucleation period, rate of conversion during the crystal growth is $1.5 \% / \mathrm{h}$. The synthesis composition was changed at 24, 48 and 72 hours after the beginning of the synthesis. These times correspond to the initial stage of the synthesis, time at $50 \%$ conversion reached, time maximum conversion reached and to synthesis completed. When membrane synthesis was considered, at short times, small number of particles are likely to exist on the membrane surface. Since the particle size will be very small, these are expected to have a very active surface for further growth. As the time increased, more particles with a less active surface are expected to exist on the support surface. Figure 4.33.c also shows the change of particle size during the synthesis. 

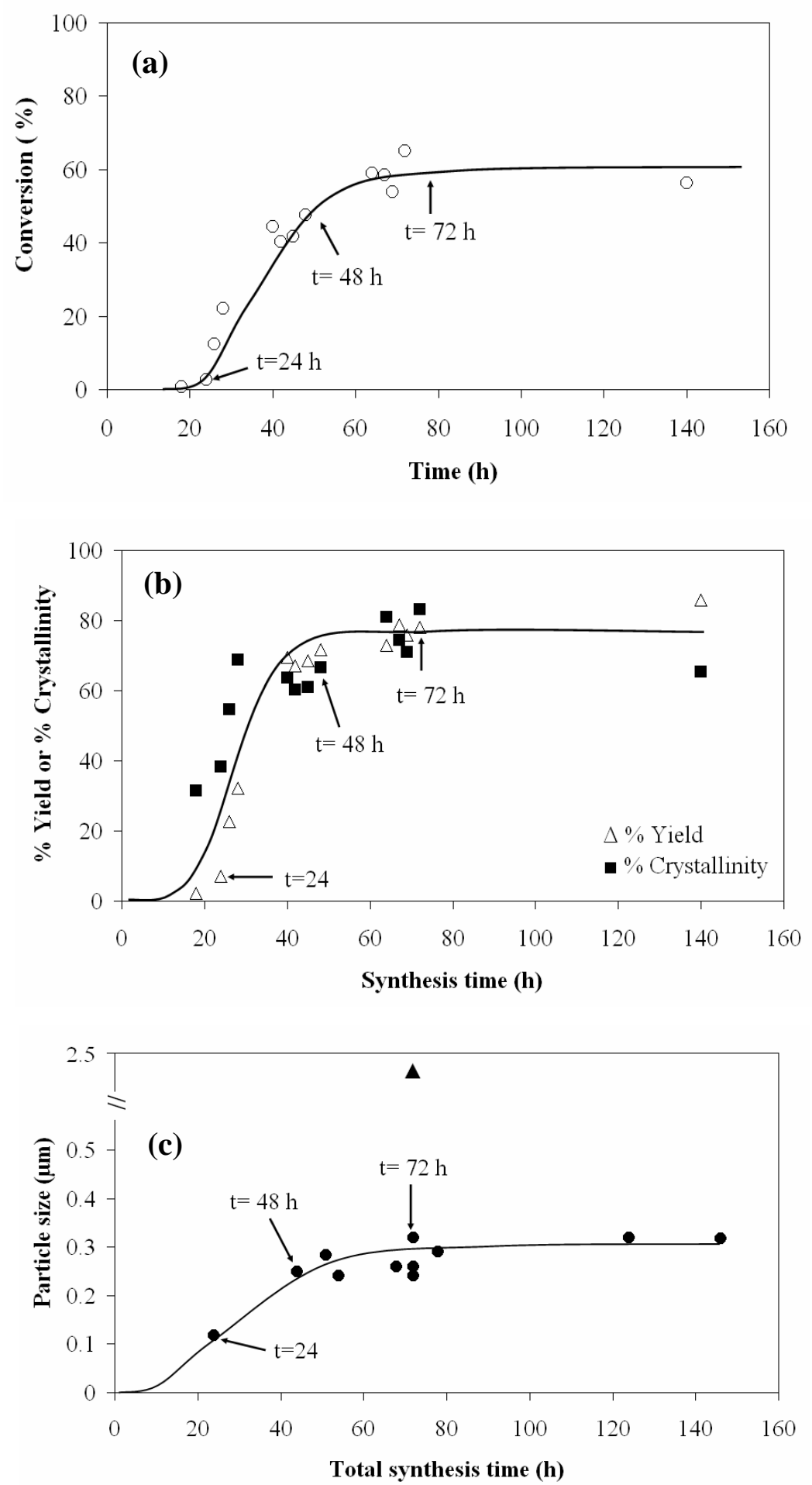

Figure 4.33 (a) Conversion and (b) crystallization of silica in batch to silicalite for the powders synthesized with constant composition of $80 \mathrm{SiO}_{2}: 30 \mathrm{TPAOH}: 1500 \mathrm{H}_{2} \mathrm{O}$ at atmospheric pressure and $95^{\circ} \mathrm{C}$; (c) the particle size in synthesis mixture with the molar composition 80 $\mathrm{SiO}_{2}: 30 \mathrm{TPAOH}: 1500 \mathrm{H}_{2} \mathrm{O}(\bullet)$ and $80 \mathrm{SiO}_{2}: 9 \mathrm{TPAOH}: 1500 \mathrm{H}_{2} \mathrm{O}(\boldsymbol{\Delta})$ 
Table 4.7 shows the composition of liquid phase after 24,48 and $72 \mathrm{~h}$ of crystallization. The composition is estimated using the conversion values given in Figure 4.32 and assuming that one unit cell of silicalite contains 87.6 wt $\%$ of $\mathrm{SiO}_{2}$ and 12.4 wt $\%$ of $\mathrm{TPA}^{+}$which corresponds to 4 moles of $\mathrm{TPA}^{+}$ for every 96 moles of silica. It was also assumed that no water exists in the silicalite pores.

The limiting reactant is silica so there exists large quantity of template although silica was consumed significantly. Therefore liquid phase composition should be adjusted by silica addition rather than template.

Table 4.7 Estimated liquid phase compositions of the synthesis solution at different synthesis times at $95^{\circ} \mathrm{C}$ and atmospheric pressure

Basis: $150 \mathrm{~g}$ synthesis solution

Initial amount of $\mathrm{SiO}_{2}$ in synthesis solution: $18.69 \mathrm{~g}$

Initial amount of TPAOH in synthesis solution: $23.72 \mathrm{~g}$

\begin{tabular}{cccccc}
\hline $\begin{array}{c}\text { Synthesis } \\
\text { time } \\
(\mathrm{h})\end{array}$ & $\begin{array}{c}\% \\
\text { Conversion }\end{array}$ & $\begin{array}{c}\text { Amount } \\
\text { of } \\
\text { silicalite } \\
\text { formed } \\
(\mathrm{g})\end{array}$ & $\begin{array}{c}\text { Remaining } \\
\text { amount of } \\
\mathrm{SiO}_{2} \text { in } \\
\text { synthesis } \\
\text { solution }(\mathrm{g})\end{array}$ & $\begin{array}{c}\text { Remaining } \\
\text { amount of } \\
\mathrm{TPA} \text { in } \\
\text { synthesis } \\
\text { solution }(\mathrm{g})\end{array}$ & $\begin{array}{c}\text { Estimated } \\
\text { liquid phase } \\
\text { compositions }\end{array}$ \\
\hline 0 & 0 & 0 & 18.69 & 23.72 & $\mathrm{~S}_{80} \mathrm{~T}_{30} \mathrm{H}_{1500}$ \\
24 & 2.7 & 0.50 & 18.25 & 23.66 & $\mathrm{~S}_{78} \mathrm{~T}_{29} \mathrm{H}_{1500}$ \\
48 & 47.6 & 8.90 & 10.90 & 22.61 & $\mathrm{~S}_{43} \mathrm{~T}_{26} \mathrm{H}_{1500}$ \\
72 & 64.9 & 12.13 & 8.06 & 22.22 & $\mathrm{~S}_{31} \mathrm{~T}_{25} \mathrm{H}_{1500}$ \\
\hline
\end{tabular}

Figure 4.34 shows how the liquid phase composition changed during the course of crystallization on the ternary diagram. The paths $\mathrm{K}, \mathrm{M}$ and $\mathrm{Y}$ show that silica sol was added to the medium after 24,48 and $72 \mathrm{~h}$ of synthesis. Besides number (1) shows the beginning composition which is the same for all paths. Numbers (2) and (3) represent the compositions before and after silica addition, 
respectively. Recall that we aimed only the present nuclei to grow without formation of a new generation of nuclei. The compositions after addition of silica were concentrated with respect to the compositions used in the literature to make membranes (Figure 4.32). Relatively concentrated compositions were preferred since this is the first study in the literature applying the mid-synthesis addition of silica during the membrane synthesis.

Finally number (4) shows the compositions at the end of the synthesis. Number (4) for all routes shows the compositions having low amount of $\mathrm{SiO}_{2}$ and TPA and high amount of $\mathrm{H}_{2} \mathrm{O}$ which indicates that high conversion of silica after silica addition was obtained for all different composition change times.

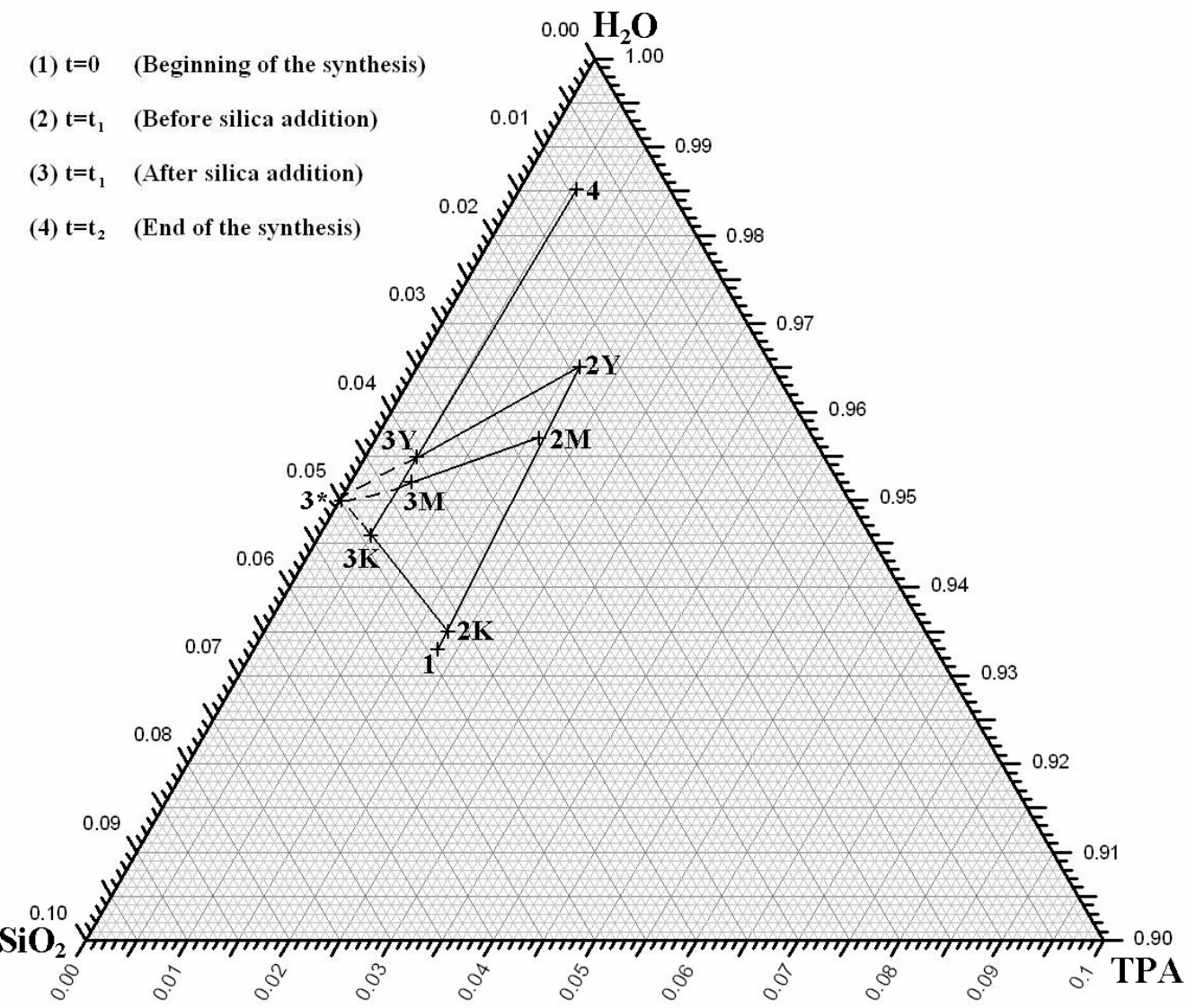

Figure 4.34 Solution compositions during the course of crystallization with mid synthesis addition of silica at different synthesis times 
Table 4.8 shows the compositions used in ternary diagram. The conversion values in first and fourth column shows the silica conversion in the batch to MFI before and after addition of silica, respectively. The maximum conversion that can be reached in the case of constant composition synthesis with 80 $\mathrm{SiO}_{2}: 30 \mathrm{TPAOH}: 1500 \mathrm{H}_{2} \mathrm{O}$ and $80 \mathrm{SiO}_{2}: 9 \mathrm{TPAOH}: 1500 \mathrm{H}_{2} \mathrm{O}$ was only $65 \%$ and $10 \%$ in $72 \mathrm{~h}$. However composition change during synthesis gave almost greater than $80 \%$ zeolite conversion in $72 \mathrm{~h}$.

Table 4.8 Liquid phase compositions of the synthesis solution used in the ternary diagram (T: TPA; $\mathrm{S}: \mathrm{SiO}_{2} ; \mathrm{H}: \mathrm{H}_{2} \mathrm{O}$ )

Initial composition: $\mathrm{S}_{80} \mathrm{~T}_{30} \mathrm{H}_{1500}$

\begin{tabular}{ccccc}
\hline $\begin{array}{c}\% \\
\begin{array}{c}\text { Conversion } \\
\text { before silica } \\
\text { addition }\end{array}\end{array}$ & $\begin{array}{c}\text { Compositions } \\
\text { before silica } \\
\text { addition } \\
\mathrm{t}=\mathrm{t}_{1}\end{array}$ & $\begin{array}{c}\text { Compositions } \\
\text { after silica } \\
\text { addition } \\
\mathrm{t}=\mathrm{t}_{1}\end{array}$ & $\begin{array}{c}\% \\
\text { Conversion } \\
\text { after silica } \\
\text { addition }\end{array}$ & $\begin{array}{c}\text { Compositions } \\
\text { at the end of the } \\
\text { synthesis } \\
\mathrm{t}=\mathrm{t}_{2}\end{array}$ \\
\hline $0\left(\mathrm{t}_{1}=0\right)$ & $\mathrm{S}_{80} \mathrm{~T}_{30} \mathrm{H}_{1500}$ & $\mathrm{~S}_{80} \mathrm{~T}_{9} \mathrm{H}_{1500}$ & $0\left(\mathrm{t}_{2}=0\right)$ & $\mathrm{S}_{80} \mathrm{~T}_{9} \mathrm{H}_{1500}$ \\
$2.7\left(\mathrm{t}_{1}=24\right)$ & $\mathrm{S}_{78} \mathrm{~T}_{29} \mathrm{H}_{1500}$ & $\mathrm{~S}_{79} \mathrm{~T}_{9} \mathrm{H}_{1500}$ & $86\left(\mathrm{t}_{2}=24+72\right)$ & $\mathrm{S}_{17} \mathrm{~T}_{6} \mathrm{H}_{1500}$ \\
$47.6\left(\mathrm{t}_{1}=48\right)$ & $\mathrm{S}_{43} \mathrm{~T}_{26} \mathrm{H}_{1500}$ & $\mathrm{~S}_{68} \mathrm{~T}_{8} \mathrm{H}_{1500}$ & $76\left(\mathrm{t}_{2}=48+72\right)$ & $\mathrm{S}_{20} \mathrm{~T}_{6} \mathrm{H}_{1500}$ \\
$64.9\left(\mathrm{t}_{1}=72\right)$ & $\mathrm{S}_{31} \mathrm{~T}_{25} \mathrm{H}_{1500}$ & $\mathrm{~S}_{64} \mathrm{~T}_{8} \mathrm{H}_{1500}$ & $81\left(\mathrm{t}_{2}=72+72\right)$ & $\mathrm{S}_{16} \mathrm{~T}_{6} \mathrm{H}_{1500}$ \\
\hline
\end{tabular}

$\mathrm{t}_{1}$ : composition change time

$\mathrm{t}_{2}$ : synthesis time after composition change

\subsubsection{Characterization of the membranes}

Membrane synthesis was started with two disc supports in two separate membrane modules. After 28, 48 and $72 \mathrm{~h}$ one of the module was removed from the system and synthesis composition was changed by adding silica sol to the synthesis medium.

Total synthesis time was kept constant as $72 \mathrm{~h}$ during the preparation of a 
group of membranes. Table 4.9 shows the synthesis periods for this group of membranes as well as the membranes prepared without mid-synthesis addition of silica. For example, during the synthesis of membrane BS121, composition was changed after $24 \mathrm{~h}$. The crystallization process was then proceeded for 48 $\mathrm{h}$ more. Thus the total synthesis time was $72 \mathrm{~h}$.

Table 4.9 Synthesis conditions and properties of the membranes prepared with composition change during the synthesis, synthesis temperature: $95^{\circ} \mathrm{C}$

\begin{tabular}{ccc}
\hline Membrane Codes & $\begin{array}{c}\text { Synthesis composition } \\
\text { 80SiO }\end{array}$ :xTPAOH: $1500 \mathrm{H}_{2} \mathrm{O}$ & Total synthesis time $(\mathrm{h})\left(\mathrm{t}_{1}+\mathrm{t}_{2}\right)$ \\
\hline BS122, 169 & 30 & 24 \\
\hline BS123, 165, 167, 173 & 30 & 48 \\
\hline BS115, 175 & 30 & 72 \\
\hline BS119 & 9 & 72 \\
\hline BS121 & $30 \rightarrow 9$ & $24+48$ \\
\hline BS124, 166, 168 & $30 \rightarrow 9$ & $48+24$ \\
\hline
\end{tabular}

$\mathrm{t}_{1}$ : composition change time

$\mathrm{t}_{2}$ : synthesis time after composition change

Figure 4.35 shows the XRD patterns of the membranes before silica addition and after synthesis completed. No silicalite was observed on the support surface after $24 \mathrm{~h}$ of synthesis (Figure 4.35.a). After change of composition and extending the synthesis time for $48 \mathrm{~h}$ more, silicalite crystals formed on the surface (Figure 4.35.b). When the membrane was synthesized for $72 \mathrm{~h}$ without addition of silica, the surface was again coated with silicalite crystals (Figure 4.35.c). 


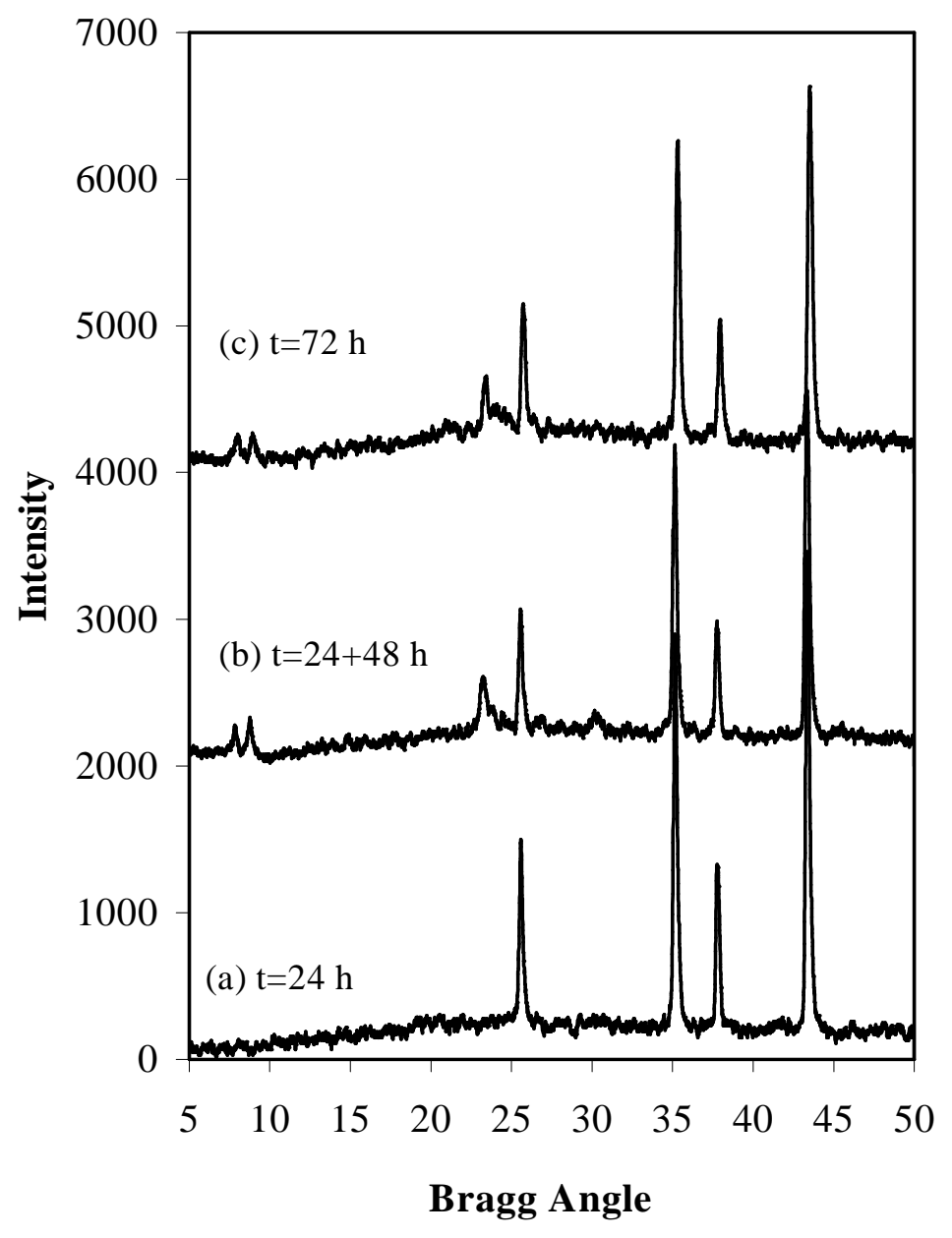

Figure 4.35 XRD patterns of the membranes before changing the composition (a), after $48 \mathrm{~h}$ of crystallization following the composition change (b), and after $72 \mathrm{~h}$ of crystallization without composition change (c). The patterns of membranes BS-121 (a), BS-122 (b) and BS-175 (c).

Figure 4.36 shows the intensity and weight fractions of the membranes. After $24 \mathrm{~h}$ and $48 \mathrm{~h}$ of synthesis almost nothing is deposited on the surface. After changing the composition at $48 \mathrm{~h}$ and extending for $24 \mathrm{~h}$ more, the increase in the weight fraction indicates that significant amount of silicalite deposited. The high intensity fraction shows that the reflection from the alumina is weak, indicating that silicalite particles formed a thick layer. Both intensity and weight fractions after $48+24 \mathrm{~h}$ are higher than those obtained after $72 \mathrm{~h}$ of synthesis without mid-synthesis addition of silica. Apparently mid-synthesis addition of silica increases the extent of crystallization. 


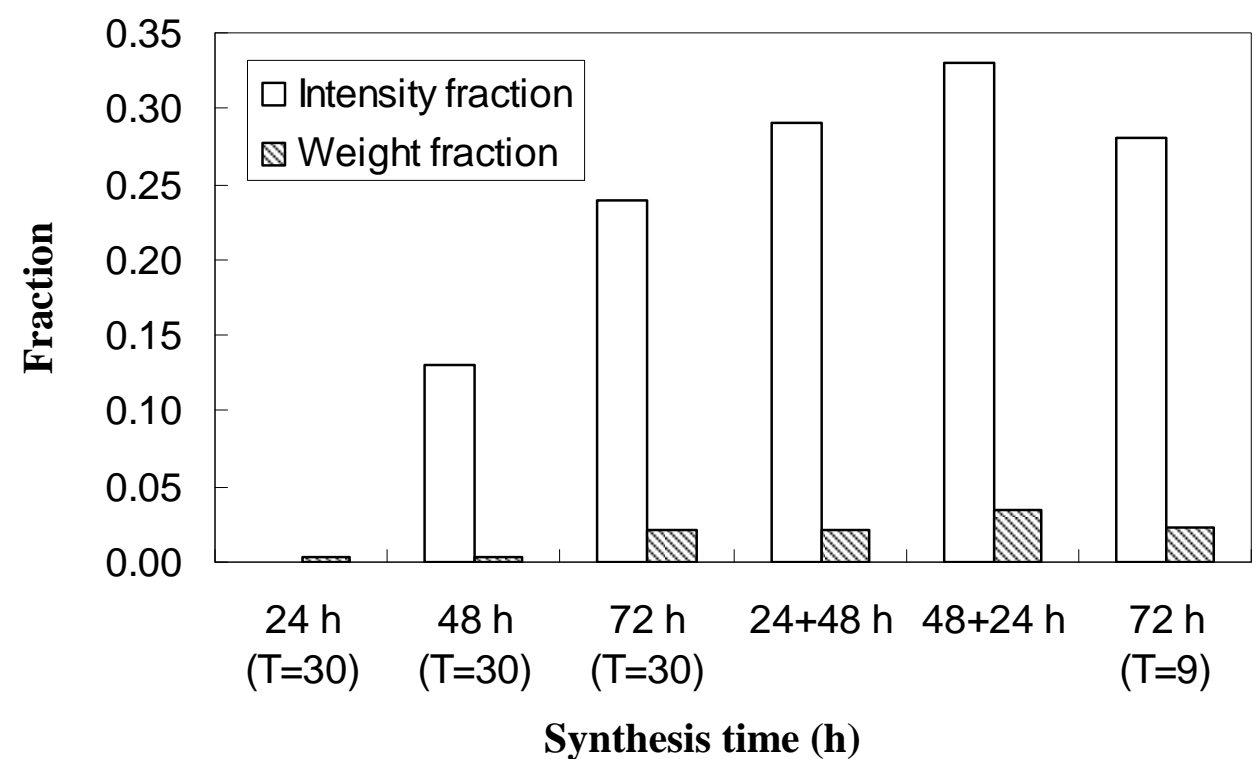

Figure 4.36 Intensity and weight fractions of membranes prepared with and without mid-synthesis addition of silica.

Figure 4.37 shows that the powder that was obtained during the membrane synthesis has monomodal particle size distribution when the synthesis was carried out without mid-synthesis addition of silica. On the other hand, the powder that was synthesized with the silica addition at 24 hours has a small shoulder as shown with an arrow in Figure 4.37. This shoulder can be attributed to the further growth of crystals on the existing small crystals. No shoulder was seen on the powder synthesized with the silica addition at 48 hours. This can be attributed to that additional $24 \mathrm{~h}$ is not sufficient for the further growth of crystals. 


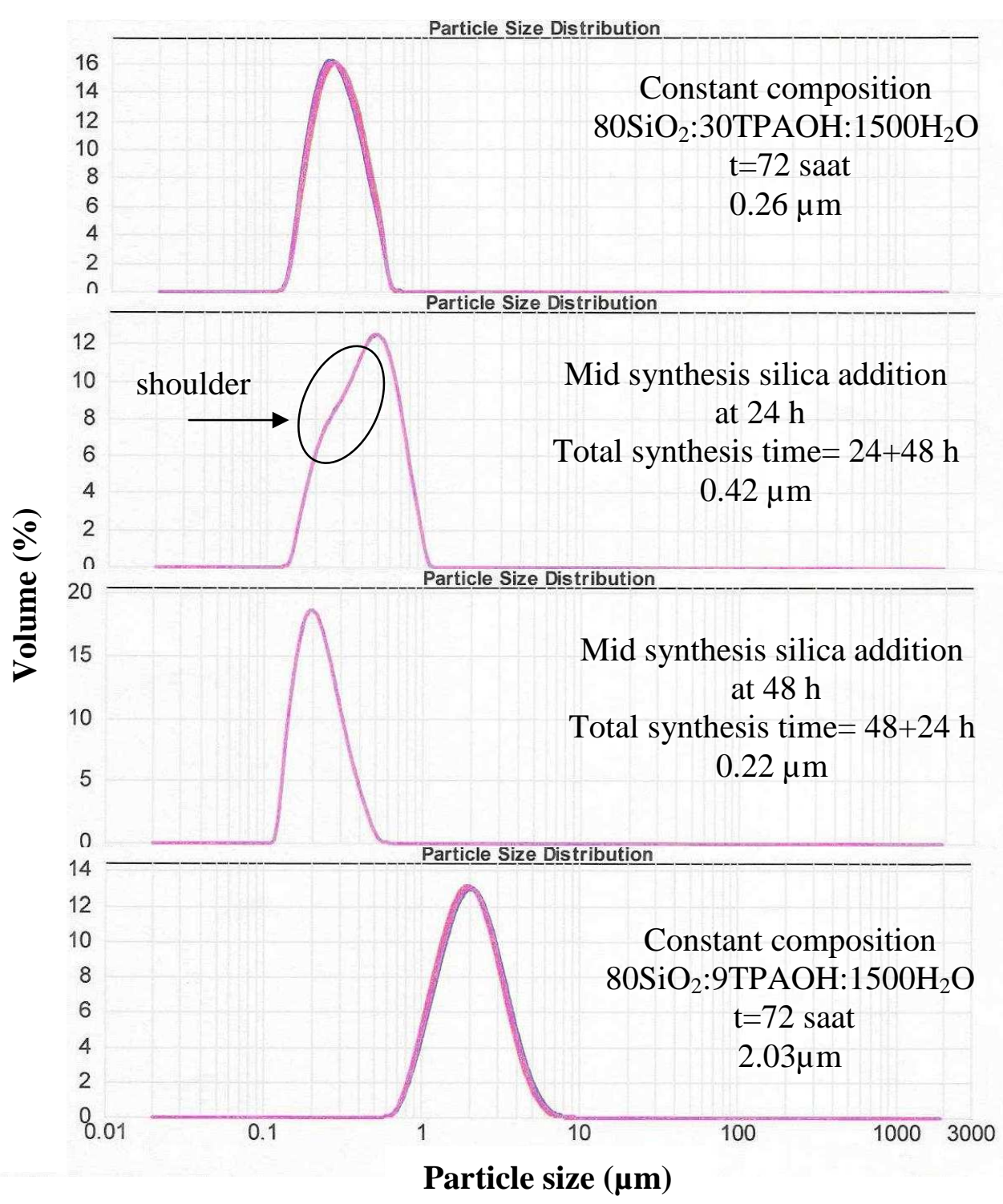

Figure 4.37 Particle size distributions of the powders remained from membranes synthesized with constant composition and mid synthesis addition of silica at different synthesis times

The change of the crystal sizes as a function of total synthesis time can be seen in Figure 4.38. In this figure circular symbols were used for the crystals synthesized with the constant molar composition $80 \mathrm{SiO}_{2}: 30 \mathrm{TPAOH}: 1500 \mathrm{H}_{2} \mathrm{O}$. It is seen that crystals in constant composition synthesis are growing in the initial stages of the synthesis and reach to ultimate value of $300 \mathrm{~nm}$ after $40 \mathrm{~h}$. After about $40 \mathrm{~h}$ crystallization the crystal size had not changed so much. Figure 4.38 also shows the change in crystal sizes as a result of silica addition 
at $24 \mathrm{~h}, 48 \mathrm{~h}$ and $72 \mathrm{~h}$ and triangular symbols were used for those crystals. The crystal sizes in experiments which silica was added at $24 \mathrm{~h}$ after beginning of the synthesis are 0.45 and $0.50 \mu \mathrm{m}$.

Figure 4.38 also shows that when we complete the synthesis in $24 \mathrm{~h}$ after silica addition at $48 \mathrm{~h}, 0.22 \mu \mathrm{m}$ sized crystals were obtained whereas $0.35 \mu \mathrm{m}$ crystals formed if the synthesis was continued for an additional $72 \mathrm{~h}$ after composition change at $48 \mathrm{~h}$. This result points out that the synthesis should be ended in a longer time after silica addition because crystals cannot complete their growth in $24 \mathrm{~h}$ after silica addition.

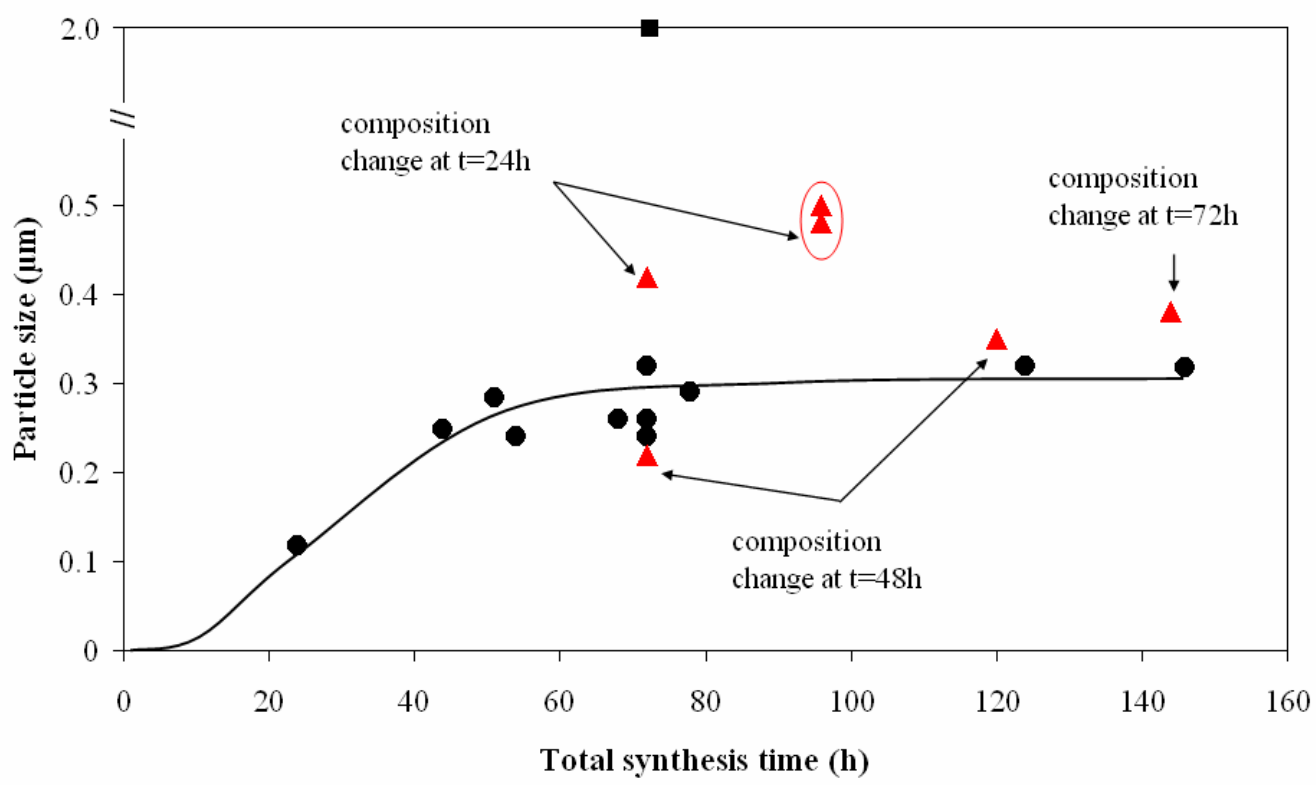

Figure 4.38 The particle size in synthesis mixture with the molar composition $80 \mathrm{SiO}_{2}: 30 \mathrm{TPAOH}: 1500 \mathrm{H}_{2} \mathrm{O}(\bullet), 80 \mathrm{SiO}_{2}: 9 \mathrm{TPAOH}: 1500 \mathrm{H}_{2} \mathrm{O}(\boldsymbol{\bullet})$ and with composition change during synthesis $(\boldsymbol{\Delta})$ as a function of synthesis time

In another group of membranes, the synthesis time after changing the composition was kept constant for $72 \mathrm{~h}$. Table 4.10 shows the synthesis periods for this group of membranes. For example, during the synthesis of 
membrane BS170, composition was changed after $24 \mathrm{~h}$. The crystallization process was then proceeded for $72 \mathrm{~h}$ more. Thus the total synthesis time was $96 \mathrm{~h}$.

Table 4.10 Synthesis conditions and properties of the membranes prepared with composition change during the synthesis

\begin{tabular}{ccc}
\hline Membrane Codes & $\begin{array}{c}\text { Synthesis composition } \\
\text { 80 } \mathrm{SiO}_{2}: \mathrm{xTPAOH}: 1500 \mathrm{H}_{2} \mathrm{O}\end{array}$ & $\begin{array}{c}\text { Total synthesis } \\
\text { time }(\mathrm{h})\left(\mathrm{t}_{1}+\mathrm{t}_{2}\right)\end{array}$ \\
\hline BS170, 178, 179 & $30 \rightarrow 9$ & $24+72$ \\
\hline BS174, 177 & $30 \rightarrow 9$ & $48+72$ \\
\hline BS176 & $30 \rightarrow 9$ & $72+72$ \\
\hline
\end{tabular}

$\mathrm{t}_{1}$ : composition change time

$\mathrm{t}_{2}$ : synthesis time after composition change

Figure 4.39 shows the SEM micrographs of the membrane surfaces and cross sections before composition change at 24,48 and $72 \mathrm{~h}$ synthesis times. These photographs show that the coating over the support surfaces gets denser as time proceeds before composition change. That means at early stages of synthesis like at $24 \mathrm{~h}$, there are very little amount of crystals on the support surface while crystals start to form a layer after $48 \mathrm{~h}$. At early stages of the synthesis crystal formation is still continuing and crystals placed separately on the support while after $24 \mathrm{~h}$, crystals start to form a continuous layer. Figure 4.40 and 4.41 show the SEM photographs of the membrane surfaces and cross sections after composition change at 24,48 and $72 \mathrm{~h}$ synthesis times. All membranes have thin $(1-2 \mu \mathrm{m})$ and continuous zeolite layer after silica addition regardless of the silica addition time. No individual crystals were observed between membrane layer and support indicates that all crystals formed before composition change contribute the layer formation after silica addition. 

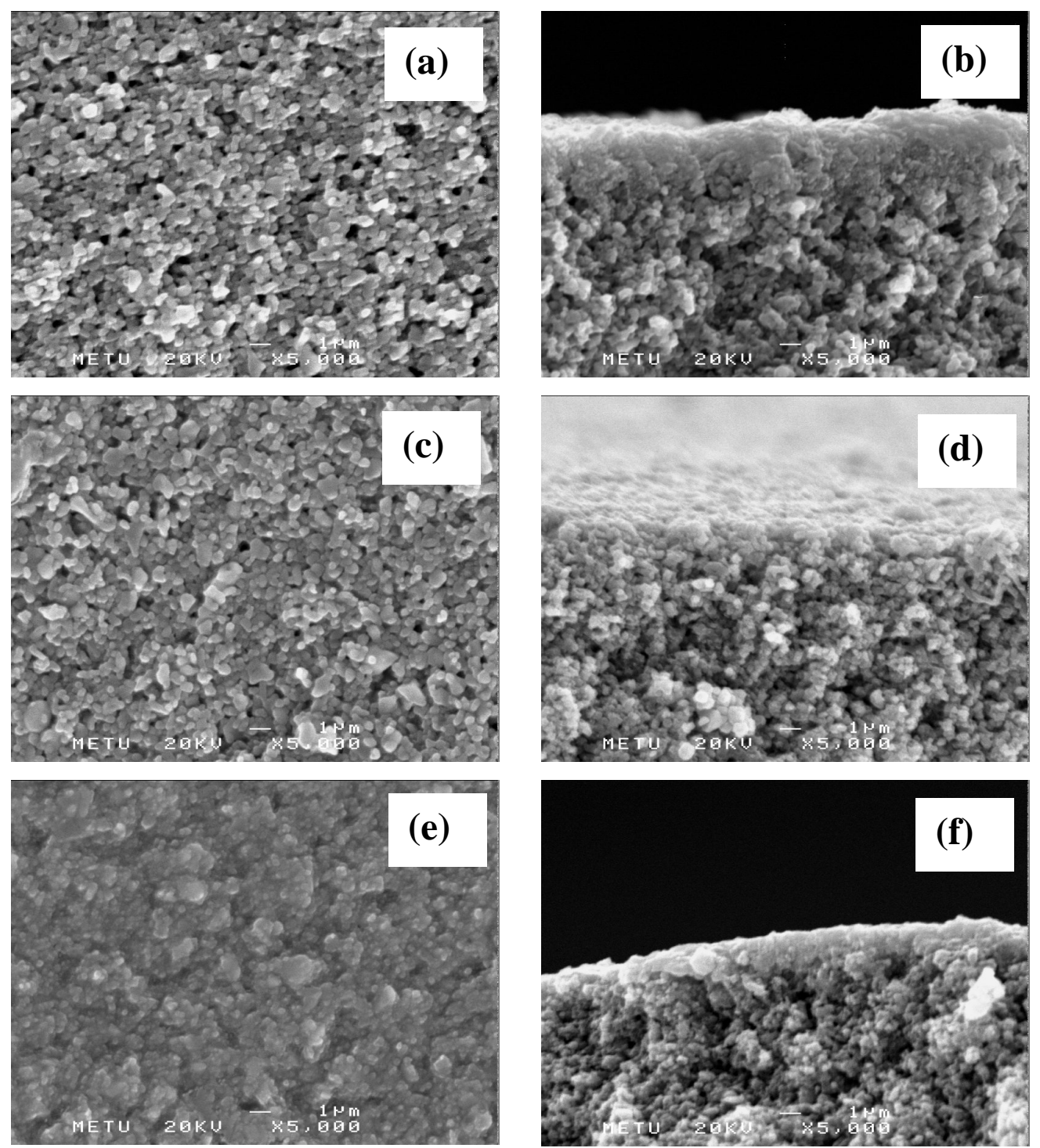

Figure 4.39 Surface (a, c, e) and cross section (b, d, f) SEM images of the membranes before silica addition (a, b) $24 \mathrm{~h},(\mathrm{c}, \mathrm{d}) 48 \mathrm{~h},(\mathrm{e}, \mathrm{f}) 72 \mathrm{~h}$ 

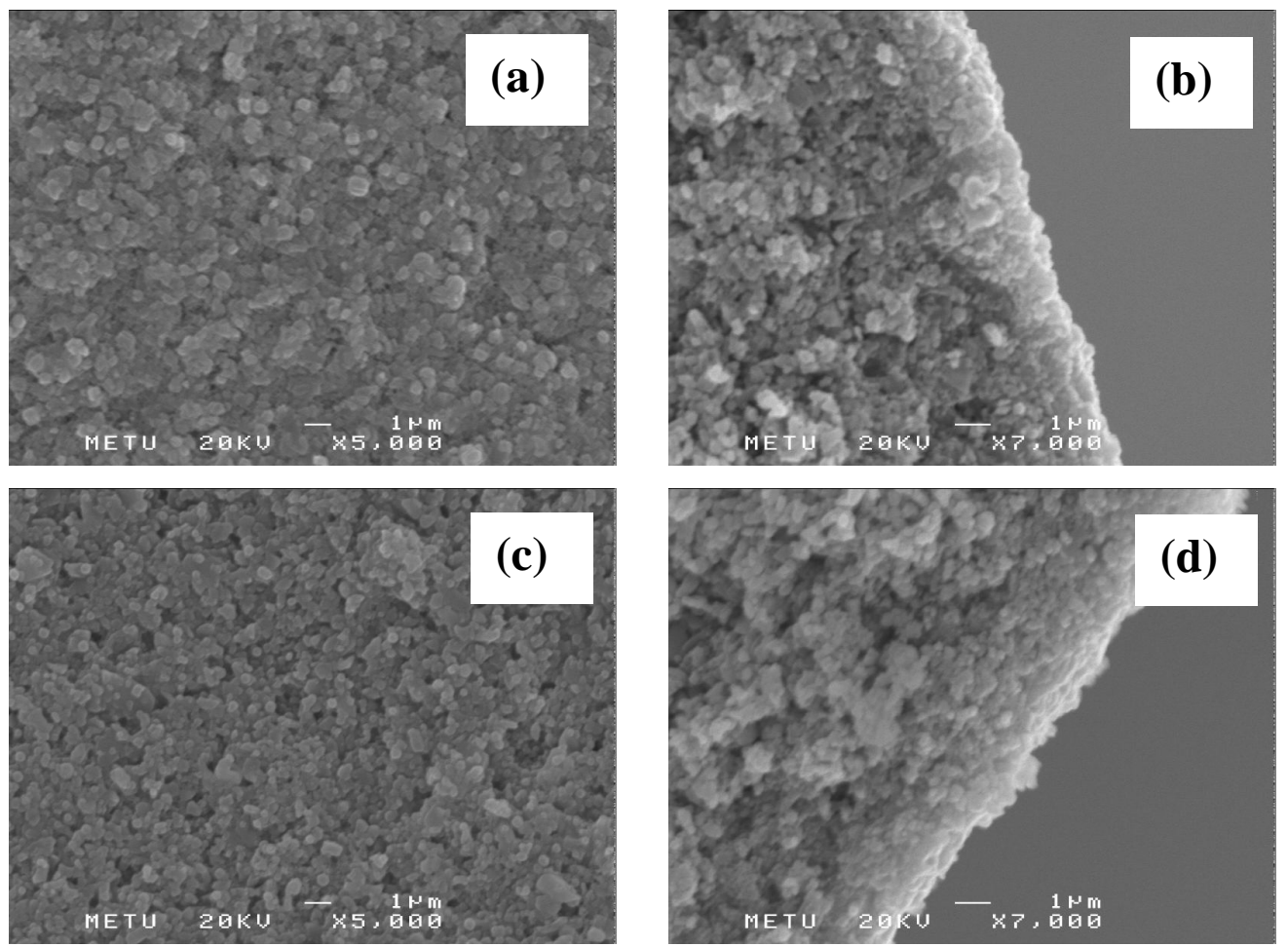

Figure 4.40 Surface $(a, c)$ and cross section (b, d) SEM images of the membranes after silica addition (a, b) 24+48 h, (c, d) 48+24 h

Midsynthesis addition of silica supplies extra nutrient to the system and this nutrient provides further growth of existing crystals. This can be regarded as "in-situ seeding" method. Because before the composition change formation of crystals is provided over the support and after midsynthesis addition of silica growth of these crystals and thus formation of a zeolite layer is achieved. The first part of this mechanism resembles to the seeding and as a whole to secondary growth in the conventional zeolite membrane synthesis. 

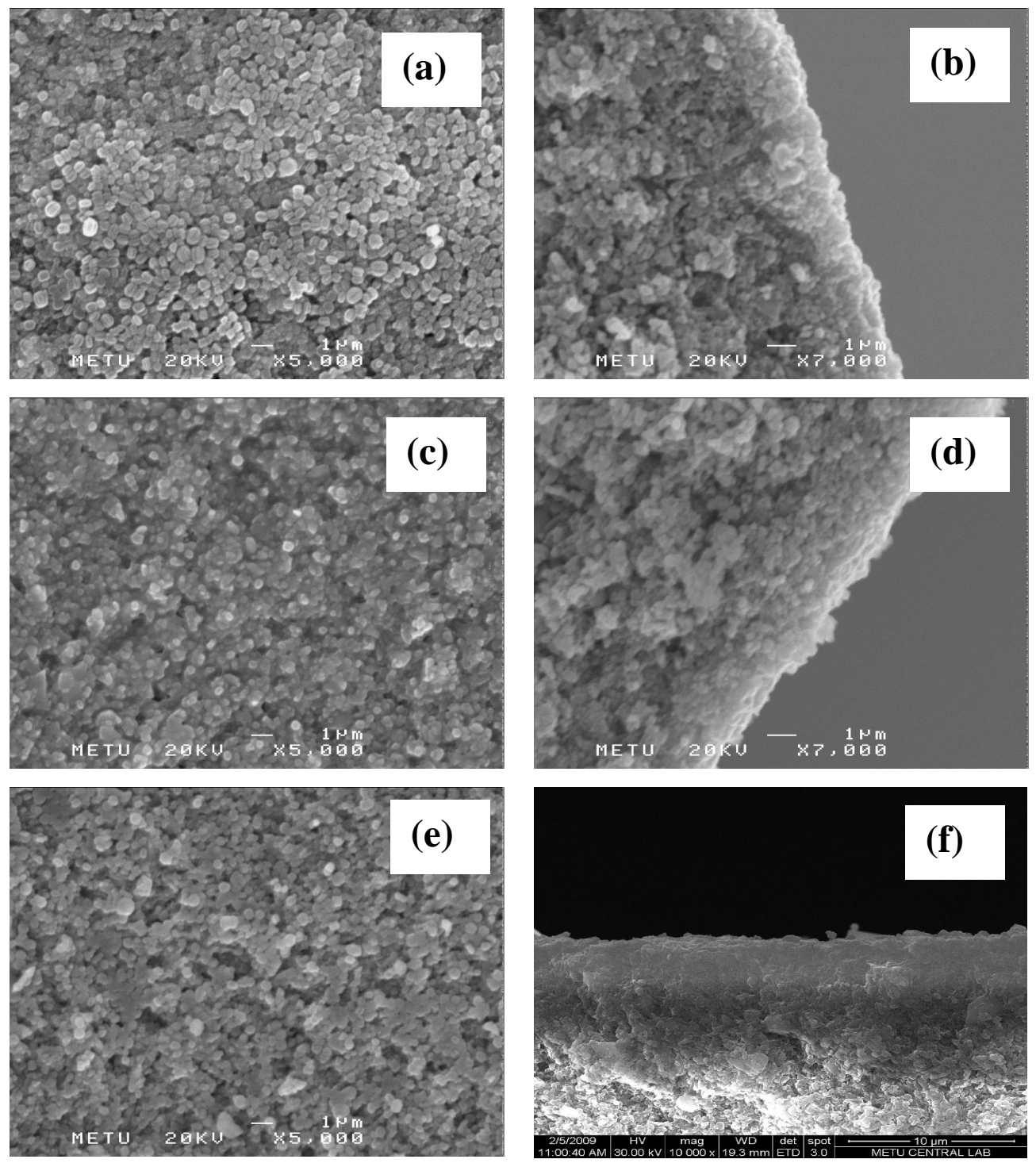

Figure 4.41 Surface (a, c, e) and cross section (b, d, f) SEM images of the membranes after silica addition (a, b) $24+72 \mathrm{~h},(\mathrm{c}, \mathrm{d}) 48+72 \mathrm{~h},(\mathrm{e}, \mathrm{f}) 72+72$

\subsubsection{Characterization of membranes by gas permeation measurements}

All membranes were impermeable to $\mathrm{N}_{2}$ before calcination after mid synthesis addition of silica while these membranes have some $\mathrm{N}_{2}$ fluxes before silica addition. Membranes are expected to have zero flux before calcination if good integrity was provided in membrane layer. 
The single gas permeances of the membranes synthesized with either constant or varying synthesis compositions are given in Table 4.11. Here membrane BS115 and BS119 were synthesized with $80 \mathrm{SiO}_{2}: 30 \mathrm{TPAOH}: 1500 \mathrm{H}_{2} \mathrm{O}$ and $80 \mathrm{SiO}_{2}: 30 \mathrm{TPAOH}: 1500 \mathrm{H}_{2} \mathrm{O}$ constant molar compositional batchs, respectively. For the synthesis of BS121 and BS125 membranes synthesis compositions was changed by adding silica at $24 \mathrm{~h}$ and $124 \mathrm{~h}$.

The $\mathrm{n}-\mathrm{C}_{4} \mathrm{H}_{10}$ permeances of $\mathrm{BS} 119$ and $\mathrm{BS} 115$ membranes at $100^{\circ} \mathrm{C}$ are $4.7 \times 10^{-7}$ and $2.9 \times 10^{-6} \mathrm{~mol} / \mathrm{m}^{2} \mathrm{sPa}$, respectively. Permeances increased with increasing template amount. On the other hand BS121 and BS125 membranes have the $\mathrm{n}-\mathrm{C}_{4} \mathrm{H}_{10}$ permeances of $8 \times 10^{-8}$ and $7.4 \times 10^{-7} \mathrm{~mol} / \mathrm{m}^{2} \mathrm{sPa}$, respectively. The $n-\mathrm{C}_{4} \mathrm{H}_{10} / \mathrm{n}-\mathrm{C}_{4} \mathrm{H}_{10}$ ideal selectivity of BS121 membrane is 47 while BS119 and BS115 membranes 4 and 8 at $100^{\circ} \mathrm{C}$, respectively. Although membranes synthesized with constant concentration have higher or comparable permeances, the BS121 and BS125 membranes prepared by mid synthesis silica addition has higher ideal selectivity than the other membranes. Silica addition during the synthesis increased the membrane quality significantly. Apparently thin and continuous membranes that have high potential in the separation of gas mixtures can be prepared by changing the composition during the synthesis.

Membranes synthesized with composition change at different synthesis times were also tested for the $n-\mathrm{C}_{4} \mathrm{H}_{10} / \mathrm{CH}_{4}$ and $\mathrm{n}-\mathrm{C}_{4} \mathrm{H}_{10} / \mathrm{N}_{2}$ binary mixture separation at $25^{\circ} \mathrm{C}$ and $100^{\circ} \mathrm{C}$ (Table 4.12 ). Among those membranes the ones synthesized with mid synthesis addition of silica at $24 \mathrm{~h}$ gave reproducibly higher $\mathrm{n}$ $\mathrm{C}_{4} \mathrm{H}_{10} / \mathrm{CH}_{4}$ and $\mathrm{n}-\mathrm{C}_{4} \mathrm{H}_{10} / \mathrm{N}_{2}$ separation selectivities at $25{ }^{\circ} \mathrm{C}$. The $\mathrm{n}-\mathrm{C}_{4} \mathrm{H}_{10}$ permeances of $\mathrm{BS} 170$ and $\mathrm{BS} 174$ at $25^{\circ} \mathrm{C}$ are $7.2 \times 10^{-9}$ and $1.5 \times 10^{-7}$ $\mathrm{mol} / \mathrm{m}^{2} \mathrm{sPa}$, respectively. The $\mathrm{n}-\mathrm{C}_{4} \mathrm{H}_{10} / \mathrm{CH}_{4}$ and $\mathrm{n}-\mathrm{C}_{4} \mathrm{H}_{10} / \mathrm{N}_{2}$ separation selectivities of BS170 membrane are 41 and 27 at $25^{\circ} \mathrm{C}$, respectively. On the other hand the $\mathrm{n}-\mathrm{C}_{4} \mathrm{H}_{10} / \mathrm{CH}_{4}$ separation selectivities of $\mathrm{BS} 174$ and $\mathrm{BS} 176$ 
membranes are nearly 2.4 and 1.0, respectively. These results indicate that the mid synthesis addition of silica at early stages of synthesis improves the membrane selectivity at the expense of reduced permeance. The main idea of mid synthesis addition of silica to the medium was to change the growth rate of the crystals after nucleation. Since crystals reach to ultimate size and crystal growth almost ended after $48 \mathrm{~h}$ it is not possible to affect on the crystal growth of existing crystals by addition of further nutrient.

Table 4.11 Single gas permeances through the membranes synthesized with constant composition $80 \mathrm{SiO}_{2}: 30 \mathrm{TPAOH}: 1500 \mathrm{H}_{2} \mathrm{O}$ (BS115), $80 \mathrm{SiO}_{2}: 9 \mathrm{TPAOH}: 1500 \mathrm{H}_{2} \mathrm{O}$ (BS119) at $72 \mathrm{~h}$ and mid-synthesis addition of silica at $24 \mathrm{~h}(\mathrm{BS} 121)$ and $124 \mathrm{~h}(\mathrm{BS} 125)$ at $95^{\circ} \mathrm{C}$.

\begin{tabular}{|c|c|c|c|c|c|c|}
\hline \multirow{2}{*}{ Membrane } & \multirow{2}{*}{$\begin{array}{c}\text { Temperature } \\
\left({ }^{\circ} \mathrm{C}\right)\end{array}$} & \multicolumn{4}{|c|}{ Permeancex $10^{-7}\left(\mathrm{~mol} / \mathrm{m}^{2} \mathrm{sPa}\right)$} & \multirow{2}{*}{$\begin{array}{l}\mathrm{n}-\mathrm{C}_{4} \mathrm{H}_{10} / \mathrm{i}-\mathrm{C}_{4} \mathrm{H}_{10} \\
\text { Ideal Selectivity }\end{array}$} \\
\hline & & $\mathrm{H}_{2}$ & $\mathrm{~N}_{2}$ & $\mathrm{n}-\mathrm{C}_{4} \mathrm{H}_{10}$ & $\mathrm{i}-\mathrm{C}_{4} \mathrm{H}_{10}$ & \\
\hline \multirow{2}{*}{ BS115 } & 25 & 33.5 & 26.6 & 13.9 & 3.2 & 4.3 \\
\hline & 100 & - & - & 29 & 3.48 & 8.3 \\
\hline \multirow{2}{*}{ BS119 } & 25 & 8.14 & 4.76 & 1.82 & 1.39 & 1.3 \\
\hline & 100 & - & - & 4.68 & 1.14 & 4.1 \\
\hline \multirow{2}{*}{ BS121 } & 25 & 0.67 & 0.17 & 0.07 & 0.014 & 5.0 \\
\hline & 100 & & 0.8 & 0.017 & - & 47 \\
\hline \multirow{2}{*}{ BS125 } & 25 & 2.53 & 2.29 & 2.09 & 0.025 & 84 \\
\hline & 100 & - & - & 7.44 & 0.31 & 25 \\
\hline
\end{tabular}

To sum up attempts to synthesize MFI membranes with either $80 \mathrm{SiO}_{2}: 30 \mathrm{TPAOH}: 1500 \mathrm{H}_{2} \mathrm{O}$ or $80 \mathrm{SiO}_{2}: 9 \mathrm{TPAOH}: 1500 \mathrm{H}_{2} \mathrm{O}$ molar batch compositions without addition of silica also gave continuous MFI layer with respect to SEM images but those membranes have very low $n-\mathrm{C}_{4} \mathrm{H}_{10} / \mathrm{i}-\mathrm{C}_{4} \mathrm{H}_{10}$ separation selectivities compared to membranes synthesized with midsynthesis addition of silica. This results point out that membrane quality can be increased 
by composition change during synthesis. Those results also indicate that the time at which the silica is introduced to the synthesis medium is critical for the membrane quality.

Table 4.12 Gas permeances and separation selectivities of the membranes synthesized with mid synthesis addition of silica in $\% 50 / \% 50 \mathrm{n}-\mathrm{C}_{4} \mathrm{H}_{10} / \mathrm{CH}_{4}$ and $\mathrm{n}-\mathrm{C}_{4} \mathrm{H}_{10} / \mathrm{N}_{2}$ binary mixtures

\begin{tabular}{|c|c|c|c|c|c|}
\hline \multirow{2}{*}{ Membrane } & \multirow{2}{*}{$\mathrm{t}_{1}+\mathrm{t}_{2}$} & \multirow{2}{*}{$\begin{array}{c}\text { Temperature } \\
\left({ }^{\circ} \mathrm{C}\right)\end{array}$} & \multicolumn{2}{|c|}{ Permeancex $10^{-7}\left(\mathrm{~mol} / \mathrm{m}^{2} \mathrm{sPa}\right)$} & \multirow{2}{*}{$\begin{array}{r}\begin{array}{l}\text { Separation } \\
\text { selectivity }\end{array} \\
\mathrm{n}-\mathrm{C}_{4} \mathrm{H}_{10} / \mathrm{CH}\end{array}$} \\
\hline & & & $\mathrm{CH}_{4}$ & $\mathrm{n}-\mathrm{C}_{4} \mathrm{H}_{10}$ & \\
\hline \multirow{2}{*}{ BS170 } & \multirow{2}{*}{$24+72$} & 25 & $4.2 \times 10^{-10}$ & $1.1 \times 10^{-8}$ & 27.3 \\
\hline & & 100 & $1.9 \times 10^{-8}$ & $7.7 \times 10^{-8}$ & 4.4 \\
\hline \multirow{2}{*}{ BS178 } & \multirow{2}{*}{$24+72$} & 25 & $4.7 \times 10^{-11}$ & $1.2 \times 10^{-9}$ & 26.1 \\
\hline & & 100 & $3.8 \times 10^{-9}$ & $8.2 \times 10^{-9}$ & 2.1 \\
\hline \multirow{2}{*}{ BS179 } & \multirow{2}{*}{$24+72$} & 25 & $8.4 \times 10^{-11}$ & $1.8 \times 10^{-9}$ & 21.3 \\
\hline & & 100 & $1.1 \times 10^{-9}$ & $5.1 \times 10^{-9}$ & 4.4 \\
\hline \multirow{2}{*}{ BS124 } & \multirow{2}{*}{$48+24$} & 25 & $5.7 \times 10^{-6}$ & $1.1 \times 10^{-5}$ & 1.9 \\
\hline & & 100 & $4.1 \times 10^{-6}$ & $9.9 \times 10^{-6}$ & 2.4 \\
\hline \multirow{2}{*}{ BS166 } & \multirow{2}{*}{$48+24$} & 25 & $>10^{-5}$ & $>10^{-5}$ & Not selective \\
\hline & & 100 & $>10^{-5}$ & $>10^{-5}$ & Not selective \\
\hline \multirow{2}{*}{ BS168 } & \multirow{2}{*}{$48+24$} & 25 & $1.1 \times 10^{-8}$ & $4.1 \times 10^{-6}$ & 1.5 \\
\hline & & 100 & - & - & - \\
\hline \multirow{2}{*}{ BS174 } & \multirow{2}{*}{$48+72$} & 25 & $6.2 \times 10^{-8}$ & $1.5 \times 10^{-7}$ & 2.4 \\
\hline & & 100 & - & - & - \\
\hline \multirow{2}{*}{ BS177 } & \multirow{2}{*}{$48+72$} & 25 & $3.2 \times 10^{-7}$ & $1.3 \times 10^{-7}$ & 2.1 \\
\hline & & 100 & - & - & - \\
\hline \multirow{2}{*}{ BS176 } & \multirow{2}{*}{$72+72$} & 25 & $>10^{-5}$ & $>10^{-5}$ & Not selective \\
\hline & & 100 & $>10^{-5}$ & $>10^{-5}$ & Not selective \\
\hline
\end{tabular}

$\mathrm{t}_{1}$ : composition change time

$\mathrm{t}_{2}$ : synthesis time after composition change 


\subsection{Separation of binary and ternary gas mixtures by MFI type zeolite membranes synthesized in a flow system}

Zeolite membranes are characterized by separation of gas or liquid mixtures to improve the membrane synthesis procedures according to the requirements of the separation process visualized. Thin MFI membranes combining high permeability with high selectivity are desired for a number of applications such as pervaporation, gas separation and membrane reactors $[11,19,49]$. In this part of the study MFI type membranes were synthesized at $95^{\circ} \mathrm{C}$ on tubular $\alpha-$ alumina supports in a recirculating flow system and were characterized by separating equimolar binary mixtures of $n-\mathrm{C}_{4} \mathrm{H}_{10} / \mathrm{i}-\mathrm{C}_{4} \mathrm{H}_{10}, \mathrm{n}-\mathrm{C}_{4} \mathrm{H}_{10} / \mathrm{CH}_{4}, \mathrm{n}$ $\mathrm{C}_{4} \mathrm{H}_{10} / \mathrm{CO}_{2}, \mathrm{n}-\mathrm{C}_{4} \mathrm{H}_{10} / \mathrm{N}_{2}$, and ternary mixture of $\mathrm{CO}_{2}, \mathrm{CH}_{4}$ and $\mathrm{n}-\mathrm{C}_{4} \mathrm{H}_{10}$ between 25 and $200^{\circ} \mathrm{C}$. The synthesis conditions of the membranes that were used for separating gas and liquid mixtures are shown in Table 4.13.

Table 4.13 Synthesis method, number of synthesis steps and $\mathrm{N}_{2}$ permeances before calcination for the MFI membranes

\begin{tabular}{ccccc}
\hline & & & \multicolumn{2}{c}{$\begin{array}{c}\mathrm{N}_{2} \text { Permeances before calcination } \\
\left(\mathrm{mol} / \mathrm{m}^{2} \mathrm{sPa}\right)\end{array}$} \\
\cline { 4 - 5 } Membrane & $\begin{array}{c}\text { Synthesis } \\
\text { method }\end{array}$ & $\begin{array}{c}\text { Number of } \\
\text { synthesis steps }\end{array}$ & \multicolumn{2}{c}{ After first synthesis } \\
\cline { 4 - 5 } F1 & Flow & 1 & $<10^{-12}$ & - \\
F2 & Flow & 2 & $<10^{-12}$ & $<10^{-12}$ \\
F3 & Flow & 2 & $10^{-8}$ & $<10^{-12}$ \\
F4 & Flow & 2 & $10^{-7}$ & $<10^{-12}$ \\
B1 & Batch & 1 & $<10^{-12}$ & - \\
B2 & Batch & 2 & $10^{-8}$ & $<10^{-12}$ \\
\hline
\end{tabular}




\subsubsection{Membrane preparation and characterization with XRD and SEM}

The synthesis system composed of a membrane module in which the alumina support was placed and a reservoir with a reflux condenser for the synthesis solution. The synthesis solution was pumped between two pieces, which were connected to each other by silicon tubing. The entire apparatus was a closed system operating at atmospheric pressure without any input of reactants. However, the membrane module by itself was an open system, through which the synthesis solution was flown steadily. Therefore the membranes were synthesized in a semi-batch system. Synthesis was carried out at $95^{\circ} \mathrm{C}$, which was lower than the temperatures commonly applied to synthesize MFI type membranes in the literature [15-18]. Low temperature synthesis may yield smaller crystals and thinner membranes.

The membranes F3 and B2, which were synthesized in the recirculating flow and the batch systems, respectively, were broken for XRD analysis and SEM characterization. MFI was the only crystalline phase grown on the alumina supports and in the residual powder remained after the synthesis of membranes (Figure 4.42) [40, 96].

MFI type crystals completely covered the surface as shown from the surface SEM images (Figure 4.43a and d). The shape and size of the crystals can barely be recognized because of intensive intergrowth, especially in membrane F3. The membrane F3 has a smoother surface than the membrane B2 because MFI crystals formed in the bulk solution can be swept by the stream during the crystallization in the recirculating flow system. On the other hand MFI crystals may settle from the bulk solution onto the membrane surface during the synthesis in the batch system. 


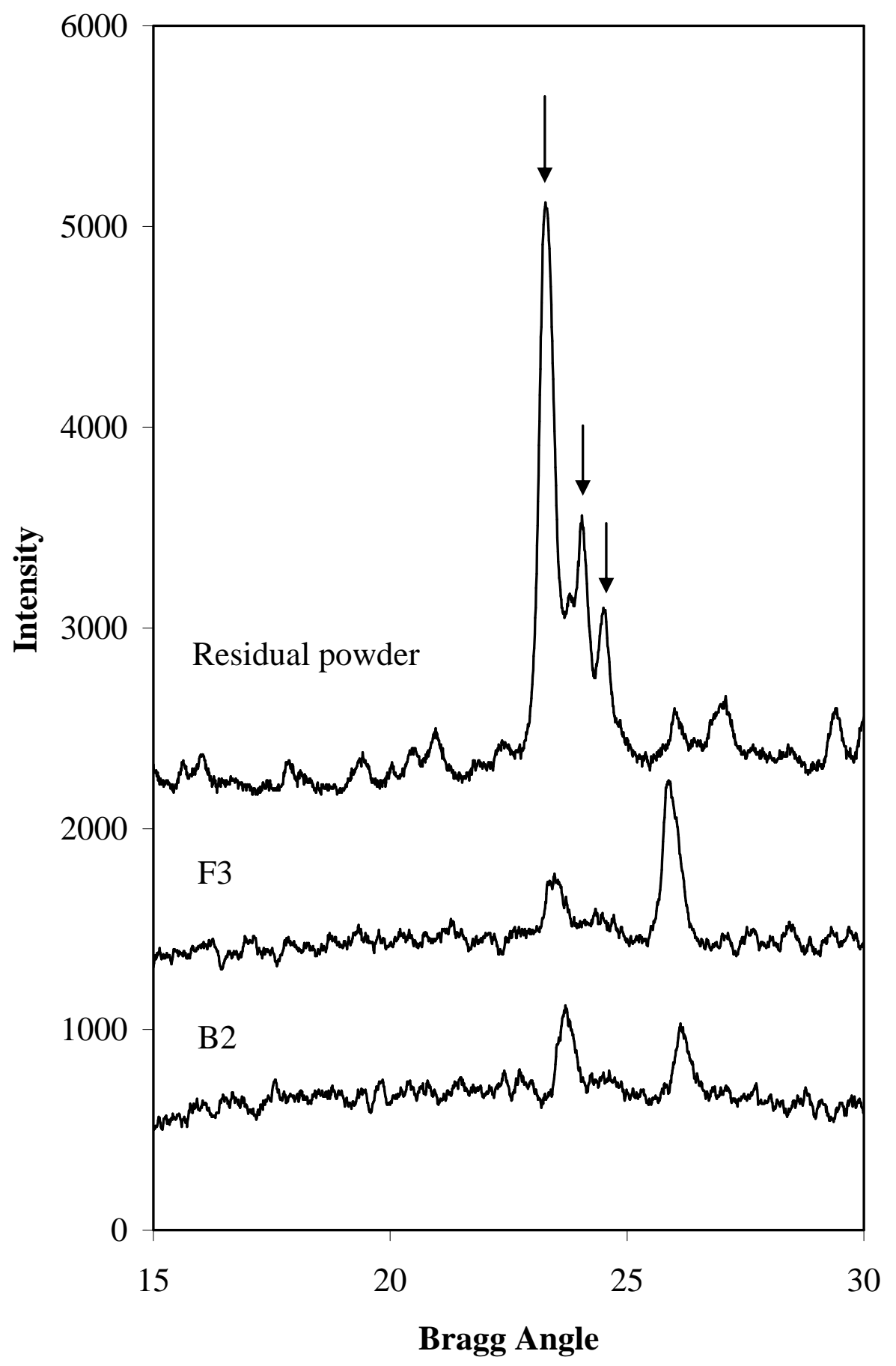

Figure 4.42. XRD patterns of the surfaces of membranes $F 3$ and $B 2$, and of the residual powder obtained from membrane synthesis in the flow system, arrows show the MFI peaks 

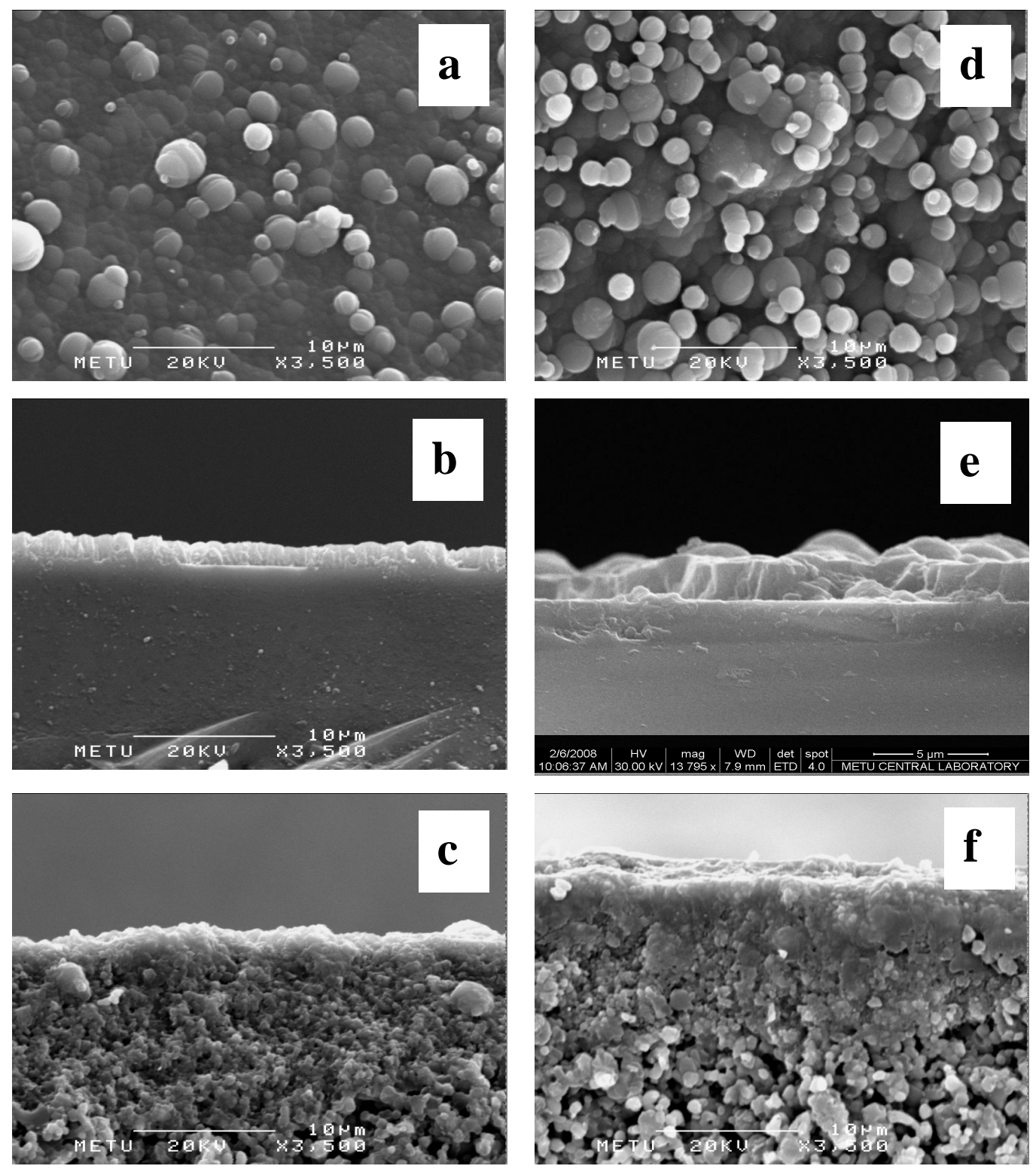

Figure 4.43 The cross-section and surface SEM micrographs of membranes F3 (a) surface, (b) cross section from glazed part, (c) cross section on porous alumina and B2 (d) surface, (e) cross section from glazed part, (f) cross section on porous alumina. Membranes B2 and F3 were synthesized with two synthesis steps in batch and recirculating flow systems, respectively.

The MFI layers on the glazed parts and on the porous parts of the alumina tube were shown part in Figures 4.43b/c and 4.43e/f, respectively. Both membranes have continuous MFI layers with reasonably uniform thicknesses along the support. The MFI layers can be identified more clearly on the glazed parts. 
The layers measured from the glazed parts are approximately $2 \mu \mathrm{m}$-thick on both type of membranes. No orientation of constituent crystals was observed owing to the flow of synthesis solution.

\subsubsection{Gas permeation through membranes synthesized in the recirculating flow and batch system}

The $\mathrm{N}_{2}$ permeance through dried membranes was measured before calcination. Only impermeable membranes were used for separation processes. If the uncalcined membrane had $\mathrm{N}_{2}$ permeability after the first synthesis, a second synthesis was carried out to plug the non-zeolitic pores. Membranes impermeable to $\mathrm{N}_{2}$ were calcined at $450^{\circ} \mathrm{C}$ for $12 \mathrm{~h}$ in air with a heating rate of $0.6^{\circ} \mathrm{C} / \mathrm{min}$. Before each permeation experiment, membranes were again calcined at $250^{\circ} \mathrm{C}$ for $4 \mathrm{~h}$.

Figure 4.44 shows the single gas permeances through different membranes at $200^{\circ} \mathrm{C}$. The single-gas permeances of $\mathrm{H}_{2}, \mathrm{~N}_{2}, \mathrm{CO}_{2}, \mathrm{CH}_{4}, \mathrm{n}-\mathrm{C}_{4} \mathrm{H}_{10}$ and $\mathrm{i}-\mathrm{C}_{4} \mathrm{H}_{10}$ were measured since these gases have often been used to characterize MFI membranes [3, 4, 15, 16, 40]. All membranes regardless of the synthesis method exhibited similar trends of decreasing single gas permeances with increasing kinetic diameter, but $\mathrm{CH}_{4}$ permeated faster than $\mathrm{CO}_{2}$ and $\mathrm{N}_{2}$ and n$\mathrm{C}_{4} \mathrm{H}_{10}$ permeated faster than $\mathrm{N}_{2}$. Similar results were also observed in other studies $[15,97,98] . \mathrm{i}-\mathrm{C}_{4} \mathrm{H}_{10}$ permeances were the lowest since the kinetic diameter of $\mathrm{i}-\mathrm{C}_{4} \mathrm{H}_{10}$ is similar to the pore size of MFI type zeolites. Membranes prepared with two consecutive syntheses had lower permeances than the membranes synthesized with a single synthesis step, for example, the $n-C_{4} H_{10}$ permeance through membrane $\mathrm{F} 1$ was 5 times as fast as the $n-\mathrm{C}_{4} \mathrm{H}_{10}$ permeance through membrane F2. The permeances may decrease because of plugging of the non-zeolitic pores [99] or increasing the membrane thickness by consecutive synthesis steps [3]. 
No significant difference was observed between the thicknesses of membranes synthesized as single layer [29] and as two layers from the SEM images, suggesting that permeances decreased because consecutive synthesis mainly blocked the non-zeolitic pores in the membrane layer.

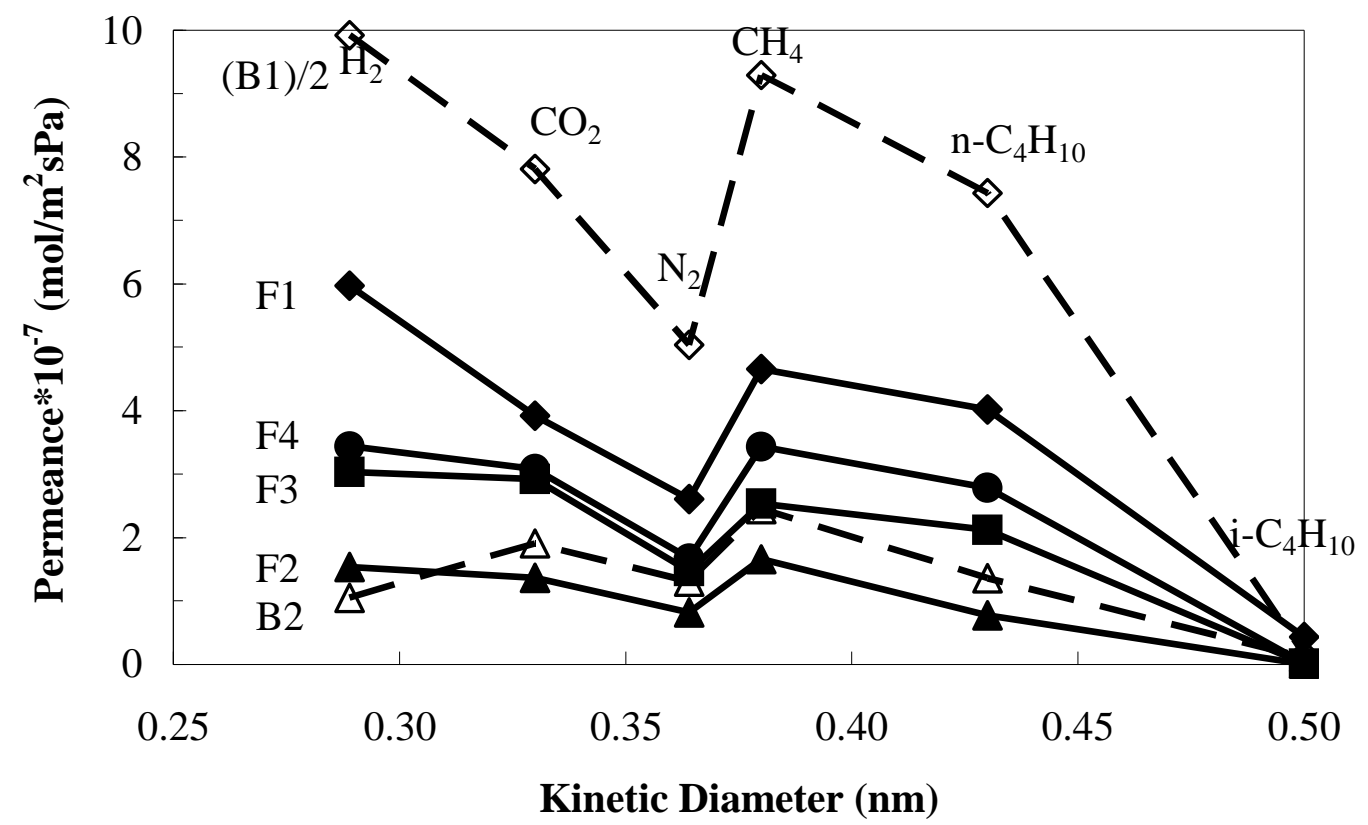

Figure 4.44 Single gas permeances at $200^{\circ} \mathrm{C}$ as a function of kinetic diameter

The $n-/ i-C_{4} \mathrm{H}_{10}$ ideal selectivities also increased with the consecutive synthesis. The n-/i- $\mathrm{C}_{4} \mathrm{H}_{10}$ ideal selectivities at $200^{\circ} \mathrm{C}$ for membranes $\mathrm{F} 2, \mathrm{~F} 3$ and $\mathrm{F} 4$ are 131, 180 and 139, respectively while 9 for membrane F1. The n-/i- $\mathrm{C}_{4} \mathrm{H}_{10}$ ideal selectivities for B1 and B2 membranes are about 50 and 12, respectively which are lower than those of flow system. The ideal selectivities for membranes F2, F3 and F4 were 13-18 times higher than the quality criteria proposed based on the permeation rates of $\mathrm{C}_{4} \mathrm{H}_{10}$ isomers through MFI membranes in the literature $[3,4,16,38]$. 
Figure 4.45 shows the $n-\mathrm{C}_{4} \mathrm{H}_{10}$ and $\mathrm{i}-\mathrm{C}_{4} \mathrm{H}_{10}$ permeances as pure component and in the mixture. $\mathrm{i}-\mathrm{C}_{4} \mathrm{H}_{10}$ permeates slower as a single gas or in a binary mixture. In mixture $n-C_{4} \mathrm{H}_{10}$ molecules blocked the membrane pores and hinder the passage of the $\mathrm{i}-\mathrm{C}_{4} \mathrm{H}_{10}$ molecules.

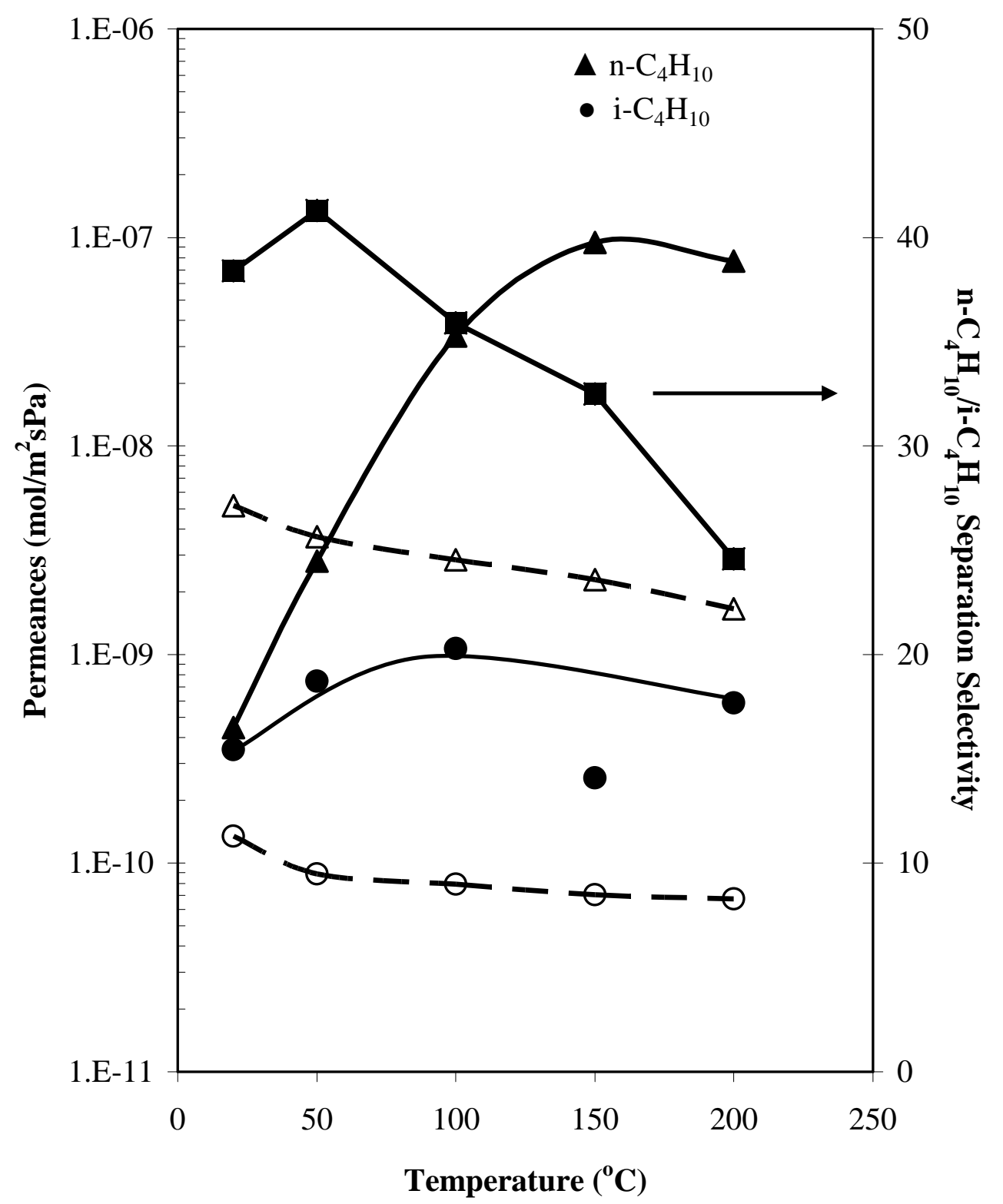

Figure 4.45 $n-\mathrm{C}_{4} \mathrm{H}_{10}$ permeances as pure component and in $50 \%-50 \%$ mixture and $n-\mathrm{C}_{4} \mathrm{H}_{10} / \mathrm{i}-\mathrm{C}_{4} \mathrm{H}_{10}$ separation selectivities as a function of temperature for 
F2 membrane. Solid lines: Single gas permeances, Dashed lines: Mixture permeances.

Since $n-\mathrm{C}_{4} \mathrm{H}_{10}$ and $\mathrm{i}-\mathrm{C}_{4} \mathrm{H}_{10}$ have similar heats of adsorption in MFI [100] i$\mathrm{C}_{4} \mathrm{H}_{10}$ permeance is less affected from the pore blockage of the $\mathrm{n}-\mathrm{C}_{4} \mathrm{H}_{10}$ molecules which gives the smaller $n-\mathrm{C}_{4} \mathrm{H}_{10} / \mathrm{i}-\mathrm{C}_{4} \mathrm{H}_{10}$ separation selectivities at all temperatures.

The single gas permeances and ideal selectivities of these gases may indicate good membrane quality, but ideal gas selectivities often do not correlate with separation selectivities [10, 16, 19]. Figure 4.46 shows the single gas permeances of $\mathrm{CH}_{4}, \mathrm{CO}_{2}, \mathrm{~N}_{2}$ and $\mathrm{n}-\mathrm{C}_{4} \mathrm{H}_{10}$ and the permeances of each component in a 50\%-50\% binary mixture. As expected the $\mathrm{CO}_{2}, \mathrm{CH}_{4}$ and $\mathrm{N}_{2}$ permeances decreased continuously, though $n-\mathrm{C}_{4} \mathrm{H}_{10}$ permeances exhibited a maximum with increasing temperature $[15,98,70,101]$. With increasing temperature, diffusivity increases but coverage decreases, therefore a maximum in permeances is observed during the permeation of strongly adsorbed $n-C_{4} H_{10}$. This maximum is likely to be observed at much lower temperatures for weakly adsorbed species like $\mathrm{CH}_{4}, \mathrm{CO}_{2}$ and $\mathrm{N}_{2}[15,70,25]$. Therefore a continuous decrease was observed in the permeances of these species through membrane F2 in the temperature range studied $[9,101]$.

In the temperature range studied $\mathrm{CH}_{4}, \mathrm{CO}_{2}$ and $\mathrm{N}_{2}$ permeances in the presence of $\mathrm{n}-\mathrm{C}_{4} \mathrm{H}_{10}$ were smaller than the corresponding single gas permeances. The lower permeances were due to the inhibition by $n-C_{4} H_{10}$, which is adsorbed more strongly than $\mathrm{CH}_{4}, \mathrm{CO}_{2}$ and $\mathrm{N}_{2}$ on MFI crystals $[19,25,98,100]$. The inhibition was more effective at low temperatures so that the mixture permeances of $\mathrm{CH}_{4}, \mathrm{CO}_{2}$ and $\mathrm{N}_{2}$ are about three orders of magnitude smaller than the single gas permeances. For instance, the single gas and mixture $\mathrm{N}_{2}$ permeances are $1.26 \times 10^{-7} \mathrm{~mol} / \mathrm{m}^{2} \mathrm{sPa}$ and $5.11 \times 10^{-11} \mathrm{~mol} / \mathrm{m}^{2} \mathrm{sPa}$ at $25^{\circ} \mathrm{C}$, respectively. As the temperature increased, the single gas and mixture permeances approached each other because the coverage of $n-C_{4} H_{10}$ decreases and it allows the passage of other gases $[10,16,19]$. On the other hand the n- 
$\mathrm{C}_{4} \mathrm{H}_{10}$ permeances were not significantly affected by the presence of the other molecules $[3,10,16]$.

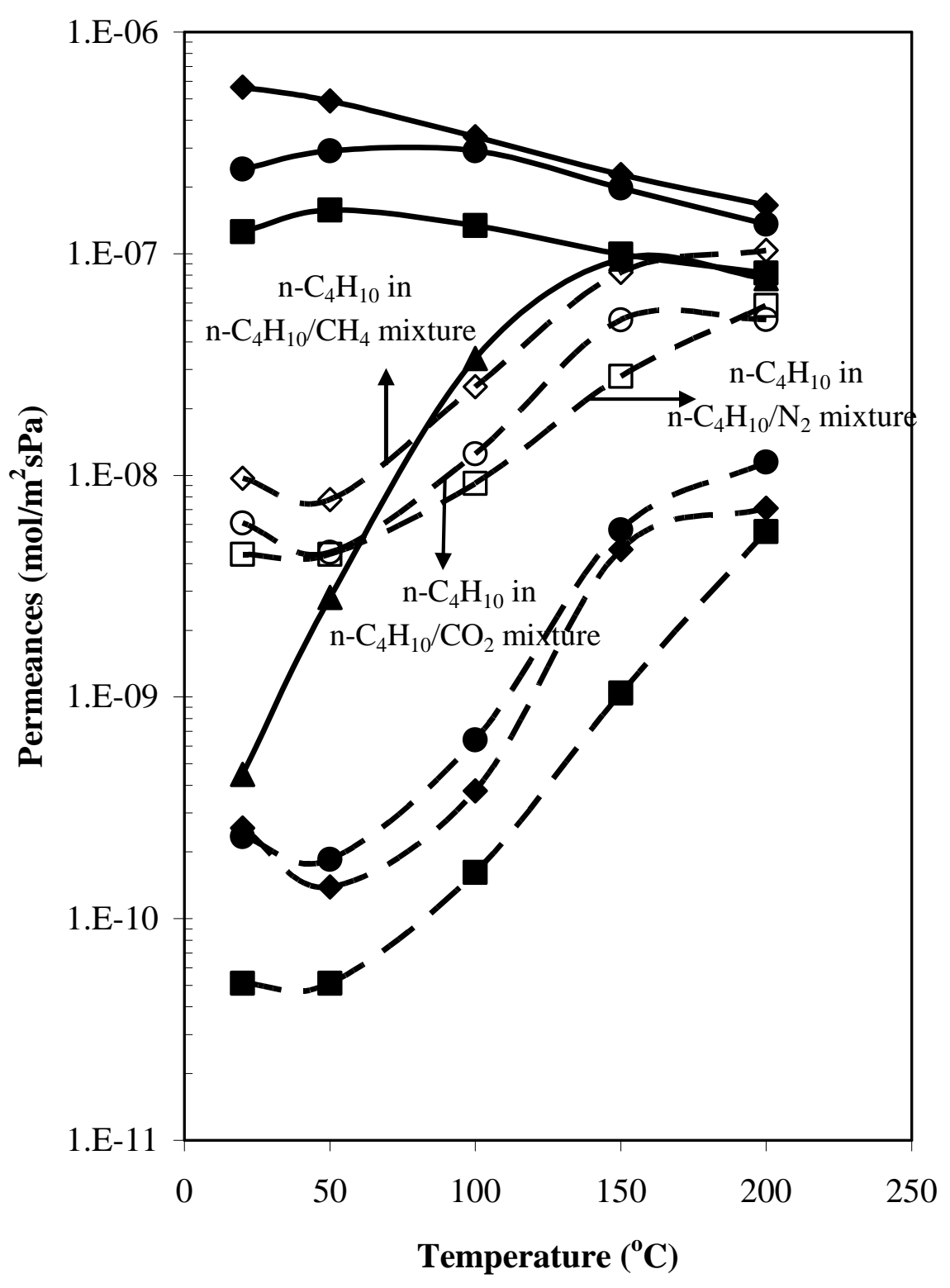

Figure 4.46 $\mathrm{N}_{2}, \mathrm{CO}_{2}, \mathrm{CH}_{4}$ and $\mathrm{n}-\mathrm{C}_{4} \mathrm{H}_{10}$ permeances through membrane $\mathrm{F} 2$ as single gas and in $50 \%-50 \%$ binary mixtures as a function of temperature (a: $\mathrm{N}_{2} ; \bullet: \mathrm{CO}_{2} ; \bullet: \mathrm{CH}_{4} ; \boldsymbol{\Lambda}: \mathrm{n}-\mathrm{C}_{4} \mathrm{H}_{10}$ ). Solid lines show single gas permeances, and dashed lines show the permeances in the mixtures 
Figure 4.47 shows separation selectivities in equimolar binary mixtures and the ideal selectivities of the membrane F2 as a function of temperature. Over the entire temperature range studied, the separation factors were greater than the ideal selectivities. The $n-\mathrm{C}_{4} \mathrm{H}_{10}$ over $\mathrm{N}_{2}, \mathrm{CO}_{2}$ and $\mathrm{CH}_{4}$ separation selectivities are 86, 26 and 38 at room temperature whereas the ideal selectivities of those gas pairs are significantly lower than one. A similar trend was also observed by other researchers $[3,10,16]$, who attributed this behavior to the preferential adsorption of $n-\mathrm{C}_{4} \mathrm{H}_{10}$ and to the prohibiting of other gases from the zeolite pores. The separation factors and ideal selectivities, however, approach to each other with increasing temperature $[3,10,16,102]$. In the case of $\mathrm{i}-\mathrm{C}_{4} \mathrm{H}_{10} / \mathrm{CH}_{4}$ and $\mathrm{i}-\mathrm{C}_{4} \mathrm{H}_{10} / \mathrm{N}_{2}$ mixtures, no separation selectivity was observed, which were about 3.0 and 1.0 at all temperatures, respectively. The coverage of $\mathrm{i}-\mathrm{C}_{4} \mathrm{H}_{10}$ is lower than that of $n-\mathrm{C}_{4} \mathrm{H}_{10}$ in MFI type crystals though both have similar adsorption strength [103]. Therefore $\mathrm{i}-\mathrm{C}_{4} \mathrm{H}_{10}$ may not block the MFI pores as effective as $n-C_{4} \mathrm{H}_{10}[40,98]$ so that lower separation factors can be obtained in the presence of $\mathrm{i}-\mathrm{C}_{4} \mathrm{H}_{10}$. The ideal selectivities for permanent gases over i$\mathrm{C}_{4} \mathrm{H}_{10}$ were significantly greater than one and almost independent of temperature.

Figure 4.48 shows the effect of $n-C_{4} H_{10}$ concentration in the feed on the n$\mathrm{C}_{4} \mathrm{H}_{10} / \mathrm{CH}_{4}$ separation selectivity. The $\mathrm{n}-\mathrm{C}_{4} \mathrm{H}_{10} / \mathrm{CH}_{4}$ separation selectivities were 22,47 and 67 for $n-\mathrm{C}_{4} \mathrm{H}_{10}$ concentrations of $20 \%, 30 \%$ and $50 \%$ at $100^{\circ} \mathrm{C}$, respectively; indicating that $n-\mathrm{C}_{4} \mathrm{H}_{10}$ effectively blocked the $\mathrm{CH}_{4}$ even at low concentrations of $n-\mathrm{C}_{4} \mathrm{H}_{10}$ in the feed. The non-zeolitic pores much larger than the MFI pores in the membrane are likely to reduce the separation selectivity since $n-C_{4} \mathrm{H}_{10}$ cannot block these pores effectively [104-106], apparently no large non-zeolitic pores exist on the membrane prepared in the recirculating flow system. The size of small non-zeolitic pores may be reduced because of swelling of MFI crystals by $n-\mathrm{C}_{4} \mathrm{H}_{10}$ adsorption as proposed by Lee et al.[107] which may also contribute to the separation selectivity. 

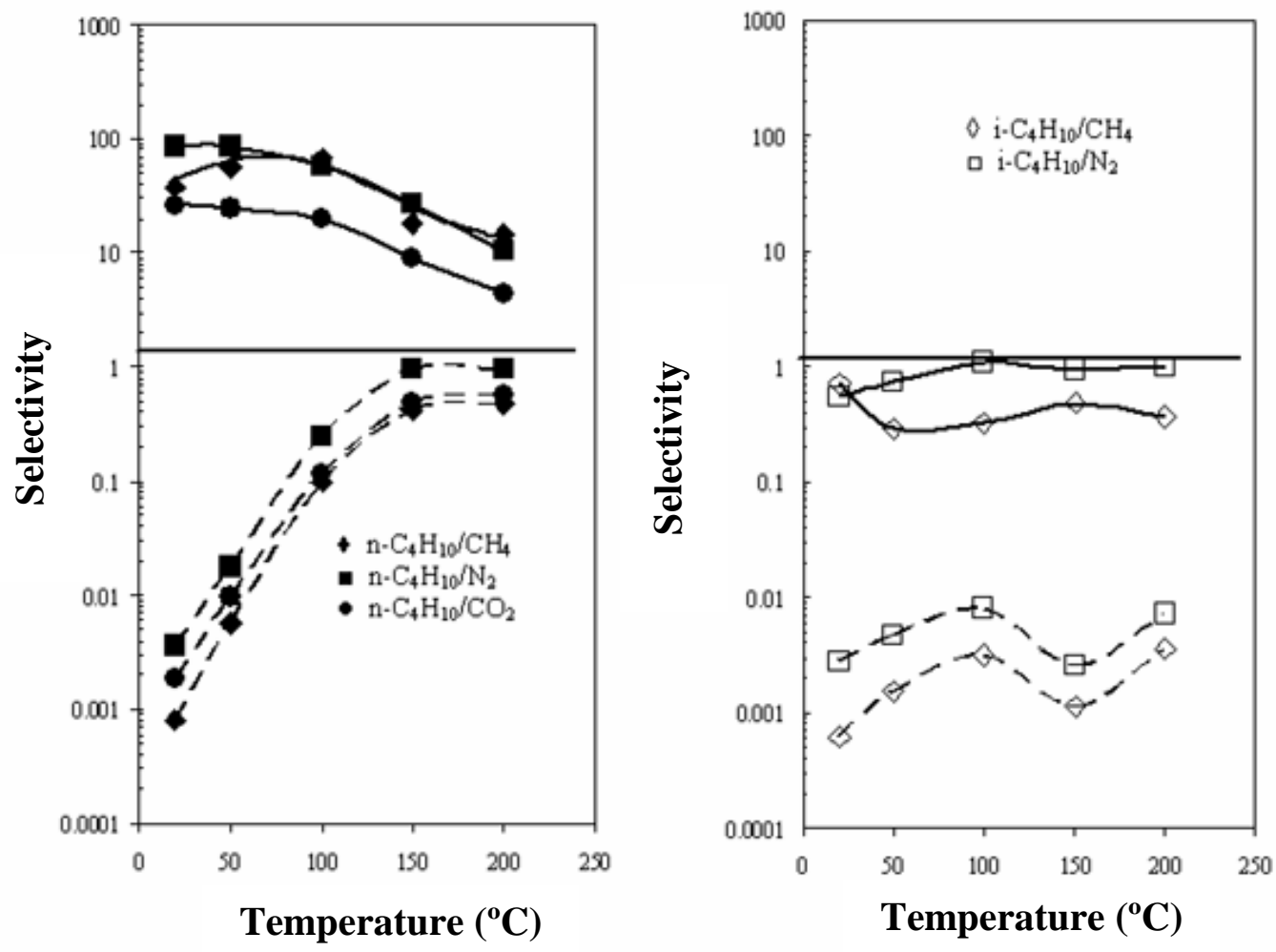

Figure 4.47 Ideal selectivities and separation for 50\%-50\% mixture as a function of temperature for $\mathrm{F} 2$ membrane (a) $n-\mathrm{C}_{4} \mathrm{H}_{10}$ over $\mathrm{CH}_{4}, \mathrm{CO}_{2}$ and $\mathrm{N}_{2}$ and (b) i- $\mathrm{C}_{4} \mathrm{H}_{10}$ over $\mathrm{CH}_{4}$ and $\mathrm{N}_{2}$. Solid lines: Separation selectivities, Dashed lines: Ideal selectivities 


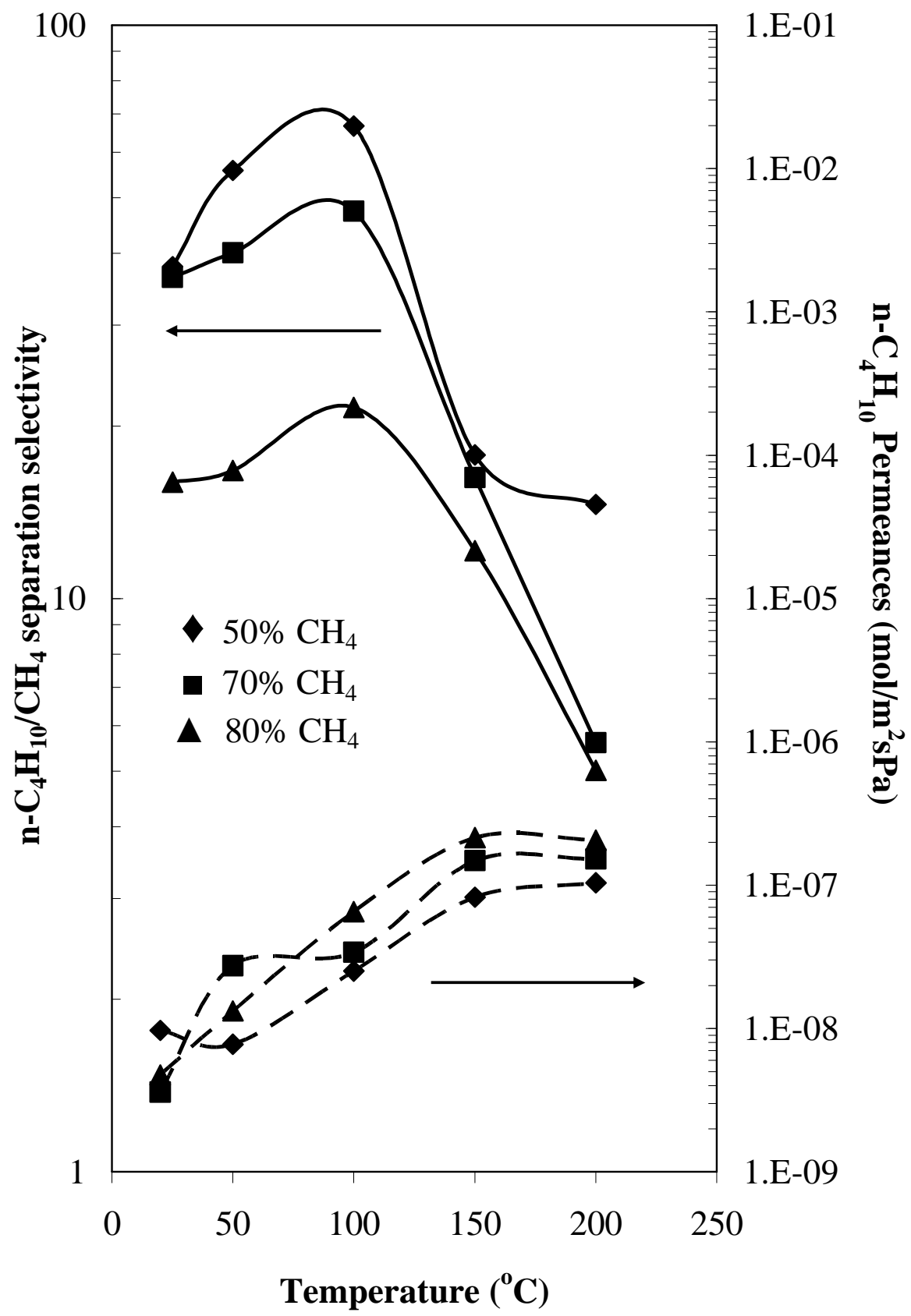

Figure 4.48 Effect of $n-\mathrm{C}_{4} \mathrm{H}_{10}$ concentration in the feed on the $n-\mathrm{C}_{4} \mathrm{H}_{10} / \mathrm{CH}_{4}$ separation selectivities and $\mathrm{C}_{4} \mathrm{H}_{10}$ permeance as a function of temperature 


\subsubsection{Separation of ternary gas mixtures with a good quality membrane}

In this work, MFI membranes prepared in a flow system were also used for the separation of ternary gas mixture at different temperatures and pressures. A gas mixture with a molar composition of $70 \% \mathrm{CH}_{4}, 20 \% \mathrm{CO}_{2}$ and $10 \% \mathrm{n}-\mathrm{C}_{4} \mathrm{H}_{10}$ was used as feed.

Table 4.14 shows the $n-\mathrm{C}_{4} \mathrm{H}_{10}$ and $\mathrm{CH}_{4}$ permeances and $\mathrm{n}-\mathrm{C}_{4} \mathrm{H}_{10} / \mathrm{CH}_{4}$, n$\mathrm{C}_{4} \mathrm{H}_{10} / \mathrm{CO}_{2}$ separation selectivities of the membrane $\mathrm{F} 2$. As in the case of binary gas mixtures, membrane is selective to $n-\mathrm{C}_{4} \mathrm{H}_{10}$ over $\mathrm{CH}_{4}$ and $\mathrm{CO}_{2}$.

Table 4.14 The permeances and $n-\mathrm{C}_{4} \mathrm{H}_{10}, \mathrm{CH}_{4}$ permeate compositions for the ternary gas mixture separation at 1.9 bar feed pressure (Mixture composition: $\mathrm{CH}_{4}: 70 \% ; \mathrm{CO}_{2}: 20 \% ; \mathrm{n}-\mathrm{C}_{4} \mathrm{H}_{10} 10 \%$ )

\begin{tabular}{cccccc}
\hline \multirow{2}{*}{$\begin{array}{c}\text { Temperature } \\
\left({ }^{\circ} \mathrm{C}\right)\end{array}$} & \multicolumn{2}{c}{ Mixture permeance* $10^{+7}\left(\mathrm{~mol} / \mathrm{m}^{2} \mathrm{sPa}\right)$} & \multicolumn{2}{c}{ Separation selectivity } \\
\cline { 2 - 6 } & $\mathrm{n}-\mathrm{C}_{4} \mathrm{H}_{10}$ & $\mathrm{CH}_{4}$ & $\mathrm{CO}_{2}$ & $\mathrm{n}-\mathrm{C}_{4} \mathrm{H}_{10} / \mathrm{CH}_{4}$ & $\mathrm{n}-\mathrm{C}_{4} \mathrm{H}_{10} / \mathrm{CO}_{2}$ \\
\hline 20 & 0.21 & 0.006 & 0.011 & 34.4 & 19.4 \\
100 & 1.36 & 0.051 & 0.088 & 26.9 & 15.5 \\
200 & 2.08 & 0.643 & 0.647 & 3.2 & 3.2 \\
\hline
\end{tabular}

Competitive adsorption and blockage of zeolite channels are the governing mechanisms in permeation. Thus $n-\mathrm{C}_{4} \mathrm{H}_{10}$ permeates faster than $\mathrm{CH}_{4}$ and $\mathrm{CO}_{2}$ in the mixtures. The $n-\mathrm{C}_{4} \mathrm{H}_{10} / \mathrm{CH}_{4}$ selectivity decreases from about 34 to 27 and then to 3 with increasing temperature from room temperature to $100^{\circ} \mathrm{C}$, and finally to $200^{\circ} \mathrm{C}$. A similar trend was also observed for $\mathrm{CO}_{2}$. As temperature increases, the surface coverage of $n-C_{4} \mathrm{H}_{10}$ and thus its permeances decreases. In addition the blocking effect of $n-\mathrm{C}_{4} \mathrm{H}_{10}$ decreases at elevated temperatures so that the mobility of $\mathrm{CH}_{4}$ and $\mathrm{CO}_{2}$ increases. As a result, the separation selectivities decrease with increasing temperature. 


\section{CHAPTER 5}

\section{CONCLUSIONS}

In the first part of this study the effect of soda concentration on the membrane morphology and crystal orientation was investigated. Membranes and films were synthesized over porous $\alpha-\mathrm{Al}_{2} \mathrm{O}_{3}$ supports and nonporous glass supports. The following conclusions were drawn from this part:

- Thin layers of oriented MFI zeolites were successfully synthesized on seeded macroporous $\alpha-\mathrm{Al}_{2} \mathrm{O}_{3}$ discs.

- Seeding of the support contributes the orientation of crystals forming the membrane layer.

- At low soda concentrations the membranes were (h0h)/c-oriented, at high soda concentrations membrane layer formed from randomly oriented crystals.

- The degree of preferred orientation passes through a maximum with increasing soda content.

- At 1 mole $\mathrm{Na}_{2} \mathrm{O} /$ mole batch content (h0h)/c-oriented and randomly oriented films were observed on alumina and glass supports, respectively, where amorphous phase was obtained in the bulk. The presence of a surface plays crucial role in the crystal growth and film formation process. Different surfaces strongly affect the crystal morphology.

- The membranes showed high $\mathrm{H}_{2} / \mathrm{n}-\mathrm{C}_{4} \mathrm{H}_{10}$ and $\mathrm{CH}_{4} / \mathrm{n}-\mathrm{C}_{4} \mathrm{H}_{10}$ ideal selectivities indicating the preparation of good quality membranes.

In the second part our objective was to investigate the effects of template and hydroxyl ion concentration on the crystallization rate and crystal size of the 
MFI powders and membranes. The following conclusions were drawn from this part:

- All samples that can be recovered from the synthesis solution with different compositions were pure and highly crystalline MFI. Thin and continuous membranes were observed from all compositions.

- The nucleation time decreases and crystallization is completed earlier as the template amount is increased in batch composition for both systems containing $\mathrm{TPAOH}$ or $\mathrm{TPABr}$ at different synthesis temperatures.

- The silica conversion passes through a maximum with TPAOH concentration in agreement with the literature.

- As template amount increases the particle size decreases in both the powder and membrane synthesis.

In the third part, the composition of the synthesis solution was changed by adding silica to the synthesis solution during the course of crystallization so that the silica/TPAOH ratio of the solution was increased. The following conclusions were drawn from this part:

- All membranes and remaining powders synthesized with mid synthesis addition of silica have MFI type crystals as well as those synthesized with constant composition.

- Mid synthesis addition of silica allows the crystal growth on existing crystals without the formation of new crystals.

- Silica addition during the synthesis increased the membrane quality significantly. Apparently thin and continuous membranes that have high potential in the separation of gas mixtures can be prepared by changing the composition during the synthesis. 
- Among the membranes the ones synthesized with mid synthesis addition of silica at $24 \mathrm{~h}$ gave reproducibly higher $n-\mathrm{C}_{4} \mathrm{H}_{10} / \mathrm{CH}_{4}$ and n$\mathrm{C}_{4} \mathrm{H}_{10} / \mathrm{N}_{2}$ separation selectivities at $25^{\circ} \mathrm{C}$.

- Membrane quality can be increased by composition change during synthesis. The time at which the silica is introduced to the synthesis medium is critical for the membrane quality.

In the last part of the study the main purpose was to separate binary and ternary gas mixtures. Tubular membranes were synthesized in a recirculating flow system and used in the separation of equimolal binary mixtures of $n-\mathrm{C}_{4} \mathrm{H}_{10} / \mathrm{i}$ $\mathrm{C}_{4} \mathrm{H}_{10}, \mathrm{n}-\mathrm{C}_{4} \mathrm{H}_{10} / \mathrm{CH}_{4}, \mathrm{n}-\mathrm{C}_{4} \mathrm{H}_{10} / \mathrm{CO}_{2}, \mathrm{n}-\mathrm{C}_{4} \mathrm{H}_{10} / \mathrm{N}_{2}$ and ternary mixture of $\mathrm{CO}_{2}$, $\mathrm{CH}_{4}$ and $\mathrm{n}-\mathrm{C}_{4} \mathrm{H}_{10}$ between 25 and $200^{\circ} \mathrm{C}$. The following conclusions were drawn from this part:

- Thin membranes were synthesized in a flow system where the synthesis solution was recirculated through the membrane support.

- Membranes prepared with two consecutive syntheses had lower permeances but higher $\mathrm{n}-\mathrm{i}-\mathrm{C}_{4} \mathrm{H}_{10}$ ideal selectivities than the membranes synthesized with a single synthesis step.

- Membranes showed reasonable separation performances in both binay and ternary gas separation. They were able to separate $n-\mathrm{C}_{4} \mathrm{H}_{10}$ from $\mathrm{CH}_{4}$ even at low $\mathrm{n}-\mathrm{C}_{4} \mathrm{H}_{10}$ concentrations in the feed. The separation is based on competitive adsorption between permeating molecules. 


\section{CHAPTER 6}

\section{RECOMMENDATIONS}

In this study MFI type membranes were synthesized and characterized. The main aim was to investigate the effects of some synthesis parameters on membrane morphology and quality and also to use the good quality membranes in gas mixture separations.

In addition to what has been done in this study, suggestions on further work to be done are as follows:

- It was observed that support surface plays crucial role for the crystal growth, crystal orientation and film formation process in synthesis at different soda concentrations. Synthesis should be done on different support surfaces other than glass and alumina. Metal surfaces should be used to prevent any leaching from the support which alter the local synthesis chemistry on the surface.

- Mid synthesis addition of silica should be applied to glass support. It would be simpler to monitor the crystal morphology and crystal growth on the glass surfaces.

- Mid synthesis addition of nutrient should be applied to other types of zeolite membrane synthesis. In that case according to the growth limiting nutrient sodium or aluminium can be added to the synthesis medium during the course of the crystallization. 
- Since the synthesis conditions in the flow system are settled well now, flow system synthesis should be applied to different support geometries, such as multi channel tubes or monoliths.

- Separation of ternary gas mixtures with different gas compositions and at different feed pressures should be performed with tubular membranes. 


\section{REFERENCES}

[1] Sirkar, K.K., "Membrane separation technologies: Current developments", Chem. Eng. Comm., 157 (1997) 145.

[2] Singh, R., "Industrial membrane separation processes", Chem. Tech, 27 (1998) 33.

[3] Vroon, Z.A.E.P., Keizer, K., Burggraaf, A.J., Verweij, H., "Preparation and characterization of thin zeolite MFI membranes on porous supports", J. Membr. Sci., 144 (1998) 65.

[4] Xomeritakis, G., Nair, S., Tsapatsis, M., "Transport properties of alumina supported MFI membranes made by secondary (seeded) growth", Micropor. Mesopor. Mat., 38 (2000) 61.

[5] Jareman, F., Hedlund, J., "Single gas permeance ratios in MFI membranes: Effects of material properties and experimental conditions", Micropor. Mesopor. Mat., 82 (2005) 201.

[6] Dong, W. Y., Long, Y. C., "Preparation and characterization of preferentially oriented continuous MFI-type zeolite membranes from porous glass", Micropor. Mesopor. Mat., 76 (2004) 9.

[7] Coronas, J., Noble, R. D., Falconer, J. L., "Separations of $\mathrm{C}_{4}$ and $\mathrm{C}_{6}$ isomers in ZSM-5 tubular membranes", Ind. Eng. Chem. Res., 37 (1998) 166. 
[8] Flanigen, E. M., Bennet, J. M., Grose, R. W., Cohen, J. P., Patton, R. L., Kichner, R. M., Smith, J. V., "Silicalite, a new hydrophobic crystalline silica molecular sieve", Nature, 271 (1978) 512.

[9] Poshusta, J.C., Noble, R.D., Falconer, J.L., "Temperature and pressure effects on $\mathrm{CO}_{2}$ and $\mathrm{CH}_{4}$ permeation through MFI zeolite membranes", J. Membr. Sci., 160 (1999) 115.

[10] Arruebo, M., Coronas, J., Menendez, M., Santamaria, J., "Separation of hydrocarbons from natural gas using silicalite membranes", Sep. Purif. Technol., 25 (2001) 275.

[11] Wee, S. L., Tye, C.T., Bhatia, S., "Membrane separation processPervaporation through zeolite membrane", Sep. Purif. Technol., 63 (2008) 500.

[12] Funke, H.H., Kovalchick, M.G., Falconer, J.L., Noble, R.D., “Separation of hydrocarbon vapors with silicalite zeolite membranes", Ind. Eng. Chem. Res., 35 (1996) 1575.

[13] Lassinantti, M., Jareman, F., Hedlund, J., Creaser, D., and Sterte, J., "Preparation and evaluation of thin ZSM-5 membranes synthesized in the absence of organic template molecules", Catal. Today, 67 (2001) 109.

[14] Hedlund, J., Sterte, J., Anthonis, M., Bons, A., Crastensen, B., Corcorand, N., Cox, D., Deckman, H., Gijnst, W. D., Moor, P., Lai, F., Mchenry, J., Mortier, W., Reinoso, J., and Peters, J., "High-flux MFI membranes", Micropor. Mesopor. Mat., 52 (2002) 179.

[15] Burggraff, A.J., Vroon, Z.A.E.P., Keizer, K., Verweij, H., "Permeation of single gases in thin zeolite MFI membranes" , J. Membr. Sci., 144 (1998) 77. 
[16] Van de Graaf, J. M., Van der Bijl, E., Stol, A., Kapteijn, F., Moulijn, J. A., "Effect of operating conditions and membrane quality on the separation performance of composite silicalite-1 membranes", Ind. Eng. Chem. Res., 37 (1998) 4071.

[17] Xomeritakis, G., Gouzinis, A., Nair, S., Tsapatsis, M.., "Growth, microstructure, and permeation properties of supported zeolite (MFI) films and membranes prepared by secondary growth", Chem. Eng. Sci., 54 (1999) 3521.

[18] Kalipçilar, H. , Çulfaz, A., "Role of the water content of clear synthesis solutions on the thickness of silicalite layers grown on porous $\alpha$-alumina supports”, Micropor. Mesopor. Mat., 52 (2002) 39.

[19] Caro, J., Noack, M., Kölsch, P., Schafer, R., “ Zeolite membranes - state of their development and perspective", Micropor. Mesopor. Mat., 38 (2000) 3 .

[20] Lai, R., Gavalas, G.R., "Surface seeding in ZSM-5 membrane preparation”, Ind. Eng. Chem. Res., 37 (1998) 4275.

[21] Nakazawa, T., Sadakata, M., Okuba, T., "Early stages of MFI film formation”, Micropor. Mesopor. Mat., 21 (1998) 325.

[22] Gora, L., Nishiyama, N., Jansen, J. C., Kapteijn, F., Teplyakov, V., Maschmeyer, Th., "Highly reproducible high-flux silicalite-1 membrances: Optimization of silicalite-1 membrane preparation", Sep. Purif. Technol. 22 (2001) 223.

[23] Kalıpçılar, H., and Çulfaz, A., "Synthesis of submicron silicalite-1 crystals from clear solutions", Cryst. Res. Technol. 35, 2000, 933. 
[24] Yang, S., Navrotsky, A., Wesolowski, D. J., Pople, A. J., "Study on Synthesis of TPA-Silicalite-1 from Initially Clear Solutions of Various Base Concentrations by in Situ Calorimetry, Potentiometry, and SAXS", Chem. Mater. 16 (2004) 210.

[25] Coronas, J., Santamaria, J., “Separations using zeolite membranes”, Sep. Purif. Methods 28 (2) (1999) 127.

[26] Noack, M., Kölsch, P., Schafer, R., Toussaint, P., Caro, J., "Molecular sieve membranes for industrial application: Problems, progress, solutions", Chem. Eng. Technol. 25 (3) (2002) 221.

[27] Pina, M.P., Arruebo, M., Felipe, M., Fleta, F., Bernal, M.P., Coronas, J., M. Menéndez, Santamaría, J., "A semi-continuous method for the synthesis of NaA zeolite membranes on tubular supports", J. Membr. Sci., 244 (2004) 141.

[28] Richter, H., Voigt, I., Fischer, G., Puhlfürß, "Preparation of zeolite membranes on the inner surface of ceramic tubes and capillaries", Sep. Purif. Technol., 32 (2003) 133.

[29] Çulfaz, P. Z., Çulfaz, A., and Kalıpçllar, H., "Preparation of MFI type zeolite membranes in a flow system with circulation of the synthesis solution”, Micropor. Mesopor. Mat., 92 (2006) 134.

[30] Wong, W., Au, L., Ariso, C., Yeung, K., "Effects of synthesis parameters on the zeolite membrane growth, J. Membr. Sci., 191 (2001) 143.

[31] Wong, W.C., Au, L.T.Y., Lau, P.S., Ariso, C.T., Yeung, K.L., “ Effects of synthesis parameters on the zeolite membrane morphology, J. Membr. Sci., 193 (2001) 141-161. 
[32] Szostak, R., "Handbook of Molecular Sieves", Van Nostrand Reinhold, New York, 1992.

[33] Breck, D.W., "Zeolite Molecular Sieves Structure, Chemistry, and Use”, John Wiley and Sons, New York, 1974.

[34] Mulder, M., "Basic Principles of of Membrane Technology", Kluver Academic Publishers, London, 1997.

[35] Noack, M., Kolsch, P., Coro, J., Schneider, M., Toussaint, P., Sieber, I. "MFI membranes of different $\mathrm{Si} / \mathrm{Al}$ ratios for pervaporation and steam permeation”, Micropor. Mesopor. Mat., 35 (2000) 253.

[36] Hedlund, J., Mintova, S., Sterte, J., "Controlling the preferred orientation in silicalite-1 films synthesized by seeding", Micropor. Mesopor. Mat., 28 (1999) 183.

[37] Vroon, Z.A.E.P., Keizer, K., Gilde, M.J., Burggraaf, A.J., "Transport properties of alkanes through ceramic thin zeolite MFI membranes", J. Membr. Sci., 113 (1996) 293.

[38] Lovallo, M.C., Gouzinis, A., Tsapatsis, M., "Synthesis and characterization of oriented MFI membranes prepared by secondary growth”, AlChE J., 44 (1998) 1903.

[39] Piera, E., Brenninkmeijer, A.M.C., Santamaria, J., Coronas, J., "Seperation of traces of CO from air using MFI type zeolite membranes", J. Membr. Sci., 201 (2002) 229.

[40] Coronas, J., Falconer, J.L., Noble, R.D., "Characterization and permeation properties of ZSM-5 tubular membranes”, AlChe J., 43 (1997) 1797. 
[41] Van de Graaf, J. M., Kapteijn, F., Moulijn, J. A., "Methodological and operational aspects of permeation measurements on silicalite-1 membranes", J. Membr. Sci., 144 (1998) 87.

[42] Caro, J., Noack, M., Kölsch, P., “Zeolite Membanes: From the Labaratory scale to technical applications", Adsorption, 11 (2005) 215.

[43] Zhang, X., Liu, H., Yeung, K., "Influence of seed size on the formation and microstructure of zeolite silicalite-1 membranes by seeded growth", Mat. Chem. and Phys., 96 (2006) 42.

[44] Yan Y., M. E. Davis, G. R. Gavalas, "Use of diffusion barriers in the preparation of supported zeolite ZSM-5 membranes”, J. Membr. Sci., 126 (1) (1997) 53.

[45] Piera, E., Giroir-Fendler, A., Alain Dalmon, J., Moueddeb, H., Coronas, J., Menendez, M., Santamaria, J., "Separation of alcohols and alcohols/O2 mixtures using zeolite MFI membranes”, J. Membr. Sci., 142 (1998) 97.

[46] Ravishankar, R., Kirschhock, C.E.A., Knops-Gerrits, P.-P., Feijen, E.J.P., Grobet, P.J., Vanoppen, P., De Schryver, F.C., Martens, J.A. "Characterization of nanosized material extracted from clear suspensions for MFI zeolite synthesis”, J. Phys. Chem. B-103 (1999) 4960.

[47] Schoeman, B.J., Sterte, J., Otterstedt, J.-E. B. J. Schoeman, J. Sterte, and J. E. Otterstedt., "Analysis of the crystal growth mechanism of TPAsilicalite-1", Zeolites 14 (1994) 568.

[48] Choi, J., Ghosh, S., King, L., Tsapatsis, M., "MFI zeolite membranes from a- and oriented monolayers", Adsorption, 12 (2006) 339. 
[49] Caro, J., Noack, M., "Zeolite membranes - Recent developments and progress", Micropor. Mesopor. Mat., 115 (2008) 215.

[50] Li, Y., Wang, J., Shi, J., Zhang, X., Lu, J., Bao, Z., Yan, D., "Synthesis of ZSM-5 zeolite membranes with large area on porous, tubular alphaalumina supports", Sep. Pur. Technol., 32 (2003) 397.

[51] Bernal, M.P., Xomeritakis, G., Tsapatsis, M., "Tubular MFI zeolite membranes made by secondary (seeded) growth", Catalysis Today, 67, (2001) 101.

[52] Li, G., Kikuchi, E., Matsukata, M., "ZSM-5 zeolite membranes prepared from a clear template-free solution”, Micropor. Mesopor. Mat., 60, (2003) 225.

[53] Huang, A., Lin, Y.S., Yang, W., "Synthesis and properties of A-type zeolite membranes by secondary growth method with vacuum seeding", J. Membr. Sci., 245 (2004) 41.

[54] Dinçer, E., Çulfaz, A., Kalıpçılar, H., "Synthesis of ZSM-5 type zeolite membranes on porous disks loaded with different amounts of seed", Ind. Eng. Chem. Res.,47 (2008) 4743.

[55] Bonhomme, F.; Welk, M. E.; Nenoff, T. M., "CO2 Selectivity and Lifetimes of High Silica ZSM-5 Membranes", Micropor. Mesopor. Mat., 66, (2003) 181.

[56] Lin, X.; Kita, H.; Okamoto, K., "Silicalite Membrane Preparation, Characterization and Separation Performance", Ind. Eng. Chem. Res., 40 (2001) 4069. 
[57] Nair, S., Lai, Z., Xomeritakis, G., Tsapatsis, M., "Seperation of closeboiling hydrocarbon mixtures by MFI and FAU membranes made by secondary growth”, Micropor. Mesopor. Mat., 48, (2001) 219.

[58] Bernal, M. P., Coronas, J., Menendez, M., Santamaria, J., "On the effect of morphological features on the properties of MFI zeolite membranes", Micropor. Mesopor. Mat., 60, (2003) 99.

[59] Li, G., Kikuchi, E., Matsukata, M., "The control of phase and orientation in zeolite membranes by the secondary growth method", Micropor. Mesopor. Mat., 62 (2003) 211.

[60] Kim, S. D., Hoh, S. H., Kim, W. J., "Compositional and kinetic study on the rapid crystallization of ZSM-5 in the absence of organic template under stirring”, Micropor. Mesopor. Mat., 72 (2004) 1851.

[61] Kim, S. D., Hoh, S. H., Kim, W. J., "Organic-free synthesis of ZSM-5 with narrow crystal size distribution using two-step temperature process", Micropor. Mesopor. Mat., 92, (2006) 181.

[62] Wang, Z. and Yan, Y., "Controlling crystal orientation in zeolite MFI thin films by direct in-situ crystallization”, Chem. Mater., 13 (2001) 1101.

[63] Jansen, K., Maschmeyer, A., "Progress in zeolitic membranes", Topics in Catalysis, 9 (1999) 113.

[64] McLeary, E.E., Jansen, J. C., Kapteijn, F., Z., "Zeolite based films, membranes and membrane reactors: Progress and prospects", Micropor. Mesopor. Mat., 90 (2006) 198. 
[65] Lai, Z., Bonilla, G., Diaz, J. G., Nery, J. G., Sujaoti, K., Amat, M., Kokkoli, E., Terasaki, O., Thompson, R. W., Tsapatsis, M., Vlachos, D., "Microstructural optimization of a zeolite membrane for organic vapor separation", Science, 300 (2003) 456.

[66] Choi, J., Ghosh, S., Lai, Z., Tsapatsis, M., "Uniformly a-Oriented MFI Films by Secondary Growth”, Angew. Chem. Int. Ed., 45 (2006) 1154.

[67] Gouzinis, A., Tsapatsis, M., "On the preferred orientation and microstructural manipulation of molecular sieve films prepared by secondary growth”, Chem. Mater., 10 (1998) 2497.

[68] Hasegawa, Y., Ikeda, T., Nagase, Y., Kiyozumi, Y., Hanaoka, T., Mizukami, F., "Preparation and characterization of silicalite-1 membranes prepared by secondary growth of seeds with different crystal sizes”, J. Membr. Sci., 280 (2006) 397.

[69] Bakker, W. J. W.;F. Kapteijn, J. Poppe; Moulijn, J. A. "Permeation characteristics of a metal -supported silicalite-1 zeolite membrane", J. Membr. Sci., 117 (1996) 57.

[70] Bakker, W. J. W., Van den Brooke, J. L. P.; Moulijn, J. A., “Temperature Dependence of One-Component Permeation through a Silicalite- 1 Membrane”, AIChE J., 43 (1997) 2203.

[71] Funke, H.H., Frender K.R., Falconer J.L., Noble, R.D., "Influence of adsorbed molecules on the permeation properties of silicalite membranes", J. Membr. Sci., 129 (1997) 77.

[72] MacDougall, H., Ruthven, D.M., Brandani, S., "Sorption and diffusion of SF6 in silicalite crystals", Adsorption, 5 (1999) 369. 
[73] Nishiyema, N., Gora, L., Kapteijn, F., Moulijn, J. A., "Evaluation of reproducible high flux silicalite-1 membranes: gas permeation and separation characterization”, Sep. Purif. Technol., 22 (2001) 295.

[74] Van de Graaf, J. M., Kapteijn, F., Moulijn, J. A., "Permeation of weakly adsorbing components through a silicalite-1 membrane", Chem. Engineer. Sci., 54 (1999) 1081.

[75] Gopalakrishnan, S., Yamaguchi, T., Nakao, S., "Permeation properties of templated and template-free ZSM-5 membranes", J. Membr. Sci., 274 (2006) 102.

[76] Jareman, F., Hedlund,J.,Sterte, J., "Effects of aluminum content on the separation properties of MFI membranes", Sep. Purif. Technol., 32 (2003) 159.

[77] Dong, J., Lin, Y.S., Liu, W., ”Multicomponent Hydrogen/Hydrocarbon separation by MFI-type zeolite membranes”, AIChE J., 46 (2000) 1957.

[78] Chau, J. L. H., Tellez, C., Yeung K. L., Ho, K., "The role of surface chemistry in zeolite membrane formation", J. Membr. Sci., 164 (2000) 257.

[79] Engström, V., Mihailova, B., Hedlund, J., Sterte, J., "The effect of seed size on the growth of silicalite-1 films on gold surfaces", Micropor. Mesopor. Mat., 38 (2000) 51.

[80] Li, Q., Hedlund, J., Sterte, J., Creaser, D., Bons, A., "Synthesis and characterization of zoned MFI films by seeded growth", Micropor. Mesopor. Mat., 56, (2002) 291. 
[81] Bons, A., Bons, P.D., "The development of oblique preferred orientations in zeolite films and membranes”, Micropor. Mesopor. Mat., 62 (2003) 9.

[82] Lovallo, M. C., Tsapatsis, M., "Preferentially oriented submicron silicalite membranes", AIChE Journal, 42 (1996) 3020.

[83] Fegan, S. G. and Lowe, B. M., "Effcet of alkalinity on the crystallization of silicalite-1 precursors", J. Chem. Soc. 82 (1986) 785.

[84] Jareman, F., Hedlund, J., "Single gas permeance ratios in MFI membranes: Effects of material properties and experimental conditions", Micropor. Mesopor. Mat., 82, (2005) 201.

[85] Çulfaz, A. and Sand, L. B., "Mechanism of nucleation and crystallization of zeolites from gels", Adv. Chem. Ser. 121 (1973) 140.

[86] Çulfaz, A., Gündüz, U., and Orbey, H., "Crystallization kinetics of Silicalite-1: Use of tetrapropylammonium bromide and chloride as Templates", Cryst. Res. Technol. 28 (1993) 29.

[87] Lai, R., Yan, Y., and Gavalas, G. R., "Growth of ZSM-5 films on alumina and other surfaces", Micropor. Mesopor. Mat. 37 (2000) 9.

[88] Crea, F., Nastro, A., Nagy, J. B., and Aiello, R., "Synthesis of silicalite 1 from systems with different TPABr/SiO2 ratios", Zeolites 8 (1988) 262.

[89] Li, Q., Mihaliova, B., Creaser, D., and Sterte, J., “The nucleation period for crystallization of colloidal TPA-silicalite-1 with varying silica source", Micropor. and Mesopor. Mat., 40 (2000) 53. 
[90] Hedlund, J., and Jareman, F., "Texture of MFI films grown from seeds", Current Opinion in Colloidal and Interface Science, 10 (2005) 226.

[91] Li, Y., Zhang, X., and Wang, J., "Preparation for ZSM-5 membranes by a two-stage varying-temperature synthesis”, Sep. Purif. Technol., 25 (2001) 459.

[92] Davis, T., Drews, T., Ramanan, H., He, C., Dong, J., Penn, R. L., Tsapatsis, M., "Mechanistics principles of nanoparticle evolution to zeolite crystals", Nature materials, 5 (2006) 4000.

[93] Fedeyko J. M., J. D., Rimer, R. F. Lobo, D. G. Vlachos, “Spontaneous formation of silica nanoparticles in basic solutions of small tetraalkylammonium cations", J. Phys. Chem. B, 108 (2004) 12271.

[94] Kumar, S., Davis, T. M., Ramanan, H., Penn, R. L., Tsapatsis, M., “Aggregative growth of silica”, J. Phys. Chem. B, 111 (2007) 3398.

[95] Yan, Y., Davis, M. E., Gavalas, G. R., "Preparation of zeolite ZSM-5 membranes by in-situ crystallization on porous $\alpha$-A12O3”, Ind. Eng. Chem. Res., 34 (1995) 1652.

[96] Oonkhanond, B., Mullins, M. E., "The preparation and analysis of zeolite ZSM-5 membranes on porous alumina supports", J.Memb.Sci., 194 (2001) 3 .

[97] Aoki, K., Tuan, V., Falconer, J. L., Noble, R. D., “Gas permeation properties of ion-exchanged ZSM-5 zeolite membranes", Microp.Mesop. Mat., 39 (2000) 485. 
[98] Tuan, V., Falconer, J. L., Noble, R. D, "Isomorphous substitution of Al, Fe, B, and Ge into MFI-zeolite membranes”, Micropor. Mesopor. Mat. 41 (2000) 269.

[99] Weh, K., Noack, M., Sieber, I., Caro, J., "Permeation of single gases and gas mixtures through faujasite-type molecular sieve membranes", Micropor. Mesopor. Mat. 54 (2002) 27.

[100] Gardner, T. Q., Falconer, J. L., Noble, R. D., "Adsorption and differential heats of adsorption of normal and iso-butane on zeolite MFI”, Desalination 149 (2002) 435.

[101] Algieri C., Bernardo, P., Golemme, G., Barbieri, G., Drioli, E., "Permeation properties of a thin silicalite-1 (MFI) membrane", J. Membr. Sci, 222 (2003) 181.

[102] Geus, E. R., Bekkum, H., Bakker, W.J.W., Moulijn, J. A., "High temperature stainless steel supported zeolite (MFI) membranes: Preparation, module construction, and permeation experiments", Micropor. Mat. 1 (1993) 131.

[103] Ferriera, A. F., Hazeleger, M. C., Bliek, A., “Adsorption and differential heats of adsorption of normal and iso-butane on zeolite MFI", Micropor. Mesopor. Mat. 91 (2006) 47.

[104] Alshebani, A., Pera-Titus, M., Landrivon, E., Schiestel, T., Miachon, S., Dalmon, J. A., "Nanocomposite MFI - Ceramic hollow fibres: Prospects for $\mathrm{CO}_{2}$ separation”, Micropor. Mesopor. Mat. 115 (2008) 197 
[105] Miachon, S., Kumakiri, I., Ciavarella, P., Dyk, L., Fiaty, K., Schuurman, Y., Dalmon, J. A., "Nanocomposite MFI-alumina membranes via poreplugging synthesis: Specific transport and separation properties", J. Membr. Sci. 298 (2007) 71.

[106] Miachon, S., Landrivon, E., Aouine, M., Sun, Y., Kumakiri, I., Li, Y., Guilhaume, N., Giroir-Fendler, A., Mozzanega, H., Dalmon, J. A., "Nanocomposite MFI-alumina membranes via pore-plugging synthesis: Preparation and morphological characterisation", J. Membr. Sci., 281, (2006) 228.

[107] Lee, J. B., Funke, H., Noble, R. D., Falconer, J. L., "High selectivities in defective MFI membranes”, J. Membr. Sci., 321 (2008) 309. 


\section{APPENDIX A}

\section{SAMPLE CALCULATION OF SYNTHESIS RECIPE FROM A BATCH COMPOSITION}

A sample calculation for amounts of reagents to prepare $100 \mathrm{~g}$ synthesis solution for a molar batch composition of $25 \mathrm{SiO}_{2}: 6.9 \mathrm{TPABr}: 6.5 \mathrm{Na}_{2} \mathrm{O}$ : $1136 \mathrm{H}_{2} \mathrm{O}$ is given below. LUDOX AS-30 (Aldrich) as silica source, TPABr (TPABr powder, pure, Merck), $\mathrm{NaOH}$ pellets (97 wt $\% \mathrm{NaOH}, 2$ wt $\%$ water, Merck) as soda source and deionized water (DI water) were used.

Table A. 1 Molecular weights of reactants

\begin{tabular}{|c|c|}
\hline Reactant & Molecular Weight (g/gmole) \\
\hline $\mathrm{SiO}_{2}$ & 60.09 \\
\hline $\mathrm{TPABr}$ & 266.27 \\
\hline $\mathrm{NaOH}$ & 40.08 \\
\hline $\mathrm{Na}_{2} \mathrm{O}$ & 60.09 \\
\hline $\mathrm{H}_{2} \mathrm{O}$ & 18.016 \\
\hline
\end{tabular}

Molar composition of the batch: $6.5 \mathrm{Na}_{2} \mathrm{O}: 25 \mathrm{SiO}_{2}: 6.9 \mathrm{TPABr}: 1136 \mathrm{H}_{2} \mathrm{O}$

Formula weight of the batch:

$6.5 \times 61.99+25 \times 60.09+6.9 \times 266.27+1136 \times 18.016=24208.62 \mathrm{~g} / \mathrm{gmole}$

Silica source: Ludox AS-30

Template Source: $\mathrm{TPABr}\left(\mathrm{C}_{12} \mathrm{H}_{28} \mathrm{BrN}\right)$

Sodium source: $\mathrm{Na}_{2} \mathrm{O}$

$\mathrm{Na}_{2} \mathrm{O}+\mathrm{H}_{2} \mathrm{O} \rightarrow 2 \mathrm{NaOH}$ 
Basis: $100 \mathrm{~g}$ batch

Calculation of amounts of raw materials required to prepare the batch:

\section{- Amount of $\mathrm{NaOH}$ :}

$100 \mathrm{~g}$ batch $\times \frac{1 \mathrm{~mol} \mathrm{batch}}{24208.62 \mathrm{~g} \mathrm{batch}} \times \frac{6.5 \mathrm{~mol} \mathrm{Na}_{2} \mathrm{O}}{1 \mathrm{~mol} \mathrm{batch}} \times \frac{2 \mathrm{~mol} \mathrm{NaOH}}{1 \mathrm{~mol} \mathrm{Na}_{2} \mathrm{O}}$

$\times \frac{40.08 \mathrm{~g} \mathrm{NaOH}}{1 \mathrm{~mol} \mathrm{NaOH}}=2.15 \mathrm{~g} \mathrm{NaOH}$

\section{-Ludox AS-30:}

$100 \mathrm{~g}$ batch $\times \frac{1 \mathrm{~mol} \text { batch }}{24208.62 \mathrm{~g} \mathrm{batch}} \times \frac{25 \mathrm{~mol} \mathrm{SiO}_{2}}{1 \mathrm{~mol} \mathrm{batch}} \times \frac{60.09 \mathrm{~g} \mathrm{SiO}_{2}}{1 \mathrm{~mol} \mathrm{SiO}_{2}}$

$\times \frac{100 \text { g Ludox AS-30 }}{30 \mathrm{~g} \mathrm{SiO}_{2}}=20.68 \mathrm{~g}$ Ludox AS-30

-TPABr:

$100 \mathrm{~g}$ batch $\times \frac{1 \mathrm{~mol} \text { batch }}{24208.62 \mathrm{~g} \mathrm{batch}} \times \frac{6.9 \mathrm{~mol} \mathrm{TPABr}}{1 \mathrm{~mol} \mathrm{TPABr}} \times \frac{60.09 \mathrm{~g} \mathrm{SiO}_{2}}{1 \mathrm{~mol} \mathrm{SiO}_{2}}$

$=7.59 \mathrm{~g} \mathrm{TPABr}$

$-\mathrm{H}_{2} \mathrm{O}$ :

$100 \mathrm{~g}$ batch $x \frac{1 \mathrm{~mol} \text { batch }}{24208.62 \mathrm{~g} \text { batch }} \times \frac{1136 \mathrm{~mol} \mathrm{H}_{2} \mathrm{O}}{1 \mathrm{~mol} \mathrm{batch}} \times \frac{18.016 \mathrm{~g} \mathrm{H}_{2} \mathrm{O}}{1 \mathrm{~mol} \mathrm{H}_{2} \mathrm{O}}=84.54 \mathrm{~g} \mathrm{H}_{2} \mathrm{O}$ 
$100 \mathrm{~g}$ batch $\times \frac{1 \mathrm{~mol} \text { batch }}{24208.62 \mathrm{~g} \text { batch }} \times \frac{(1.088 \times 6.5 \times 18.016)}{1 \mathrm{~mol} \text { batch }}=0.53 \mathrm{~g} \mathrm{H}_{2} \mathrm{O}$ from $\mathrm{NaOH}$ $20.68 \mathrm{~g}$ Ludox AS-30 $\times \frac{70 \mathrm{~g} \mathrm{H}_{2} \mathrm{O}}{100 \mathrm{~g} \mathrm{Ludox} \text { AS-30 }}=14.48 \mathrm{~g} \mathrm{H}_{2} \mathrm{O}$ from Ludox AS-30 $\mathrm{m}_{\mathrm{H}_{2} \mathrm{O} \text {,needed }}=84.54 \mathrm{~g}-(0.53 \mathrm{~g}+14.48 \mathrm{~g})=69.53 \mathrm{~g} \mathrm{H}_{2} \mathrm{O}$

Amount of reagents were calculated as in Table A.2

Table A. 2 Amount of reagents for $100 \mathrm{~g}$ batch preparation

\begin{tabular}{|c|c|}
\hline Reactant & Amount (g) \\
\hline Ludox AS-30 & 20.68 \\
\hline TPABr & 7.59 \\
\hline $\mathrm{NaOH}$ & 2.15 \\
\hline $\mathrm{H}_{2} \mathrm{O}$ & 69.53 \\
\hline
\end{tabular}

Throughout this study different reactants were used as silica and template sources in the synthesis of zeolite powder and membranes: 30 or $40 \mathrm{wt} \%$ colloidal suspension of silica particles in water (LUDOX AS-30 or LUDOX AS-40, Aldrich) as silica sources, tetrapropylammonium hydroxide (TPAOH, 25 or $40 \mathrm{wt} \%$ in water, Merck) or tetrapropylammonium bromide ( $\mathrm{TPABr}$ powder, pure, Merck) as template sources, $\mathrm{NaOH}$ pellets (97 wt $\% \mathrm{NaOH}, 2$ $\mathrm{wt} \%$ water, Merck) as soda source and deionized water (DI water).

Amount of reagents used for the preparation of $100 \mathrm{~g}$ batch with all compositions used in this study are listed in Table A.3. 
Table A. 3 Amount of reagents calculated for $100 \mathrm{~g}$ batch for all compositions used in this study

\begin{tabular}{|c|c|c|c|c|c|c|c|c|c|}
\hline \multirow{2}{*}{$\begin{array}{c}\text { BATCH } \\
\text { COMPOSITION }\end{array}$} & \multicolumn{9}{|c|}{ REAGENTS } \\
\hline & $\begin{array}{l}\text { Ludox } \\
\text { AS-30 }\end{array}$ & \begin{tabular}{|l|} 
Ludox \\
AS-40
\end{tabular} & $\begin{array}{l}\mathrm{NaOH} \\
\text { pellets }\end{array}$ & $\begin{array}{l}\text { 1M NaOH } \\
\text { solution }\end{array}$ & $\begin{array}{l}\text { TPABr } \\
\text { powder }\end{array}$ & $\begin{array}{l}\text { 1M TPABr } \\
\text { solution }\end{array}$ & $\begin{array}{l}25 \% \mathrm{TPAOH} \\
\text { solution }\end{array}$ & $\begin{array}{c}40 \% \text { TPAOH } \\
\text { solution }\end{array}$ & $\begin{array}{c}\text { Deionized } \\
\text { water }\end{array}$ \\
\hline $\mathrm{S}_{25} \mathrm{~T}_{6.9} \mathrm{H}_{1136}$ & 21.035 & - & - & - & - & 28.985 & - & - & 49.981 \\
\hline $\mathrm{N}_{0.05} \mathrm{~S}_{25} \mathrm{~T}_{69} \mathrm{H}_{1136}$ & 21.032 & - & - & 0.419 & - & 28.981 & - & - & 49.572 \\
\hline $\mathrm{N}_{0.15} \mathrm{~S}_{25} \mathrm{~T}_{69} \mathrm{H}_{1136}$ & 21.027 & - & - & 1.260 & - & 28.973 & - & - & 48.751 \\
\hline $\mathrm{N}_{0.25} \mathrm{~S}_{25} \mathrm{~T}_{69} \mathrm{H}_{1136}$ & 21.021 & - & - & 2.098 & - & 28.966 & - & - & 48.028 \\
\hline $\mathrm{N}_{0.30} \mathrm{~S}_{25} \mathrm{~T}_{69} \mathrm{H}_{1136}$ & 21.019 & - & - & 2.517 & - & 28.962 & - & - & 47.525 \\
\hline $\mathrm{N}_{0.35} \mathrm{~S}_{25} \mathrm{~T}_{69} \mathrm{H}_{1136}$ & 21.016 & - & - & 2.937 & - & 28.958 & - & - & 47.116 \\
\hline $\mathrm{N}_{0.4} \mathrm{~S}_{25} \mathrm{~T}_{6.9} \mathrm{H}_{1136}$ & 21.013 & - & - & 3.358 & - & 28.954 & - & - & 46.705 \\
\hline $\mathrm{N}_{0.5} \mathrm{~S}_{25} \mathrm{~T}_{6.9} \mathrm{H}_{1136}$ & 21.008 & - & - & 4.194 & - & 28.946 & - & - & 45.890 \\
\hline $\mathrm{N}_{0.6} \mathrm{~S}_{25} \mathrm{~T}_{6.9} \mathrm{H}_{1136}$ & 21.002 & - & - & 5.032 & - & 28.939 & - & - & 45.072 \\
\hline $\mathrm{N}_{0.65} \mathrm{~S}_{25} \mathrm{~T}_{69} \mathrm{H}_{1136}$ & 20.999 & - & - & 5.452 & - & 28.936 & - & - & 44.663 \\
\hline
\end{tabular}


Table A.3.cont'd. Amount of reagents calculated for $100 \mathrm{~g}$ batch for all compositions used in this study

\begin{tabular}{|c|c|c|c|c|c|c|c|c|c|}
\hline \multirow{2}{*}{$\begin{array}{c}\text { BATCH } \\
\text { COMPOSITION }\end{array}$} & \multicolumn{9}{|c|}{ REAGENTS } \\
\hline & $\begin{array}{l}\text { Ludox } \\
\text { AS-30 }\end{array}$ & $\begin{array}{l}\text { Ludox } \\
\text { AS-40 }\end{array}$ & \begin{tabular}{|l|}
$\mathrm{NaOH}$ \\
pellets
\end{tabular} & $\begin{array}{l}1 \mathrm{M} \mathrm{NaOH} \\
\text { solution }\end{array}$ & $\begin{array}{l}\text { TPABr } \\
\text { powder }\end{array}$ & $\begin{array}{l}\text { 1M TPABr } \\
\text { solution }\end{array}$ & $\begin{array}{l}25 \% \mathrm{TPAOH} \\
\text { solution }\end{array}$ & $\begin{array}{l}40 \% \text { TPAOH } \\
\text { solution }\end{array}$ & $\begin{array}{c}\text { Deionized } \\
\text { water }\end{array}$ \\
\hline $\mathrm{N}_{0.75} \mathrm{~S}_{25} \mathrm{~T}_{69} \mathrm{H}_{1136}$ & 20.994 & - & - & 6.290 & - & 28.928 & - & - & 43.845 \\
\hline $\mathrm{N}_{0.85} \mathrm{~S}_{25} \mathrm{~T}_{69} \mathrm{H}_{1136}$ & 20.988 & - & - & 7.131 & - & 28.921 & - & - & 43.025 \\
\hline $\mathrm{N}_{1.0} \mathrm{~S}_{25} \mathrm{~T}_{6.9} \mathrm{H}_{1136}$ & 20.980 & - & - & 8.381 & - & 28.909 & - & - & 41.806 \\
\hline $\mathrm{N}_{1.0} \mathrm{~S}_{25} \mathrm{~T}_{6.9} \mathrm{H}_{1136}$ & 20.980 & - & 0.341 & - & 7.698 & - & - & - & 71.102 \\
\hline $\mathrm{N}_{1.1} \mathrm{~S}_{25} \mathrm{~T}_{6.9} \mathrm{H}_{1136}$ & 20.975 & - & - & 9.215 & - & 28.902 & - & - & 40.992 \\
\hline $\mathrm{N}_{1.25} \mathrm{~S}_{25} \mathrm{~T}_{69} \mathrm{H}_{1136}$ & 20.967 & - & - & 10.467 & - & 28.891 & - & - & 39.771 \\
\hline $\mathrm{N}_{1.35} \mathrm{~S}_{25} \mathrm{~T}_{69} \mathrm{H}_{1 \mathrm{1} 6}$ & 20.961 & - & - & 11.302 & - & 28.883 & - & - & 38.956 \\
\hline $\mathrm{N}_{1.5} \mathrm{~S}_{25} \mathrm{~T}_{6.9} \mathrm{H}_{1136}$ & 20.953 & - & - & 12.552 & - & 28.872 & - & - & 37.737 \\
\hline $\mathrm{N}_{1.75} \mathrm{~S}_{25} \mathrm{~T}_{69} \mathrm{H}_{1136}$ & 20.940 & - & - & 14.633 & - & 28.853 & - & - & 35.707 \\
\hline $\mathrm{N}_{1.85} \mathrm{~S}_{25} \mathrm{~T}_{69} \mathrm{H}_{1 \mathrm{~B} 6}$ & 20.934 & - & - & 15.469 & - & 28.846 & - & - & 34.892 \\
\hline
\end{tabular}


Table A.3.cont. Amount of reagents calculated for $100 \mathrm{~g}$ batch for all compositions used in this study

\begin{tabular}{|c|c|c|c|c|c|c|c|c|c|}
\hline \multirow{2}{*}{$\begin{array}{c}\text { BATCH } \\
\text { COMPOSITION }\end{array}$} & \multicolumn{7}{|c|}{ REAGENTS } \\
\cline { 2 - 11 } & Ludox & $\begin{array}{c}\text { Ludox } \\
\text { AS-40 }\end{array}$ & $\begin{array}{c}\text { NaOH } \\
\text { pellets }\end{array}$ & $\begin{array}{c}\text { 1M NaOH } \\
\text { solution }\end{array}$ & $\begin{array}{c}\text { TPABr } \\
\text { powder }\end{array}$ & $\begin{array}{c}\text { 1M TPABr } \\
\text { solution }\end{array}$ & $\begin{array}{c}\text { 25\% TPAOH } \\
\text { solution }\end{array}$ & $\begin{array}{c}\text { 40 TPAOH } \\
\text { solution }\end{array}$ & $\begin{array}{c}\text { Deionized } \\
\text { water }\end{array}$ \\
\hline $\mathrm{N}_{2.0} \mathrm{~S}_{25} \mathrm{~T}_{6.9} \mathrm{H}_{1136}$ & 20.953 & - & - & 16.741 & - & 28.835 & - & - & 33.677 \\
\hline $\mathrm{N}_{2.5} \mathrm{~S}_{25} \mathrm{~T}_{6.9} \mathrm{H}_{1136}$ & 20.926 & - & - & 20.896 & - & 28.835 & - & - & 29.553 \\
\hline $\mathrm{N}_{3.0} \mathrm{~S}_{25} \mathrm{~T}_{6.9} \mathrm{H}_{1136}$ & 20.872 & - & - & 25.008 & - & 28.760 & - & - & 25.588 \\
\hline $\mathrm{N}_{3.0} \mathrm{~S}_{25} \mathrm{~T}_{6.9} \mathrm{H}_{1136}$ & 20.872 & - & 1.023 & - & 7.667 & - & - & - & 70.621 \\
\hline $\mathrm{N}_{3.55} \mathrm{~S}_{25} \mathrm{~T}_{6.9} \mathrm{H}_{1136}$ & 20.845 & - & - & 27.971 & - & 28.723 & - & - & 21.558 \\
\hline $\mathrm{N}_{4.0} \mathrm{~S}_{25} \mathrm{~T}_{6.9} \mathrm{H}_{1136}$ & 20.818 & - & - & 33.259 & - & 28.575 & - & - & 5.546 \\
\hline $\mathrm{N}_{5.0} \mathrm{~S}_{25} \mathrm{~T}_{6.9} \mathrm{H}_{1136}$ & 20.762 & - & 1.690 & - & 7.623 & - & - & - & 69.931 \\
\hline $\mathrm{N}_{5.5} \mathrm{~S}_{25} \mathrm{~T}_{6.9} \mathrm{H}_{1136}$ & 20.738 & - & - & 45.555 & - & 28.891 & - & - & 39.771 \\
\hline $\mathrm{N}_{6.5} \mathrm{~S}_{25} \mathrm{~T}_{6.9} \mathrm{H}_{1136}$ & 20.685 & - & 2.15 & - & 7.59 & - & - & - & 69.531 \\
\hline $\mathrm{N}_{1.0} \mathrm{~S}_{25} \mathrm{~T}_{5} \mathrm{H}_{800}$ & 28.932 & - & - & 11.554 & - & 28.888 & - & - & 30.748 \\
\hline
\end{tabular}


Table A.3.cont'd. Amount of reagents calculated for $100 \mathrm{~g}$ batch for all compositions used in this study

\begin{tabular}{|c|c|c|c|c|c|c|c|c|c|}
\hline \multirow{2}{*}{$\begin{array}{c}\text { BATCH } \\
\text { COMPOSITION }\end{array}$} & \multicolumn{9}{|c|}{ REAGENTS } \\
\hline & $\begin{array}{l}\text { Ludox } \\
\text { AS-30 }\end{array}$ & $\begin{array}{l}\text { Ludox } \\
\text { AS-40 }\end{array}$ & \begin{tabular}{l|}
$\mathrm{NaOH}$ \\
pellets
\end{tabular} & $\begin{array}{c}1 \mathrm{M} \mathrm{NaOH} \\
\text { solution }\end{array}$ & $\begin{array}{l}\text { TPABr } \\
\text { powder }\end{array}$ & $\begin{array}{c}\text { 1M TPABr } \\
\text { solution }\end{array}$ & $\begin{array}{l}25 \% \text { TPAOH } \\
\text { solution }\end{array}$ & $\begin{array}{c}40 \% \mathrm{TPAOH} \\
\text { solution }\end{array}$ & $\begin{array}{c}\text { Deionized } \\
\text { water }\end{array}$ \\
\hline $\mathrm{N}_{1.0} \mathrm{~S}_{25} \mathrm{~T}_{5} \mathrm{H}_{800}$ & 29.196 & - & - & 11.662 & - & 14.576 & - & 7.411 & 37.261 \\
\hline $\mathrm{N}_{1.0} \mathrm{~S}_{25} \mathrm{~T}_{5} \mathrm{H}_{800}$ & 29.467 & - & - & 11.769 & - & - & - & 14.959 & 43.912 \\
\hline $\mathrm{N}_{3.0} \mathrm{~S}_{25} \mathrm{~T}_{5} \mathrm{H}_{800}$ & 28.731 & - & 1.40 & - & 7.64 & - & - & - & 63.23 \\
\hline $\mathrm{N}_{3.0} \mathrm{~S}_{25} \mathrm{~T}_{5} \mathrm{H}_{800}$ & 28.991 & - & 1.42 & - & 3.85 & - & 11.77 & - & 53.96 \\
\hline $\mathrm{N}_{3.0} \mathrm{~S}_{25} \mathrm{~T}_{5} \mathrm{H}_{800}$ & 29.250 & - & 1.43 & - & - & - & 23.76 & - & 45.66 \\
\hline $\mathrm{N}_{3.0} \mathrm{~S}_{25} \mathrm{~T}_{5} \mathrm{H}_{800}$ & 28.725 & - & - & 34.419 & - & 28.682 & - & - & 8.511 \\
\hline $\mathrm{N}_{3.0} \mathrm{~S}_{25} \mathrm{~T}_{5} \mathrm{H}_{800}$ & 28.987 & - & - & 34.733 & - & 14.472 & - & 7.358 & 14.791 \\
\hline $\mathrm{N}_{3.0} \mathrm{~S}_{25} \mathrm{~T}_{5} \mathrm{H}_{800}$ & 29.253 & - & - & 35.052 & - & - & - & 14.851 & 21.188 \\
\hline $\mathrm{S}_{80} \mathrm{~T}_{5} \mathrm{H}_{1536}$ & 47.838 & - & - & - & - & - & - & 7.589 & 44.573 \\
\hline $\mathrm{S}_{80} \mathrm{~T}_{5} \mathrm{H}_{1536}$ & - & 35.878 & - & - & - & - & - & 7.589 & 56.523 \\
\hline
\end{tabular}


Table A.3.cont'd. Amount of reagents calculated for $100 \mathrm{~g}$ batch for all compositions used in this study

\begin{tabular}{|c|c|c|c|c|c|c|c|c|c|}
\hline \multirow{2}{*}{$\begin{array}{c}\text { BATCH } \\
\text { COMPOSITION }\end{array}$} & \multicolumn{9}{|c|}{ REAGENTS } \\
\hline & $\begin{array}{l}\text { Ludox } \\
\text { AS-30 }\end{array}$ & $\begin{array}{l}\text { Ludox } \\
\text { AS-40 }\end{array}$ & $\begin{array}{l}\mathrm{NaOH} \\
\text { pellets }\end{array}$ & $\begin{array}{l}1 \mathrm{M} \mathrm{NaOH} \\
\text { solution }\end{array}$ & $\begin{array}{l}\text { TPABr } \\
\text { powder }\end{array}$ & $\begin{array}{c}\text { IM TPABr } \\
\text { solution }\end{array}$ & $\begin{array}{l}25 \% \mathrm{TPAOH} \\
\text { solution }\end{array}$ & $\begin{array}{c}40 \% \mathrm{TPAOH} \\
\text { solution }\end{array}$ & $\begin{array}{l}\text { Deionized } \\
\text { water }\end{array}$ \\
\hline $\mathrm{S}_{80} \mathrm{~T}_{9} \mathrm{H}_{1536}$ & 46.703 & - & - & - & - & - & - & 13.337 & 39.960 \\
\hline $\mathrm{S}_{80} \mathrm{~T}_{9} \mathrm{H}_{1536}$ & - & 35.028 & - & - & - & - & - & 13.337 & 51.636 \\
\hline $\mathrm{S}_{80} \mathrm{~T}_{16} \mathrm{H}_{1536}$ & 44.843 & - & - & - & - & - & - & 22.765 & 32.392 \\
\hline $\mathrm{S}_{80} \mathrm{~T}_{16} \mathrm{H}_{1536}$ & - & 33.632 & - & - & - & - & - & 22.765 & 43.603 \\
\hline $\mathrm{S}_{80} \mathrm{~T}_{30} \mathrm{H}_{1536}$ & 41.534 & - & - & - & - & - & - & 39.535 & 18.932 \\
\hline $\mathrm{S}_{80} \mathrm{~T}_{30} \mathrm{H}_{1536}$ & - & 31.150 & - & - & - & - & - & 39.535 & 29.315 \\
\hline
\end{tabular}




\section{APPENDIX B}

\section{SAMPLE CALCULATION FOR MAXIMUM YIELD AND PERCENT CONVERSION}

Composition: $80 \mathrm{SiO}_{2}: 30 \mathrm{TPAOH}: 1536 \mathrm{H}_{2} \mathrm{O}$

$100 \mathrm{~g}$ basis:

41.53 g Ludox AS-30

$39.54 \mathrm{~g}$ ТРAOH (40 wt \% in water)

$18.93 \mathrm{~g}$ Deionized water

In 100 g synthesis solution:

41.53 g Ludox AS-30 x $\left(\frac{30 \mathrm{~g} \mathrm{SiO}_{2}}{100 \mathrm{~g} \text { Ludox AS-30 }}\right)=12.46 \mathrm{~g} \mathrm{SiO}_{2}$

$12.46 \mathrm{~g} \mathrm{SiO}_{2} \times\left(\frac{1{\text { mole } \mathrm{SiO}_{2}}}{60.09 \mathrm{~g} \mathrm{SiO}_{2}}\right)=0.207{\text { mole } \mathrm{SiO}_{2}}$

In one unit cell of silicalite-1, there exist 4 moles of $\mathrm{SiO}_{2}$ and 96 moles of TPAOH

0.207 mole $\mathrm{SiO}_{2} \times\left(\frac{4 \text { mole TPAOH }}{96 \text { mole } \mathrm{SiO}_{2}}\right) \times\left(\frac{203.4 \mathrm{~g} \mathrm{TPAOH}}{1 \text { mole TPAOH }}\right)=1.75 \mathrm{~g} \mathrm{TPAOH}$

For $100 \mathrm{~g}$ synthesis solution the maximum yield that can be obtained is:

$12.46 \mathrm{~g} \mathrm{SiO}_{2}+1.75 \mathrm{~g}$ TPAOH $=14.21 \mathrm{~g}$ silicalite -1

So, the maximum yield $14.21 \%$. 
Sample calculation for percent crystallinity and conversion:

For BSt 105 sample

Yield of solid product in $100 \mathrm{~g}$ product solution: $11.10 \mathrm{~g}$

Before percent conversion calculation we need to calculate percent crystallinity by using XRD pattern of BSt105 sample which is given in Figure B1.

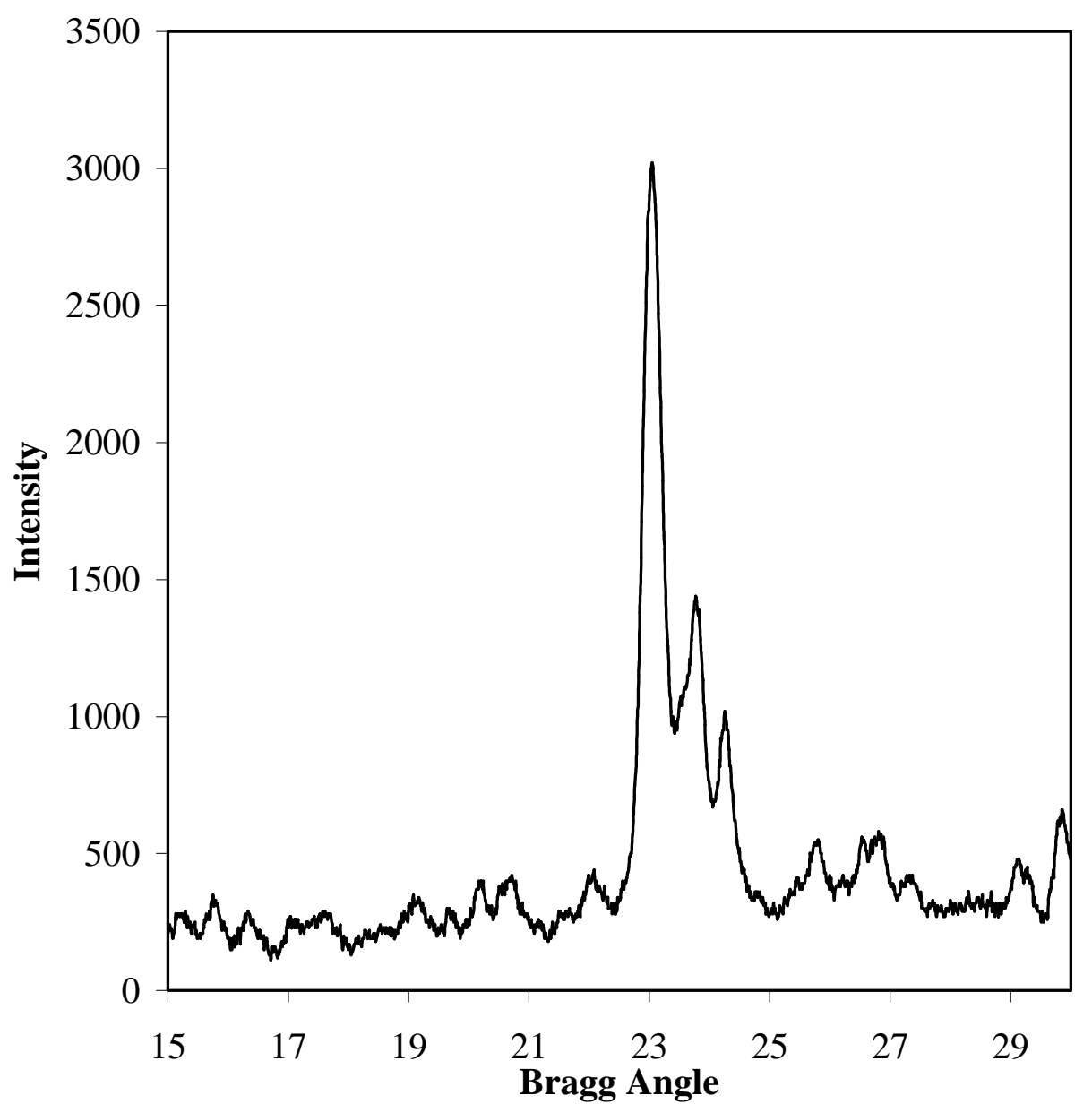

Figure B. 1 XRD pattern of BSt105 powder sample 


$$
\% \text { Crystallinity }=\frac{\left(I_{23^{\circ}}+I_{24^{\circ}}+I_{24.5^{\circ}}\right)_{\text {sample }}}{\left(I_{23^{\circ}}+I_{24^{\circ}}+I_{24.5^{\circ}}\right)_{\text {reference }}} \times 100
$$

where, I= intensity

$$
\% \text { Crystallinity }=\frac{4550}{5520} \times 100=83 \%
$$

Then percent conversion can be calculated as:

$$
\begin{gathered}
\% \text { conversion }=\frac{\left(\frac{\text { yield of solid product in grams }}{\text { grams of reactant mixture }}\right)\left(\begin{array}{c}
\% \text { relative crystallinity } \\
\text { of product }
\end{array}\right)}{\left(\frac{\text { maximum yield in grams }}{\text { grams of reactant mixture }}\right)} \\
\% \text { conversion }=\frac{\left(\frac{11.10 \mathrm{~g}}{100 \mathrm{~g}}\right)(83)}{\left(\frac{14.21 \mathrm{~g}}{100 \mathrm{~g}}\right)}=64.8 \%
\end{gathered}
$$




\section{APPENDIX C}

\section{PREPARATION OF HOME MADE $\mathrm{Al}_{2} \mathrm{O}_{3}$ DISKS}

$\alpha-\mathrm{Al}_{2} \mathrm{O}_{3}$ powder (Riedel de Haen), sodium silicate solution, stearic acid and ethanol solution was used for the preparation of home made alumina disc supports. $10 \mathrm{~g}$ of $\mathrm{Al}_{2} \mathrm{O}_{3}$ powder mixed with $1.3 \mathrm{ml}$ sodium silicate solution. 1.3 $\mathrm{ml}$ sodium silicate was added drop by drop that means first part of the solution was added, mixed with powder until all the sample dried, then other part of solution was added and the same steps were followed.

For the lubrication of molding steraic acid solution was used. Approximately $20-30 \mathrm{ml}$ of ethanol solution was added to $0.1 \mathrm{~g}$ of stearic acid to get stearic acid solution.

$0.8 \mathrm{~g}$ of prepared $\mathrm{Al}_{2} \mathrm{O}_{3}$ powder mixture was put into the lubricated molding and approximately $20000 \mathrm{lb}$ load was applied on top it. All discs were sintered at $1200^{\circ} \mathrm{C}$ for $22 \mathrm{~h}$.

Pore size distribution of alumina disc with surface area and pore volume obtained from mercury porosimetry is shown in Figure C.1. 

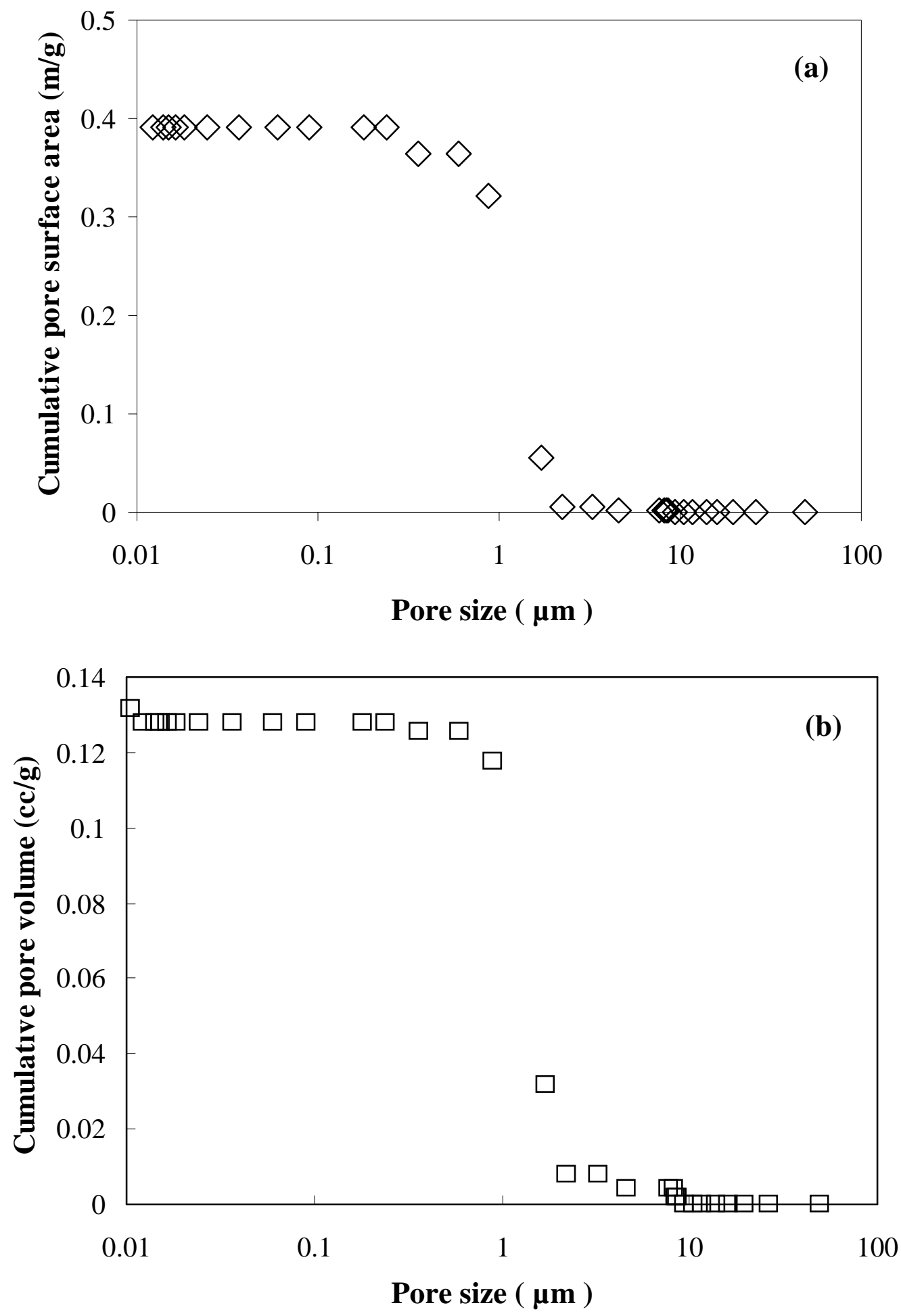

Figure C.1 Pore size distribution of alumina disc with surface area (a) and pore volume (b) obtained from mercury porosimetry 


\section{APPENDIX D}

\section{SAMPLE CALCULATION FOR SINGLE GAS PERMEANCE AND IDEAL SELECTIVITY}

For the single gas permeation experiments constant pressure variable volume method was used. In this method the pressure at the feed side was kept constant at 1.9 bar absolute while the permeate side was at atmospheric pressure $(0.91$ bar). The permeate side flow rate was measured by bubble flow meter. For the permeance calculation steady state flow rate values were used. Table D.1 includes the data required for single gas permeance calculation.

Table D.1 Single gas permeation experiment data for membrane BS125 at $100^{\circ} \mathrm{C}$

\begin{tabular}{|l|l|l|}
\hline Gases & $\mathrm{n}-\mathrm{C}_{4} \mathrm{H}_{10}$ & $\mathrm{i}-\mathrm{C}_{4} \mathrm{H}_{10}$ \\
\hline Volume change $(\mathrm{ml})$ & 2.0 & 1.0 \\
\hline Time interval $(\mathrm{s})$ & $5.9 \mathrm{~s}$ & $69.1 \mathrm{~s}$ \\
\hline Effective membrane area $\left(\mathrm{m}^{2}\right)$ & $1.77 \times 10^{-4}$ & $1.77 \times 10^{-4}$ \\
\hline Pressure difference $(\mathrm{Pa})$ & $1.04 \times 10^{+5}$ & $1.05 \times 10^{+5}$ \\
\hline
\end{tabular}

Flow rate $=v=\left(\frac{2 \mathrm{ml}}{5.98 \mathrm{~s}}\right) \times\left(\frac{1 \mathrm{~L}}{1000 \mathrm{ml}}\right)=3.3 \times 10^{-4} \mathrm{~L} / \mathrm{s}$

Assuming the permeating gas to be ideal, molar flow rate was calculated as; 
Number of mole permeated $=n=\left(\frac{v \times P}{R \times T}\right)$

$=\frac{\left(3.3 \times 10^{-4} \mathrm{~L} / \mathrm{s}\right) \times\left(1.04 \times 10^{+5} \mathrm{~Pa}\right)}{(8314.34 \mathrm{~L} . \mathrm{Pa} / \mathrm{mol} \mathrm{K}) \times(298 \mathrm{~K})}=1.40 \times 10^{-5} \mathrm{~mol} / \mathrm{s}$

Permeance through the membrane is calculated as:

$$
\begin{aligned}
& \text { Permeance }=P=\left(\frac{n}{A_{\text {membrane }} \times \Delta P}\right) \\
& P_{n-C_{4} H_{10}}=\frac{\left(1.40 \times 10^{-5} \mathrm{~mol} / \mathrm{s}\right)}{\left(1.77 \times 10^{-4} \mathrm{~m}^{2}\right) \times\left(1.04 \times 10^{+5} \mathrm{~Pa}\right)}=7.44 \times 10^{-7} \mathrm{~mol} / \mathrm{m}^{2} \mathrm{sPa}
\end{aligned}
$$

Similarly $\mathrm{i}-\mathrm{C}_{4} \mathrm{H}_{10}$ permeance is calculated as:

$P_{i-C_{4} H_{10}}=3.10 \times 10^{-8} \mathrm{~mol} / \mathrm{m}^{2} \mathrm{sPa}$

Ideal selectivity is defined as:

Ideal Selectivity $=\alpha_{\mathrm{i} / \mathrm{j}}$

$\alpha_{\mathrm{n}-\mathrm{C}_{4} \mathrm{H}_{10} / \mathrm{i}-\mathrm{C}_{4} \mathrm{H}_{10}}=\left(\frac{7.44 \times 10^{-7} \mathrm{~mol} / \mathrm{m}^{2} s \mathrm{~Pa}}{3.10 \times 10^{-8} \mathrm{~mol} / \mathrm{m}^{2} s \mathrm{~Pa}}\right)=24$ 


\section{APPENDIX E \\ CALIBRATION OF MASS FLOW CONTROLLERS}

In binary and ternary gas mixture separation experiments the feed mixture compositions were adjusted by using mass flow controllers. Three mass flow controllers were used throughout the study and calibrated for $n-\mathrm{C}_{4} \mathrm{H}_{10}$, i- $\mathrm{C}_{4} \mathrm{H}_{10}$, and $\mathrm{CH}_{4}$. Figure E.1, E.2, and E.3 show the calibration curves of mass flow controllers for these gases.

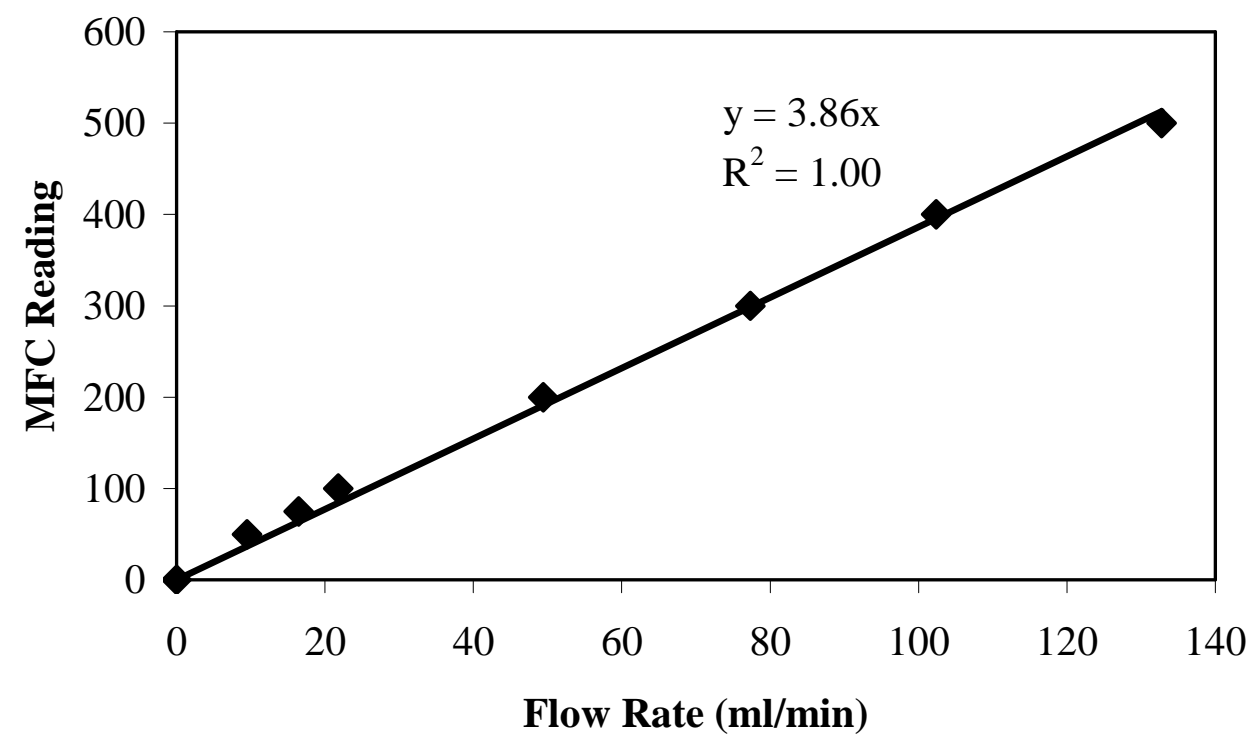

Figure E. 1 Calibration of the mass flow controller for $n-\mathrm{C}_{4} \mathrm{H}_{10}$ 


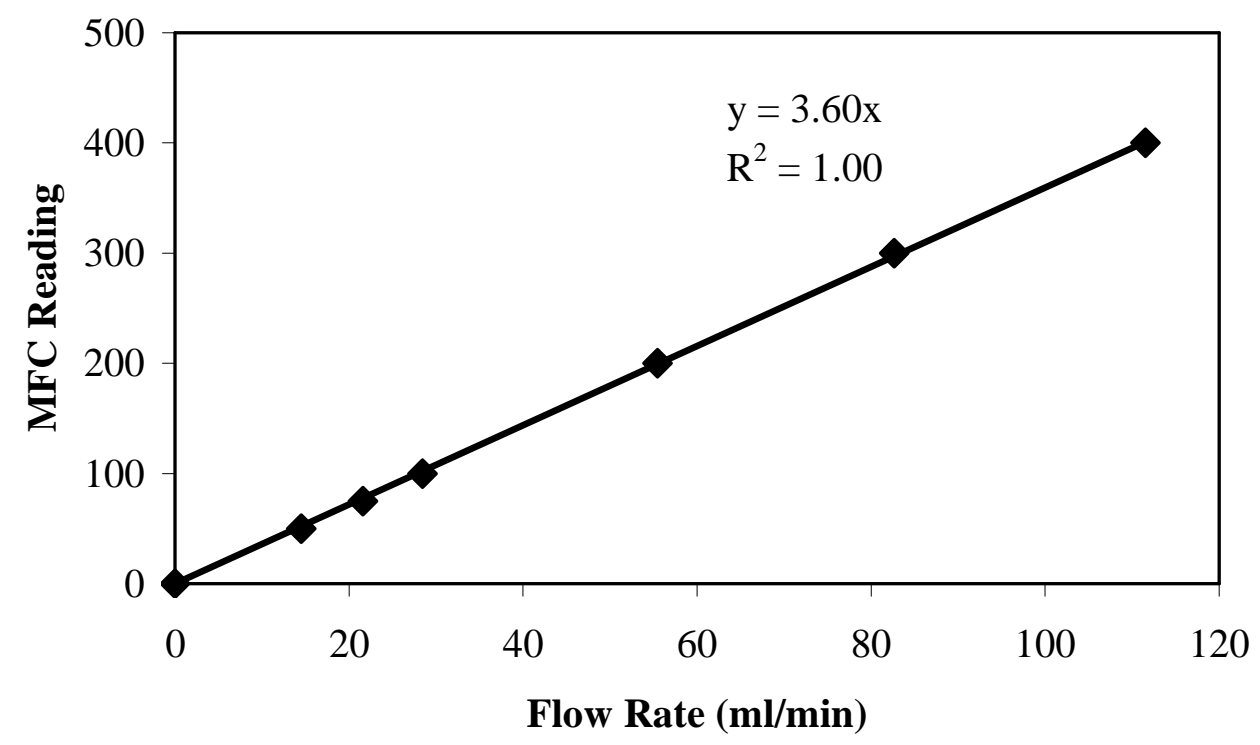

Figure E. 2 Calibration of the mass flow controller for i- $\mathrm{C}_{4} \mathrm{H}_{10}$

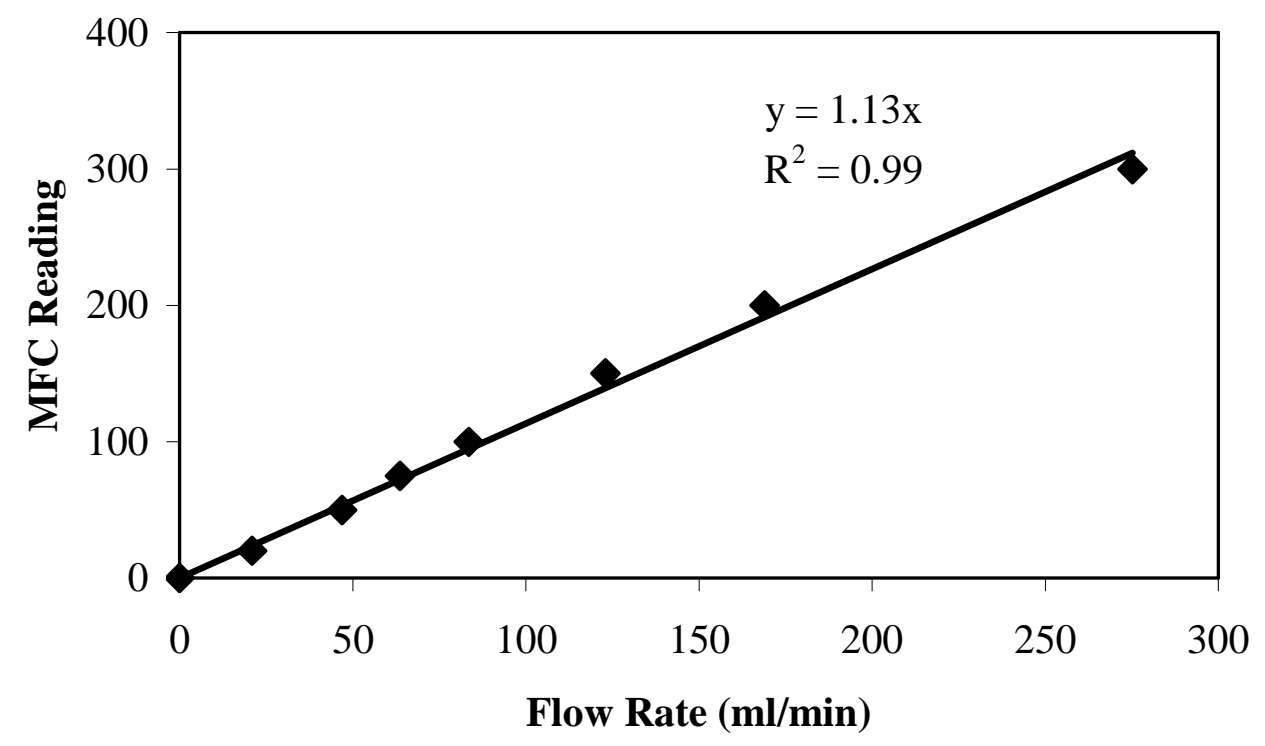

Figure E. 3 Calibration of the mass flow controller for $\mathrm{CH}_{4}$ 


\section{APPENDIX F}

\section{CALIBRATION OF GAS CHROMOTOGRAPH}

In the binary and ternary gas mixture separation experiments prior to sample analysis, $\mathrm{GC}$ calibration was done for $\mathrm{N}_{2}, \mathrm{CH}_{4}, \mathrm{CO}_{2}, \mathrm{n}-\mathrm{C}_{4} \mathrm{H}_{10}$ and $\mathrm{i}-\mathrm{C}_{4} \mathrm{H}_{10}$ gases. Calibration curves were obtained by relating the chromatographic peak area to the partial pressures of each gas under fixed operating conditions of GC. The amount of each gas in the binary and ternary gas mixtures was determined from these calibration curves. The GC calibration curves for each gas are shown in Figure F.1-F.5.

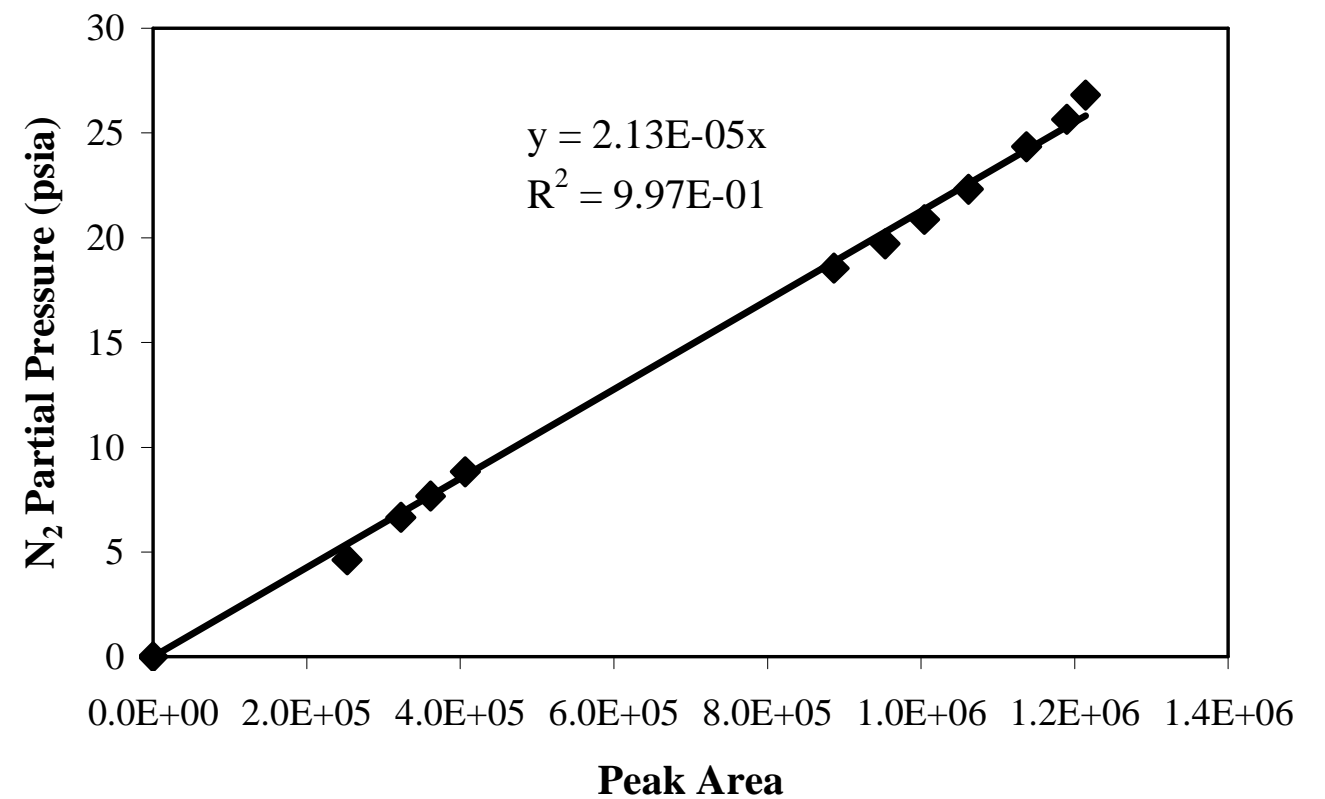

Figure F. 1 Gas chromatograph calibration for $\mathrm{N}_{2}$ 


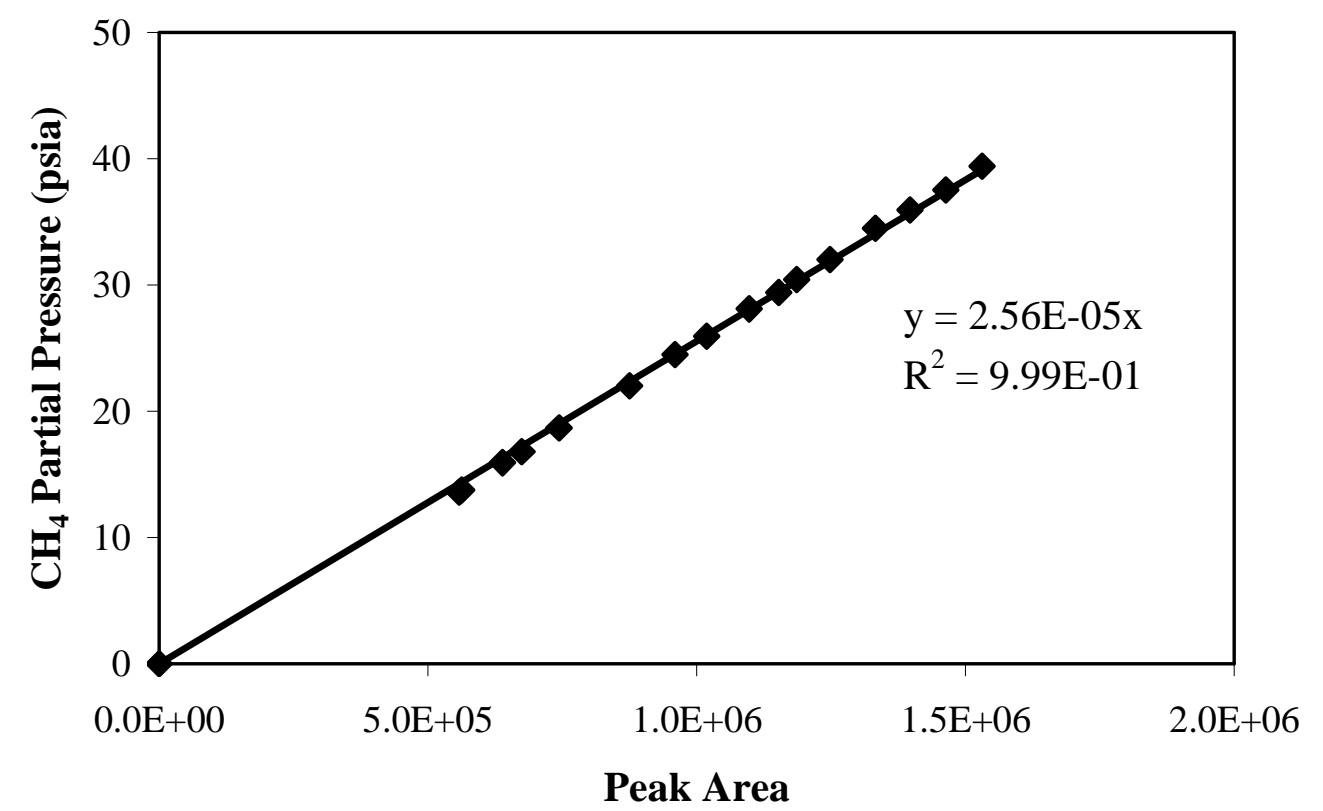

Figure F. 2 Gas chromatograph calibration for $\mathrm{CH}_{4}$

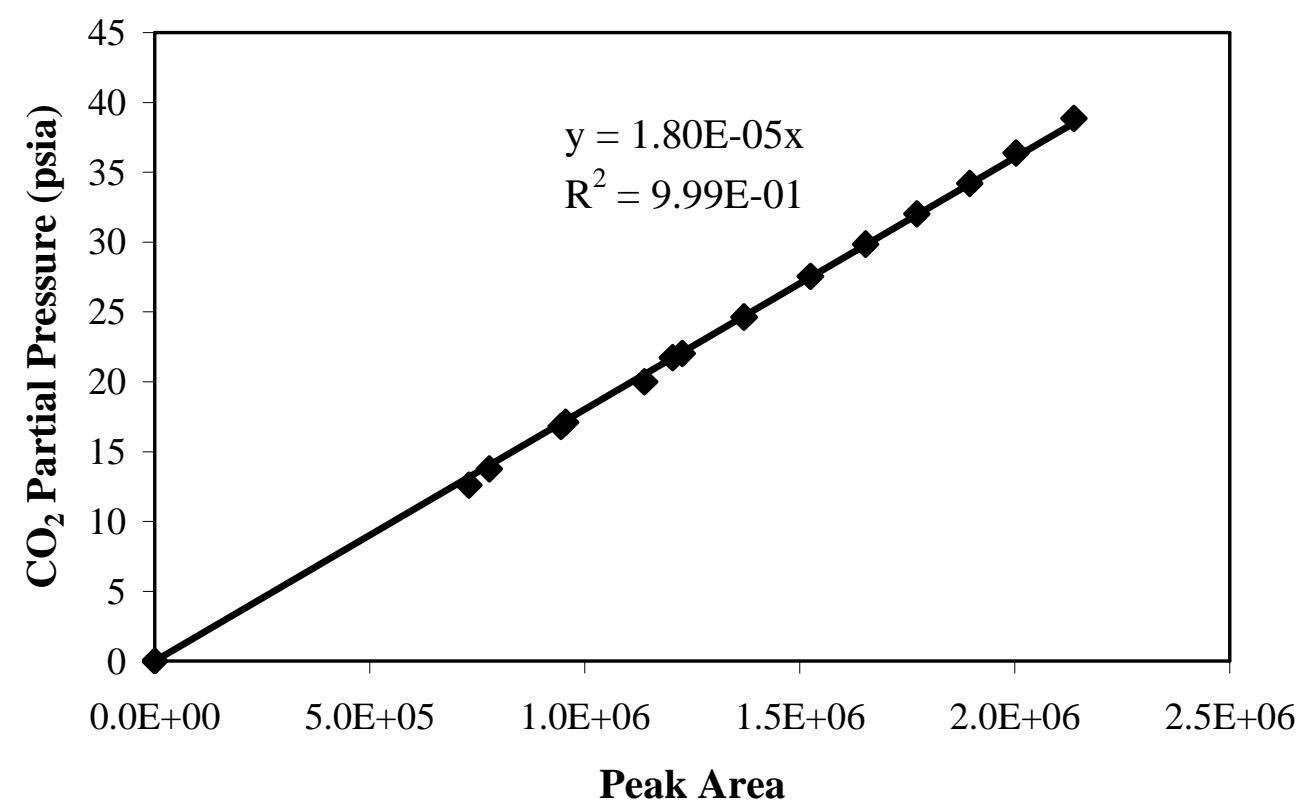

Figure F. 3 Gas chromatograph calibration for $\mathrm{CO}_{2}$ 


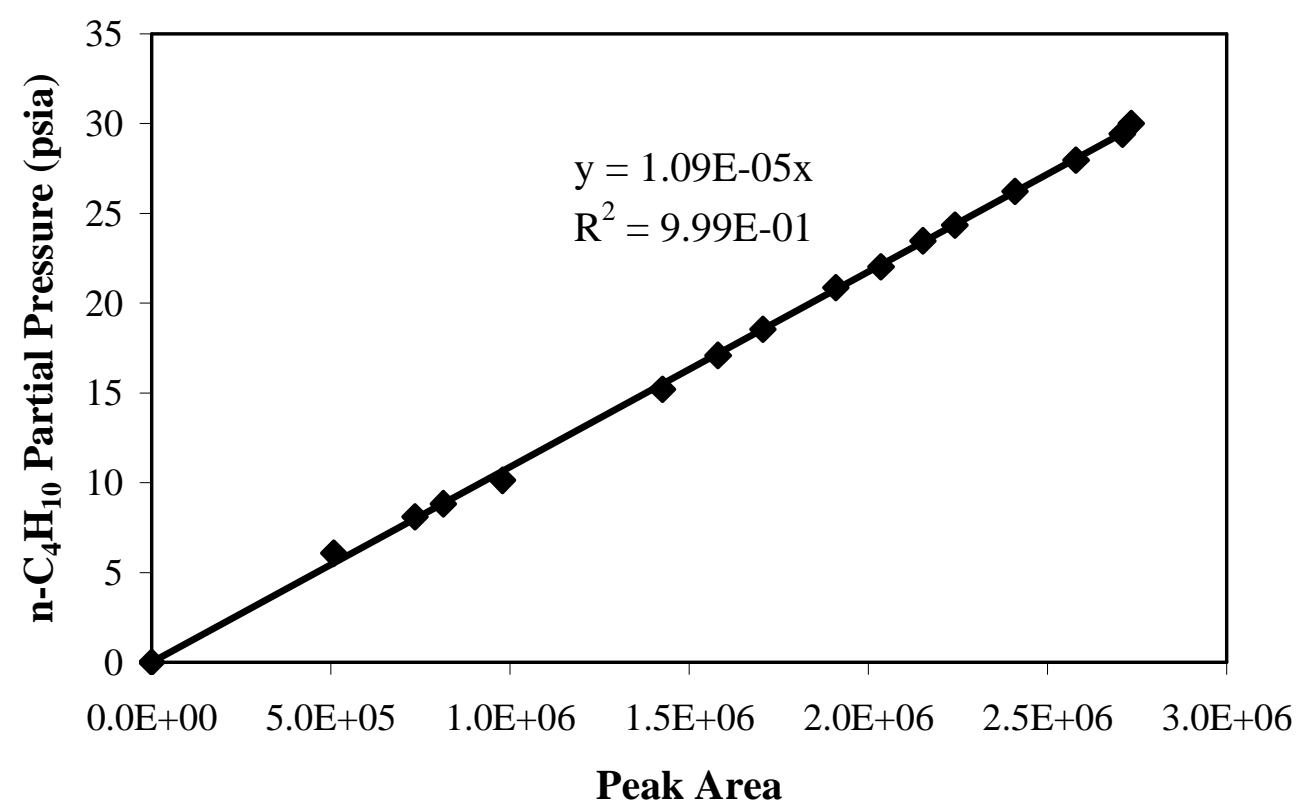

Figure F. 4 Gas chromatograph calibration for $n-\mathrm{C}_{4} \mathrm{H}_{10}$

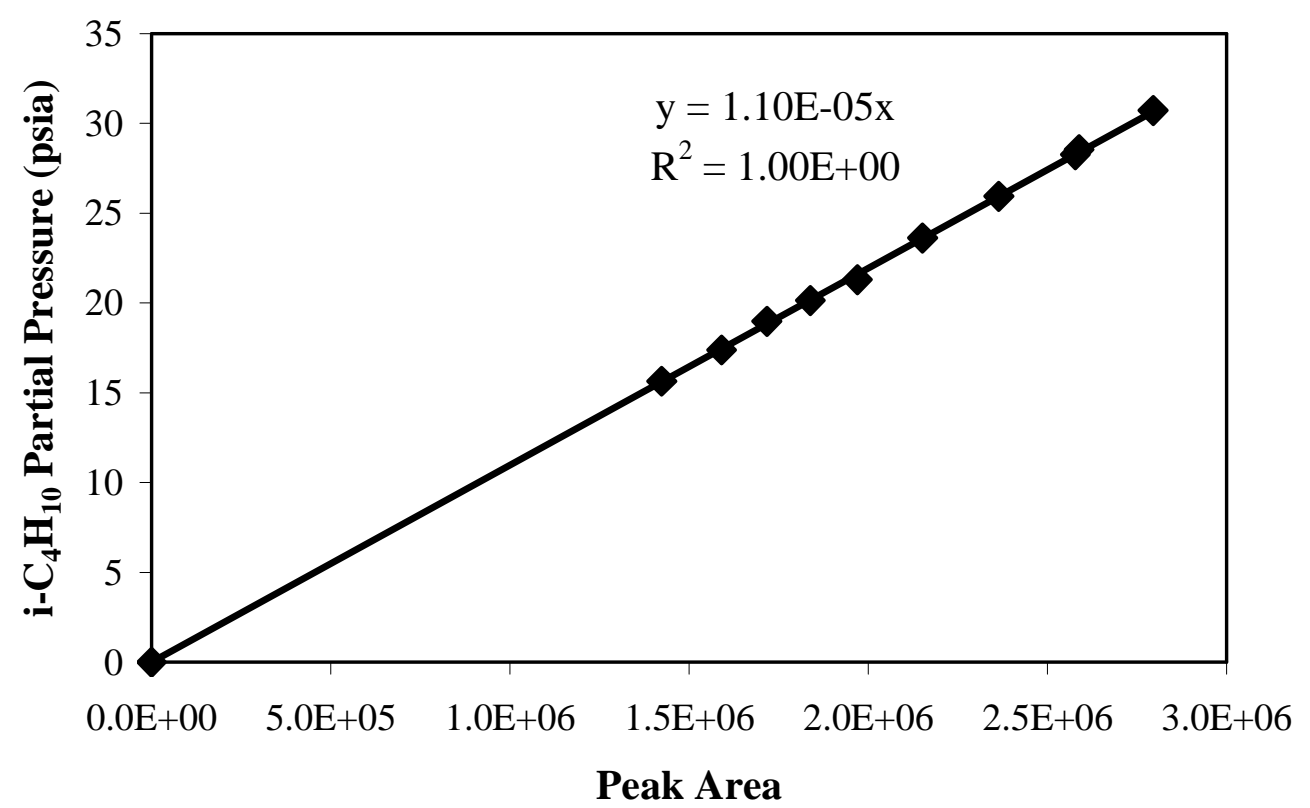

Figure F. 5 Gas chromatograph calibration for i- $\mathrm{C}_{4} \mathrm{H}_{10}$ 


\section{APPENDIX G}

\section{SAMPLE CALCULATION FOR THE DETERMINATION OF GAS COMPOSITIONS IN GAS MIXTURES}

As mentioned in experimental part (Section 3.4) the feed, permeate and retentate gas mixture compositions were calculated by using the GC calibration curves and GC outputs. A sample of GC output is shown in Figure G1. GC analyses the retentate side gas mixture in the first 4 minutes and after that permeate side is analyzed. The first peak corresponds to $\mathrm{CH}_{4}$ and second peak corresponds to $\mathrm{n}-\mathrm{C}_{4} \mathrm{H}_{10}$. The retention times for $\mathrm{CH}_{4}$ and $\mathrm{n}-\mathrm{C}_{4} \mathrm{H}_{10}$ are $0.261 \mathrm{~min}$ and $2.423 \mathrm{~min}$, respectively.

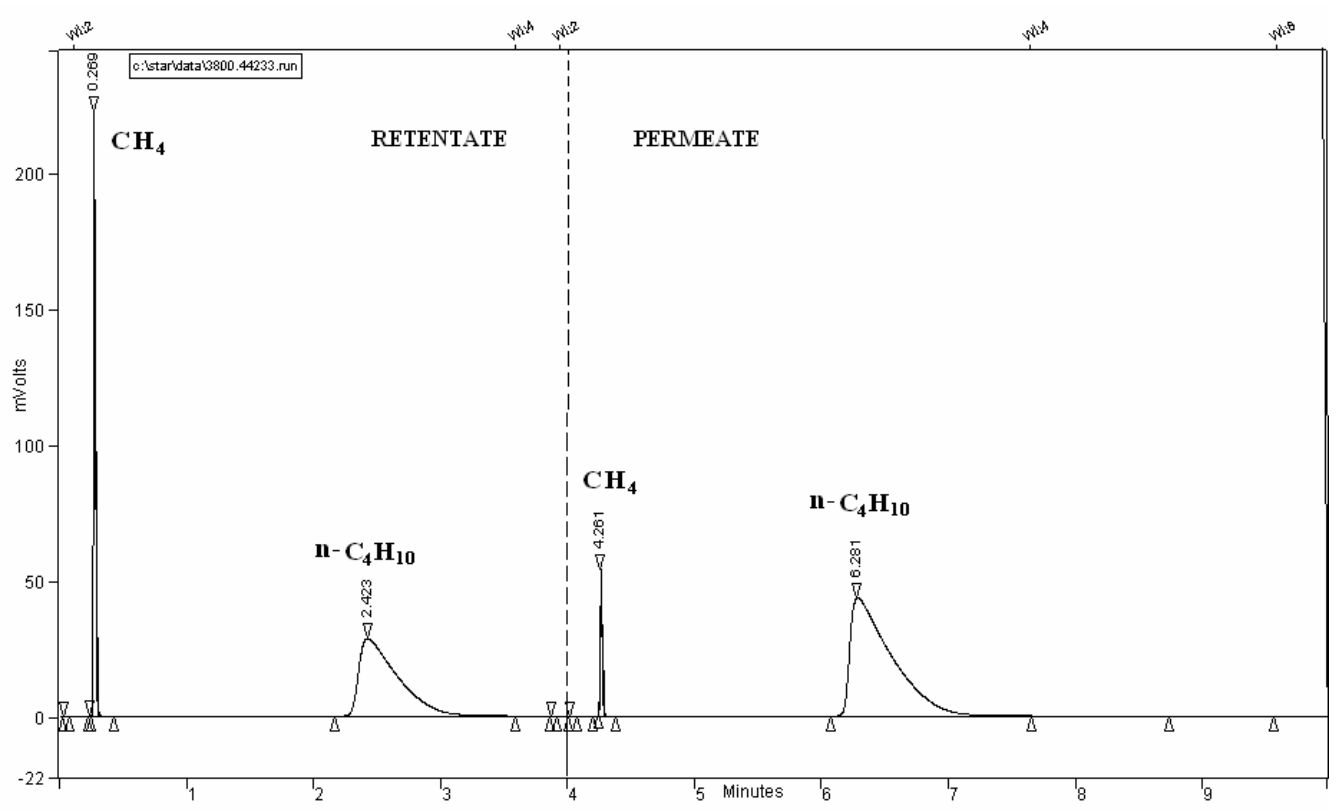

Figure G. 1 Sample GC output for permate and retentate stream (This output belongs to membrane BS170) 
From the GC output and calibration curves the permeate and retentate side compositions can be calculated as follows:

$$
\begin{aligned}
& y_{n-C_{4} H_{10}}=\frac{\left(\text { Area of } \mathrm{n}_{-} \mathrm{C}_{4} \mathrm{H}_{10}\right) \times\left(1.09 \times 10^{-5}\right)}{\left[\left(\text { Area of } \mathrm{n}-\mathrm{C}_{4} \mathrm{H}_{10}\right) \times\left(1.09 \times 10^{-5}\right)+\left(\text { Area of } \mathrm{CH}_{4}\right) \times\left(2.56 \times 10^{-5}\right)\right]} \\
& y_{\mathrm{CH}_{4}}=\frac{\left(\text { Area of } \mathrm{CH}_{4}\right) \times\left(2.56 \times 10^{-5}\right)}{\left[\left(\text { Area of } n-\mathrm{C}_{4} \mathrm{H}_{10}\right) \times\left(1.09 \times 10^{-5}\right)+\left(\text { Area of } \mathrm{CH}_{4}\right) \times\left(2.56 \times 10^{-5}\right)\right]}
\end{aligned}
$$

where

$\mathrm{y}_{\mathrm{n}-\mathrm{C}_{4} \mathrm{H}_{10}}$ : Permeate composition of $\mathrm{n}-\mathrm{C}_{4} \mathrm{H}_{10}$

$\mathrm{y}_{\mathrm{CH}_{4}}$ : Permeate composition of $\mathrm{CH}_{4}$

Sample calculation of permeate composition through membrane BS170 is as follows:

$$
\begin{aligned}
y_{n-C_{4} H_{10}} & =\frac{(986938) \times\left(1.09 \times 10^{-5}\right)}{\left[(986938) \times\left(1.09 \times 10^{-5}\right)+(53996) \times\left(2.56 \times 10^{-5}\right)\right]}=0.116 \\
y_{C_{4}} & =\frac{(53996) \times\left(2.56 \times 10^{-5}\right)}{\left[(986938) \times\left(1.09 \times 10^{-5}\right)+(53996) \times\left(2.56 \times 10^{-5}\right)\right]}=0.884
\end{aligned}
$$

The feed and retentate side compositions can also be calculated similarly. 


\section{APPENDIX H}

\section{SAMPLE CALCULATION FOR THE DETERMINATION OF PERMEANCES AND SEPARATION SELECTIVITIES OF BINARY GAS MIXTURES}

For the permeance calculation;

$$
P_{A}=\frac{J_{A}}{\Delta P_{\text {transmembrane }}} \quad \text { and } \quad J_{A}=\frac{P_{\text {atm }}}{R \times T \times A_{\text {membrane }}} \times y_{A} \times\left(\frac{\Delta V}{\Delta t}\right)
$$

where;

$J_{A}:$ Flux of A component

$P_{a t m}:$ Atmospheric pressure, atm

$T$ : Temperature, $\mathrm{K}$

$A_{\text {membrane }}:$ Membrane surface area, $\mathrm{m} 2$

$y_{A}$ : Mole fraction of $\mathrm{A}$ in permeate side

$$
\begin{aligned}
& \frac{\Delta V}{\Delta t}: \text { Total flow rate in permeate side } \\
& \Delta P_{\text {transmembrane }}: \text { Transmembrane pressure difference, } \mathrm{Pa}
\end{aligned}
$$


$\Delta P_{\text {transmembrane }}=\frac{\left(P_{A}^{\text {feed }}-P_{A}^{\text {permeate }}\right)-\left(P_{A}^{\text {retentate }}-P_{A}^{\text {permeate }}\right)}{\ln \left(\frac{P_{A}^{\text {feed }}-P_{A}^{\text {permeate }}}{P_{A}^{\text {retentate }}-P_{A}^{\text {permeate }}}\right)}$

$P_{A}^{i}$ : partial pressure of component $\mathrm{A}$ in feed, permeate or retentate side

After calculating the permeances of the components the separation selectivity can be calculated as:

Separation selectivity $=\alpha_{A / B}=\left(\frac{P_{A}}{P_{B}}\right)$

Sample calculation for membrane BS170:

Table H.1 Feed, retentate and permeate compositions in binary mixture separation with BS170 membrane

\begin{tabular}{|c|c|c|c|c|c|c|}
\hline \multirow{2}{*}{ Stream } & \multirow{2}{*}{$\begin{array}{c}\text { Flowrate } \\
(\mathrm{ml} / \mathrm{min})\end{array}$} & \multirow{2}{*}{$\begin{array}{c}\text { Pressure } \\
(\mathrm{atm})\end{array}$} & \multicolumn{2}{|c|}{ Mole fractions } & \multicolumn{2}{c|}{ Partial pressures } \\
\cline { 4 - 7 } & & $\mathrm{CH}_{4}$ & $\mathrm{n}-\mathrm{C}_{4} \mathrm{H}_{10}$ & $\mathrm{CH}_{4}$ & $\mathrm{n}-\mathrm{C}_{4} \mathrm{H}_{10}$ \\
\hline FEED & 39.63 & 1.88 & 0.46 & 0.54 & 0.87 & 1.02 \\
\hline PERMEATE & 0.25 & 0.90 & 0.12 & 0.88 & 0.10 & 0.79 \\
\hline RETENTATE & 39.47 & 1.88 & 0.47 & 0.53 & 0.88 & 1.01 \\
\hline
\end{tabular}

$T: 298 K$

$A_{\text {membrane }}: 1.77 \times 10^{-4} \mathrm{~m}^{2}$ 
$\mathrm{n}-\mathrm{C}_{4} \mathrm{H}_{10}$ flux in the permeate

$$
\begin{aligned}
J_{n-C_{4} H_{10}} & =\frac{0.90 \mathrm{~atm}}{(0.082 \mathrm{~L} . \mathrm{atm} / \mathrm{mol} . \mathrm{K}) \times(298 \mathrm{~K}) \times\left(1.77 \times 10^{-4} \mathrm{~m}^{2}\right)} \\
& \times 0.88 \times(0.25 \mathrm{ml} / \mathrm{min}) \times\left(\frac{1 \mathrm{~L}}{1000 \mathrm{ml}}\right) \times\left(\frac{1 \mathrm{~min}}{60 \mathrm{~s}}\right)=7.69 \times 10^{-4} \mathrm{~mol} / \mathrm{m}^{2} \mathrm{~s}
\end{aligned}
$$

Similarly $\mathrm{CH}_{4}$ flux in the permeate side is calculated as

$$
\begin{aligned}
J_{\mathrm{CH}_{4}}= & \frac{0.90 \mathrm{~atm}}{(0.082 \mathrm{~L} . \mathrm{atm} / \mathrm{mol} . \mathrm{K}) \times(298 \mathrm{~K}) \times\left(1.77 \times 10^{-4} \mathrm{~m}^{2}\right)} \\
& \times 0.12 \times(0.25 \mathrm{ml} / \mathrm{min}) \times\left(\frac{1 \mathrm{~L}}{1000 \mathrm{ml}}\right) \times\left(\frac{1 \mathrm{~min}}{60 \mathrm{~s}}\right)=1.01 \times 10^{-4} \mathrm{~mol} / \mathrm{m}^{2} \mathrm{~s}
\end{aligned}
$$

The transmembrane pressure differences are:

$$
\begin{aligned}
\Delta P_{\text {transmembrane, } n-C_{4} H_{10}}= & \frac{(1.02-0.79)-(1.01-0.79)}{\ln \left(\frac{1.02-0.79}{1.01-0.79}\right)} \\
& =0.215 \mathrm{~atm} \times\left(\frac{1 \mathrm{~Pa}}{0.9869 \times 10^{-5}}\right)=21810 \mathrm{~Pa}
\end{aligned}
$$




$$
\begin{aligned}
\Delta P_{\text {transmembrane, } C_{4}} & =\frac{(0.87-0.10)-(0.88-0.10)}{\ln \left(\frac{0.87-0.10}{0.88-0.10}\right)} \\
& =0.771 \mathrm{~atm} \times\left(\frac{1 \mathrm{~Pa}}{0.9869 \times 10^{-5}}\right)=78110 \mathrm{~Pa}
\end{aligned}
$$

The permeances of $n-\mathrm{C}_{4} \mathrm{H}_{10}$ and $\mathrm{CH}_{4}$ are calculated as;

$$
\begin{aligned}
& P_{n-C_{4} H_{10}}=\frac{7.69 \times 10^{-4} \mathrm{~mol} / \mathrm{m}^{2} \mathrm{~s}}{21810 \mathrm{~Pa}}=3.53 \times 10^{-8} \mathrm{~mol} / \mathrm{m}^{2} \mathrm{sPa} \\
& P_{\mathrm{CH}_{4}}=\frac{1.01 \times 10^{-4} \mathrm{~mol} / \mathrm{m}^{2} \mathrm{~s}}{78110 \mathrm{~Pa}}=1.29 \times 10^{-9} \mathrm{~mol} / \mathrm{m}^{2} \mathrm{sPa}
\end{aligned}
$$

and the separation selectivity of $n-\mathrm{C}_{4} \mathrm{H}_{10}$ over $\mathrm{CH}_{4}$ is,

Separation selectivity $=\alpha_{\mathrm{n}-\mathrm{C}_{4} \mathrm{H}_{10} / \mathrm{CH}_{4}}=\left(\frac{3.53 \times 10^{-8} \mathrm{~mol} / \mathrm{m}^{2} \mathrm{sPa}}{1.29 \times 10^{-9} \mathrm{~mol} / \mathrm{m}^{2} \mathrm{sPa}}\right)=27.3$ 


\section{APPENDIX I}

\section{SAMPLE CALCULATION FOR THE DETERMINATION OF PERMEANCES AND SEPARATION SELECTIVITIES OF TERNARY GAS MIXTURES}

For the calculation of separation selectivity in ternary gas mixture same procedure as binary mixture separation can be followed, but in ternary mixtures the transmembrane pressure difference is calculated as follows:

$\Delta P_{\text {transmembrane }}=\frac{\left(P_{A}^{\text {feed }}-P_{A}^{\text {permeate }}\right)+\left(P_{A}^{\text {retentate }}-P_{A}^{\text {permeate }}\right)}{2}$

$P_{A}^{i}$ : partial pressure of component $\mathrm{A}$ in feed, permeate or retentate side

Sample calculation for membrane F2:

Table I.1 Feed, retentate and permeate compositions in ternary mixture separation with BS170 membrane

\begin{tabular}{|c|c|c|c|c|c|c|c|c|}
\hline \multirow{2}{*}{ Stream } & Flowrate & \multirow{2}{*}{$\begin{array}{c}\text { Pressure } \\
(\mathrm{ml} / \mathrm{min})\end{array}$} & \multicolumn{3}{|c|}{ Mole fractions } & \multicolumn{4}{|c|}{ Partial pressures } \\
\cline { 4 - 10 } & & & $\mathrm{CH}_{4}$ & $\mathrm{CO}_{2}$ & $\mathrm{n}-\mathrm{C}_{4} \mathrm{H}_{10}$ & $\mathrm{CH}_{4}$ & $\mathrm{CO}_{2}$ & $\mathrm{n}-\mathrm{C}_{4} \mathrm{H}_{10}$ \\
\hline FEED & 40.24 & 1.90 & 0.67 & 0.19 & 0.13 & 1.279 & 0.368 & 0.250 \\
\hline PERMEATE & 0.08 & 0.90 & 0.54 & 0.21 & 0.26 & 0.481 & 0.188 & 0.229 \\
\hline RETENTATE & 40.16 & 1.90 & 0.69 & 0.19 & 0.12 & 1.303 & 0.364 & 0.230 \\
\hline
\end{tabular}

$T: 298 \mathrm{~K} \quad$ and $\quad A_{\text {membrane }}: 5.5 \times 10^{-4} \mathrm{~m}^{2}$ 
$\mathrm{n}-\mathrm{C}_{4} \mathrm{H}_{10}$ flux in the permeate

$$
\begin{aligned}
J_{n-C_{4} H_{10}} & =\frac{0.90 \mathrm{~atm}}{(0.082 \mathrm{~L} . \mathrm{atm} / \mathrm{mol} . \mathrm{K}) \times(298 \mathrm{~K}) \times\left(5.5 \times 10^{-4} \mathrm{~m}^{2}\right)} \\
& \times 0.26 \times(0.08 \mathrm{ml} / \mathrm{min}) \times\left(\frac{1 L}{1000 \mathrm{ml}}\right) \times\left(\frac{1 \mathrm{~min}}{60 \mathrm{~s}}\right)=2.40 \times 10^{-5} \mathrm{~mol} / \mathrm{m}^{2} \mathrm{~s}
\end{aligned}
$$

Similarly $\mathrm{CH}_{4}$ flux in the permeate side is calculated as

$$
\begin{aligned}
J_{\mathrm{CH}_{4}}= & \frac{0.90 \mathrm{~atm}}{(0.082 \mathrm{~L} . \mathrm{atm} / \mathrm{mol} . \mathrm{K}) \times(298 \mathrm{~K}) \times\left(5.5 \times 10^{-4} \mathrm{~m}^{2}\right)} \\
& \times 0.54 \times(0.08 \mathrm{ml} / \mathrm{min}) \times\left(\frac{1 \mathrm{~L}}{1000 \mathrm{ml}}\right) \times\left(\frac{1 \mathrm{~min}}{60 \mathrm{~s}}\right)=5.04 \times 10^{-5} \mathrm{~mol} / \mathrm{m}^{2} \mathrm{~s}
\end{aligned}
$$

The transmembrane pressure differences are:

$$
\begin{aligned}
\Delta P_{\text {transmembrane, }{\mathrm{n}-\mathrm{C}_{4} \mathrm{H}_{10}}}=\frac{(0.250-0.229)+(0.230-0.229)}{2} \\
=0.011 \mathrm{~atm} \times\left(\frac{1 \mathrm{~Pa}}{0.9869 \times 10^{-5} \mathrm{~atm}}\right)=1136 \mathrm{~Pa}
\end{aligned}
$$

$\Delta P_{\text {transmembrane, } \mathrm{CH}_{4}}=\frac{(1.279-0.481)+(1.303-0.481)}{2}$

$$
=0.81 \mathrm{~atm} \times\left(\frac{1 \mathrm{~Pa}}{0.9869 \times 10^{-5} \mathrm{~atm}}\right)=82090 \mathrm{~Pa}
$$


The permeances of $\mathrm{n}-\mathrm{C}_{4} \mathrm{H}_{10}$ and $\mathrm{CH}_{4}$ are calculated as;

$$
\begin{gathered}
P_{n-C_{4} H_{10}}=\frac{2.40 \times 10^{-5} \mathrm{~mol} / \mathrm{m}^{2} \mathrm{~s}}{82090 \mathrm{~Pa}}=3.78 \times 10^{-8} \mathrm{~mol} / \mathrm{m}^{2} \mathrm{sPa} \\
P_{C H_{4}}=\frac{5.04 \times 10^{-5} \mathrm{~mol} / \mathrm{m}^{2} \mathrm{~s}}{1136 \mathrm{~Pa}}=6.14 \times 10^{-10} \mathrm{~mol} / \mathrm{m}^{2} \mathrm{sPa}
\end{gathered}
$$

and the separation selectivity of $n-\mathrm{C}_{4} \mathrm{H}_{10}$ over $\mathrm{CH}_{4}$ is,

Separation selectivity $=\alpha_{\mathrm{n}-\mathrm{C}_{4} \mathrm{H}_{10} / \mathrm{CH}_{4}}=\left(\frac{3.78 \times 10^{-8} \mathrm{~mol} / \mathrm{m}^{2} \mathrm{sPa}}{6.14 \times 10^{-10} \mathrm{~mol} / \mathrm{m}^{2} \mathrm{sPa}}\right)=34.4$ 


\section{APPENDIX J \\ CALCULATION OF AMOUNT OF SILICA ADDED DURING CRYSTALLIZATION}

Initial molar composition of the batch : $80 \mathrm{SiO}_{2}: 30 \mathrm{TPAOH}: 1536 \mathrm{H}_{2} \mathrm{O}$

Silica source: Ludox AS-30

Template Source: TPAOH (40 wt \%)

Formula weight of the batch:

$(80 \times 60.09)+(30 \times 203.37)+(1536 \times 18.016)=38581 \mathrm{~g} / \mathrm{gmole}$

Before silica addition in $100 \mathrm{~g}$ batch

Ludox AS-30 $=31.15 \mathrm{~g}$

TPAOH $(40 \mathrm{wt} \%)=39.53 \mathrm{~g}$

$\mathrm{H}_{2} \mathrm{O}=29.32 \mathrm{~g}$

After silica addition of the batch : $80 \mathrm{SiO}_{2}: 9 \mathrm{TPAOH}: \mathrm{xH}_{2} \mathrm{O}$

Since the silica source is Ludox AS-30 some water will introduce to the synthesis medium

After " $y$ " g silica addition the batch will be $(100+y) g$

Ludox AS-30 = $(31.15+\mathrm{y}) \mathrm{g}$

TPAOH $(40 \mathrm{wt} \%)=39.53 \mathrm{~g}$

$\mathrm{H}_{2} \mathrm{O}=29.32 \mathrm{~g}$ 
Formula weight of batch after silica addition

$(80 \times 60.09)+(9 \times 203.37)+(\mathrm{x}) \times 18.016=(6637.5+18.016 \mathrm{x}) \mathrm{g} / \mathrm{gmole}$

\section{-Ludox AS-30:}

$(100+y) \mathrm{g}$ batch $\times \frac{1 \mathrm{~mol} \text { batch }}{(6637.5+18.016 \mathrm{x}) \mathrm{g} \text { batch }} \times \frac{80 \mathrm{~mol} \mathrm{SiO}}{1 \mathrm{~mol} \mathrm{batch}} \times \frac{60.09 \mathrm{~g} \mathrm{SiO}_{2}}{1 \mathrm{~mol} \mathrm{SiO}_{2}}$

$\times \frac{100 \mathrm{~g} \mathrm{Ludox} \text { AS-30 }}{40 \mathrm{~g} \mathrm{SiO}_{2}}=(31.15+\mathrm{y}) \mathrm{g}$ Ludox AS -30

\section{-TPAOH:}

$(100+y) \mathrm{g}$ batch $\times \frac{1 \mathrm{~mol} \text { batch }}{(6637.53+18.016 \mathrm{x}) \mathrm{g} \text { batch }} \times \frac{9 \mathrm{~mol} \mathrm{TPAOH}}{1 \mathrm{~mol} \mathrm{batch}}$

$\times \frac{203.37 \mathrm{~g} \mathrm{TPAOH}}{1 \mathrm{~mol} \mathrm{TPAOH}} \times \frac{100}{40}=39.53 \mathrm{~g} \mathrm{TPABr}$

$\frac{4807.2}{1830.33}=\frac{31.15+\mathrm{y}}{39.53}$

$\mathrm{y}=72.68 \mathrm{~g}$ Ludox AS-40 must be added 


\section{APPENDIX K}

\section{LIST OF SYNTHESIZED MEMBRANES}

Table K. 1 List of synthesized membranes at different synthesis conditions

\begin{tabular}{|c|c|c|c|c|c|}
\hline $\begin{array}{l}\text { Membrane } \\
\text { Code }\end{array}$ & $\begin{array}{l}\text { Synthesis } \\
\text { Composition }\end{array}$ & $\begin{array}{c}\text { Silica and } \\
\text { template source }\end{array}$ & $\begin{array}{c}\text { Synthesis } \\
\text { Temperature } \\
\left({ }^{\circ} \mathrm{C}\right)\end{array}$ & $\begin{array}{c}\text { Time } \\
\text { (h) }\end{array}$ & $\begin{array}{c}\text { Synthesis } \\
\text { Method }\end{array}$ \\
\hline $\begin{array}{l}\text { BS1- } \\
\text { BS21 }\end{array}$ & $\mathrm{N}_{6.5} \mathrm{~S}_{25} \mathrm{~T}_{6.9} \mathrm{H}_{1136}$ & $\begin{array}{c}\text { Silisic acid } \\
\text { TPABr }\end{array}$ & 180 & 24 & $\begin{array}{c}\text { Unseeded } \\
\text { Batch }\end{array}$ \\
\hline $\begin{array}{l}\text { BS22- } \\
\text { BS38 }\end{array}$ & $\mathrm{N}_{6.5} \mathrm{~S}_{25} \mathrm{~T}_{6.9} \mathrm{H}_{1136}$ & $\begin{array}{c}\text { Silisic acid } \\
\text { TPABr }\end{array}$ & 150 & 24 & $\begin{array}{l}\text { Unseeded, } \\
\text { Batch }\end{array}$ \\
\hline $\begin{array}{l}\text { BS38- } \\
\text { BS53 }\end{array}$ & $\mathrm{N}_{6.5} \mathrm{~S}_{25} \mathrm{~T}_{6.9} \mathrm{H}_{1136}$ & $\begin{array}{c}\text { Ludox AS-30 } \\
\text { TPABr }\end{array}$ & 150 & 48 & $\begin{array}{c}\text { Unseeded, } \\
\text { Batch }\end{array}$ \\
\hline $\begin{array}{l}\text { BS54- } \\
\text { BS57 }\end{array}$ & $\mathrm{N}_{6.5} \mathrm{~S}_{25} \mathrm{~T}_{1.0} \mathrm{H}_{1136}$ & $\begin{array}{c}\text { Ludox AS-30 } \\
\text { TPAOH }\end{array}$ & 150 & 16 & $\begin{array}{c}\text { Unseeded, } \\
\text { Batch }\end{array}$ \\
\hline $\begin{array}{l}\text { BS58- } \\
\text { BS59 }\end{array}$ & $\mathrm{N}_{1.0} \mathrm{~S}_{25} \mathrm{~T}_{6.9} \mathrm{H}_{1136}$ & $\begin{array}{c}\text { Ludox AS-30 } \\
\text { TPABr }\end{array}$ & 150 & 24 & $\begin{array}{c}\text { Unseeded, } \\
\text { Batch }\end{array}$ \\
\hline $\begin{array}{l}\text { BS60- } \\
\text { BS61 }\end{array}$ & $\mathrm{N}_{3.0} \mathrm{~S}_{25} \mathrm{~T}_{6.9} \mathrm{H}_{1136}$ & $\begin{array}{c}\text { Ludox AS-30 } \\
\text { TPABr }\end{array}$ & 150 & 24 & $\begin{array}{c}\text { Unseeded, } \\
\text { Batch }\end{array}$ \\
\hline $\begin{array}{l}\text { BS62- } \\
\text { BS63 }\end{array}$ & $\mathrm{N}_{5.0} \mathrm{~S}_{25} \mathrm{~T}_{6.9} \mathrm{H}_{1136}$ & $\begin{array}{c}\text { Ludox AS-30 } \\
\text { TPABr }\end{array}$ & 150 & 24 & $\begin{array}{c}\text { Unseeded, } \\
\text { Batch }\end{array}$ \\
\hline $\begin{array}{l}\text { BS64- } \\
\text { BS65 }\end{array}$ & $\mathrm{N}_{5.0} \mathrm{~S}_{25} \mathrm{~T}_{6.9} \mathrm{H}_{1136}$ & $\begin{array}{c}\text { Ludox AS-30 } \\
\text { TPABr }\end{array}$ & 150 & 24 & $\begin{array}{c}\text { Unseeded, } \\
\text { Batch }\end{array}$ \\
\hline $\begin{array}{l}\text { BS66- } \\
\text { BS67 }\end{array}$ & $\mathrm{N}_{5.0} \mathrm{~S}_{25} \mathrm{~T}_{6.9} \mathrm{H}_{1136}$ & $\begin{array}{c}\text { Ludox AS-30 } \\
\text { TPABr }\end{array}$ & 150 & 24 & $\begin{array}{c}\text { Unseeded, } \\
\text { Batch }\end{array}$ \\
\hline $\begin{array}{l}\text { BS68- } \\
\text { BS69 }\end{array}$ & $\mathrm{N}_{6.5} \mathrm{~S}_{25} \mathrm{~T}_{6.9} \mathrm{H}_{1136}$ & $\begin{array}{c}\text { Ludox AS-30 } \\
\text { TPABr }\end{array}$ & 150 & 24 & $\begin{array}{l}\text { Seeded, } \\
\text { Batch }\end{array}$ \\
\hline $\begin{array}{l}\text { BS70- } \\
\text { BS72 }\end{array}$ & $\mathrm{N}_{1.0} \mathrm{~S}_{25} \mathrm{~T}_{6.9} \mathrm{H}_{1136}$ & $\begin{array}{c}\text { Ludox AS-30 } \\
\text { TPABr }\end{array}$ & 150 & 24 & $\begin{array}{l}\text { Seeded, } \\
\text { Batch }\end{array}$ \\
\hline $\begin{array}{l}\text { BS71- } \\
\text { BS74 }\end{array}$ & $\mathrm{N}_{1.0} \mathrm{~S}_{25} \mathrm{~T}_{6.9} \mathrm{H}_{1136}$ & $\begin{array}{c}\text { Ludox AS-30 } \\
\text { TPABr }\end{array}$ & 150 & 24 & $\begin{array}{c}\text { Unseeded, } \\
\text { Batch }\end{array}$ \\
\hline $\begin{array}{l}\text { BS73- } \\
\text { BS75 }\end{array}$ & $\mathrm{N}_{1.0} \mathrm{~S}_{25} \mathrm{~T}_{6.9} \mathrm{H}_{1136}$ & $\begin{array}{c}\text { Ludox AS-30 } \\
\text { TPABr }\end{array}$ & 150 & 24 & $\begin{array}{l}\text { Seeded, } \\
\text { Batch }\end{array}$ \\
\hline $\begin{array}{l}\text { BS75- } \\
\text { BS77 }\end{array}$ & $\mathrm{N}_{1.0} \mathrm{~S}_{25} \mathrm{~T}_{6.9} \mathrm{H}_{1136}$ & $\begin{array}{c}\text { Ludox AS-30 } \\
\text { TPABr }\end{array}$ & 150 & 24 & $\begin{array}{l}\text { Seeded, } \\
\text { Batch }\end{array}$ \\
\hline $\begin{array}{l}\text { BS78- } \\
\text { BS79 }\end{array}$ & $\mathrm{N}_{6.5} \mathrm{~S}_{25} \mathrm{~T}_{6.9} \mathrm{H}_{1136}$ & $\begin{array}{c}\text { Ludox AS-30 } \\
\text { TPAOH }\end{array}$ & 150 & 24 & $\begin{array}{c}\text { Unseeded, } \\
\text { Batch }\end{array}$ \\
\hline $\begin{array}{l}\text { BS80- } \\
\text { BS81 }\end{array}$ & $\mathrm{N}_{6.5} \mathrm{~S}_{25} \mathrm{~T}_{6.9} \mathrm{H}_{1136}$ & $\begin{array}{c}\text { Ludox AS-30 } \\
\text { TPAOH+TPABr }\end{array}$ & 150 & 24 & $\begin{array}{c}\text { Unseeded, } \\
\text { Batch }\end{array}$ \\
\hline $\begin{array}{l}\text { BS82- } \\
\text { BS83 }\end{array}$ & $\mathrm{N}_{6.5} \mathrm{~S}_{25} \mathrm{~T}_{6.9} \mathrm{H}_{1136}$ & $\begin{array}{c}\text { Ludox AS-30 } \\
\text { TPABr }\end{array}$ & 150 & 24 & $\begin{array}{l}\text { Unseeded, } \\
\text { Batch }\end{array}$ \\
\hline BS84 & $\mathrm{S}_{80} \mathrm{~T}_{16} \mathrm{H}_{1536}$ & $\begin{array}{c}\text { Ludox AS-30 } \\
\text { TPAOH }\end{array}$ & 95 & 72 & $\begin{array}{l}\text { Seeded, } \\
\text { Flow }\end{array}$ \\
\hline
\end{tabular}


Table K1-cont'd. List of synthesized membranes at different synthesis conditions

\begin{tabular}{|c|c|c|c|c|c|}
\hline $\begin{array}{l}\text { Membrane } \\
\text { Code }\end{array}$ & $\begin{array}{l}\text { Synthesis } \\
\text { Composition }\end{array}$ & $\begin{array}{c}\text { Silica and } \\
\text { template source }\end{array}$ & $\begin{array}{c}\text { Synthesis } \\
\text { Temperature } \\
\left({ }^{\circ} \mathrm{C}\right)\end{array}$ & $\begin{array}{l}\text { Time } \\
\text { (h) }\end{array}$ & $\begin{array}{l}\text { Synthesis } \\
\text { Method }\end{array}$ \\
\hline $\begin{array}{l}\text { BS85- } \\
\text { BS86 }\end{array}$ & $\mathrm{N}_{3.0} \mathrm{~S}_{25} \mathrm{~T}_{5} \mathrm{H}_{800}$ & $\begin{array}{c}\text { Ludox AS-30 } \\
\text { TPAOH }\end{array}$ & 150 & 24 & $\begin{array}{l}\text { Seeded, } \\
\text { Batch }\end{array}$ \\
\hline $\begin{array}{l}\text { BS87- } \\
\text { BS88 }\end{array}$ & $\mathrm{N}_{3.0} \mathrm{~S}_{25} \mathrm{~T}_{5} \mathrm{H}_{800}$ & $\begin{array}{c}\text { Ludox AS-30 } \\
\text { TPABr }\end{array}$ & 150 & 24 & $\begin{array}{l}\text { Seeded, } \\
\text { Batch }\end{array}$ \\
\hline $\begin{array}{l}\text { BS89- } \\
\text { BS90 }\end{array}$ & $\mathrm{N}_{3.0} \mathrm{~S}_{25} \mathrm{~T}_{5} \mathrm{H}_{800}$ & $\begin{array}{c}\text { Ludox AS-30 } \\
\text { TPAOH } \\
\end{array}$ & 150 & 24 & $\begin{array}{l}\text { Seeded, } \\
\text { Batch }\end{array}$ \\
\hline $\begin{array}{l}\text { BS91- } \\
\text { BS92 }\end{array}$ & $\mathrm{N}_{3.0} \mathrm{~S}_{25} \mathrm{~T}_{5} \mathrm{H}_{800}$ & $\begin{array}{c}\text { Ludox AS-30 } \\
\text { TPAOH+TPABr }\end{array}$ & 150 & 24 & $\begin{array}{l}\text { Seeded, } \\
\text { Batch }\end{array}$ \\
\hline $\begin{array}{l}\text { BS93- } \\
\text { BS94 }\end{array}$ & $\mathrm{N}_{3.0} \mathrm{~S}_{25} \mathrm{~T}_{5} \mathrm{H}_{800}$ & $\begin{array}{c}\text { Ludox AS-30 } \\
\text { TPABr }\end{array}$ & 150 & 24 & $\begin{array}{l}\text { Seeded, } \\
\text { Batch }\end{array}$ \\
\hline $\begin{array}{l}\text { BS95- } \\
\text { BS96 }\end{array}$ & $\mathrm{N}_{3.0} \mathrm{~S}_{25} \mathrm{~T}_{5} \mathrm{H}_{800}$ & $\begin{array}{c}\text { Ludox AS-30 } \\
\text { TPAOH }\end{array}$ & 150 & 24 & $\begin{array}{c}\text { Unseeded, } \\
\text { Batch }\end{array}$ \\
\hline $\begin{array}{l}\text { BS97- } \\
\text { BS98 }\end{array}$ & $\mathrm{N}_{3.0} \mathrm{~S}_{25} \mathrm{~T}_{5} \mathrm{H}_{800}$ & $\begin{array}{c}\text { Ludox AS-30 } \\
\text { TPABr }\end{array}$ & 150 & 24 & $\begin{array}{c}\text { Unseeded, } \\
\text { Batch }\end{array}$ \\
\hline $\begin{array}{l}\text { BS99- } \\
\text { BS100 }\end{array}$ & $\mathrm{N}_{3.0} \mathrm{~S}_{25} \mathrm{~T}_{5} \mathrm{H}_{800}$ & $\begin{array}{c}\text { Ludox AS-30 } \\
\text { TPAOH }\end{array}$ & 150 & 24 & $\begin{array}{l}\text { Seeded, } \\
\text { Batch }\end{array}$ \\
\hline $\begin{array}{l}\text { BS101- } \\
\text { BS102 }\end{array}$ & $\mathrm{N}_{3.0} \mathrm{~S}_{25} \mathrm{~T}_{5} \mathrm{H}_{800}$ & $\begin{array}{c}\text { Ludox AS-30 } \\
\text { TPAOH+TPABr }\end{array}$ & 150 & 24 & $\begin{array}{l}\text { Seeded, } \\
\text { Batch }\end{array}$ \\
\hline $\begin{array}{l}\text { BS103- } \\
\text { BS104 }\end{array}$ & $\mathrm{N}_{3.0} \mathrm{~S}_{25} \mathrm{~T}_{5} \mathrm{H}_{800}$ & $\begin{array}{c}\text { Ludox AS-30 } \\
\text { TPABr }\end{array}$ & 150 & 24 & $\begin{array}{l}\text { Seeded, } \\
\text { Batch }\end{array}$ \\
\hline $\begin{array}{l}\text { BS105- } \\
\text { BS106 }\end{array}$ & $\mathrm{N}_{3.0} \mathrm{~S}_{25} \mathrm{~T}_{5} \mathrm{H}_{800}$ & $\begin{array}{c}\text { Ludox AS-30 } \\
\text { TPAOH }\end{array}$ & 150 & 24 & $\begin{array}{l}\text { Seeded, } \\
\text { Batch }\end{array}$ \\
\hline $\begin{array}{l}\text { BS107- } \\
\text { BS108 }\end{array}$ & $\mathrm{N}_{3.0} \mathrm{~S}_{25} \mathrm{~T}_{5} \mathrm{H}_{800}$ & $\begin{array}{c}\text { Ludox AS-30 } \\
\text { TPAOH }\end{array}$ & 150 & 24 & $\begin{array}{l}\text { Seeded, } \\
\text { Batch }\end{array}$ \\
\hline BS109 & $\mathrm{S}_{80} \mathrm{~T}_{5} \mathrm{H}_{1536}$ & $\begin{array}{c}\text { Ludox AS-30 } \\
\text { TPAOH }\end{array}$ & 95 & 72 & $\begin{array}{l}\text { Seeded, } \\
\text { Flow }\end{array}$ \\
\hline BS 110 & $\mathrm{~S}_{80} \mathrm{~T}_{9} \mathrm{H}_{1536}$ & $\begin{array}{c}\text { Ludox AS-30 } \\
\text { TPAOH }\end{array}$ & 95 & 72 & $\begin{array}{l}\text { Seeded, } \\
\text { Flow }\end{array}$ \\
\hline BS111 & $\mathrm{S}_{80} \mathrm{~T}_{16} \mathrm{H}_{1536}$ & $\begin{array}{c}\text { Ludox AS-30 } \\
\text { TPAOH }\end{array}$ & 95 & 72 & $\begin{array}{l}\text { Seeded, } \\
\text { Flow }\end{array}$ \\
\hline BS112 & $\mathrm{S}_{80} \mathrm{~T}_{30} \mathrm{H}_{1536}$ & $\begin{array}{c}\text { Ludox AS-30 } \\
\text { TPAOH }\end{array}$ & 95 & 72 & $\begin{array}{l}\text { Seeded, } \\
\text { Flow }\end{array}$ \\
\hline BS113 & $\mathrm{S}_{80} \mathrm{~T}_{5} \mathrm{H}_{1536}$ & $\begin{array}{c}\text { Ludox AS-30 } \\
\text { TPAOH }\end{array}$ & 95 & 72 & $\begin{array}{l}\text { Seeded, } \\
\text { Flow }\end{array}$ \\
\hline BS114 & $\mathrm{S}_{80} \mathrm{~T}_{9} \mathrm{H}_{1536}$ & $\begin{array}{c}\text { Ludox AS-30 } \\
\text { TPAOH }\end{array}$ & 95 & 72 & $\begin{array}{l}\text { Seeded, } \\
\text { Flow }\end{array}$ \\
\hline BS127 & $\mathrm{N}_{0.5} \mathrm{~S}_{25} \mathrm{~T}_{6.9} \mathrm{H}_{1136}$ & $\begin{array}{c}\text { Ludox AS-30 } \\
\text { TPABr }\end{array}$ & 150 & 24 & $\begin{array}{l}\text { Seeded, } \\
\text { Batch }\end{array}$ \\
\hline BS 128 & $\mathrm{~N}_{1.0} \mathrm{~S}_{25} \mathrm{~T}_{6.9} \mathrm{H}_{1136}$ & $\begin{array}{c}\text { Ludox AS-30 } \\
\text { TPABr }\end{array}$ & 150 & 24 & $\begin{array}{l}\text { Seeded, } \\
\text { Batch }\end{array}$ \\
\hline BS129 & $\mathrm{N}_{1.5} \mathrm{~S}_{25} \mathrm{~T}_{6.9} \mathrm{H}_{1136}$ & $\begin{array}{c}\text { Ludox AS-30 } \\
\text { TPABr }\end{array}$ & 150 & 24 & $\begin{array}{l}\text { Seeded, } \\
\text { Batch }\end{array}$ \\
\hline BS130 & $\mathrm{N}_{2.0} \mathrm{~S}_{25} \mathrm{~T}_{6.9} \mathrm{H}_{1136}$ & $\begin{array}{c}\text { Ludox AS-30 } \\
\text { TPABr }\end{array}$ & 150 & 24 & $\begin{array}{l}\text { Seeded, } \\
\text { Batch }\end{array}$ \\
\hline
\end{tabular}


Table K1-cont'd. List of synthesized membranes at different synthesis conditions

\begin{tabular}{|c|c|c|c|c|c|}
\hline $\begin{array}{l}\text { Membrane } \\
\text { Code }\end{array}$ & $\begin{array}{l}\text { Synthesis } \\
\text { Composition }\end{array}$ & $\begin{array}{c}\text { Silica and } \\
\text { template source }\end{array}$ & $\begin{array}{l}\text { Synthesis } \\
\text { Temperature } \\
\left({ }^{\circ} \mathrm{C}\right)\end{array}$ & $\begin{array}{l}\text { Time } \\
\text { (h) }\end{array}$ & $\begin{array}{c}\text { Synthesis } \\
\text { Method }\end{array}$ \\
\hline BS131 & $\mathrm{N}_{2.5} \mathrm{~S}_{25} \mathrm{~T}_{6.9} \mathrm{H}_{1136}$ & $\begin{array}{c}\text { Ludox AS-30 } \\
\text { TPABr }\end{array}$ & 150 & 24 & $\begin{array}{l}\text { Seeded, } \\
\text { Batch }\end{array}$ \\
\hline BS132 & $\mathrm{N}_{3.0} \mathrm{~S}_{25} \mathrm{~T}_{6.9} \mathrm{H}_{1136}$ & $\begin{array}{c}\text { Ludox AS-30 } \\
\text { TPABr }\end{array}$ & 150 & 24 & $\begin{array}{l}\text { Seeded, } \\
\text { Batch }\end{array}$ \\
\hline $\begin{array}{l}\text { BS133- } \\
\text { BS137 }\end{array}$ & $\mathrm{N}_{1.0} \mathrm{~S}_{25} \mathrm{~T}_{6.9} \mathrm{H}_{1136}$ & $\begin{array}{c}\text { Ludox AS-30 } \\
\text { TPABr }\end{array}$ & 150 & 24 & $\begin{array}{l}\text { Seeded, } \\
\text { Batch }\end{array}$ \\
\hline BS134 & $\mathrm{N}_{0} \mathrm{~S}_{25} \mathrm{~T}_{6.9} \mathrm{H}_{1136}$ & $\begin{array}{c}\text { Ludox AS-30 } \\
\text { TPABr }\end{array}$ & 150 & 24 & $\begin{array}{l}\text { Seeded, } \\
\text { Batch }\end{array}$ \\
\hline BS135 & $\mathrm{N}_{0.25} \mathrm{~S}_{25} \mathrm{~T}_{6.9} \mathrm{H}_{1136}$ & $\begin{array}{c}\text { Ludox AS-30 } \\
\text { TPABr }\end{array}$ & 150 & 24 & $\begin{array}{l}\text { Seeded, } \\
\text { Batch }\end{array}$ \\
\hline BS136 & $\mathrm{N}_{0.75} \mathrm{~S}_{25} \mathrm{~T}_{6.9} \mathrm{H}_{1136}$ & $\begin{array}{c}\text { Ludox AS-30 } \\
\text { TPABr }\end{array}$ & 150 & 24 & $\begin{array}{c}\text { Seeded, } \\
\text { Batch }\end{array}$ \\
\hline BS138 & $\mathrm{N}_{1.25} \mathrm{~S}_{25} \mathrm{~T}_{6.9} \mathrm{H}_{1136}$ & $\begin{array}{c}\text { Ludox AS-30 } \\
\text { TPABr }\end{array}$ & 150 & 24 & $\begin{array}{c}\text { Seeded, } \\
\text { Batch }\end{array}$ \\
\hline BS139 & $\mathrm{N}_{1.0} \mathrm{~S}_{25} \mathrm{~T}_{5} \mathrm{H}_{800}$ & $\begin{array}{c}\text { Ludox AS-30 } \\
\text { TPABr }\end{array}$ & 150 & 24 & $\begin{array}{l}\text { Seeded, } \\
\text { Batch }\end{array}$ \\
\hline BS140 & $\mathrm{N}_{1.0} \mathrm{~S}_{25} \mathrm{~T}_{5} \mathrm{H}_{800}$ & $\begin{array}{c}\text { Ludox AS-30 } \\
\text { TPAOH+TPABr }\end{array}$ & 150 & 24 & $\begin{array}{l}\text { Seeded, } \\
\text { Batch }\end{array}$ \\
\hline BS141 & $\mathrm{N}_{3.0} \mathrm{~S}_{25} \mathrm{~T}_{5} \mathrm{H}_{800}$ & $\begin{array}{c}\text { Ludox AS-30 } \\
\text { TPAOH }\end{array}$ & 150 & 24 & $\begin{array}{c}\text { Seeded, } \\
\text { Batch }\end{array}$ \\
\hline BS142 & $\mathrm{N}_{0.25} \mathrm{~S}_{25} \mathrm{~T}_{6.9} \mathrm{H}_{1136}$ & $\begin{array}{c}\text { Ludox AS-30 } \\
\text { TPABr }\end{array}$ & 150 & 24 & $\begin{array}{l}\text { Seeded, } \\
\text { Batch }\end{array}$ \\
\hline BS143 & $\mathrm{N}_{0.5} \mathrm{~S}_{25} \mathrm{~T}_{6.9} \mathrm{H}_{1136}$ & $\begin{array}{c}\text { Ludox AS-30 } \\
\text { TPABr }\end{array}$ & 150 & 24 & $\begin{array}{l}\text { Seeded, } \\
\text { Batch }\end{array}$ \\
\hline BS144 & $\mathrm{N}_{0.75} \mathrm{~S}_{25} \mathrm{~T}_{6.9} \mathrm{H}_{1136}$ & $\begin{array}{c}\text { Ludox AS-30 } \\
\text { TPABr }\end{array}$ & 150 & 24 & $\begin{array}{c}\text { Seeded, } \\
\text { Batch }\end{array}$ \\
\hline BS145 & $\mathrm{N}_{1.0} \mathrm{~S}_{25} \mathrm{~T}_{6.9} \mathrm{H}_{1136}$ & $\begin{array}{c}\text { Ludox AS-30 } \\
\text { TPABr }\end{array}$ & 150 & 24 & $\begin{array}{c}\text { Seeded, } \\
\text { Batch }\end{array}$ \\
\hline BS146 & $\mathrm{N}_{1.25} \mathrm{~S}_{25} \mathrm{~T}_{6.9} \mathrm{H}_{1136}$ & $\begin{array}{c}\text { Ludox AS-30 } \\
\text { TPABr }\end{array}$ & 150 & 24 & $\begin{array}{c}\text { Seeded, } \\
\text { Batch }\end{array}$ \\
\hline BS147 & $\mathrm{N}_{1.5} \mathrm{~S}_{25} \mathrm{~T}_{6.9} \mathrm{H}_{1136}$ & $\begin{array}{c}\text { Ludox AS-30 } \\
\text { TPABr }\end{array}$ & 150 & 24 & $\begin{array}{c}\text { Seeded, } \\
\text { Batch }\end{array}$ \\
\hline BS148 & $\mathrm{N}_{0.25} \mathrm{~S}_{25} \mathrm{~T}_{6.9} \mathrm{H}_{1136}$ & $\begin{array}{c}\text { Ludox AS-30 } \\
\text { TPABr }\end{array}$ & 150 & 24 & $\begin{array}{l}\text { Seeded, } \\
\text { Batch }\end{array}$ \\
\hline BS149 & $\mathrm{N}_{0.4} \mathrm{~S}_{25} \mathrm{~T}_{6.9} \mathrm{H}_{1136}$ & $\begin{array}{c}\text { Ludox AS-30 } \\
\text { TPABr }\end{array}$ & 150 & 24 & $\begin{array}{c}\text { Seeded, } \\
\text { Batch }\end{array}$ \\
\hline BS150 & $\mathrm{N}_{0.5} \mathrm{~S}_{25} \mathrm{~T}_{6.9} \mathrm{H}_{1136}$ & $\begin{array}{c}\text { Ludox AS-30 } \\
\text { TPABr }\end{array}$ & 150 & 24 & $\begin{array}{c}\text { Seeded, } \\
\text { Batch }\end{array}$ \\
\hline BS151 & $\mathrm{N}_{0.65} \mathrm{~S}_{25} \mathrm{~T}_{6.9} \mathrm{H}_{1136}$ & $\begin{array}{c}\text { Ludox AS-30 } \\
\text { TPABr }\end{array}$ & 150 & 24 & $\begin{array}{c}\text { Seeded, } \\
\text { Batch }\end{array}$ \\
\hline BS152 & $\mathrm{N}_{0.75} \mathrm{~S}_{25} \mathrm{~T}_{6.9} \mathrm{H}_{1136}$ & $\begin{array}{c}\text { Ludox AS-30 } \\
\text { TPABr }\end{array}$ & 150 & 24 & $\begin{array}{c}\text { Seeded, } \\
\text { Batch }\end{array}$ \\
\hline BS153 & $\mathrm{N}_{1.0} \mathrm{~S}_{25} \mathrm{~T}_{6.9} \mathrm{H}_{1136}$ & $\begin{array}{c}\text { Ludox AS-30 } \\
\text { TPABr }\end{array}$ & 150 & 24 & $\begin{array}{c}\text { Seeded, } \\
\text { Batch }\end{array}$ \\
\hline
\end{tabular}


Table K1-cont'd. List of synthesized membranes at different synthesis conditions

\begin{tabular}{|c|c|c|c|c|c|}
\hline $\begin{array}{c}\text { Membrane } \\
\text { Code }\end{array}$ & $\begin{array}{c}\text { Synthesis } \\
\text { Composition }\end{array}$ & $\begin{array}{c}\text { Silica and } \\
\text { template source }\end{array}$ & $\begin{array}{c}\text { Synthesis } \\
\text { Temperature } \\
\left({ }^{\circ} \mathrm{C}\right)\end{array}$ & $\begin{array}{c}\text { Time } \\
(\mathrm{h})\end{array}$ & $\begin{array}{c}\text { Synthesis } \\
\text { Method }\end{array}$ \\
\hline BS154 & $\mathrm{N}_{0.75} \mathrm{~S}_{25} \mathrm{~T}_{6.9} \mathrm{H}_{1136}$ & $\begin{array}{c}\text { Ludox AS-30 } \\
\text { TPABr }\end{array}$ & 150 & 24 & $\begin{array}{c}\text { Seeded, } \\
\text { Batch }\end{array}$ \\
\hline BS155 & $\mathrm{N}_{1.0} \mathrm{~S}_{25} \mathrm{~T}_{6.9} \mathrm{H}_{1136}$ & $\begin{array}{c}\text { Ludox AS-30 } \\
\text { TPABr }\end{array}$ & 150 & 24 & $\begin{array}{c}\text { Seeded, } \\
\text { Batch }\end{array}$ \\
\hline BS156 & $\mathrm{N}_{1.25} \mathrm{~S}_{25} \mathrm{~T}_{6.9} \mathrm{H}_{1136}$ & $\begin{array}{c}\text { Ludox AS-30 } \\
\text { TPABr }\end{array}$ & 150 & 24 & $\begin{array}{c}\text { Seeded, } \\
\text { Batch }\end{array}$ \\
\hline BS157 & $\mathrm{N}_{5.0} \mathrm{~S}_{25} \mathrm{~T}_{6.9} \mathrm{H}_{1136}$ & $\begin{array}{c}\text { Ludox AS-30 } \\
\text { TPABr }\end{array}$ & 150 & 24 & $\begin{array}{c}\text { Seeded, } \\
\text { Batch }\end{array}$ \\
\hline BS158 & $\mathrm{N}_{6.5} \mathrm{~S}_{25} \mathrm{~T}_{6.9} \mathrm{H}_{1136}$ & $\begin{array}{c}\text { Ludox AS-30 } \\
\text { TPABr }\end{array}$ & 150 & 24 & $\begin{array}{c}\text { Seeded, } \\
\text { Batch }\end{array}$ \\
\hline BS159 & $\mathrm{N}_{0.85} \mathrm{~S}_{25} \mathrm{~T}_{6.9} \mathrm{H}_{1136}$ & $\begin{array}{c}\text { Ludox AS-30 } \\
\text { TPABr }\end{array}$ & 150 & 24 & $\begin{array}{c}\text { Seeded, } \\
\text { Batch }\end{array}$ \\
\hline BS160 & $\mathrm{N}_{1.10} \mathrm{~S}_{25} \mathrm{~T}_{6.9} \mathrm{H}_{1136}$ & $\begin{array}{c}\text { Ludox AS-30 } \\
\text { TPABr }\end{array}$ & 150 & 24 & $\begin{array}{c}\text { Seeded, } \\
\text { Batch }\end{array}$ \\
\hline BS161 & $\mathrm{N}_{1.35} \mathrm{~S}_{25} \mathrm{~T}_{6.9} \mathrm{H}_{1136}$ & $\begin{array}{c}\text { Ludox AS-30 } \\
\text { TPABr }\end{array}$ & 150 & 24 & $\begin{array}{c}\text { Seeded, } \\
\text { Batch }\end{array}$ \\
\hline BS162 & $\mathrm{N}_{4.0} \mathrm{~S}_{25} \mathrm{~T}_{6.9} \mathrm{H}_{1136}$ & $\begin{array}{c}\text { Ludox AS-30 } \\
\text { TPABr }\end{array}$ & 150 & 24 & $\begin{array}{c}\text { Seeded, } \\
\text { Batch }\end{array}$ \\
\hline
\end{tabular}




\section{APPENDIX L \\ LIST OF MEMBRANES SYNTHESIZED WITH COMPOSITION CHANGES}

Table L.1 Synthesis conditions and properties of the membranes prepared with composition change during the synthesis, synthesis temperature: $95^{\circ} \mathrm{C}$

\begin{tabular}{|c|c|c|c|}
\hline $\begin{array}{l}\text { Membrane } \\
\text { Code }\end{array}$ & $\begin{array}{c}\text { Synthesis composition } \\
\text { 80 } \mathrm{SiO}_{2}: \text { xTPAOH: } 1500 \mathrm{H}_{2} \mathrm{O}\end{array}$ & $\begin{array}{c}\text { Composition change } \\
\text { time }(\mathrm{h})\end{array}$ & $\begin{array}{c}\text { Total synthesis } \\
\text { time }(\mathrm{h})\end{array}$ \\
\hline BS119 & $x=9$ & - & 72 \\
\hline BS115 & $\mathrm{x}=30$ & - & 72 \\
\hline BS122 & $\mathrm{x}=30$ & - & 24 \\
\hline BS121 & $\mathrm{x}$ was changed from 30 to 9 & 24 & $24+48$ \\
\hline BS123 & $x=30$ & - & 48 \\
\hline BS124 & $\mathrm{x}$ was changed from 30 to 9 & 48 & $48+24$ \\
\hline BS126 & $\mathrm{x}=30$ & - & 124 \\
\hline BS125 & $\mathrm{x}$ was changed from 30 to 9 & 124 & $124+24$ \\
\hline BS165 & $x=30$ & - & 48 \\
\hline BS166 & $\mathrm{x}$ was changed from 30 to 9 & 48 & $48+24$ \\
\hline BS167 & $x=30$ & - & 48 \\
\hline BS168 & $\mathrm{x}$ was changed from 30 to 9 & 48 & $48+24$ \\
\hline BS169 & $x=30$ & - & 24 \\
\hline BS170 & $\mathrm{x}$ was changed from 30 to 9 & 24 & $24+72$ \\
\hline BS178 & $\mathrm{x}$ was changed from 30 to 9 & 24 & $24+72$ \\
\hline BS179 & $\mathrm{x}$ was changed from 30 to 9 & 24 & $24+72$ \\
\hline BS173 & $x=30$ & - & 48 \\
\hline BS174 & $\mathrm{x}$ was changed from 30 to 9 & 48 & $48+72$ \\
\hline BS177 & $\mathrm{x}$ was changed from 30 to 9 & 48 & $48+72$ \\
\hline BS175 & $x=30$ & - & 72 \\
\hline BS176 & $\mathrm{x}$ was changed from 30 to 9 & 72 & $72+72$ \\
\hline
\end{tabular}




\section{CURRICULUM VITAE}

\section{PERSONAL DETAILS}

$\begin{array}{ll}\text { Name, Surname: } & \text { Belma SOYDAŞ } \\ \text { Gender } \quad & \text { Female } \\ \text { Date of Birth : } & 24 / 06 / 1979 \\ \text { Place of Birth : } & \text { Konya, Turkiye } \\ \text { E-mail: } & \text { soydas@metu.edu.tr }\end{array}$

\section{EDUCATION:}

September 2003 - June 2009: PhD,

Middle East Technical University (METU),

Turkiye Department of Chemical Engineering CGPA: $3.25 / 4.00$

Thesis Title: "Characterization of MFI type zeolite membranes by gas permeation",

March 2008-August 2008: V Visiting Scholar,

Department of Chemical and Biological Engineering, Membrane Applied Science and Technology Center at University of Colorado at Boulder, CO, USA

September 1997 - June 2002: $\quad$ B.S.,

Gazi University, Turkiye

Faculty of Engineering and Architecture,

Department of Chemical Engineering

CGPA: $3.27 / 4.00$ 


\section{SCHOLARSHIPS AND AWARDS}

- International Research Fellowship, The Scientific and Technological Research Council of Turkey, 2008.

- Best Poster Presentation Award, 'Effect of soda and hydroxyl ion concentration on the morphology of the MFI type zeolite membranes', Somer's Symposium Series, METU, May 2007.

- Gazi University, Faculty of Engineering and Architecture, Department of Chemical Engineering, Honour Degree, 1999-2002.

\section{ACADEMIC EXPERIENCE:}

- Teaching assistantship in Middle East Technical University, Chemical Engineering Department (January 2004 - present):

- Internship in PETKİM (Turkish Petrochemical Corporation), Kocaeli / TURKIYE (July-August 2000).

- Internship in TÜPRAŞ, (Turkish Petroleum Refineries Corporation), Kırıkkale / TURKIYE (July-August 2001).

\section{COMPUTER/LANGUAGE SKILLS:}

- Microsoft Office Applications (Word, Excel, Power Point, Front Page)

- Fortran 77

- ChemCad Applications, ChemKin Applications

- Proficient in written and spoken English.

\section{SUMMER SCHOOL ATTENDED:}

- Attendee to 'Inorganic Membranes: Preparation, Characterization and Applications', University of Zaragoza XXII European Membrane Society Summer School, Zaragoza, Spain, September 2005. 


\section{JOURNAL ARTICLES COVERED BY SCIENCE CITATION INDEX:}

- Belma Soydaş, Ali Çulfaz, Halil Kalıpçılar, 'Preparation of silicalite membranes with mid-synthesis change of synthesis composition in a flow system', in preparation.

- Belma Soydas, Hans H. Funke, Yanfeng Zhang, John. L. Falconer, Richard D. Noble, 'Selective Zeolite A Membranes due to WaterInduced Crystal Swelling', Journal of Membrane Science, submitted.

- Belma Soydaş, Özlem Dede, Ali Çulfaz, Halil Kalıpçılar, 'Separation of gas and organic/water mixtures by MFI type zeolite membranes synthesized in a flow system', Microporous and Mesoporous Materials, submitted.

- Belma Soydaş, P. Zeynep Çulfaz, Halil Kalıpçılar, Ali Çulfaz, 'Crystallization of silicalite-1 from clear synthesis solutions: Effect of template concentration on crystallization rate and crystal size', Crystallization Research and Technology, article in press.

- Belma Soydaş, Ali Çulfaz, Halil Kalıpçılar, 'Effect of soda concentration on the morphology of the MFI type zeolite membranes', Chemical Engineering Communications, 196 (1) 2009, 182-193.

- Belma Soydaş, Ali Çulfaz, Halil Kalıpçılar, 'Characterization of zeolite membranes by gas permeation',_Desalination, 199 (1-3) 2006, 371-372. 


\section{INTERNATIONAL CONFERENCES ATTENDED AND ABSTRACTS PUBLISHED IN THE PROCEEDINGS}

- Belma Soydaş, Ali Çulfaz, Halil Kalıpçılar, 'Effect of mid synthesis addition of silica to the synthesis medium on the properties of MFI type zeolite membranes', Euromembrane 2009, Montpellier, France, September 2009, abstract accepted for poster presentation.

- Özlem Dede, Belma Soydaş, Ali Çulfaz, Halil Kalıpçılar, 'Characterization of MFI type zeolite membranes synthesized in a flow system by separation of gas and liquid mixtures' Poster Presentation, International Zeolite Membrane Meeting 2007 (IZMM 2007), Zaragoza, Spain, June 2007.

- Belma Soydaş, Ali Çulfaz, Halil Kalıpçılar, 'Preparation of silicalite membranes with mid-synthesis change of synthesis composition in a flow system' Oral Presentation, International Zeolite Membrane Meeting 2007 (IZMM 2007), Zaragoza, Spain, June 2007.

- Belma Soydaş, Ali Çulfaz, Halil Kalıpçılar, 'Effect of Hydroxyl Ion Concentration on the Morphology of the MFI Type Zeolite Membranes' Poster Presentation, Somer's Symposium Series, METU, Ankara, Turkiye, May 2007.

- Belma Soydaş, Ali Çulfaz, Halil Kalıpçılar, 'Characterization of zeolite membranes by gas permeation', Oral Presentation, Euromembrane 2006, September 2006, Italy.

- Belma Soydaş, Halil Kalıpçılar, Ali Çulfaz, 'Characterization of zeolite membranes by gas permeation', Oral Presentation, 7th Network Young Membrains (NYM-7), Encshede, Holland, June 2005. 
- Halil Kalıpçılar, Eser Dinçer, Zeynep Çulfaz, Belma Soydaş, 'MFI type zeolite membranes synthesized in batch and continuous systems and the effect of seeding', Application of Nanotechnologies for the Recovery of Volatile Organic Compounds from Waste Air Streams (ANVOC-2005), ANVOC-2005, İstanbul, Turkiye, June 2005.

\section{NATIONAL CONFERENCES ATTENDED AND ABSTRACTS PUBLISHED IN THE PROCEEDINGS}

- Belma Soydaş, Halil Kalıpçılar, Ali Çulfaz, 'Effect of template molecules on MFI type zeolite membrane morphology', Oral presentation, 8th National Congress of Chemical Engineering,Inonu University, Malatya, Turkiye, August 2008.

- Belma Soydaş, Ali Çulfaz, Halil Kalıpçılar, 'Characterization of MFI Type Zeolite Membranes Synthesized in a continuous system with Single Gas Permeation and Binary Gas Seperation', oral presentation, 7th National Congress of Chemical Engineering, Anadolu University, Eskişehir, Turkiye, September 2006.

- Belma Soydaş, Halil Kalıpçılar, Ali Çulfaz, 'Characterization of alumina supported MFI type zeolite membranes by single gas permeation' , Poster presentation, 6th National Congress of Chemical Engineering, Ege University, İzmir, Turkiye, September 2004.

- Aslı Tolga, Cem Ekizce, Belma Şoydaş, Ufuk Gündüz, 'Protein extraction by hydrogels', Poster presentation, 5th National Congress of Chemical Engineering, Ankara University, September 2002. 


\section{PROJECTS:}

- 'Sıvı karışımlarının döngülü akış sisteminde üretilmiş zeolit membranlar kullanılarak ayırımı' Project Code: TUBITAK-106M176 (Researcher)

- 'Zeolit Membranlarin Gaz Geçirgenlik Ölçümleriyle Karakterizasyonu', Project Code: BAP-08-11-DPT2002K120510 (Researcher)

- 'MFI Tipi Zeolit Membranların Çok Bileşenli Gaz Karışımlarının Ayrımında Kullanılması' Project Code: BAP-2006-03-04-03 (Researcher)

- 'Zeolit-Seramik Kompozit Membranların Hazırlanması ve Gaz Geçirgenlik Ölçümleri' Project Code: BAP-2004-03-04-04 (Researcher)

\section{TECHNICAL EXPERIENCES :}

- Synthesis of zeolite membranes by hydrothermal method (in a batch or continuous system).

- Construction and operation of single and binary gas permeation set-ups.

- Operation of gas chromatography and X-ray diffraction instruments. 